UNIVERSIDADE DE SÃO PAULO

FACULDADE DE ARQUITETURA E URBANISMO

ANA BEATRIZ DE FIGUEIREDO OLIVEIRA

Processo de produção integrado: aplicabilidade na construção industrializada 



\title{
Processo de produção integrado: aplicabilidade na construção industrializada
}

\author{
Exemplar revisado e alterado em relação à versão original, sob responsabilidade do \\ autor e anuência do orientador. \\ O original se encontra disponível na sede do programa \\ São Paulo, 07 de maio de 2019.
}

Tese apresentada à Faculdade de Arquitetura e Urbanismo da Universidade de São Paulo para a obtenção do título de Doutor em Arquitetura e Urbanismo.

Área de concentração: Tecnologia da Arquitetura

Orientador: Prof. Dr. Marcelo Eduardo Giacaglia

São Paulo 
Autorizo a reprodução e divulgação total ou parcial deste trabalho, por qualquer meio convencional ou eletrônico, para fins de estudo e pesquisa, desde que citada a fonte.

Catalogação na Publicação

Serviço Técnico de Biblioteca

Faculdade de Arquitetura e Urbanismo da Universidade de São Paulo

Oliveira, Ana Beatriz de Figueiredo

Processo de produção integrado: aplicabilidade na construção industrializada / Ana Beatriz de Figueiredo Oliveira; orientador Marcelo Eduardo Giacaglia. - São Paulo, 2019.

$291 \mathrm{p}$.

Tese (Doutorado) - Faculdade de Arquitetura e Urbanismo da Universidade de São Paulo. Área de concentração: Tecnologia da Arquitetura.

1. Industrialização da Construção. 2. Gerenciamento da Construção. 3. Contratação de obras e Serviços. 4. Tecnologia da Informação. I. Giacaglia, Marcelo Eduardo, orient. II. Título.

Elaborada eletronicamente através do formulário disponível em: <http://www.fau.usp.br/fichacatalografica/> 
OLIVEIRA, Ana Beatriz de Figueiredo

Processo de produção integrado: aplicabilidade na construção industrializada

Tese apresentada à Faculdade de Arquitetura e Urbanismo da Universidade de São Paulo para obtenção do título de Doutor em Arquitetura e Urbanismo.

Aprovado em: 22 de abril de 2019.

Banca Examinadora

Prof. Dr.

Instituição:

Julgamento:

Assinatura:

Prof. Dr.

Instituição:

Julgamento:

Assinatura:

Prof. Dr.

Instituição:

Julgamento:

Assinatura:

Prof. Dr.

Instituição:

Julgamento:

Assinatura:

Prof. Dr.

Instituição:

Julgamento:

Assinatura: 



\section{AGRADECIMENTOS}

Ao Programa de Pós-Graduação em Arquitetura e Urbanismo da Universidade de São Paulo pela oportunidade de realizar este Doutorado e aos professores e funcionários do Departamento de Tecnologia da Arquitetura.

Ao meu orientador Prof. Dr. Marcelo Eduardo Giacaglia pela atenção, apoio e pelas contribuições valiosas para o desenvolvimento desta pesquisa.

A todos os profissionais que se dispuseram a participar desta pesquisa e que foram essenciais para sua realização.

À CAPES pelo apoio financeiro que viabilizou a realização deste Doutorado.

À minha família por todo o apoio e incentivo, o que me permitiu concluir mais esta etapa da minha vida.

A todos que de alguma maneira contribuíram e incentivaram a realização desta tese. 

"O emprego da ciência só requer disciplina dentro da arte da simplificação - à qual se chega por meio da separação dos fatores constituintes do problema, para observá-los um por um, e daí deduzir e classificar os princípios fundamentais envolvidos."

Buckminster Fuller (1963) 



\section{RESUMO}

A construção industrializada se mostra como uma oportunidade para aperfeiçoar o processo de produção na construção civil, mas para sua efetiva aplicação é preciso estabelecer um processo de produção condizente com suas características. O objetivo desta pesquisa é analisar como cada uma das perspectivas da integração - contratual, organizacional e de tecnologia da informação - pode aperfeiçoar e ampliar o uso da construção industrializada. A integração do processo de produção é considerada como uma solução para aumentar a qualidade e produtividade na construção civil e suas características estão alinhados aos requisitos da industrialização, seja por meio do uso da pré-fabricação e/ou de técnicas de racionalização da construção. Na literatura afirma-se que, na construção em geral, só é possível alcançar a integração do processo com mudanças estruturais nas três perspectivas. Investigou-se, no caso da construção industrializada, se um alto nível de integração em uma ou duas dessas perspectivas pode compensar a menor ou a sua ausência em outra(s). Para tanto, criou-se um ordenamento do grau de integração relativo a cada perspectiva, pela análise em detalhe de suas características, com a ajuda de diagramas específicos. Também foi elaborada uma tabela geral, com as interdependências entre as três perspectivas dado a graduação em cada uma. Tal método serviu de base para a análise de cinco estudos de caso de construção industrializada. Observouse que, características da integração organizacional são as que mais favorecem o uso da industrialização, estabelecendo uma visão sistêmica ao processo. É possível estabelecer o trabalho colaborativo sem que a integração esteja definida no modelo de contrato. A integração pela tecnologia da informação, especificamente por meio do BIM, ainda que não se tenha mostrado essencial, permite antecipar possíveis incompatibilidades entre os sistemas construtivos.

Palavras-chave: Construção Industrializada. Processo Integrado. Trabalho Colaborativo. Contratos relacionais. Modelagem da Informação da Construção. BIM. 



\begin{abstract}
Industrialized construction is an opportunity to improve project delivery process; however, it is crucial to reorganize the methods of the process, for its successful use. The aim of this research is to analyze how each perspective of integration - contract, organization and information technology - can improve and expand the use of industrialized construction. Integration of the project process is assumed as a solution to increase quality and efficiency in construction and, its features are aligned with the requirements for industrialized construction, be it through prefabrication and/or rationalization of the construction. It has been stated that, for the general case in construction, its integration can only be achieved from structural changes in all three approaches. It was investigated if a high level of integration in one or two of these perspectives can compensate for lower or absent in the other(s). For that matter, an ordering of the relative degree of integration within each perspective, was derived from the analysis of their characteristics, through the use of specific diagrams. Also, a general table of the interdependencies among the three perspectives was built. This method was used to analyze five case studies of industrialized construction. It was realized that the features of organization integration are those that give better support to the use of industrialized construction. Also, that it is possible to achieve collaboration even when it is not ruled in the contracts. Integration by information technology, specifically through BIM, although not proved essential, allows for anticipation of possible incompatibilities between construction systems.
\end{abstract}

Keywords: Industrialized construction. Integration of the building process. Collaborative work. Relational contracts. Building Information Modeling. BIM. 



\section{LISTA DE ILUSTRAÇÕES}

Figura 1 - Diagrama elaborado pela AIA - Processo de Produção Tradicional e Integrado .... 29

Figura 2 - Referência para a elaboração dos diagramas de integração organizacional 31

Figura 3 - Oportunidade de integrar a pré-fabricação ao longo do processo de produção........73

Figura 4 - Relação entre o tempo e o impacto das modificações de projeto 79

Figura 5 - Modelos de contrato transacionais. 85

Figura 6 - Estrutura típica da equipe no Project Alliancing ..... 98

Figura 7 - Processo de produção do Early Contractor Involvement - modelo britânico ...... 105

Figura 8 - Comparação do Integrated Project Delivery ao processo tradicional 111

Figura 9 - Métodos racional e reflexivo para execução do projeto

Figura 10 - Códigos, conceitos e categorias do efeito da colaboração no uso do BIM.....

Figura 11 - Níveis de Maturidade do BIM por Succar

Figura 12 - Nível de Maturidade BIM por Bew e Richards

Figura 13 - Processo de produção pelo Lean Project Delivery System . 152

Figura 14 - Comparação entre os contratos transacionais e relacionais 161

Figura 15 - Legenda dos diagramas dos métodos de produção dos empreendimentos 163

Figura 16 - Síntese do processo de produção utilizado na elaboração dos diagramas de integração contratual

Figura 17 - Diagrama com primeiro nível de detalhamento do Design-Bid-Build 165

Figura 18 - Diagrama com primeiro nível de detalhamento do Design and Build...... 166

Figura 19 - Diagrama com primeiro nível de detalhamento do Construction Management at Risk

Figura 20 - Diagrama com primeiro nível de detalhamento do Project Partnering e Project Alliancing.

Figura 21 - Diagrama com primeiro nível de detalhamento do Early Contractor Involvement

Figura 22 - Diagrama com primeiro nível de detalhamento do Integrated Project Delivery 171 

Figura 23 - Diagrama com segundo nível de detalhamento do Design-Bid-Build

Figura 24 - Diagrama com segundo nível de detalhamento do Design and Build

Figura 25 - Diagrama com segundo nível de detalhamento do Construction Management at Risk

Figura 26 - Diagrama com segundo nível de detalhamento do Project Partnering e Project Aliancing

Figura 27 - Diagrama com segundo nível de detalhamento do Early Constructor Involvement

Figura 28 - Diagrama com segundo nível de detalhamento do Integrated Project Delivery.183

Figura 29 - Níveis de Integração Contratual

Figura 30 - Legenda dos diagramas de Integração Organizacional.

Figura 31 - Interações de um processo segmentado sem gestor. 188

Figura 32 - Interações de um processo segmentado com gestor

Figura 33 - Interações de um processo com colaboração na etapa de projeto sem gestor

Figura 34 - Interações de um processo com colaboração na etapa de projeto com gestor

Figura 35 - Interações de um processo com colaboração na etapa de obra sem gestor 191

Figura 36 - Interações de um processo com colaboração na etapa de obra com gestor 192

Figura 37 - Interações de um processo com colaboração na etapa de projeto e obra sem gestor

Figura 38 - Interações de um processo com colaboração na etapa de projeto e obra com gestor

Figura 39 - Interações de um processo com colaboração ao longo de todo o processo sem gestor.

Figura 40 - Interações de um processo com colaboração ao longo de todo o processo com gestor.

Figura 41 - Interações de um processo turnkey segmentado sem gestor 196

Figura 42 - Interações de um processo turnkey segmentado com gestor 197 

Figura 43 - Interações de um processo turnkey com colaboração na etapa de projeto sem gestor

Figura 44 - Interações de um processo turnkey com colaboração na etapa de projeto com gestor

Figura 45 - Interações de um processo turnkey com colaboração na etapa de obra sem gestor

Figura 46 - Interações de um processo turnkey com colaboração na etapa de obra com gestor

Figura 47 - Interações de um processo turnkey com colaboração ao longo de todo o processo sem gestor

Figura 48 - Interações de um processo turnkey com colaboração ao longo de todo o processo com gestor.

Figura 49 - Níveis de Integração Organizacional ...............................................................202

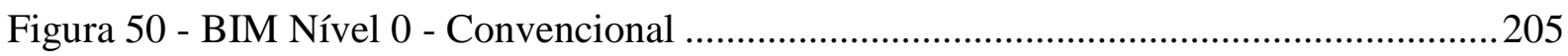

Figura 51 - BIM Nível 1 - BIM-Convencional ..................................................................205

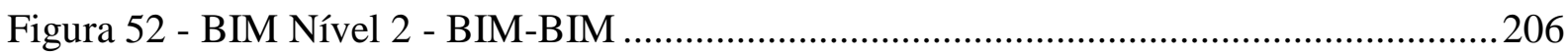

Figura 53 - BIM Nível 3 - BIM Modelo único ou federado...............................................206

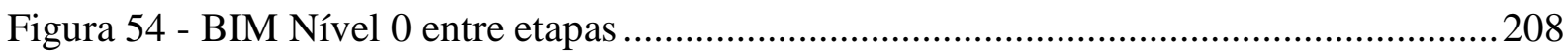

Figura 55 - BIM Nível 1 entre etapas: BIM-Convencional.............................................209

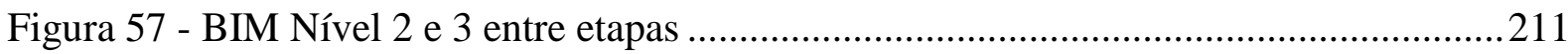

Figura 58 - Legenda dos diagramas de Integração pela Tecnologia da Informação ..............212

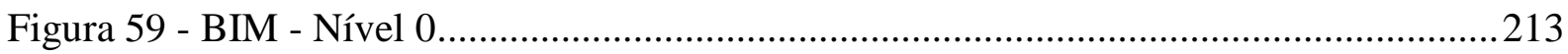

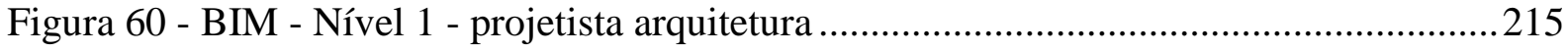

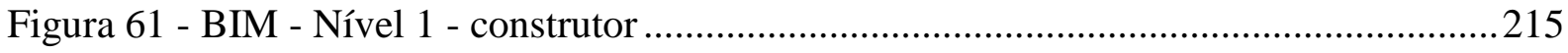

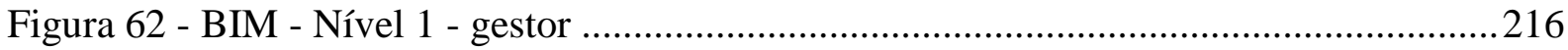

Figura 63 - BIM - Nível 1 - projetista arquitetura e construtor .........................................216

Figura 64 - BIM - Nível 2 entre projetista arquitetura e gestor ..........................................2217

Figura 65 - BIM - Nível 2 na etapa de projeto .................................................................2 218 

Figura 66 - BIM - Nível 2 na etapa de projeto com o gestor.

Figura 67 - BIM - Nível 2 entre construtor e gestor

Figura 68 - BIM - Nível 2 na etapa de execução 220

Figura 69 - BIM - Nível 2 na etapa de execução com o gestor .220

Figura 70 - BIM - Nível 2 na etapa de projeto e execução isoladamente 221

Figura 71 - BIM - Nível 2 entre projeto e construtor com gestor .222

Figura 72 - BIM - Nível 2 - entre execução e arquiteto com gestor 223

Figura 73 - BIM - Nível 3 - ao longo de todo o processo 224

Figura 74 - Níveis de Integração pela Tecnologia da Informação 225

Figura 75 - Correlação entre as perspectivas de integração 227

Figura 76 - Diagrama de contratação do EC-1 235

Figura 77 - Diagrama organizacional do EC-1 238

Figura 78 - Diagrama do uso do BIM do EC-1 239

Figura 79 - Diagrama de contratação do EC-2 243

Figura 80 - Diagrama organizacional do EC-2. 245

Figura 81 - Diagrama do uso do BIM do EC-2 246

Figura 82 - Diagrama de contratação do EC-3 249

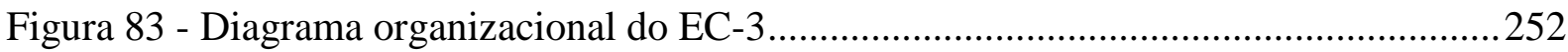

Figura 84 - Diagrama do uso do BIM do EC-3 ...................................................................253

Figura 85 - Diagrama de contratação do EC-4 ..............................................................2256

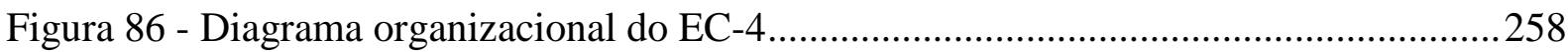

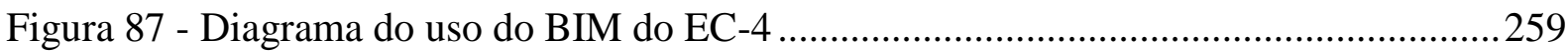





\section{LISTA DE TABELAS}

Tabela 1 - Comparação entre as características das relações com grande envolvimento e das relações típicas da construção civil

Tabela 2 - Comparação das referências que consideram o processo de produção com uma sequência definida de atividades

Tabela 3 - Questões fundamentais para as mudanças tecnológicas da construção industrializada.

Tabela 4 - Benefícios da construção industrializada pela percepção dos clientes.

Tabela 5 - Características do Design-Bid-Build (DBB) ou Método Tradicional 86

Tabela 6 - Características do Design and Build (DB) ou Projeto-Construção 88

Tabela 7 - Características do Construction Management at Risk (CMAR) ou Gestão da Construção por Administração com Risco para a Gestora 90

Tabela 8 - Características do Project Partnering (PP) ou Projeto de Parceria. .93

Tabela 9 - Características do Project Alliancing (PA) ou Aliança de Projeto 97

Tabela 10 - Características do Early Contractor Involvement (ECI) ou Participação Precoce do Construtor

Tabela 11 - Características do Integrated Project Delivery (IPD) 107

Tabela 12 - Comparação entre os instrumentos para a integração dos métodos PP, PA, ECI e IPD.

Tabela 13 - Responsabilidades dos participantes em um processo não integrado

Tabela 14 - Responsabilidades dos participantes em um processo integrado

Tabela 15 - Características das atividades no processo BIM 146

Tabela 16 - Tendência de mudança da indústria da construção 157

Tabela 17 - Descrição dos Níveis de Integração Vertical 203

Tabela 18 - Descrição dos Níveis de Integração Horizontal 203

Tabela 19 - Comparação dos níveis de integração dos estudos de caso 261 



\section{LISTA DE ABREVIATURAS}

ABCIC - Associação Brasileira da Construção Industrializada de Concreto

ABDI - Agência Brasileira de Desenvolvimento Industrial

ABNT - Associação Brasileira de Normas Técnicas

ACA - Association of Consultant Architects

AGESC - Associação Brasileira dos Gestores e Coordenadores de Projetos

AIA - American Institute of Architects

ANAC - Agência Nacional de Aviação Civil

BIM - Building Information Modeling/Modelagem da Informação da Construção

BPMN - Business Process Model and Notation

CBCA - Centro Brasileiro da Construção em Aço

CIB - International Council for Research and Innovation in Building and Construction

CIC - Construction Industry Council

CII - Construction Industry Institute

$\mathrm{CM}-$ Construction Management

CMAA - Construction Management Association of America

CMAR - Construction Management at Risk

CSI - Construction Specifications Institute

CTRS - Centro de Tecnologia da Rede Sarah

DB - Design-Build

DBB - Design-Bid-Build

DTF - Department of Treasury and Finance

EC - Estudo de caso

ECI - Early Contractor Involvement

FAU USP - Faculdade de Arquitetura e Urbanismo da Universidade de São Paulo

FMI - Fails Management Institute

GC - General Contractor

GLP - Gás liquefeito de petróleo

ICT - Information Communication Technologies 

IDDS - Integrated Design and Delivery Solutions

IDM - Information Delivery Manuals

IFC - Industry Foundation Classes

IPD - Integrated Project Delivery

ISO - International Organization for Standardization

IT - Information Technology

LOD - Level of Development

LPDS - Lean Project Delivery System

MDIC - Ministério da Indústria, Comércio Exterior e Serviços

NASFA - National Association of State Facilities

NBIMS - National BIM Standard

NEC - New Engineering Contract

NOPs - Non-owner Participants

OCCS - OmniClass Construction Classification System

OMG - Object Management Group

ONU - Organização das Nações Unidas

ORs - Owners Representative

PA - Project Alliancing

PP - Project Partnering

PPC2000 - Project Partnering Contract

RFP - Request for Proposals/Requisição de Proposta

RIBA - Royal Institute of British Architects

ROI - Return of Investment

Sinduscon-MG - Sindicato da Indústria da Construção Civil no Estado de Minas Gerais SP - Separable Portions

SPDA - Sistema de proteção contra descargas atmosféricas

STS - Sociotecnical System

USACE - United States Army Corps of Engineers 



\section{SUMÁRIO}

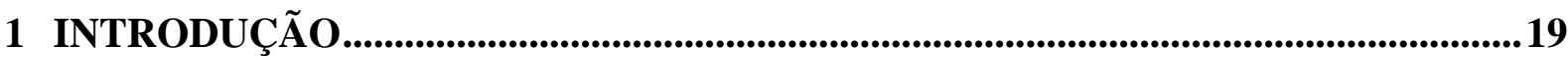

1.1 Objetivos e hipótese da pesquisa.............................................................................................20

1.2 Justificativa ..............................................................................................................................21

1.2.1 Realidade da construção industrializada ....................................................................22

1.3 Estrutura da tese ......................................................................................................................24

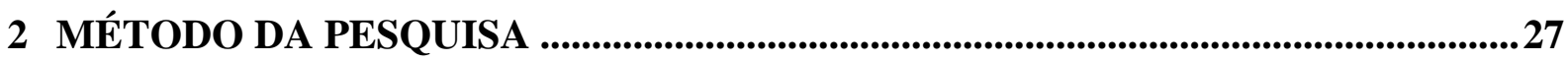

2.1 Categorização do problema..........................................................................................27

2.2 Explicitação das perspectivas de integração......................................................................28

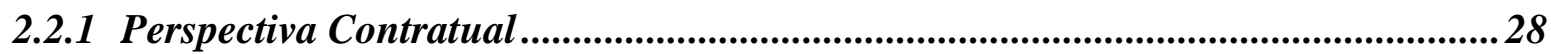

2.2.2 Perspectiva Organizacional...........................................................................................30

2.2.3 Perspectiva de Tecnologia da Informação …………………………………….............32

2.3 Estudos de Caso........................................................................................................................33

3 PROCESSO DE PRODUÇÃO DO EMPREENDIMENTO.............................................37

3.1 Etapas ou fases do processo de produção ............................................................................38

3.1.1 Processo de produção com uma sequência definida de etapas...................................39

3.1.2 Processo de produção sem uma sequência definida de etapas...................................43

3.2 Agentes do processo de produção ......................................................................................49

4 CONSTRUÇÃO INDUSTRIALIZADA .........................................................................53

4.1 Industrialização pelo sistema construtivo .........................................................................53

4.2 Industrialização pelo método de produção ………………………………………………...56

4.3 Evolução da construção industrializada ........................................................................60

4.3.1 Industrialização Fechada............................................................................................63

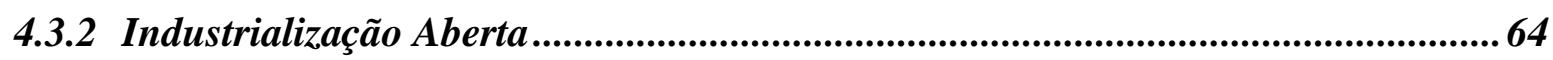

4.4 Vantagens e empecilhos da construção industrializada ..................................................65

4.5 Especificidades do processo de produção na construção industrializada..................71

5 INTEGRAÇÃO NA CONSTRUÇÃO CIVIL ................................................................ 77

5.1 Perspectiva contratual ............................................................................................................. 81 



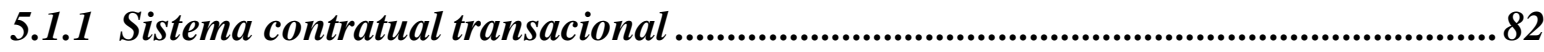

5.1.1.1 Design-Bid-Build (DBB) ou Método Tradicional................................................... 85

5.1.1.2 Design and Build ou Projeto-Construção ............................................................ 87

5.1.1.3 Construction Management at Risk (CMAR) ou Gestão da Construção por Administração com Risco para a Gestora............................................................ 89

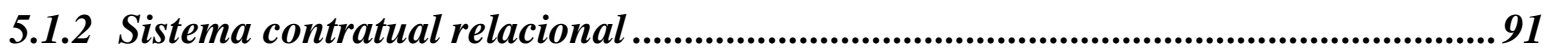

5.1.2.1 Project Partnering (PP) ou Projeto de Parceria .................................................. 92

5.1.2.2 Project Alliancing (PA) ou Aliança de Projeto .................................................... 96

5.1.2.3 Early Contractor Involvement (ECI) ou Participação Precoce do Construtor .. 102

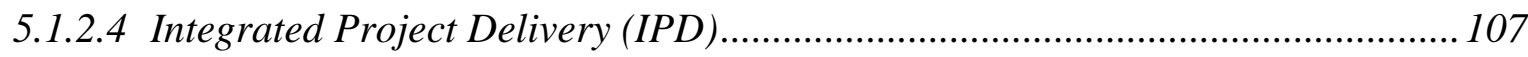

5.1.2.5 Análise comparativa dos tipos de contrato relacional ........................................ 113

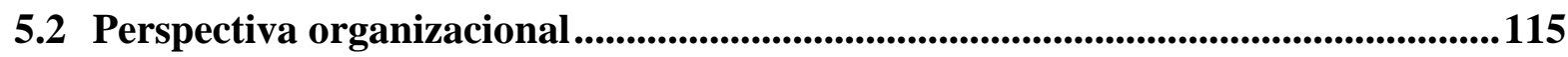

5.2.1 Integração da equipe e trabalho colaborativo ...................................................117

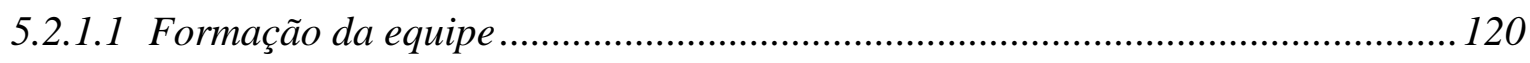

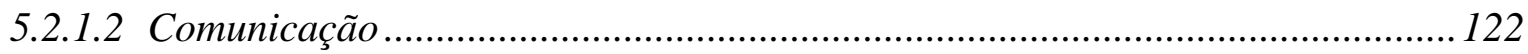

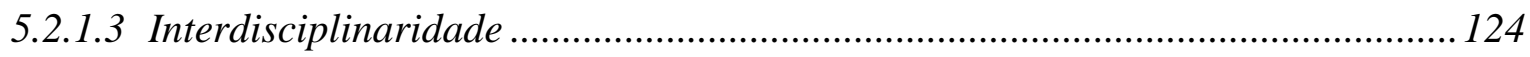

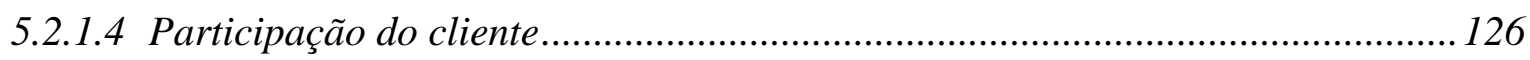

5.2.1.5 Relações de trabalho de longo prazo .................................................................. 128

5.2.1.6 Gestão do processo de produção do empreendimento ........................................ 130

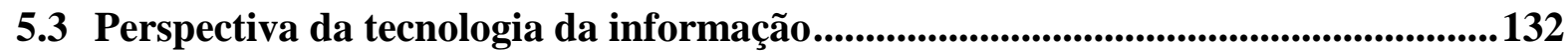

5.3.1 Modelagem da Informação da Construção (BIM)............................................... 132

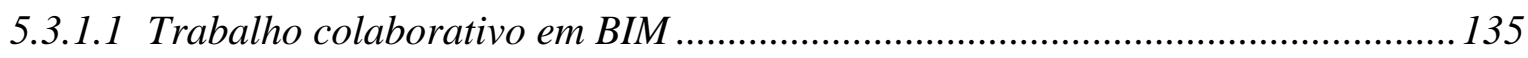

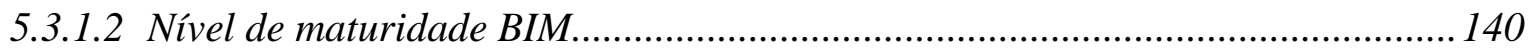

5.3.1.3 Guias de inserção do BIM nos processos de produção....................................... 143

5.4 Interdependência das perspectivas da integração ..................................................151

5.4.1 Lean Project Delivery System (LPDS) ................................................................... 151

5.4.2 Integrated Design and Delivery Solutions (IDDS) ..........................................156 



\section{ANÁLISE DAS PERSPECTIVAS DE INTEGRAÇÃO E SUAS}

INTERDEPENDÊNCIAS

6.1 Integração Contratual .................................................................................................................... 159

6.1.1 Primeiro nível de detalhamento dos contratos transacionais............................... 164

6.1.2 Primeiro nível de detalhamento dos contratos relacionais ..................................168

6.1.3 Segundo nível de detalhamento dos contratos transacionais .............................. 171

6.1.4 Segundo nível de detalhamento dos contratos relacionais ................................. 178

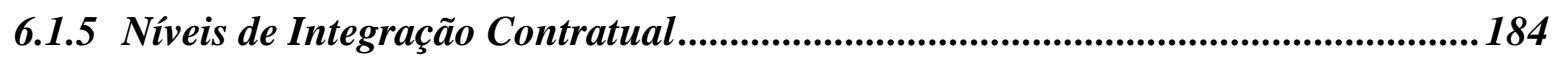

6.2 Integraçãa Organizacional ......................................................................................................... 185

6.2.1 Processo de produção sem colaboração ...........................................................187

6.2.2 Processo colaborativo na etapa de projeto e/ou de obra ...................................... 189

6.2.3 Colaboração ao longo de todo o processo ................................................................. 194

6.2.4 Processo “chave na mão" ou turnkey............................................................... 195

6.2.5 Níveis de Integração Organizacional .............................................................201

6.3 Integração pela Tecnologia de Informação ........................................................................203

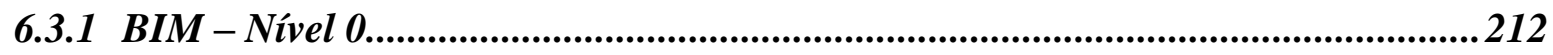

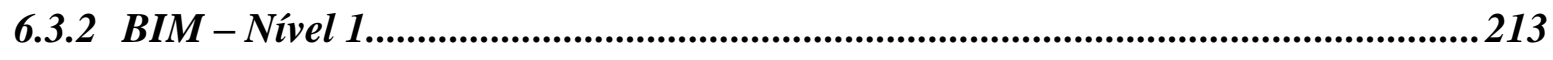

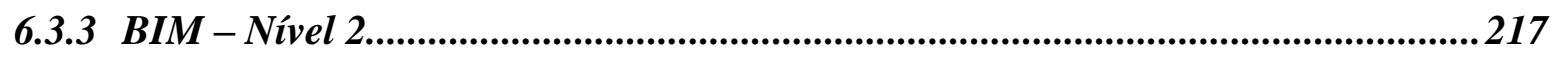

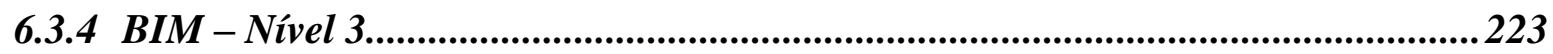

6.3.5 Niveis de Integração pela Tecnologia da Informação ...........................................224

6.4 Correlação entre as perspectivas contratual, organizacional e de tecnologia da informação ..................................................................................................................................................225

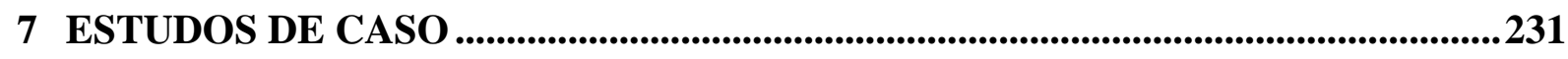

7.1 Caso da literatura (EC-0) - Industrialização de ciclo fechado (Lelé e Prouvé) ....231

7.2 Estudo de Caso 1 (EC-1) - Contratação turnkey.........................................................233

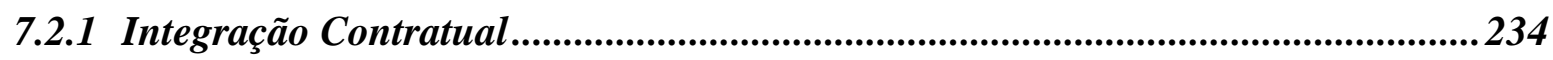

7.2.2 Integração Organizacional .......................................................................................2237

7.2.3 Integração pela Tecnologia de Informação ....................................................239

7.3 Estudo de Caso 2 (EC-2) - Processo como linha de produção................................241 



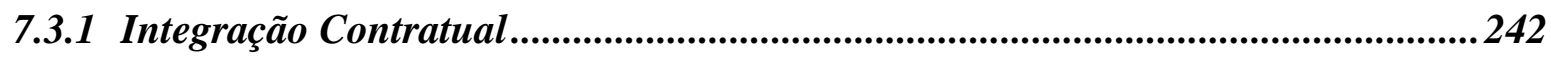

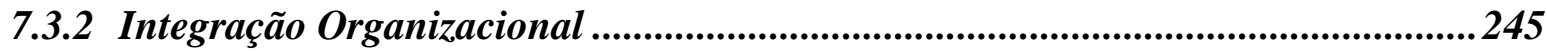

7.3.3 Integração pela Tecnologia de Informação ..........................................................246

7.4 Estudo de Caso 3 (EC-3) - Gestão do processo sem BIM .........................................247

7.4.1 Integração Contratual ............................................................................................. 248

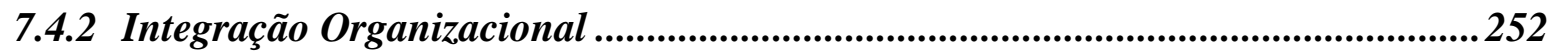

7.4.3 Integração pela Tecnologia de Informação ....................................................253

7.5 Estudo de Caso 4 (EC-4) - Gestão do processo com BIM .......................................254

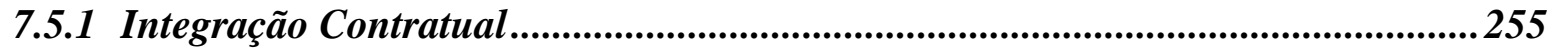

7.5.2 Integração Organizacional .......................................................................................258

7.5.3 Integração pela Tecnologia de Informação .....................................................259

7.6 Comparação dos estudos de caso .......................................................................260

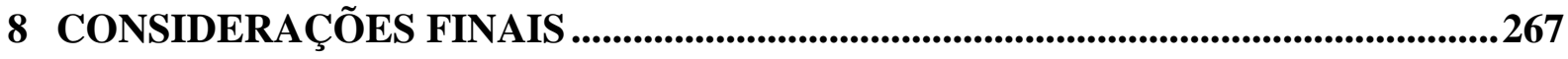

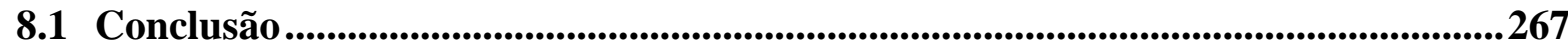

8.2 Limitações e futuros desdobramentos da pesquisa ..............................................269

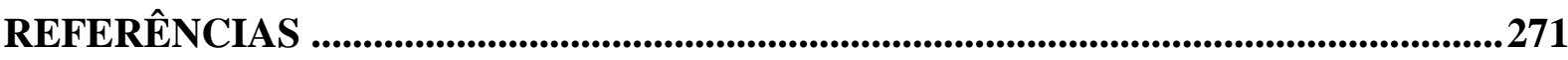

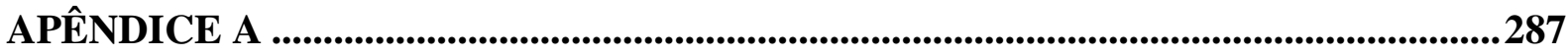

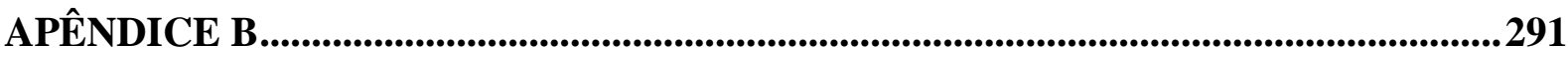





\section{INTRODUÇÃO}

Diz-se que o uso de sistemas industrializados traz benefícios ao mercado da construção civil, tanto em questões econômicas, quanto de produção. Por meio da padronização de componentes, da agilidade na etapa de execução e da redução da mão de obra empregada no canteiro, é possível aumentar a eficiência do processo construtivo. Esses benefícios refletem tanto no impacto da construção civil ao meio ambiente quanto no custo final da edificação.

Mesmo com as vantagens desse sistema em relação à construção in loco, sua utilização é inferior ao potencial que o setor apresenta (ASSOCIAÇÃO BRASILEIRA DA CONSTRUÇÃO METÁLICA, 2018a; 2018b; ASSOCIAÇÃO BRASILEIRA DA CONSTRUÇÃO INDUSTRIALIZADA DE CONCRETO, 2016). Os empecilhos encontrados na inserção da industrialização na construção podem estar relacionados não à tecnologia, mas sim ao método de produção do empreendimento.

Ao longo dos anos, o aperfeiçoamento da produção na construção civil foi um tema presente em diversas pesquisas do setor (NAM; TATUM, 1992; LATHAN, 1994; EGAN, 1998; 2002; FORBES; AHMED, 2011; EASTMAN; et al., 2011; AMERICAN INSTITUTE OF ARCHITECTS, 2007a). Nam e Tatum (1992), indicaram que a integração entre projeto e construção é a melhor oportunidade para aperfeiçoar os processos na construção civil.

Desde os primeiros relatórios elaborados pelo Governo Britânico para caracterizar o setor da construção civil, a fragmentação do processo de produção foi identificada como um dos principais problemas. A integração passou a ser uma meta para se alcançar a melhor qualidade e produtividade na execução dos empreendimentos (MURRAY; LANGFORD, 2003). No relatório elaborado por Egan (1998) a integração tanto do processo como da equipe foi considerada como um elemento essencial para melhorar o desempenho da indústria, e por consequência, melhorar a qualidade dos empreendimentos.

Pesquisas recentes continuaram a abordar a integração, passando a investigar sua aplicabilidade em áreas específicas da construção civil, como no setor público (AZHAR; KANG; AHMAD, 2015) e para alcançar a sustentabilidade (MOLENAAR; SOBIN, 2009; MOLLAOGLUKORKMAZ; SWARUP; RILEY, 2013); ou realizando análises comparativas de desempenho entre diferentes métodos de execução do empreendimento (EL ASMAR; HANNA; LOH, 2013; 2015). 
As indústrias da construção civil têm voltado à atenção na busca por melhores práticas de produção visando à eficiência e qualidade do processo e do edifício. Os projetos que utilizam a industrialização possuem um alto nível de complexidade, o que exige que diferentes especialistas trabalhem em conjunto, buscando atender às demandas dos clientes, de forma técnico e economicamente viáveis. Portanto, é essencial estudar a inserção de processos de produção estruturados na integração da equipe e no trabalho colaborativo.

No entanto, o processo de produção possui diferentes aspectos que podem sofrer influência da integração. Nam e Tatum (1992) identificaram três perspectivas para a integração: contratual, em que os instrumentos dos contratos definem como será alcançada a integração; organizacional, onde são consideradas as relações entre os participantes na execução do processo; e tecnologia de processamento da informação, em que o uso ferramentas computacionais possibilitam a integração do processo.

Diversos autores (EASTMAN; et al., 2011; FORBES; AHMED, 2011; AMERICAN INSTITUTE OF ARCHITECTS, 2014) defendem que para alcançar a completa integração é necessário abranger todas as três dimensões. Esta pesquisa de doutorado analisa como cada perspectiva da integração pode aperfeiçoar o processo de produção na construção industrializada.

Como a essência da construção industrializada está na visão sistêmica do processo de produção, é possível que a integração das etapas e o trabalho colaborativo possam favorecer o maior uso desse tipo de construção. Por meio da integração pode ser possível superar os desafios para uma comunicação eficiente entre os agentes do processo de produção, como: incorporadores, projetistas, construtores, fornecedores e subcontratados.

\subsection{Objetivos e hipótese da pesquisa}

O objeto de estudo desta pesquisa é o processo de produção de empreendimentos que utilizam sistemas construtivos industrializados. A análise do processo, considerando o desenvolvimento do projeto, produção dos componentes e montagem da edificação, possibilita investigar a integração sob as três perspectivas - contratual, organizacional, e de tecnologia da informação. O objetivo geral desta pesquisa é analisar como cada uma das perspectivas da integração pode aperfeiçoar e ampliar o uso da construção industrializada. Esta pesquisa visa ainda detalhar o impacto da integração em cada uma das etapas do processo de produção. 
A hipótese a se verificar é que a integração do processo de produção, no contexto da industrialização da construção, pode ser alcançada sem que sejam atingidos os níveis máximos de integração em cada perspectiva, ou seja, a ausência da integração em uma dimensão pode ser compensada pelas demais. Cada uma das perspectivas pode ter maior ou menor influência sobre o processo de produção, o que representaria maiores ou menores oportunidades para integrar o processo de produção utilizando a construção industrializada.

\subsection{Justificativa}

O processo de produção na construção civil se caracteriza pela interação de diversas atividades em vários níveis de amadurecimento, envolvendo profissionais de diferentes especialidades. Algumas pesquisas recentes (EL ASMAR; HANNA; LOH, 2013, 2015; FRANZ et al., 2016; HARPER; MOLENAAR; CANNON, 2016) demonstraram que o método de execução do empreendimento influencia no desempenho em relação ao prazo, custo, qualidade, quantidade de disputas judiciais, ambiente de colaboração entre os agentes e na satisfação do cliente.

Os processos integrados abordam a construção civil não como uma sucessão de atividades, que ganham complexidade linearmente ao logo do tempo, mas como um conjunto de atividades interdependentes, onde são consideradas as diferentes disciplinas em todas as etapas. Como consequência, todos os agentes trabalham em busca das melhores soluções para o empreendimento, independentemente das atividades em que eles são responsáveis.

A importância desta pesquisa na área da Arquitetura e Urbanismo está no estudo de um tema que ainda está em vias de desenvolvimento. Várias pesquisas recentes na área de gestão e tecnologia da construção estão abordando a integração sob diferentes aspectos, como: sustentabilidade (MOLENAAR; SOBIN, 2009; MOLLAOGLU-KORKMAZ; SWARUP; RILEY, 2013); aplicação em setores além de edificações, como no caso de infraestrutura urbana (FRANCOM; ARIARATNAM; EL ASMAR, 2016); interação entre integração e BIM (SACKS; et al., 2010; YALCINKAYA; SINGH , 2015; LIU; NEDERVEEN; HERTOGH, 2017); e avaliação de métodos integrados em comparação aos demais processos de produção (EL ASMAR; HANNA; LOH, 2013, 2015).

Por se tratar de pesquisas recentes, é evidente o grande interesse do setor acadêmico neste tema. Além disso, existe um campo a ser explorado especificamente no caso de projetos de edificações executadas com sistemas construtivos industrializados, o que aponta a necessidade de aprofundamento dos estudos sobre sua aplicabilidade. 


\subsubsection{Realidade da construção industrializada}

Apesar do aumento dos investimentos na construção civil ao longo dos anos, as inovações e modernizações não seguiram o mesmo ritmo. A indústria da construção é vista como conservadora em relação às inovações, se comparadas às demais indústrias (GOH; LOOSEMORE, 2017).

Enquanto os demais segmentos industriais investem principalmente no aprimoramento dos processos de produção e no desenvolvimento de novos produtos (BYGBALLE; INGEMANSSON, 2014), os investimentos na construção civil são destinados principalmente à manutenção de recursos, sejam eles pessoas ou equipamentos (CÂMARA BRASILEIRA DA INDÚSTRIA DA CONSTRUÇÃO, 2012).

Ao longo dos anos, muitas pesquisas buscaram analisar o setor da construção civil, identificando os problemas e as oportunidades de aperfeiçoamento. Dentre as oportunidades de melhorias, o tema da construção industrializada esteve presente em muitas delas (TATUM; VANEGAS; WILLIAMS, 1987; MURRAY; LANGFORD, 2003; TAM; et al., 2007; GIRMSCHEID; SCHEUBLIN, 2010; MCGRAW HILL CONSTRUCTION, 2011; FORBES; AHMED, 2011; HM GOVERNMENT, 2013).

Uma das formas de industrializar a construção é com o uso de sistemas pré-fabricados. Apesar das vantagens desse tipo de construção em relação à construção in loco, seu uso é inferior ao potencial que o mercado apresenta. Em uma pesquisa em torno da construção industrializada realizada pelo Fails Management Institute (FMI) e BIMForum (HOOVER; TROMBITAS; COWLES, 2017), foi investigada a maneira como os profissionais utilizam os sistemas construtivos pré-fabricados em seus projetos e como eles consideram os benefícios para o empreendimento.

Cerca de metade dos entrevistados usaram sistemas pré-fabricados em mais de $20 \%$ dos empreendimentos. Esse valor representa um crescimento em relação às pesquisas anteriores, 0 que mostra um maior interesse das empresas nesse tipo de sistema construtivo. No entanto, ainda é um número pequeno em relação ao total de empreendimentos.

Dentre os entrevistados que utilizaram sistemas pré-fabricados na construção, apenas 14\% consideraram que o processo de produção se mostrou eficiente. Os demais entrevistados $-86 \%$ - consideraram que os sistemas industrializados ainda precisam ser aperfeiçoados para que os benefícios propostos possam ser alcançados. 
No Brasil, o uso de sistemas construtivos industrializados também é pequeno. Tendo como exemplo o aço, o país possui a maior produção da América Latina e é o nono maior produtor mundial, porém o consumo é inferior à média dos países latino-americanos (ASOCIACIÓN LATINOAMERICANA DEL ACERO, 2018).

Segundo dados da Asociación Latinoamericana del Acero (2018) o Brasil possui um consumo aparente per capita de $95 \mathrm{~kg}$ de aço laminado, enquanto México consome $200 \mathrm{~kg}$ e o Chile 152 kg. No caso dos Estados Unidos, dos países da União Europeia e da Coréia do Sul os índices são ainda maiores, sendo de $306 \mathrm{~kg}, 327 \mathrm{~kg}$ e $1057 \mathrm{~kg}$, respectivamente. De acordo com o Worldsteel Association (2018), dentre as aplicações do aço, a indústria da construção civil representa $51 \%$ do consumo total desse material.

Esses dados mostram que o Brasil possui um potencial para o uso do aço na construção. Além disso, pesquisas do Centro Brasileiro da Construção em Aço (CBCA) indicam que a capacidade produtiva das indústrias de estruturas metálicas é maior do que sua real produção.

A produção de aço das empresas brasileiras representou $71 \%$ da capacidade produtiva em 2014, e teve uma queda acentuada nos últimos anos, devido à crise político econômica que o país passou e que refletiu na queda da produção na construção civil. Os índices caíram para $58 \% \mathrm{em}$ 2015, 43\% em 2016 e 41\% em 2017 (ASSOCIAÇÃO BRASILEIRA DA CONSTRUÇÃO METÁLICA, 2015a; 2016a; 2017a; 2018a).

Situação semelhante pode ser observada no caso específico do sistema construtivo Light Steel Frame $^{1}$. A produção nos anos de 2014 e 2015 representou cerca de 50\% da capacidade produtiva das empresas (ASSOCIAÇÃO BRASILEIRA DA CONSTRUÇÃO METÁLICA, 2015b; 2016b). Nas últimas pesquisas, referentes aos anos de 2016 e 2017, esse percentual caiu para $23 \%$ e $20 \%$ respectivamente (ASSOCIAÇÃO BRASILEIRA DA CONSTRUÇÃO METÁLICA, 2017b; 2018b).

No caso da industrialização por meio de elementos pré-fabricados em concreto armado, existiu uma redução no uso desse sistema, apesar do aumento do consumo total de cimento. Os dados dos Relatórios Anuais de 2007 até 2013 do Sindicato Nacional da Indústria do Cimento (2018) indicaram que o consumo de cimento pelas indústrias de pré-fabricados se manteve em uma média de $2,5 \%$ do consumo total no Brasil, com uma leve queda nos dois últimos anos da

\footnotetext{
${ }^{1}$ Sistema estrutural industrializado, constituído por painéis compostos de perfis de aço galvanizado formado a frio. (SANTIAGO; FREITAS; CRASTO, 2012)
} 
pesquisa. Enquanto isso, o consumo total de cimento aumentou $57 \%$ no mesmo período e o consumo pelas concreteiras passou de 14,4\% em 2007 para 19,6\% em 2013.

A partir dos dados da Associação Brasileira da Construção Industrializada de Concreto (ABCIC), percebe-se que a capacidade produtiva das empresas é bem maior do que a demanda pelos componentes pré-fabricados em concreto no Brasil. No ano de 2014, a produção representou $63 \%$ da capacidade de produção (ASSOCIAÇÃO BRASILEIRA DA CONSTRUÇÃO INDUSTRIALIZADA DE CONCRETO, 2015), e teve uma queda na última pesquisa de 2015, com 55\% de utilização da capacidade produtiva (ASSOCIAÇÃO BRASILEIRA DA CONSTRUÇÃO INDUSTRIALIZADA DE CONCRETO, 2016).

Percebe-se que existe um campo a ser explorado no setor da construção civil em relação aos sistemas construtivos industrializados. A cadeia produtiva possui um grande potencial para atender a uma demanda maior da construção civil. Além disso, a recente retração na economia brasileira e a redução da demanda, indica que é essencial que as empresas revejam suas estruturas, processos e sistemas gerenciais para que possam permanecer no mercado.

Ao inserir mudanças na estrutura do processo, a integração altera significativamente a visão da produção do empreendimento. No caso da construção industrializada, a necessidade de uma visão sistêmica, requer uma aproximação entre as etapas de planejamento, desenvolvimento do projeto e obra. Portanto, é essencial entender como as diferentes perspectivas da integração influenciam a inserção da industrialização na construção civil, de forma a facilitar e orientar os clientes na escolha do método de execução do empreendimento mais eficiente para cada situação.

\subsection{Estrutura da tese}

A tese está estruturada em oito capítulos:

- Capítulo 1 - Introdução: em que foram definidas as informações essenciais da pesquisa, como, contextualização do tema, objeto de estudo, objetivos, hipótese a ser investigada, justificativa e importância do tema para a área de pesquisa;

- Capítulo 2 - Método da Pesquisa: em que foram definidos os procedimentos usados para investigar a hipótese da pesquisa.

- Capítulo 3 - Processo de produção do empreendimento: onde foram definidos como se estabelece um processo de produção de um empreendimento a partir da análise da 
literatura, considerando diferentes perspectivas e setores da construção civil; nesse capítulo foram identificadas as etapas e agentes do processo de produção que embasaram o desenvolvimento dos diagramas e a análise dos estudos de caso;

- Capítulo 4 - Construção industrializada: neste capítulo investiga-se por meio da literatura quais as influências e especificidades do uso da construção industrializada no processo de produção do empreendimento; além disso, considerou-se duas abordagens para o conceito de industrialização - pelo sistema construtivo e pelo método de produção;

- Capítulo 5 - Integração na construção civil: neste capítulo foi definido o conceito de integração do processo produtivo a partir das três perspectivas - contratual, organizacional e de tecnologia da informação - e analisada as interdependências entre elas;

- Capítulo 6 - Análise das perspectivas da integração e suas interdependências: em que foram apresentados e analisados os diagramas desenvolvidos por esta pesquisadora para melhor compreensão das perspectivas da integração; além da definição dos níveis de integração e a interdependência entre eles;

- Capítulo 7 - Estudos de caso: nesse capítulo foram descritos e analisados cinco estudos de caso e definidos os diagramas das três perspectivas para cada um deles; além de uma análise comparativa dos níveis de integração alcançados por cada estudo de caso e sua relação com o nível de industrialização dos empreendimentos; e

- Capítulo 8 - Considerações finais: em que as informações da análise teórica, da explicitação das perspectivas de integração e dos estudos de caso foram sintetizadas e confrontadas com a hipótese inicial da tese. 


\section{MÉTODO DA PESQUISA}

O método para realizar esta pesquisa está dividido em três etapas: categorização do problema; explicitação das perspectivas de integração do processo de produção; e análise de estudos de caso.

\subsection{Categorização do problema}

Para atingir os objetivos propostos nesta pesquisa, foram detalhados os elementos que influenciam na análise da integração da construção civil, com o uso da industrialização. Dentre os elementos estão o processo de produção do empreendimento, em que foram caracterizadas suas bases, ou seja, as etapas e atividades que o compõem e o papel de cada um dos agentes. Para definir o processo, foram consideradas a visão de diferentes autores, associações e instituições, considerando as características locais das publicações.

Em relação à construção industrializada, definiu-se quais suas características e o que a diferencia dos demais sistemas construtivos. Além disso, identificou-se os requisitos para a viabilidade da industrialização na construção civil, considerando as características do projeto, planejamento de obra, etapa de montagem e interação com a indústria de componentes.

Para definir o conceito de integração, considerou-se a divisão em três perspectivas, proposta por Nam e Tatum (1992), e que foi usada como referência em outras pesquisas (MITROPOULOS; TATUM, 2000; AZARI; KIM, 2015; LIU; SKIBNIEWSKI; WANG, 2016; PAPADONIKOLAKI; WAMELINK, 2017) - contratual, organizacional e de tecnologia da informação.

Na perspectiva contratual foram investigados como os modelos de contrato e os métodos de produção dos empreendimentos podem influenciar na integração do processo de produção. $\mathrm{O}$ sistema contratual determina o vínculo entre os profissionais e seus deveres sobre a produção do empreendimento, o que pode indicar que o modelo adotado exerça grande influência na integração do processo. Dois tipos de contrato foram identificados e foram analisados os principais modelos utilizados pela construção civil:

- Transacional: que compreende os modelos Design-Bid-Build (DBB); Design and Build (DB); e Construction Management at Risk (CMAR); e

- Relacional: com os modelos Early Contractor Involvement (ECI), Project Partnering (PP), Project Alliancing (PA) e Integrated Project Delivery (IPD). 
A perspectiva organizacional compreende as interações entre os agentes do processo de produção, considerando o fator humano na formação e no trabalho da equipe. Nesta área, foram analisados os fatores que favorecem ou dificultam o trabalho colaborativo e que não estão atrelados ao sistema contratual.

Na perspectiva de tecnologia da informação, foi investigado como a Modelagem da Informação da Construção (BIM) pode facilitar ou até demandar a integração dos processos e da equipe. Ao estabelecer uma mudança de paradigma nos procedimentos de produção do empreendimento, o BIM possibilita integrar, em um único modelo computacional, as informações de projeto, fabricação, execução e gestão da construção. Além disso, o BIM permite que os profissionais trabalhem simultaneamente em um mesmo modelo, reduzindo a troca de cópias de arquivos e documentos, o retrabalho e os erros de coordenação.

Por fim, foi investigada a existência de interdependência entre as três perspectivas, por meio da análise de dois procedimentos que visam estabelecer um processo de produção integrado: Lean Project Delivery System (LPDS) e Integrated Design and Delivery Solutions (IDDS).

\subsection{Explicitação das perspectivas de integração}

As informações sobre a integração presente na literatura estão descritas em grande parte na forma textual, o que dificulta sua análise e comparação. Cada perspectiva da integração foi detalhada e suas características foram descritas em forma de diagramas para sua melhor compreensão ${ }^{2}$.

\subsubsection{Perspectiva Contratual}

No caso da perspectiva contratual, partiu-se do modelo desenvolvido pelo AIA (AMERICAN INSTITUTE OF ARCHITECTS, 2014) para analisar as características de cada tipo de contrato - transacional e relacional (Figura 1). No entanto, percebeu-se que os diagramas definidos pelo AIA são simplificados e não indicam todas as características do processo de produção que permitiriam comparar e diferenciar os modelos de cada tipo contratual. Por essa razão tornouse necessário expressar esses diagramas em maior detalhe a partir das características significantes de cada modelo que se desejou estudar, por comparação com os demais.

\footnotetext{
${ }^{2}$ As características dos diagramas de cada perspectiva de integração estão detalhadas no capítulo 6.
} 
Figura 1 - Diagrama elaborado pela AIA - Processo de Produção Tradicional e Integrado

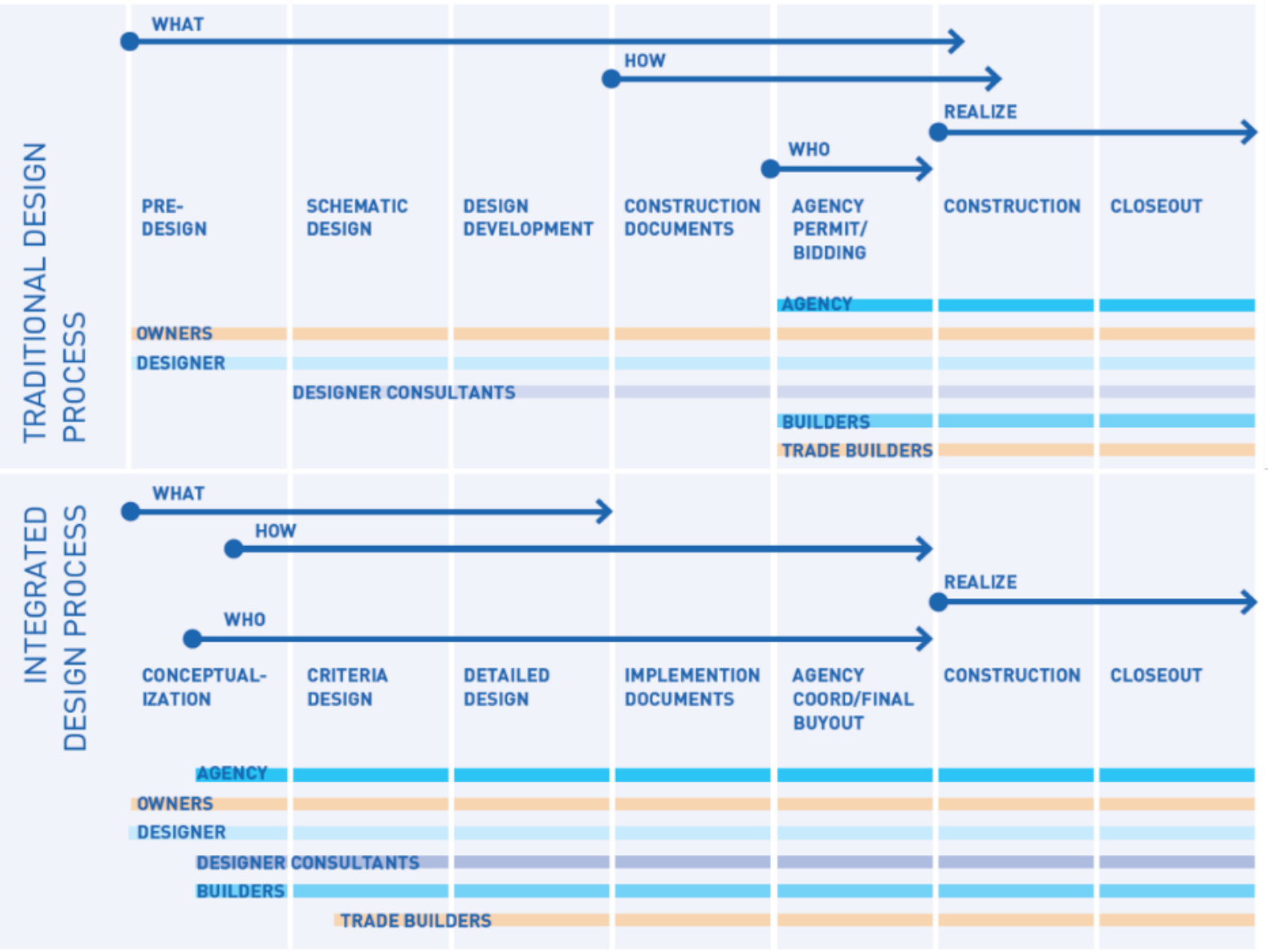

Fonte: AMERICAN INSTITUTE OF ARCHITECTS, 2014.

Para os modelos de diagramas mais detalhados, foi utilizada como referência a notação do Business Process Model and Notation (BPMN), ou Notação para Modelagem de Processo de Negócio. O BPMN foi desenvolvido pelo Object Management Group - OMG (2011) visando padronizar os elementos que compõem o fluxograma dos processos de negócio. Essa nomenclatura foi adotada por pesquisadores e instituições para descrever os processos de produção na construção civil (ALI; BADINELLI, 2016; ALRESHIDI; MOURSHED; REZGUI, 2016), com destaque ao buildingSMART, que indica o BPMN como um modelo para a formalização dos processos que utilizam o BIM (WIX, 2007).

Com o uso do BPMN, os diagramas foram detalhados em dois níveis. No primeiro nível foram consideradas as principais etapas do processo - planejamento, desenvolvimento e execução. Com isso, foi possível determinar o fluxo de desenvolvimento do empreendimento e os momentos em que são estabelecidos os contratos e as trocas de informação durante o processo.

No segundo nível de detalhamento, consideraram-se as principais atividades dentro de cada etapa, possibilitando entender como são as interações dos agentes em cada atividade do 
processo, ou seja, de qual agente é a responsabilidade de sua execução, quais atividades possuem dependência no seu desenvolvimento e quais as possibilidades de colaboração entre os demais profissionais.

Nos diagramas com maior nível de detalhamento, foram identificadas as possibilidades de retrabalho devido a entrada de um novo participante no processo. Esse retrabalho não significa um reinício de uma atividade, mas sim a necessidade de rever algumas questões de projeto ou execução que podem ocorrer quando da entrada de um novo participante no processo. A realização ou não de alterações deverá ser avaliada pelos profissionais, considerando os benefícios das modificações em relação ao custo e prazo para sua execução.

Posteriormente, foi realizada uma ordenação dos modelos de contrato, de acordo com seu nível de integração. Com isso foi possível compreender as semelhanças e diferenças entre os sistemas contratuais, ou seja, se favorecem ou dificultam a integração do processo de produção do empreendimento.

Os diagramas desenvolvidos para esta etapa da pesquisa indicam um modelo padrão para cada tipo de contrato, ou seja, as características descritas na literatura foram traduzidas para uma ferramenta visual, considerando o fluxo de atividades do processo de produção. No entanto, podem existir variações conforme a aplicação prática de cada modelo de contrato. A análise dos modelos de referência foi importante para identificar como cada particularidade do contrato influencia nas possibilidades de integração no processo de produção do empreendimento.

\subsubsection{Perspectiva Organizacional}

Para explicitar a integração sob a perspectiva organizacional, foi usado como referência o modelo de diagrama publicado por Molenaar e Sobin (2009) (Figura 2). Nesses diagramas, estão representadas as interações entre os principais agentes do processo de produção de cada modelo contratual transacional - DD, DB e CMAR - sendo indicados os principais agentes do processo e suas relações - contrato, comunicação e requisitos de coordenação contratual. 
Figura 2 - Referência para a elaboração dos diagramas de integração organizacional

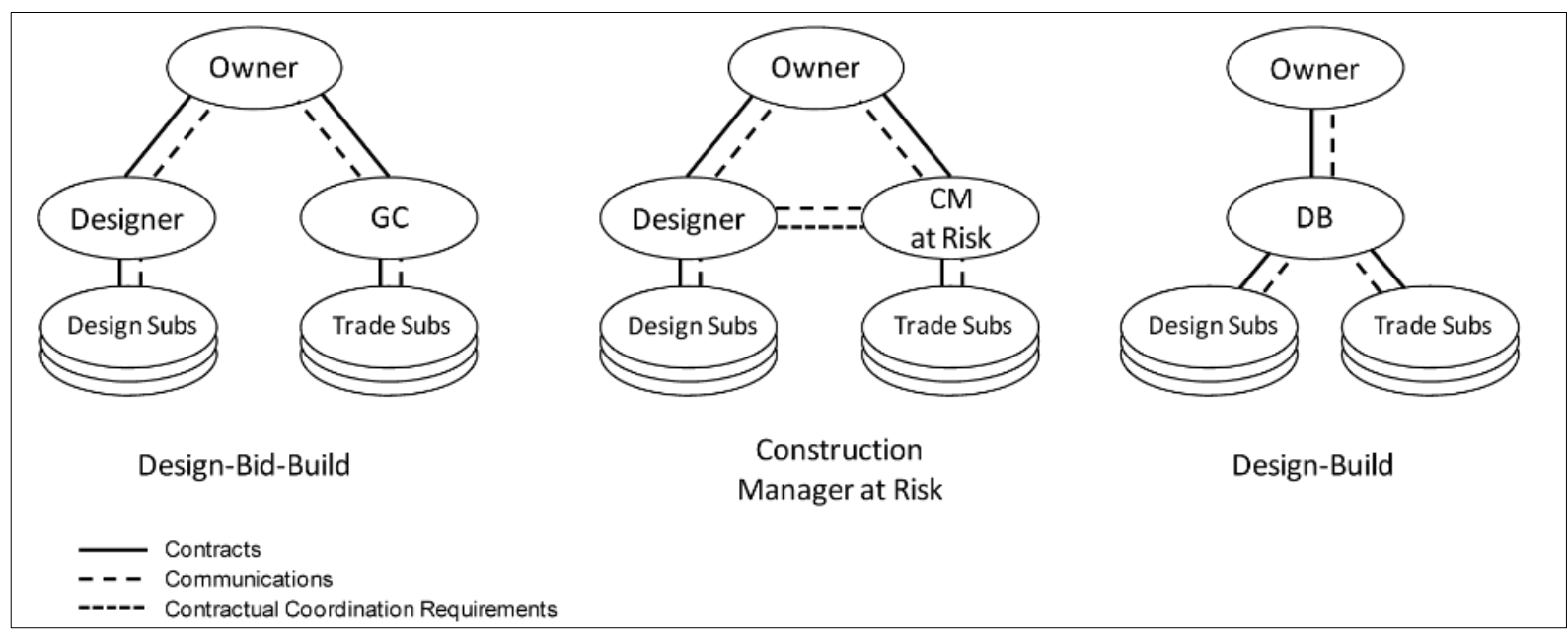

Fonte: MOLENAAR; SOBIN, 2009.

Os diagramas indicam simultaneamente o modelo de contratação e a forma mais comum de organização da produção. Os diagramas foram alterados para a análise apenas das possibilidades das interações entre os agentes, que não estão relacionadas às cláusulas contratuais. Dentre as possibilidades, foram identificadas três categorias:

- processo de produção sem colaboração, nesse caso não existe integração no processo de produção, pois cada profissional trabalha apenas na atividade de sua responsabilidade e as entregas ocorrem apenas quando sua atividade é finalizada;

- processo colaborativo na etapa de projeto elou de obra, nessa categoria foram consideradas as interações que ocorrem nas etapas de desenvolvimento de projeto ou de execução, ou quando elas ocorrem simultaneamente, mas sem que exista a colaboração entre etapas; e

- colaboração ao longo de todo o processo, essa categoria representa o maior nível de integração organizacional, ou seja, existe o trabalho colaborativo entre toda a equipe e em todas as etapas do processo de produção.

Percebeu-se que, para compreender a integração organizacional, foi necessário considerar duas variações na formação da equipe, não contempladas por Molenaar e Sobin (2009). A primeira delas é a participação ou não do gestor no processo. Esse agente influencia no modo como os demais profissionais interagem, pois ele se torna um representante do cliente e o agente central do processo.

A outra variação foi o modelo de contratação turnkey, ou seja, quando o cliente seleciona um único agente para desenvolver todo o empreendimento, desde o projeto até a obra. Nesse caso 
existe uma associação entre o projetista e o construtor, fato que altera as relações entre os agentes do processo e as possibilidades de colaboração na equipe.

Posteriormente, cada uma das possibilidades de organização da equipe foi sistematizada em relação ao nível de integração. Os modelos de equipe foram organizados conforme suas características, indicando quais são os menos integrados e quais os que apresentam maiores possibilidades para estabelecer o trabalho colaborativo.

\subsubsection{Perspectiva de Tecnologia da Informação}

Em relação à perspectiva de tecnologia da informação, foram desenvolvidos diagramas que ilustram como são estabelecidas as trocas de informações durante o processo, considerando os níveis de maturidade BIM definidos por Succar (2009): Pré-BIM, sem o uso do BIM; Nível 1, modelagem orientada a objetos; Nível 2, colaboração baseada em modelos; Nível 3, integração baseada em rede; e IPD, atualizado posteriormente para Pós-BIM (SUCCAR; SHER; WILLIAMS, 2013), com a completa integração do processo.

Para a definição dos diagramas, foram considerados somente os profissionais do processo que tem a possibilidade de usar BIM no desenvolvimento de sua atividade. Dessa forma, não foi considerado o cliente na formação da equipe, pois ele é um agente que define a demanda pelo empreendimento e valida as decisões do processo e, portanto, não poderia trabalhar colaborativamente no desenvolvimento do modelo BIM.

As interações entre os profissionais foram definidas pela possibilidade de uso do BIM entre eles:

- Convencional ${ }^{3}$, em que nenhum dos profissionais trabalha com o BIM;

- BIM-Convencional, em que apenas um dos profissionais usa o BIM, sendo necessário elaborar arquivos 2D e documentação impressa ou digital no final do desenvolvimento de sua atividade;

- BIM-BIM, em que dois dos profissionais desenvolvem e compartilham o modelo BIM; e

- BIM em todo o processo, com o uso de um modelo único ou federado.

\footnotetext{
${ }^{3}$ Termo definido por Khan e Raouf (2015) para indicar o uso de ferramentas primitivas de elaboração do projeto, podendo incluir arquivos $2 \mathrm{D}$, documentos impressos e desenhos manuais.
} 
A partir da definição de diferentes conformações da equipe, em relação às possibilidades do uso do BIM em cada um desses níveis de maturidade, foram definidos os níveis de integração pela perspectiva de tecnologia da informação. Percebeu-se que, dependendo das possibilidades de uso do BIM - por apenas uma disciplina, por todas as disciplinas de uma mesma etapa, ou com o uso entre etapas - existe uma variação do nível de integração dentro da mesma classificação de Succar (2009).

\subsection{Estudos de Caso}

Os modelos de integração pelas perspectivas contratual, organizacional e de tecnologia da informação são representações idealizadas de cada possibilidade de organização do processo de produção. No entanto, podem existir variações de cada modelo, ou mesmo a junção de dois modelos em determinado processo. Para analisar como são estabelecidos os processos de produção do empreendimento na prática, foi analisado um caso descrito na literatura e foram realizados quatro estudos de caso.

O objeto de análise foram empreendimentos que utilizam a construção industrializada. O termo industrialização da construção tem uma definição ampla e abrange diversas características, como: produção mecanizada; padronização de elementos; utilização de sistemas pré-fabricados; racionalização; e projeto modular (GIRMSCHEID; SCHEUBLIN, 2010).

O primeiro caso descreve os processos de produção de João Filgueiras Lima, o Lelé, e Jean Prouvé. Ambos profissionais trabalharam com a industrialização fechada por meio da criação de fábricas que detinham o controle completo do processo - projeto, fabricação e montagem das peças. Os dados para a análise desse caso foram obtidos pela literatura, em que foi possível identificar as características de produção por meio dos empreendimentos executados pelos arquitetos, a partir das três perspectivas da integração.

Os quatro estudos de caso são empreendimentos que utilizam sistemas construtivos da industrialização aberta. Os elementos pré-fabricados são do tipo padronizados, ou seja, definidos pela indústria e selecionados pelo profissional; ou produzidos de acordo com uma demanda única, ou seja, especificados pelo profissional e produzidos pela indústria. Em ambos os casos, os elementos construtivos são transportados até o canteiro de obras onde é feita a montagem. 
Os empreendimentos dos estudos de caso da industrialização aberta foram selecionados considerando sua adequação ao tema, com uma primeira aproximação feita aos arquitetos responsáveis pelo projeto. Foi dada prioridade aos escritórios de arquitetura da cidade de São Paulo, SP. A delimitação geográfica se deu pelo local em que esta pesquisa foi elaborada, além da importância econômica da região, o que pode indicar que existe um grande número de empreendimentos e, consequentemente, variados tipos de sistemas construtivos e de processos de produção.

Foram selecionados quatro empreendimentos de elevada complexidade, sendo dois de uso institucional, um comercial e um aeroporto. Cada estudo de caso da industrialização aberta possui uma característica diferente no desenvolvimento do processo de produção: contratação turnkey, processo como linha de produção, gestão do processo sem o uso do BIM e gestão do processo com o uso do BIM.

O estudo detalhado de cada processo de produção representou uma quantidade suficiente de informações para realizar uma análise dos dados em relação às três perspectivas da integração. Esta pesquisa é qualitativa, ou seja, os resultados obtidos no estudo de caso indicam uma tendência sobre o processo de produção. Portanto, esta pesquisa não visa definir como todo o setor da construção civil industrializada funciona.

A coleta de dados foi feita durante os anos de 2017 e 2018 por meio de entrevistas baseadas em um questionário semiestruturado com questões abertas (Apêndices A e B), que definiram um roteiro para a entrevista e permitiu um aprofundamento em determinadas questões dependendo das respostas fornecidas pelos entrevistados. Além disso, para esclarecer melhor como foi realizado o processo de produção do empreendimento, em alguns casos, novas questões foram incorporadas no questionário.

Foram entrevistados inicialmente os arquitetos responsáveis pela elaboração dos empreendimentos e depois os principais agentes que interferem no desenvolvimento do projeto e execução, como o cliente e o gestor de produção. As informações colhidas na entrevista com o profissional responsável pela gestão do processo, foram essenciais para a pesquisa, pois o gestor tem como característica participar de todo o processo e de interagir com todos os profissionais e áreas do processo de produção.

A partir dos dados coletados, foi definido o processo de produção de cada empreendimento, tendo como base os diagramas desenvolvidos para cada perspectiva de integração: contratual, organizacional e de tecnologia da informação. Após a montagem esquemática do processo, o 
documento produzido por esta pesquisadora foi mostrado aos entrevistados para que eles confirmassem os dados ou indicassem correções a serem feitas, para que os estudos de caso refletissem de maneira mais precisa o processo de produção usado para o empreendimento.

Após a análise do caso de Lelé e Prouvé e da definição de cada diagrama para os estudos de caso da industrialização aberta, foi identificado o nível de integração de cada um, em relação a cada perspectiva. Essa análise permitiu identificar qual das três dimensões são mais ou menos utilizadas para buscar a integração do processo de produção e se existe alguma interdependência entre elas. Além disso, a análise do nível de integração permitiu identificar como as perspectivas de integração estão relacionadas ao nível de industrialização dos empreendimentos e ao desempenho dos processos de produção descritos pelos entrevistados. 


\section{PROCESSO DE PRODUÇÃO DO EMPREENDIMENTO}

A construção é o produto final do processo de produção da indústria da construção civil. Cardoso (1996) descreveu o processo de produção como um conjunto de etapas, organizadas de forma coerente no tempo, visando à execução de uma obra. Nessa definição, são consideradas desde as etapas de idealização do produto, ou seja, definição dos objetivos e parâmetros do empreendimento, até a operação e manutenção do edifício.

Segundo Forbes e Ahmed (2011), as especificidades da construção civil indicam a complexidade do processo de produção da construção, se comparado à produção das demais indústrias. As seguintes características diferenciam esses dois setores:

- os produtos da construção civil são executados a partir de uma demanda individual, enquanto a produção das outras indústrias segue uma padronização com a repetição dos produtos;

- a locação do canteiro de obras é variável e está sujeita às alterações de clima, enquanto nas demais indústrias a produção acontece em um ambiente fechado e controlado;

- o tempo de produção de um empreendimento é geralmente maior em relação às demais indústrias; e

- com o fim da produção na construção, a equipe é desfeita, na maioria dos casos, e os participantes são dispensados dos compromissos com a produção; enquanto o vínculo dos agentes nas demais indústrias é de longo prazo.

A demanda pela produção do empreendimento se mostra extremamente complexa e ocorre segundo ciclos relativamente únicos, o que indica um volume de produção variável. Outras questões como, dimensão, elevado valor, importância social e econômica, bem como a longa vida útil do edifício determinam a particularidade da indústria da construção frente aos demais processos de produção (FABRICIO, 2002).

Sobre a singularidade dos processos na construção civil, Gadde e Dubois (2010) indicaram que isso dificulta o aprimoramento contínuo das atividades e não favorece o trabalho colaborativo da equipe. Como os agentes, em sua maioria, não conseguem estabelecer uma relação de trabalho de longo prazo, existe uma dificuldade em corrigir problemas observados em um processo de produção para a execução de um novo empreendimento.

Gadde e Dubois (2010) especificaram algumas diferenças entre as relações de trabalho na construção civil e nas demais indústrias, que possuem relações de trabalho com grande envolvimento Tabela 1. 
Tabela 1 - Comparação entre as características das relações com grande envolvimento e das relações típicas da construção civil

\begin{tabular}{lll}
\hline $\begin{array}{c}\text { Características } \\
\text { das relações }\end{array}$ & \multicolumn{1}{c}{ Relações com grande envolvimento } & \multicolumn{1}{c}{ Relações da construção civil } \\
\hline Longevidade & $\begin{array}{l}\text { Intercâmbio contínuo de negócios com } \\
\text { parcerias fiéis. }\end{array}$ & $\begin{array}{l}\text { Falta de continuidade nos negócios e pouca } \\
\text { fidelidade nas relações. }\end{array}$ \\
Adaptação & $\begin{array}{l}\text { A adaptação mútua entre empresas } \\
\text { proporciona benefícios ao desempenho das } \\
\text { parcerias. }\end{array}$ & $\begin{array}{l}\text { Pouca adaptação entre as empresas que têm } \\
\text { relações constantes - necessidade de } \\
\text { grandes ajustes nos serviços ou produtos. }\end{array}$ \\
& $\begin{array}{l}\text { Complexidade técnica resolvida por meio de } \\
\text { contratos que levam à dependência } \\
\text { Dependência }\end{array}$ & $\begin{array}{l}\text { Complexidade técnica resolvida por } \\
\text { padronização dos serviços. Empresas } \\
\text { evitam a dependência organizacional. }\end{array}$ \\
& $\begin{array}{l}\text { Interação intensiva entre empresas. } \\
\text { Processos anteriores geram impacto nos } \\
\text { resultados do processo atual, assim como as } \\
\text { expectativas futuras. }\end{array}$ & $\begin{array}{l}\text { Interação limitada entre empresas. Interação } \\
\text { intensiva para adaptar os serviços ou } \\
\text { produtos ao contexto específico do } \\
\text { empreendimento. Nenhum impacto sobre as } \\
\text { expectativas futuras. }\end{array}$ \\
& $\begin{array}{l}\text { Instrumentos de colaboração compensam os } \\
\text { potenciais conflitos relacionados ao } \\
\text { confronto de interesses. }\end{array}$ & $\begin{array}{l}\text { Interações não incentivam os instrumentos } \\
\text { de colaboração o que torna o ambiente } \\
\text { propício às condições adversas. }\end{array}$ \\
& $\begin{array}{l}\text { Evolui por meio das interações contínuas e } \\
\text { as sucessivas adaptações e levam ao } \\
\text { fortalecimento das interdependências e } \\
\text { aprimoramento das relações. }\end{array}$ & $\begin{array}{l}\text { Não evolui, pois as adaptações são evitadas. } \\
\text { Interações intermitentes e pontuais levam a } \\
\text { uma transferência limitada de experiência } \\
\text { entre os empreendimentos. Troca de } \\
\text { serviços é baseada no mercado. }\end{array}$ \\
\hline Orientação mútuante & &
\end{tabular}

Fonte: GADDE; DUBOIS, 2010, tradução nossa.

\subsection{Etapas ou fases do processo de produção}

Diferentes autores, associações e normas voltadas à construção civil descreveram o processo de produção do empreendimento, determinando suas etapas, atividades, produtos e agentes. Estas publicações foram atualizadas ao longo dos anos, visando se adequar aos novos métodos de produção e às novas tecnologias aplicadas aos projetos.

Dentre as referências, percebe-se que existem duas abordagens para o processo de produção do empreendimento:

- com uma sequência definida de etapas, que vão ganhando complexidade conforme a evolução do processo; cada atividade tem fim em si mesma, ou seja, após a definição completa do projeto é feita a licitação e contratação do construtor;

- sem uma sequência definida de etapas, ou seja, algumas etapas da produção do empreendimento podem ser antecipadas ou ocorrer simultaneamente com as demais; as atividades são consideradas interdependentes. 


\subsubsection{Processo de produção com uma sequência definida de etapas}

A quinta edição do Project Resource Manual do CSI (CONSTRUCTION SPECIFICATIONS INSTITUTE, 2005) descreveu a produção da construção civil como um processo cíclico, que se inicia na idealização do produto e termina com o uso e manutenção do empreendimento, podendo incluir a demolição ou reabilitação do edifício.

Segundo essa publicação, as etapas de produção do empreendimento são:

- idealização do projeto, etapa em que os requisitos estabelecidos pelo cliente são transformados em um conceito claro de projeto, com um programa, estimativa de custo e cronograma, a fim de verificar a viabilidade do empreendimento;

- escolha do método de produção, onde o cliente estabelece como o empreendimento será executado, considerando seu conhecimento técnico, a complexidade do edifício e o prazo para a execução;

- projeto, que se subdivide em duas etapas: projeto esquemático, onde são definidas as características gerais do empreendimento, como forma, escala, sistema estrutural e interação entre os componentes construtivos; e desenvolvimento do projeto, em que são detalhadas todas as informações da etapa anterior e definido o cronograma e orçamento de execução;

- documentos para execução, onde são definidas todas as informações da etapa de execução, que servirão de base para o processo de licitação e contratação dos construtores;

- licitação, onde o cliente estabelece os critérios para a seleção do construtor, finalizando com a contratação da empresa ou profissional responsável pela execução;

- execução, onde o empreendimento é construído conforme as especificações do projeto; e

- uso e manutenção, etapa posterior à entrega do empreendimento e compreende todas as atividades de ocupação do edifício, incluindo possíveis reformas, reabilitação e demolição do edifício.

Melhado (2005) descreveu o processo de produção do empreendimento, considerando a realidade brasileira e tendo como foco a gestão do empreendimento e a coordenação de projetos, sendo que a produção de um empreendimento é composta por seis etapas:

- idealização do produto, que compreende as definições preliminares e o programa de necessidades, resultando nos objetivos do empreendimento, ou seja, nos parâmetros e exigências a serem atendidas pelo edifício; 
- desenvolvimento do produto, que engloba o levantamento de dados e o estudo preliminar, no qual é possível avaliar o partido arquitetônico adotado e as configurações físicas do empreendimento;

- formalização, que abrange a elaboração do anteprojeto, projeto legal e projeto básico ou projeto pré-executivo e se caracteriza pelo maior detalhamento dos elementos gráficos do projeto;

- detalhamento, que compreende o projeto executivo e o projeto para produção e resulta na representação mais precisa do produto, com todas as informações necessárias para sua execução;

- planejamento para a execução, que representa o planejamento da obra e inclui simulações de alternativas técnicas e econômicas para atingir os requisitos do cliente em relação ao desempenho, custo e prazo de execução; e

- entrega, que resulta no projeto as built, onde são atualizadas as informações do projeto para produção, caso tenham ocorrido modificações ao longo da execução; esse documento é utilizado pelo usuário para as atividades de uso e manutenção.

Segundo Melhado (2005), o desenvolvimento do projeto consiste no detalhamento progressivo do produto, de forma que quanto mais atividades são realizadas, menos liberdade os profissionais têm para realizar alterações projetuais. No entanto, é considerada a possibilidade de execução simultânea das atividades, por meio de uma equipe multidisciplinar, em que são consideradas diferentes disciplinas de projeto em cada etapa do processo de produção.

O American Institute of Architects (AIA) (2007b), em um de seus relatórios sobre boas práticas nos serviços de arquitetura, descreveu que um processo básico de produção de um empreendimento passa por cinco etapas:

- projeto esquemático, que é precedido de um pré-projeto, nessa etapa são determinados os objetivos e requisitos do projeto e gera o programa de necessidades;

- desenvolvimento do projeto, que compreende a elaboração mais detalhada do projeto a partir dos dados obtidos na fase anterior;

- documentos para execução, onde são elaborados os detalhes e especificações para a execução da obra, com a elaboração do projeto para produção;

- licitação, que compreende a fase de seleção do construtor a partir do projeto que foi desenvolvido e culmina na contratação do construtor; além disso, é considerada a etapa de aprovação do projeto pelos órgãos de regulação; e

- execução, que termina com a entrega do empreendimento. 
Outra referência voltada à padronização das informações da construção é o OmniClass Construction Classification System (OCCS). Esse sistema de classificação é voltado principalmente para a inserção da Modelagem da Informação da Construção (BIM) nos processos de produção. O OCCS visa organizar e padronizar toda documentação gerada a partir das informações dos projetos e as bibliotecas de materiais utilizados na modelagem (OMNICLASS CONSTRUCTION CLASSIFICATION SYSTEM, 2006).

O documento que aborda o processo de produção do empreendimento foi publicado pela primeira vez em 2006 e teve uma revisão publicada em 2012 (OMNICLASS CONSTRUCTION CLASSIFICATION SYSTEM, 2012). Esse documento utilizou como referência: norma ISO 12006-2, que foi traduzida pela Associação Brasileira de Normas Técnicas (ABNT) em 2010 (ASSOCIAÇÃO BRASILEIRA DE NORMAS TÉCNICAS/INTERNATIONAL ORGANIZATION FOR STANDARDIZATION, 2010); métodos de produção tradicional e do Integrated Project Delivery (IPD), publicados pelo AIA (AMERICAN INSTITUTE OF ARCHITECTS, 2007a, 2014); Lean Project Delivery System (LPDS) (FORBES, AHMED, 2011); e Information Delivery Manuals (IDM) elaborados pelo buildingSMART (BUILDINGSMART, 2018a).

O processo de produção do empreendimento definido pelo OCCS (OMNICLASS CONSTRUCTION CLASSIFICATION SYSTEM, 2012) considera nove etapas essenciais:

- início, onde são definidos os objetivos do projeto a fim de atingir os requisitos do cliente e inclui a seleção do terreno, escolha do método de produção do empreendimento e a previsão do orçamento e cronograma;

- conceituação, em que são estabelecidas as principais ideias do projeto, gerando o programa de necessidades e os requisitos de desempenho, que vão servir de base para as considerações básicas dos elementos do projeto;

- definição de critérios, onde são estabelecidos esquematicamente os elementos básicos do projeto, como volume, estrutura, vedação e sistemas prediais, com o intuito de fornecer as informações de espaço e forma que irão nortear o desenvolvimento do projeto;

- projeto, que é a fase de elaboração e detalhamento do projeto visando atender aos requisitos definidos pelo cliente;

- coordenação, onde o projeto é avaliado conforme sua construtibilidade ${ }^{4}$;

\footnotetext{
${ }^{4} \mathrm{O}$ termo construtibilidade é definido pelo Construction Industry Institute (CII) (CONSTRUCTION INDUSTRY INSTITUTE, 2018) como sendo a efetiva integração dos conhecimentos e experiência em construção no planejamento, projeto, construção e operação no canteiro de um empreendimento, visando atingir os objetivos gerais do projeto, com o melhor prazo e precisão possíveis, com o custo mais adequado.
} 
- ехесис̧ão, que compreende a construção do empreendimento e inclui todas as atividades de planejamento e fabricação de componentes;

- entrega, onde o cliente recebe o empreendimento, mediante sua validação;

- operação, fase em que o empreendimento passa a ser utilizado, incluindo as atividades de gestão, manutenção e possíveis reformas; e

- encerramento, onde o empreendimento passa a não ter mais uso e tem como destino a demolição parcial, total, ou a reabilitação para outro uso.

No Brasil, está em elaboração um conjunto de normas que visam estabelecer uma terminologia e estrutura de classificação para o BIM. Tendo como base a ISO12006-2 (ASSOCIAÇÃO BRASILEIRA DE NORMAS TÉCNICAS/INTERNATIONAL ORGANIZATION FOR STANDARDIZATION, 2010), a NBR 15965 (ASSOCIAÇÃO BRASILEIRA DE NORMAS TÉCNICAS, 2011) foi subdividida em sete partes: parte 1 - terminologia e estrutura; parte 2 características dos objetos da construção; parte 3 - processos da construção; parte 4 - recursos da construção; parte 5 - resultados da construção; parte 6 - unidades da construção; e parte 7 informação da construção. Até o presente momento apenas as partes 1, 2, 3 e 7 foram publicadas.

Na parte 3 da NBR 15965 (ASSOCIAÇÃO BRASILEIRA DE NORMAS TÉCNICAS, 2014) é apresentada a estrutura de classificação que define os processos da construção, considerando desde as etapas de planejamento até a operação, manutenção e descarte dos empreendimentos da construção civil.

A classificação é apresentada em quatro categorias: estágio, fase, serviço e disciplina. O estágio é uma caracterização mais abrangente e a fase é uma subcategoria dentro de um estágio. Os serviços são as atividades exercidas pelos participantes dentro do processo de produção e as disciplinas são as especialidades desses participantes.

Os estágios definidos pela NBR 15965-3 (ASSOCIAÇÃO BRASILEIRA DE NORMAS TÉCNICAS, 2014) são:

- concepção, que compreende as fases de preparação das informações que irão nortear o projeto, como: identificação de necessidades, estudo de viabilidade, pré-projeto/estudo de massa e estimativas de custo e prazo;

- definição de entrega de projetos, onde são estabelecidos os critérios para o desenvolvimento do empreendimento, compreendendo as fases de seleção do método de produção; montagem e contratação da equipe; e elaboração da Requisição de Proposta 
(Request for Proposal - RFP), que é o documento que contém todas as especificações e requisitos de desempenho solicitados para o empreendimento;

- projeto, que compreende todas as fases de desenvolvimento do projeto, desde o estudo preliminar até o projeto executivo;

- documentação de construção, onde são desenvolvidos todos os detalhes para a execução, como: especificações de fabricação e estimativas de custo;

- compras e contratações, que compreende as fases de seleção do construtor e dos fornecedores para a execução, culminando na formalização do contrato da obra;

- execução, que abrange as fases de preparação e planejamento da obra, até sua efetiva execução e entrega;

- utilização, que compreende todas as fases posteriores à entrega, como o uso, gestão e manutenção do empreendimento, considerando as possíveis modificações, reformas e expansões; e

- fechamento da edificação/instalação, que compreende as fases que podem ocorrer com o encerramento das atividades no empreendimento, como o desmonte ou a requalificação.

\subsubsection{Processo de produção sem uma sequência definida de etapas}

Pode-se destacar duas referências que abordam o processo de produção sem uma sequência definida de etapas, são elas: Plan of Work do Royal Institute of British Architects (RIBA) (2013) e o Manual para Contratação de Projetos para o Desempenho de Edificações Habitacionais do Sindicato da Indústria da Construção Civil no Estado de Minas Gerais (Sinduscon-MG) (2016). O RIBA desenvolveu em 1963 o primeiro documento do Plan of Work, e realizou sua atualização ao longo dos anos, sendo que a última publicação é de 2013 (ROYAL BRITISH INSTITUTE OF ARCHITECTS, 2013). Esse documento visa orientar todos os agentes da indústria da construção civil sobre o processo de produção do empreendimento.

Na última publicação do RIBA, foram inseridos fundamentos de sustentabilidade, ferramentas de suporte ao BIM e elementos que promovem o trabalho integrado entre os agentes. A última atualização do Plan of Work também possibilitou flexibilizar a execução do processo com o objetivo de adaptar os mecanismos de contratação às necessidades dos clientes (ROYAL BRITISH INSTITUTE OF ARCHITECTS, 2013).

O documento do RIBA define as principais fases e atividades do processo de produção do empreendimento, considerando desde a idealização do projeto até o uso e operação do edifício. 
Apesar de indicarem uma progressão na definição das informações, esse documento sugere que as fases podem variar e até se sobreporem dependendo do tipo de empreendimento.

O processo de produção do RIBA é dividido em oito fases:

- fase 0 - Definição estratégica, que corresponde à avaliação inicial do empreendimento, antes do detalhamento dos requisitos do cliente;

- fase 1 - Preparação e definição das informações de projeto, onde são definidos os objetivos do empreendimento, incluindo os requisitos de qualidade, exigências de sustentabilidade e orçamento, que irão nortear a elaboração do estudo de viabilidade; nessa fase são iniciados os estudos sobre o planejamento de obra;

- fase 2 - Projeto conceitual, que resulta nas especificações do sistema construtivo, sistemas prediais, orçamento preliminar, além de considerações sobre questões de acústica, sistemas de proteção e combate a incêndio, sustentabilidade e manutenção e operação; nessa fase o planejamento de obra é atualizado e revisto a partir das novas informações;

- fase 3 - Desenvolvimento do projeto, onde as especificações da fase anterior são definidas e desenvolvidas com maiores detalhes, incluindo o orçamento final do empreendimento; nessa fase o planejamento de obra também é atualizado e inclui a previsão das possíveis alterações de projeto e execução, para controlar os riscos do processo;

- fase 4 - Projeto Técnico, em que são detalhados todos os elementos do projeto, incluindo o projeto arquitetônico, sistemas prediais e sistema estrutural, considerando a participação de todos os especialistas envolvidos na execução, além da definição do planejamento de obra;

- fase 5 - Execução, baseada no planejamento de obra finalizado na etapa anterior;

- fase 6 - Entrega e finalização, onde o contrato é finalizado, após a validação do empreendimento pelo cliente; e

- fase 7 - Uso e operação, que deve ter como base a documentação produzida nas fases anteriores e deve seguir um cronograma de manutenção.

No Plan of Work (ROYAL BRITISH INSTITUTE OF ARCHITECTS, 2013) são definidas oito atividades que possuem níveis diferentes de detalhamento em cada uma das fases descritas acima:

- objetivos principais, que são as atividades principais de desenvolvimento do empreendimento; 
- contratação, que é uma atividade genérica, ou seja, pode variar conforme o modelo de contrato definido pelo cliente, que vai definir em qual fase do processo a contratação de cada profissional vai acontecer;

- programa, que inclui informações sobre cronograma, requisitos do cliente e colaboração entre os participantes, considerando o empreendimento, projeto e execução;

- planejamento urbano, em relação às regulamentações urbanas para a instalação do empreendimento;

- sugestões de atividades de suporte, que visa deixar claro a todos os participantes os objetivos do empreendimento, referente aos requisitos de sustentabilidade, uso do BIM, regras de gestão do processo e construtibilidade do edifício;

- requisitos de sustentabilidade, que pode ser incluída ou não no processo dependendo do tipo de projeto;

- troca de informações, onde são definidas as entregas para o fim de cada fase; e

- troca de informações referentes aos requisitos do Governo Britânico.

O manual elaborado pelo Sinduscon-MG (SINDICATO DA INDÚSTRIA DA CONSTRUÇÃO CIVIL NO ESTADO DE MINAS GERAIS, 2016) teve como objetivo estabelecer o escopo para contratação de projetos de edificações, com foco nos requisitos de desempenho definidos pela NBR 15575 - Edificações habitacionais - Desempenho (ASSOCIAÇÃO BRASILEIRA DE NORMAS TÉCNICAS, 2013).

Tendo como princípio a necessidade de se considerar de maneira integrada as disciplinas de projeto, para que o desempenho de edificações seja efetivamente alcançado, o manual não seguiu uma abordagem segmentada e sequencial do processo de produção. Propôs-se que o fluxo de produção fosse baseado nos objetivos de cada fase, como concepção e definição, e não nos produtos gerados pelas atividades, como estudo preliminar e anteprojeto. Para todas as disciplinas de projeto foram definidas as mesmas fases, onde cada especialidade tem suas atividades próprias.

As disciplinas abordadas pelo manual são: incorporação; arquitetura; estrutura; desempenho térmico; projeto acústico; projeto de iluminação; ar condicionado e ventilação; sistema de proteção contra descargas atmosféricas (SPDA); instalações elétricas; instalações de telecomunicações; instalações hidrossanitárias; geração de água quente; drenagem e instalações 
de gás natural e gás liquefeito de petróleo (GLP); impermeabilização; sprinkler; e prevenção e combate a incêndio.

As fases do processo de projeto, de acordo com o manual elaborado pelo Sinduscon-MG (SINDICATO DA INDÚSTRIA DA CONSTRUÇÃO CIVIL NO ESTADO DE MINAS GERAIS, 2016), são:

- concepção do produto, onde é definido o programa de necessidades, a partir do levantamento de dados relativos ao terreno, partido arquitetônico, restrições legais e das demandas do cliente;

- definição do produto, onde são determinadas as principais soluções arquitetônicas que possibilitem o estudo do projeto pelas demais disciplinas, considerando as técnicas e o potencial construtivo, além das especificações preliminares da escolha dos materiais e do cronograma do empreendimento;

- identificação e solução de interfaces, onde o produto é consolidado, com todas as informações dos sistemas prediais, métodos construtivos e materiais de acordo com a NBR 15575; nessa fase são realizadas as aprovações do projeto junto aos órgãos de regulação;

- detalhamento das especialidades; nessa fase é apresentada a solução definitiva do produto, que possibilita a compatibilização do projeto com os agentes da execução, definindo o orçamento e cronograma da obra bem como o planejamento do funcionamento do canteiro, considerando a disponibilidade de equipamentos, suprimentos e mão de obra;

- pós-entrega dos projetos, que representa a fase de execução da obra, onde é definido o projeto para produção e é realizado o acompanhamento da obra por parte dos projetistas; e

- pós-entrega da obra, que representa a avaliação e validação do produto pelo cliente, além da avaliação crítica do processo de projeto por parte dos demais agentes.

A partir da Tabela 2, percebe-se que as referências que consideram o processo de produção com uma sequência definida de etapas, possuem etapas em comum. Em alguns casos as etapas estão subdivididas, com o processo de produção detalhado, e em outros casos são definidas as etapas principais, que englobam outras atividades.

No caso das referências que consideram o processo de produção sem uma sequência definida de etapas, percebe-se uma definição menos detalhada do processo, o que permite que os participantes adaptem o modelo para o empreendimento em questão. Essas referências não 
definem uma etapa específica para a licitação dos construtores, pois permitem que esses agentes sejam contratados em diferentes etapas do processo.

No entanto, em ambos os casos - processo com ou sem uma sequência definida - podem ser identificadas algumas etapas em comum: planejamento, projeto, execução e finalização. 
Tabela 2 - Comparação das referências que consideram o processo de produção com uma sequência definida de atividades PROCESSO DE PRODUÇÃO COM UMA SEQUÊNCIA DEFINIDA DE ETAPAS

\begin{tabular}{|c|c|c|c|c|c|c|c|c|c|c|c|}
\hline & \multirow[b]{2}{*}{$\begin{array}{c}\text { ISO12006-2 } \\
(2001)\end{array}$} & \multirow[b]{2}{*}{$\begin{array}{c}\text { CSI } \\
(2005)\end{array}$} & \multirow[b]{2}{*}{$\begin{array}{l}\text { Melhado } \\
\text { (2005) }\end{array}$} & \multirow{3}{*}{$\begin{array}{c}\begin{array}{c}\text { AIA (Integrated } \\
\text { Project Delivery) } \\
(2007)\end{array} \\
\text { Conceituação } \\
\end{array}$} & \multirow{3}{*}{$\begin{array}{c}\text { AIA } \\
\begin{array}{c}\text { (Tradicional) } \\
(\mathbf{2 0 0 7 )}\end{array} \\
\text { Pré-projeto }\end{array}$} & \multirow{3}{*}{$\begin{array}{c}\text { Building } \\
\text { SMART (IDM) } \\
\text { (2010) } \\
\text { Requisitos } \\
\end{array}$} & \multirow{3}{*}{$\begin{array}{c}\text { Lean } \\
\text { Construction } \\
(\mathbf{2 0 1 1 )} \\
\text { Definição de } \\
\text { projeto }\end{array}$} & \multirow{3}{*}{$\begin{array}{c}\begin{array}{c}\text { OmniClass } \\
(\mathbf{2 0 1 2})\end{array} \\
\text { Início }\end{array}$} & \multirow[b]{2}{*}{$\begin{array}{l}\text { NBR } 15965 \\
\quad(2014)\end{array}$} & \multicolumn{2}{|c|}{ DEFINIDA DE ETAPAS } \\
\hline & & & & & & & & & & $\begin{array}{l}\text { RIBA } \\
\text { (2013) }\end{array}$ & $\begin{array}{l}\text { Sinduscon } \\
\text { (2016) }\end{array}$ \\
\hline \multirow{4}{*}{ 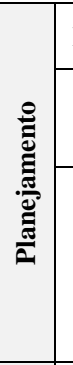 } & Início/ Aquisição & \multirow{3}{*}{$\begin{array}{l}\text { Idealização do } \\
\text { projeto }\end{array}$} & $\begin{array}{l}\text { Definições } \\
\text { preliminares }\end{array}$ & & & & & & \multirow{3}{*}{ Concepção } & \multirow[b]{2}{*}{$\begin{array}{l}\text { Definição } \\
\text { estratégica }\end{array}$} & \multirow{4}{*}{$\begin{array}{l}\text { - Concepção do } \\
\text { produto }\end{array}$} \\
\hline & Viabilidade & & \multirow{2}{*}{$\begin{array}{l}\text { Programa de } \\
\text { necessidades }\end{array}$} & \multirow{3}{*}{ - } & \multirow{3}{*}{-} & $\begin{array}{l}\text { Determinação } \\
\text { necessidades }\end{array}$ & $\begin{array}{l}\text { Determinação das } \\
\text { necessidades/ } \\
\text { valores }\end{array}$ & \multirow{3}{*}{ Conceituação } & & & \\
\hline & \multirow{2}{*}{$\begin{array}{l}\text { Esboço da } \\
\text { proposta/ } \\
\text { preparação do } \\
\text { programa }\end{array}$} & & & & & $\begin{array}{l}\text { Esboço da } \\
\text { viabilidade } \\
\text { (propostas) } \\
\end{array}$ & \multirow{2}{*}{$\begin{array}{c}\text { Projeto } \\
\text { esquemático }\end{array}$} & & & \multirow{2}{*}{$\begin{array}{l}\text { Preparação e } \\
\text { definição das } \\
\text { informações de } \\
\text { projeto }\end{array}$} & \\
\hline & & $\begin{array}{l}\text { Escolha do } \\
\text { método de } \\
\text { produção }\end{array}$ & $\begin{array}{l}\text { Levantamento de } \\
\text { dados }\end{array}$ & & & $\begin{array}{c}\text { Estudo de } \\
\text { viabilidade } \\
\text { (escolha da solução) }\end{array}$ & & & $\begin{array}{l}\text { Definição de } \\
\text { entrega de } \\
\text { projetos }\end{array}$ & & \\
\hline \multirow{6}{*}{ 尊 } & \multirow{3}{*}{$\begin{array}{l}\text { Projeto } \\
\text { esquemático/ } \\
\text { estimativa de } \\
\text { custo }\end{array}$} & \multirow{3}{*}{$\begin{array}{l}\text { Projeto } \\
\text { esquemático }\end{array}$} & Estudo preliminar & \multirow{3}{*}{$\begin{array}{c}\text { Projeto } \\
\text { esquemático }\end{array}$} & \multirow{3}{*}{$\begin{array}{l}\text { Projeto } \\
\text { esquemático }\end{array}$} & Esboço do projeto & \multirow{3}{*}{ Projeto Lean } & \multirow{3}{*}{$\begin{array}{l}\text { Definição de } \\
\text { critérios }\end{array}$} & \multirow{5}{*}{ Projeto } & \multirow{3}{*}{$\begin{array}{l}\text { Projeto } \\
\text { conceitual }\end{array}$} & \multirow{3}{*}{$\begin{array}{l}\text { Definição do } \\
\text { produto }\end{array}$} \\
\hline & & & Anteprojeto & & & conceitual & & & & & \\
\hline & & & Projeto legal & & & Projeto conceitual & & & & & \\
\hline & \multirow{2}{*}{$\begin{array}{c}\text { Projeto } \\
\text { detalhado/ } \\
\text { definição do } \\
\text { custo } \\
\end{array}$} & & Projeto básico & & & & Projeto conceitual & & & & Identificação \\
\hline & & $\begin{array}{l}\text { Desenvolvimento } \\
\text { do projeto }\end{array}$ & Projeto executivo & Projeto detalhado & $\begin{array}{l}\text { Desenvolvimento } \\
\text { do projeto }\end{array}$ & Projeto e aquisição & $\begin{array}{c}\begin{array}{c}\text { Projeto do } \\
\text { processo }\end{array} \\
\end{array}$ & Projeto & & $\begin{array}{l}\text { Desenvolvimento } \\
\text { do projeto }\end{array}$ & $\begin{array}{l}\text { e solução das } \\
\text { interfaces }\end{array}$ \\
\hline & $\begin{array}{l}\text { Informação de } \\
\text { produção/ } \\
\text { quantitativos }\end{array}$ & $\begin{array}{l}\text { Documentação } \\
\text { para execução }\end{array}$ & Projeto para produção & $\begin{array}{l}\text { Projeto para } \\
\text { Produção/ } \\
\text { Planejamento } \\
\text { Execução } \\
\end{array}$ & $\begin{array}{l}\text { Projeto para } \\
\text { Produçãa }\end{array}$ & & $\begin{array}{c}\text { Fornecimento de } \\
\text { materiais e } \\
\text { componentes }\end{array}$ & & $\begin{array}{c}\text { Documentação } \\
\text { para execução }\end{array}$ & Projeto técnico & $\begin{array}{c}\text { Detalhamento } \\
\text { das } \\
\text { especialidades }\end{array}$ \\
\hline & & & $\begin{array}{l}\text { (após o projeto básico } \\
\text { nas obras públicas e }\end{array}$ & Gestão dos & Licitação/ & $\begin{array}{l}\text { Informações de } \\
\text { produção }\end{array}$ & $\begin{array}{c}\text { Projeto } \\
\text { esquemático }\end{array}$ & Coordenação & & (licitação pode & $\begin{array}{l}\text { (licitação } \\
\text { pode variar }\end{array}$ \\
\hline 胥 & Licitação & Licitação & $\begin{array}{l}\text { após o projeto } \\
\text { executivo nas obras } \\
\text { particulares) }\end{array}$ & $\begin{array}{l}\text { critérios de } \\
\text { aprovação }\end{array}$ & $\begin{array}{l}\text { Aprovação pelos } \\
\text { órgãos } \\
\text { reguladores }\end{array}$ & & $\begin{array}{l}\text { Detalhamento do } \\
\text { projeto de } \\
\text { engenharia }\end{array}$ & & $\begin{array}{l}\text { Compras e } \\
\text { contratações }\end{array}$ & $\begin{array}{l}\text { variar conforme o } \\
\text { tipo de } \\
\text { contratação) }\end{array}$ & $\begin{array}{l}\text { conforme o } \\
\text { tipo de } \\
\text { contratação) }\end{array}$ \\
\hline 离 & $\begin{array}{l}\text { Preparação para } \\
\text { construção }\end{array}$ & & $\begin{array}{l}\text { Planejamento para a } \\
\text { execução }\end{array}$ & $\begin{array}{c}\text { Contratações/ } \\
\text { aquisições finais }\end{array}$ & & & Montagem Lean & & & & \\
\hline & Execução & Execução & Execução & Execução & Execução & Execução e entrega & $\begin{array}{c}\text { Fabricação/ } \\
\text { Logística } \\
\text { Instalação } \\
\end{array}$ & Execução & Execução & Execução & $\begin{array}{l}\text { Pós entrega } \\
\text { do projeto }\end{array}$ \\
\hline & Finalização & & Entrega & Fechamento & Fechamento & & Comissionamento & Entrega & & $\begin{array}{c}\text { Entrega e } \\
\text { finalização }\end{array}$ & \\
\hline 芯 & - & $\begin{array}{l}\text { Uso e } \\
\text { manutenção }\end{array}$ & - & - & & $\begin{array}{l}\text { Operação e } \\
\text { manutenção }\end{array}$ & $\begin{array}{c}\text { Uso } \\
\text { Operação e } \\
\text { Manutenção }\end{array}$ & Operação & Utilização & Uso e operação & $\begin{array}{l}\text { Pós entrega } \\
\text { da obra }\end{array}$ \\
\hline$\stackrel{\Xi}{*}$ & Retroalimentação & $\begin{array}{l}\text { Demolição/ } \\
\text { Descarte }\end{array}$ & - & - & & Descarte & $\begin{array}{l}\text { Alteração e } \\
\text { desativação }\end{array}$ & Encerramento & $\begin{array}{c}\text { Fechamento da } \\
\text { edificação/ } \\
\text { instalação }\end{array}$ & - & - \\
\hline
\end{tabular}

$\stackrel{\infty}{+}$ ROYAL BRITISH INSTITUTE OF ARCHITECTS, 2013; ASSOCIAÇÃO BRASILEIRA DE NORMAS TECCNICAS, 2014 ; SINDUSCON-MG, 2016 


\subsection{Agentes do processo de produção}

Em relação aos participantes do processo de produção, cada empreendimento pode demandar diferentes especialidades. Algumas referências especificam detalhadamente todos os possíveis agentes do processo de produção.

Forbes e Ahmed (2011) descrevem os agentes com grande nível de detalhe, considerando os que atuam diretamente no desenvolvimento das atividades, como também os envolvidos indiretamente no processo de produção:

- cliente, que determina o início do processo ao estabelecer a demanda pelo empreendimento;

- projetistas, que são responsáveis por traduzir os desejos dos clientes em um projeto executável;

- construtores, diretos e subcontratados, que são responsáveis pela execução do empreendimento conforme especificado no projeto;

- mão de obra, que são os trabalhadores das diversas especialidades da obra;

- fornecedores, tanto dos equipamentos quanto dos materiais da obra;

- instituições financeiras, que são responsáveis pelo financiamento da obra;

- advogados, que são responsáveis pela elaboração dos contratos entre os participantes;

- seguradoras, que estabelecem as garantia sobre os riscos do processo;

- órgãos de regulação, que especificam as normas e regras para a execução do empreendimento;

- serviços públicos, como concessionárias de água, luz e gás;

- profissionais de segurança e controle de qualidade da obra; e

- consultores, que são responsáveis por auxiliar o processo e inserem maiores informações e controle ao processo.

O RIBA (ROYAL BRITISH INSTITUTE OF ARCHITECTS, 2013) também lista detalhadamente os seguintes participantes do processo de produção:

- cliente;

- consultores dos clientes;

- líder da produção do empreendimento, considerando projeto e execução;

- líder de projeto;

- arquiteto;

- engenheiro, responsável pelos sistemas prediais;

- engenheiro civil e de estruturas; 
- consultor de orçamento;

- líder de execução;

- administrador dos contratos; e

- consultor de segurança do trabalho.

Além desses agentes, o RIBA inclui no processo os especialistas de diferentes disciplinas, como: gestão, urbanismo, paisagismo, sustentabilidade, planejamento, proteção e combate a incêndio, iluminação, acústica e interiores.

Outras referências consideram os agentes a partir da sua área de atuação no processo de produção e determinam os agentes essenciais ao processo, como é o caso do CSI (CONSTRUCTION SPECIFICATIONS INSTITUTE, 2005):

- equipe de projeto, que inclui arquitetos, engenheiros, designer de interiores e os consultores de projeto;

- equipe de execução, que compreende o construtor, gestor de projeto, gestor de construção e os subcontratados de execução;

- equipe do cliente, que inclui além do cliente, gestor de construção, gestor de instalações e manutenção e usuário final, caso este não seja o próprio cliente; e

- equipe dos fornecedores, que inclui todos os distribuidores dos materiais e componentes, além dos fabricantes.

Melhado (2005) estabelece que os principais agentes envolvidos na produção do empreendimento são:

- projetistas, responsáveis pela formalização do produto em que são considerados os projetistas responsáveis pela arquitetura, estrutura e sistemas prediais, além dos consultores de projeto, que são responsáveis pelas informações que vão auxiliar o desenvolvimento do projeto;

- empreendedor, responsável por dar início ao processo e pela geração do produto;

- construtor, agente que executa o produto; e

- usuário, quem utiliza o produto.

Além desses principais agentes, Melhado (2005) considera o gestor do empreendimento e o coordenador de projetos. O primeiro é responsável por definir as diretrizes que vão viabilizar o empreendimento, estabelecendo o planejamento, organização e controle do processo de produção como um todo, desde as atividades de viabilidade até a entrega do produto. $\mathrm{O}$ coordenador de projetos é o agente responsável pela operacionalização das diretrizes do projeto, 
ou seja, coordena o desenvolvimento do projeto, de forma que atenda às necessidades do cliente, sem que haja conflitos entre as disciplinas.

No relatório do Construction Management Association of America (CMAA) (2011), também se considera o gestor da construção como um agente essencial ao processo de produção. Além dele, são especificados ainda:

- cliente, que é o participante fundamental para a boa execução do empreendimento;

- projetista, que é responsável pelo desenvolvimento do projeto;

- consultores, que auxiliam no desenvolvimento do empreendimento, incluindo informações de diferentes especialidades, desde o projeto até a execução; e

- construtor, que é responsável pela obra e gerencia os equipamentos, materiais e mão de obra necessários para a execução do empreendimento.

O guia do AIA (AMERICAN INSTITUTE OF ARCHITECTS, 2007a) sobre o Integrated Project Delivery (IPD) é a referência que mais sintetiza os agentes do processo de produção. São definidas duas categorias na equipe de trabalho: principal e de suporte.

A equipe principal é composta por membros que possuem grande envolvimento e responsabilidade durante todo o processo, como é o caso do cliente, projetista e construtor. A equipe de suporte é composta por aqueles que exercem um papel complementar, mas de extrema importância para o desenvolvimento do empreendimento, e que são consultados pela equipe principal nas tomadas de decisão.

No entanto, a formação dessas duas equipes pode variar conforme o tipo e complexidade da edificação. Em determinados casos, agentes usualmente considerados de suporte podem fazer parte da equipe principal, caso sua disciplina seja essencial para desenvolver o conceito do projeto (AMERICAN INSTITUTE OF ARCHITECTS, 2007a).

Observou-se que existe uma grande variação sobre os participantes do processo de produção indicados nas referências. Algumas incluem todos eles, sem diferenciar a importância de cada um no processo (FORBES; AHMED, 2011; ROYAL BRITISH INSTITUTE OF ARCHITECTS, 2013), enquanto outras os subdividem entre agentes principais e secundários, ou os classificam de acordo com a área de atuação (CONSTRUCTION SPECIFICATIONS INSTITUTE, 2005; MELHADO, 2005; CONSTRUCTION MANAGEMENT ASSOCIATION OF AMERICA, 2011; AMERICAN INSTITUTE OF ARCHITECTS, 2007a). No entanto, todos consideram os seguintes agentes em comum: cliente ou empreendedor; profissionais de projeto; e profissionais de execução. 
Além disso, observou-se que as publicações são atualizadas ao longo dos anos, de forma a se adaptar às mudanças do setor da construção civil, tanto em termos de processo de produção, quanto em relação aos agentes. Um exemplo é o relatório do RIBA (ROYAL BRITISH INSTITUTE OF ARCHITECTS, 2013), que incluiu na sua última versão o BIM e o trabalho integrado e colaborativo da equipe. Com isso, algumas terminologias sobre as etapas de desenvolvimento do projeto foram alteradas. 


\section{CONSTRUÇÃO INDUSTRIALIZADA}

O termo construção industrializada possui uma definição ampla. No relatório elaborado para o International Council for Research and Innovation in Building and Construction - CIB (GIRMSCHEID; SCHEUBLIN, 2010), foram listadas algumas características comuns às diversas definições sobre a construção industrializada, como:

- uso de energia e ferramentas mecânicas;

- uso de ferramentas e sistemas computadorizados;

- processo contínuo de produção;

- aperfeiçoamento contínuo do processo;

- padronização dos produtos;

- pré-fabricação;

- racionalização;

- modulação; e

- produção em massa.

De acordo com esse relatório (GIRMSCHEID; SCHEUBLIN, 2010), existem três aspectos que definem a inserção da construção industrializada: finalidade, condições e consequências.

Existe a finalidade de se industrializar o processo, que é a busca pelos benefícios, como qualidade, segurança, redução do custo, prazo e mão de obra. As condições tecnológicas são os elementos essenciais para alcançar os benefícios e incluem a mecanização, automação e complexidade das ferramentas de produção. Com a utilização das tecnologias, tem-se as consequências do processo de industrialização, como a pré-fabricação, racionalização e modulação.

Observa-se que a construção industrializada não está relacionada apenas ao uso de sistemas construtivos pré-fabricados, mas ao uso de técnicas que visam a racionalização do processo produtivo. Portanto, podem-se destacar duas abordagens que caracterizam a industrialização na construção civil: a partir do tipo de sistema construtivo utilizado; e a partir do método de produção do empreendimento.

\subsection{Industrialização pelo sistema construtivo}

A pré-fabricação pode ser considerada como um meio para a industrialização da construção civil e definida como a produção de componentes do edifício fora do local final de sua 
utilização. A NBR 9062 - Projeto e execução de estruturas de concreto pré-moldado (ASSOCIAÇÃO BRASILEIRA DE NORMAS TÉCNICAS, 2006), define os termos préfabricado e pré-moldado:

- elemento pré-fabricado é aquele produzido industrialmente, em instalações permanentes; com a utilização de mão de obra treinada e especializada; matéria prima previamente qualificada, avaliada e inspecionada; produção com o auxílio de máquinas e equipamentos industriais; e processo de produção documentado; e

- elemento pré-moldado é aquele produzido fora do local de utilização definitiva, sem a necessidade de um ambiente específico para a produção, ou seja, pode ser executado no próprio canteiro de obras; o que indica um menor controle de qualidade, pois dispensam a necessidade de um laboratório próprio para a inspeção dos insumos e do elemento final.

Desde muito tempo tem-se estudado sobre a influência da pré-fabricação no processo de produção do empreendimento. Tatum, Vanegas e Williams (1987) definem que a pré-fabricação provoca diversas mudanças nos processos de projeto e gestão, como: na organização das atividades de projeto; no planejamento e monitoramento; nas etapas de execução; na coordenação de disciplinas; e por meio da inserção de novas atividades ao processo.

Em relação à coordenação das disciplinas, os autores (TATUM; VENEGAS; WILLIAMS, 1987) afirmam que a pré-fabricação requer que as decisões de projeto sejam tomadas precocemente, o que determina a necessidade de interdependência e colaboração entre as atividades. O papel do gestor de projetos passa a ser essencial na coordenação do projeto com o uso da industrialização.

A pré-fabricação também tem influência sobre as etapas do processo de produção (TATUM; VENEGAS; WILLIAMS, 1987):

- projeto, com a necessidade de participação dos fornecedores dos componentes ou consultores especialistas na industrialização, o que aproxima as etapas de projeto e execução;

- contratação e aquisição, com a inserção de novos critérios de escolha dos profissionais e empresas, além da necessidade de supervisão no recebimento e controle de qualidade dos componentes;

- execução, com o aumento de responsabilidade dos fornecedores dos materiais, necessidade de maior controle sobre o planejamentos e maior controle sobre a sequência das atividades no canteiro de obras; e 
- uso e manutenção, com a especificação correta dos profissionais e empresas responsáveis pelas alterações de reforma e ampliação da edificação.

Gibb (1999) descreve os benefícios de se transferir as atividades de execução do canteiro de obras para um ambiente de fábrica. Com o uso de sistemas construtivos industrializados existe um maior controle do ambiente e a redução das interrupções da produção; a repetição dos processos produtivos se torna mais fácil; os trabalhadores recebem treinamento especializado; existe a redução nos deslocamentos dos componentes durante a execução; aumenta-se o controle sobre as atividades; e existe a possibilidade de se utilizar ferramentas e técnicas inovadoras.

O uso da pré-fabricação na construção está muitas vezes associado à padronização dos componentes e dos processos de execução. Gibb (2001) define que a padronização permite o uso extensivo de elementos pré-fabricados, a partir de métodos e processos anteriormente definidos, o que possibilita prever os resultados e antecipar as correções.

No entanto, segundo Gibb (2001) a padronização deve estar associada à compatibilidade entre os diferentes componentes, de forma a permitir que os elementos construtivos produzidos por diferentes indústrias possam ser utilizados em uma mesma edificação. Nesse sentido destacase o conceito de coordenação modular, que estabelece normas e regras de compatibilização dos componentes.

Fabrício (2013) destaca que a coordenação modular deve ser vista pela indústria como o objetivo principal para o desenvolvimento e fabricação do produto. Ao coordenar as dimensões e regras de compatibilidade, a indústria permite que seus elementos pré-fabricados possam ser intercambiáveis, garantindo a racionalização durante a execução do edifício.

Outra questão associada à pré-fabricação está relacionada ao quanto ela representa do edifício, como partes da construção ou o edifício como um todo. Gibb e Isack (2003) definem os sistemas pré-fabricados a partir de quatro categorias, com base na quantidade de uso da pré-fabricação:

- componente manufaturado, que são elementos produzidos em fábrica mas que necessitam de algumas atividades no canteiro para que sejam instalados, como no caso de portas e janelas;

- elemento não volumétrico, que são elementos pré-fabricados, mas que sozinhos não definem um componente do edifício, como no caso dos perfis metálicos;

- componente volumétrico, que são estruturas completas de uma parte do edifício, como os módulos de banheiros pré-fabricados; e 
- construção modular, que são estruturas completas de um edifício ou parte dele.

Girmscheid (2010) também relaciona categorias para o uso da pré-fabricação nos empreendimentos:

- sistemas estruturais semi-pré-fabricados, ou construção híbrida, em que se utiliza sistemas produzidos in loco e componentes pré-fabricados;

- sistemas estruturais pré-fabricados, que são aqueles produzidos em uma fábrica, transportados até o local da obra, onde é feita a montagem dos elementos e finalização do acabamento;

- elementos integrados pré-fabricados, semelhante ao anterior, sendo que o componente consiste em um sistema composto por mais de um elemento, como uma parede composta por diferentes camadas; são elementos produzidos fora do canteiro de obras e com a montagem baseada em um sistema encaixes;

- módulos estruturais de ambientes pré-fabricados, semelhante ao anterior, sendo que cada módulo compõe um ambiente inteiro e não somente componentes;

- módulos de ambientes com acabamento pré-fabricados, neste caso, o interior do módulo é finalizado ainda no ambiente fabril, como por exemplo os módulos sanitários; e

- sistemas de construção, que consiste em um sistema próprio de construção, definido por uma indústria e que permite ao usuário escolher uma variedade de elementos de volume, acabamentos internos, externos e esquadrias.

\subsection{Industrialização pelo método de produção}

Algumas referências consideram a industrialização a partir de mudanças estruturais do processo de produção. Esse tipo de abordagem não é novo, como pode ser visto no relatório produzido pela Organização das Nações Unidas (ONU) em busca da redução no custo da construção civil (UNITED NATIONS, 1959).

Segundo a ONU (UNITED NATIONS, 1959), a industrialização não está necessariamente relacionada à produção de componentes em uma fábrica. $\mathrm{O}$ conceito de industrialização é definido como:

- produção contínua, que requer uma demanda constante;

- padronização dos produtos;

- integração das diferentes etapas do processo de produção;

- alto nível de organização do trabalho, como na organização das atividades de canteiro; 
- mecanização do trabalho; e

- pesquisa e experimentação integradas com a produção.

Seguindo essa mesma abordagem, Sabbatini (1978) define que a industrialização busca aumentar a produtividade e aprimorar o desempenho da construção civil, por meio de ações organizacionais e inserção de inovações tecnológicas, métodos de trabalho e técnicas de planejamento e controle.

Algumas definições sobre o termo industrialização se confundem com a definição de préfabricação. Segundo Sabbatini (1978), a industrialização pode ser considerada um conceito abstrato, o que dá margem para diferentes interpretações. Já a pré-fabricação é uma atividade produtiva bem definida, que tem características concretas que podem ser exemplificadas com o uso dos componentes nos empreendimentos.

Foster (1994) define que a industrialização é essencialmente um processo organizacional, podendo ser utilizada em diferentes tipos de sistemas construtivos. $\mathrm{O}$ autor defende que essa organização da construção pode ser alcançada a partir de cinco estratégias:

- layout eficiente do canteiro de obras;

- sequência de trabalho prática e ordenada;

- trabalho similar e executado em série;

- uso racional de componentes pré-fabricados e padronizados; e

- uso racional da mecanização do trabalho.

Segundo Foster (1994), para que a industrialização seja eficiente, as mudanças organizacionais devem fazer parte de um processo de racionalização da produção do empreendimento. Todos os detalhes de construção e especificação dos componentes devem ser definidos na etapa de projeto.

Podem-se destacar também, algumas referências mais recentes que estão alinhadas com a abordagem da industrialização da construção relacionada ao método de produção e não ao sistema construtivo.

Martinez et al. (2008) indicam que existem diversas estratégias voltadas a industrialização da construção civil, além da pré-fabricação como: automatização dos processos, com o uso da robótica; uso de sistemas racionais de produção no canteiro de obras; e sistemas de gestão da 
produção, voltadas à racionalização dos processos, como o Lean Production ${ }^{1}$ e a Engenharia Simultânea.

A automatização das atividades de execução da obra permite reduzir o uso de mão de obra, o que aumenta a segurança e qualidade dos processos. Além disso, é possível aumentar a produtividade e manter a execução ininterrupta, o que resulta na redução do custo total do empreendimento e na redução do prazo de obra (MARTINEZ; et al., 2013).

Segundo Martinez et al. (2008), a industrialização da construção civil pode ser alcançada alterando o modo como os processos são estabelecidos durante a execução. A inserção do método Lean na construção civil visa aumentar a produtividade eliminado o desperdício e as atividades que não agregam valor ao processo. A aproximação entre as etapas de projeto e execução, por meio do trabalho colaborativo; o planejamento e controle do processo do início ao fim, são formas de utilizar os princípios do Lean na construção.

De acordo com Forbes e Ahmed (2011), a aplicação do conceito da produção enxuta - Lean Production - na indústria da construção civil pode ser definida como um processo de aperfeiçoamento da produção do empreendimento, visando eliminar o desperdício de tempo e material e superar os requisitos de desempenho estipulados pelo cliente.

Salas (2008) usa o termo industrialização sutil, para designar a industrialização que está mais voltada para o processo do que para a aplicação da construção em massa com o uso da préfabricação. Segundo o autor, o termo sutil está relacionado a forma como o setor da construção civil passou a utilizar melhorias organizacionais nos empreendimentos, sem um determinado momento como um marco para a mudança, mas de forma progressiva e de acordo com o ritmo de cada país.

Segundo Salas (2008) a pré-fabricação representa apenas uma parte do que pode ser definido como industrialização. A utilização de componentes permite uma renovação de formas e materiais que podem ser aplicados ao edifício. No entanto, o uso de sistemas pré-fabricados deve estar acompanhado de mudanças organizacionais nos processos de produção, que permitam manter o fluxo de produção racional e eficiente desde o projeto até a execução.

Segundo o relatório do CIB (GIRMSCHEID; SCHEUBLIN, 2010), industrialização é um processo inevitável de transformação do setor da construção civil e representa uma mudança de pensamento e prática com o objetivo de aperfeiçoar a produção do empreendimento. Visando

\footnotetext{
${ }^{1}$ No capítulo 5 o processo de produção a partir do conceito Lean será mais detalhado.
} 
a construção de maior qualidade e adaptada às especificidades do projeto, a industrialização utiliza o processo integrado, otimização da padronização, eficiência de custo, mecanização e automação da produção.

Fabrício (2013) também aborda a industrialização a partir do método de produção, utilizando o termo industrialização flexível. Industrialização flexível é definida como o uso integrado de técnicas gerenciais e tecnologias digitais de projeto e produção, visando aumentar a produtividade, qualidade e sustentabilidade das edificações, considerando seu ciclo de vida projeto, construção, uso, manutenção e desmonte. Fabrício (2013) identifica duas abordagens para a industrialização flexível da construção: tecnológica e organizacional.

A abordagem tecnológica é determinada pelo desenvolvimento de novas ferramentas e procedimento de produção. Busca-se flexibilizar a produção, com o uso de máquinas de controle numérico e da automação, associados a projetos digitais e paramétricos. Com essas tecnologias, é possível que um único equipamento possa produzir diferentes componentes, com variados níveis de complexidade, de forma que se adaptem ao empreendimento no qual serão utilizados.

A abordagem organizacional, identificada por Fabrício (2013), está relacionada à gestão do processo produtivo. Os conceitos de racionalização e produtividade são substituídos pela eficiência da cadeia de produção, considerando projeto, produção e consumo. Nesse contexto, a industrialização está menos focada no tipo de material e voltada às novas práticas industriais, que utilizam a tecnologia da informação e a produção enxuta, em referência ao conceito de Lean Production.

Ao estabelecer o conceito de industrialização flexível, Fabrício (2013) destaca que o setor da construção civil busca a industrialização com foco nas alterações processuais, e não necessariamente em uma transformação completa da técnica e o uso intensivo de máquinas. A industrialização passa a ter como base a produção mais completa e eficiente do projeto, de maneira integrada com a execução.

O manual sobre a construção industrializada desenvolvido pela Agência Brasileira de Desenvolvimento Industrial (ABDI) (2015) caracteriza a industrialização essencialmente pelo uso da pré-fabricação, com a produção de componentes em ambiente industrial, que são posteriormente montados nos canteiros de obra, o que possibilita melhores condições de controle e inserção de novas tecnologias. 
No entanto, a ABDI (AGÊNCIA BRASILEIRA DE DESENVOLVIMENTO INDUSTRIAL, 2015) também considera como parte do conceito sobre industrialização as inovações no campo organizacional e tecnológico, que visam aumentar a produtividade e o nível de produção, e aprimorar o desempenho da atividade construtiva.

Ao considerarem a necessidade de atualizar os métodos de produção para viabilizar a construção industrializada, os autores pesquisados nesse capítulo delimitam o campo de atuação da industrialização na construção civil. Não basta apenas utilizar componentes pré-fabricados para industrializar a produção, é necessário que o processo esteja alinhado com os conceitos de racionalização e produtividade inerentes à industrialização.

As mudanças organizacionais, essenciais ao conceito de industrialização, demandam alterações que necessariamente interferem nos sistemas construtivos. Com a busca pela racionalização tanto do projeto quanto da execução, é necessário utilizar sistemas construtivos que permitam a redução do desperdício e maior eficiência dos processos.

Entende-se que a pré-fabricação não define a industrialização, mas faz parte dela. Um processo completamente industrializado, mas com um sistema construtivo "tradicional" não é eficiente, devido ao trabalho intensivo no canteiro e o uso de um grande número de mão de obra. $\mathrm{O}$ uso de componentes pré-fabricados com métodos de produção fragmentados não é eficiente, devido à falta de organização e racionalização do processo de produção. Portanto, antes de utilizar sistema construtivo industrializado é necessário rever os processos de produção, desde as etapas de projeto até a execução.

\subsection{Evolução da construção industrializada}

A industrialização no setor da construção civil não se deu a partir de um marco histórico, mas sim por meio de um processo evolutivo, que incorporou os erros e acertos das mudanças realizada ao longo do tempo. A busca pelo aperfeiçoamento dos processos de produção do empreendimento demandou que os profissionais e as indústrias introduzissem novas formas de produção do empreendimento.

Salas (2008) especificou o processo de evolução da construção industrializada, considerando o cenário europeu, a partir de uma divisão histórica em quatro períodos.

O primeiro período, que vai de 1950 a 1970, é caracterizado pela produção em massa e pelo grande entusiasmo do mercado por esse tipo de construção. No período do pós-guerra, existia 
uma urgência na construção de um grande número de edifícios, principalmente aqueles voltados à habitação.

Esse período foi o auge da utilização da industrialização fechada, ou seja, aquela em que o processo construtivo é de domínio de uma única empresa. Os projetos precisavam se adequar aos requisitos impostos pela indústria, como: um número mínimo de unidades, para viabilizar a produção; mínimas variações de forma, que dependiam da disposição dos poucos tipos de elementos construtivos disponíveis; e desenho de blocos de edificações lineares, o que facilitava a instalação das gruas durante a montagem.

O segundo período, que compreende os anos de 1970 a 1985, se caracterizou pelo questionamento sobre a viabilidade da industrialização fechada. Após o período de crise do pósguerra, a Europa passou por um período de estabilidade e houve uma redução na demanda por unidades habitacionais. Com isso, a urgência por habitação foi substituída pela busca de qualidade no edifício construído.

Para se adaptar a essa nova fase, o mercado passou a buscar em sua produção a flexibilidade e variabilidade dos componentes. Por meio da produção de pequenas séries, foi possível viabilizar a diversificação dos produtos, o que indica que as indústrias estavam caminhando em direção à industrialização aberta, ou seja, quando existe a produção de componentes para o mercado e que podem ser associados a diferentes sistemas construtivos.

O terceiro período identificado por Salas (2008) vai de 1985 a 2000, e se caracterizou pela demolição e abandono de muitos edifícios construídos no pós-guerra com sistemas préfabricados de concreto, o que levou a uma reflexão sobre os usos da pré-fabricação.

O desastre ocorrido com o edifício Ronan Point na Inglaterra, expôs a fragilidade estrutural dos sistemas propostos, gerando uma certa desconfiança por parte dos usuários. Houve uma redução de novas construções de edifícios de multipavimentos usando exclusivamente sistemas industrializados. A demanda pelo uso de sistemas industrializados passou a ser de edificações institucionais, como escolas, hospitais e, principalmente, edificações comerciais e industriais.

Salas (2008) denominou o último período, de 2000 aos dias atuais, como industrialização sutil, termo descrito no início deste capítulo. A produção desse período passa a ser de componentes diversificados e intercambiáveis, voltados a uma demanda específica.

Segundo o autor (SALAS, 2008), esse período pode ser compreendido como a síntese dos erros e acertos em relação à industrialização da construção. Algumas tendências do mercado levaram 
a mudanças tecnológicas ou de conceito da construção industrializada (Tabela 3). Ele cita também, algumas reflexões tiradas das experiências anteriores:

- a industrialização da construção não se caracteriza somente pela pré-fabricação;

- não é necessário um grande volume de produção para viabilizar a industrialização da construção, como o que ocorreu na industrialização fechada;

- os sistemas industrializados não são eficientes para todo tipo de edificação;

- a industrialização deve ser pensada de maneira sistêmica, ou seja, o projeto deve se adequar ao sistema construtivo industrializado assim como a execução; e

- os produtores deixaram de ser construtores e passaram a ser indústrias de componentes pré-fabricados.

Tabela 3 - Questões fundamentais para as mudanças tecnológicas da construção industrializada

\begin{tabular}{|c|c|c|}
\hline Tendências & Mudanças & Resultados \\
\hline $\begin{array}{l}\text { Técnicas de produção de } \\
\text { componentes. }\end{array}$ & $\begin{array}{l}\text { Flexibilização dos processos de } \\
\text { produção. }\end{array}$ & $\begin{array}{l}\text { Séries pequenas e } \\
\text { diversificadas. }\end{array}$ \\
\hline Coordenação modular. & $\begin{array}{l}\text { Menos acadêmica e mais } \\
\text { prática. }\end{array}$ & $\begin{array}{l}\text { De ferramenta de projeto a } \\
\text { suporte da produção. Do } \\
\text { módulo dimensional ao módulo } \\
\text { do objeto. }\end{array}$ \\
\hline $\begin{array}{l}\text { Mudanças de paradigmas } \\
\text { básicos. }\end{array}$ & $\begin{array}{l}\text { De produtores de pré-fabricados } \\
\text { e construtores a consumidores } \\
\text { de componentes construtivos. }\end{array}$ & $\begin{array}{l}\text { A indústria (química, de vidro, } \\
\text { de gesso, de isolantes...) invade } \\
\text { o setor da construção civil. }\end{array}$ \\
\hline $\begin{array}{l}\text { Maior influência da indústria no } \\
\text { custo final de produção. }\end{array}$ & $\begin{array}{l}\text { Concorrência de materiais, } \\
\text { técnicas e componentes. }\end{array}$ & $\begin{array}{l}\text { O valor adicionado de origem } \\
\text { industrial supera o valor dos } \\
\text { sistemas fechados de pré- } \\
\text { fabricação pesada. }\end{array}$ \\
\hline $\begin{array}{l}\text { Fim de um falso dilema: } \\
\text { Arquitetura X Indústria. }\end{array}$ & $\begin{array}{l}\text { Equipes de trabalho } \\
\text { multidisciplinares. }\end{array}$ & $\begin{array}{l}\text { Nova disciplina: Arquitetura } \\
\text { Industrializada. }\end{array}$ \\
\hline
\end{tabular}

Fonte: SALAS, 2008, tradução nossa.

Girmscheid (2010) descreve as etapas da evolução de um processo genérico de industrialização da construção. A partir da racionalização e planejamento da execução in loco, alcança-se a primeira etapa: sistematização. Com a utilização de componentes pré-fabricados, o processo passa pela etapa de padronização. A terceira etapa, denominada racionalização, é alcançada quando, além do uso de sistemas construtivos pré-fabricados, aplica-se os conceitos de industrialização na produção dentro do canteiro. A última etapa é a flexibilização, onde os sistemas construtivos utilizados, são produzidos exclusivamente para um empreendimento.

O Brasil passou por um processo de industrialização tardia, com a inserção de indústrias de componentes industrializados a partir da década de 1960. Os fatores que levaram a essa industrialização foram semelhantes aos que possibilitaram a industrialização na Europa: grande 
demanda por habitações; poucos recursos financeiros disponíveis; necessidade de racionalizar os recursos construtivos existentes; e escassez de mão de obra especializada (OLIVEIRA, 2013).

No caso do Brasil, a construção civil se caracterizou no século 20 como uma indústria manufatureira, com o uso intensivo de atividades no canteiro e um grande número de mão de obra sem o adequado conhecimento técnico. Essas características levaram a uma baixa produtividade e baixa qualidade dos edifícios (FABRICIO, 2013).

Segundo Fabrício (2013), o caso da industrialização no Brasil possui questões que impedem sua utilização eficiente na produção dos empreendimentos. Apesar do grande avanço na produção dos componentes pela indústria, as regras de compatibilização dos componentes são inexistentes ou insuficientes, o que leva a uma inadequação do sistema, pois são necessárias muitas adaptações durante a execução do edifício.

Percebe-se que, com a evolução do uso da construção industrializada, os autores indicam uma tendência da indústria em se adaptar cada vez mais às necessidades dos consumidores. Ao invés da produção em massa de componentes padronizados, busca-se a customização em massa, ou seja, produção a partir da demanda do cliente, eliminando a necessidade de uma grande linha de produção para um único modelo de componente.

\subsubsection{Industrialização Fechada}

A industrialização fechada é aquela em que todo o sistema construtivo é produzido ou gerenciado por uma única empresa. Essa empresa detém a tecnologia usada na produção dos componentes e define as regras de compatibilização dos componentes (GIRMSCHEID; SCHEUBLIN, 2010).

Fabrício (2013) cita como exemplo, o Centro de Tecnologia da Rede Sarah (CTRS), que teve como idealizador o arquiteto João Filgueiras Lima, o Lelé. A principal vantagem dos sistemas fechados é a possibilidade de uma grande produção em série de elementos padronizados.

A produção em massa permite a redução dos custos do componente construtivo, mantendo a qualidade final, pois além do controle da produção, esse sistema possibilita um maior investimento na etapa de projeto e detalhamento dos elementos. Essa vantagem permitiu que o CTRS funcionasse por quase 20 anos (TRIGO, 2009). 
No entanto, é necessário um grande volume de produção para que a industrialização fechada seja viável, o que muitas vezes reduz as possibilidades de variações de forma. Além disso, é necessário que exista sempre demanda para a produção, fato que levou ao encerramento das atividades do CTRS, já que não havia a construção de novos hospitais e a fábrica foi destinada a produzir componentes apenas para a manutenção dos edifícios existentes (TRIGO, 2009).

\subsubsection{Industrialização Aberta}

Industrialização aberta se caracteriza pela produção de componentes ou subsistemas construtivos voltados ao uso de diferentes empresas, (GIRMSCHEID; SCHEUBLIN, 2010).

De acordo com Fabrício (2013), a vantagem da industrialização aberta é permitir a execução de uma edificação utilizando componentes pré-fabricados por uma ou mais indústrias, o que gera maiores possibilidades de criação. Para isso, os componentes devem ser projetados de forma que possam ser intercambiáveis, ou seja, devem seguir regras comuns de compatibilização.

A industrialização aberta, assim como destacado por Salas (2008), foi uma resposta do mercado para a tendência do uso de sistemas industrializados na construção. A execução de um grande número de unidades utilizando os mesmos componentes já não atendia aos interesses do setor, que passou a buscar a individualização das soluções de projeto, mantendo o conceito de industrialização.

A busca por um sistema cada vez mais flexível é observado por Richard (2010), que identifica cinco níveis para a produção de componentes: pré-fabricação, mecanização, automação, robótica e reprodução.

A pré-fabricação se caracteriza como o primeiro nível e é definida como a produção de componentes em uma indústria, que são transportados até o local final de instalação. O autor descreve que os componentes são muito semelhantes aos que são produzidos in loco e muitas vezes utilizam os mesmos materiais e procedimentos de produção.

O segundo e o terceiro nível, representam aprimoramentos na produção dos componentes. A mecanização se caracteriza pelo uso de ferramentas sem o emprego de força humana na produção dos elementos pré-fabricados. A automação, permite que todo o processo seja mecanizado, como a alimentação da produção e o transporte nos componentes na linha de produção. 
O quarto nível permite a flexibilização da produção, por meio da utilização da robótica como ferramenta de produção. A partir desse nível, é possível que, em uma mesma linha de produção, possam ser produzidos diferentes tipos de componentes.

O último nível definido por Richard (2010) é denominado como reprodução, que está relacionada à tecnologia de impressão de documentos. A partir de um único documento é possível reproduzir diversas cópias em uma alta velocidade.

O conceito de reprodução aplicado à construção industrializada é definido como a inserção de inovações tecnológicas com a finalidade de simplificar o processo de produção, reduzindo tarefas de repetição. Nesse nível de industrialização, existe um maior investimento na área de pesquisa e desenvolvimento.

Por meio da flexibilização da produção, existe uma mudança de paradigma para a construção industrializada. Enquanto a produção pré-fabricada de componentes em massa busca detalhar um sistema construtivo para posteriormente ser usado em diferentes empreendimentos, a flexibilização da produção busca desenvolver detalhadamente componentes voltados a um empreendimento único.

Portanto, as inovações tecnológicas alcançadas ao longo do tempo permitiram flexibilizar a produção da indústria, de forma a atender uma demanda específica de um empreendimento. Percebe-se que, apesar das mudanças ocorridas na construção industrializada, os conceitos essenciais se mantêm, ou seja, a busca por um processo de produção eficiente e a racionalização das atividades.

\subsection{Vantagens e empecilhos da construção industrializada}

Existem diversas vantagens na industrialização do processo de produção, considerando tanto o uso de sistemas construtivos pré-fabricados, quanto o uso de novas ferramentas organizacionais.

A industrialização pode beneficiar os principais indicadores de produtividade do processo produtivo: prazo, custo e qualidade. No entanto, esses benefícios podem não estar muito claros em uma análise superficial. Segundo Gibb (1999), é necessário que a industrialização seja precedida de uma visão sistêmica do processo, pois as vantagens podem ser percebidas somente com resultado final do empreendimento. 
Gibb (1999) lista os principais benefícios da industrialização e os impactos no processo de produção:

- prazo, que indica a redução do tempo gasto na execução; o tempo de atividades no canteiro são transferidas para as fábricas, o que requer a antecipação na especificação dos componentes para que estejam disponíveis no momento da obra;

- custo, que está diretamente relacionado à redução das atividades in loco; mesmo que seja necessário acrescentar novas atividades ao processo para o uso da pré-fabricação, a velocidade na execução permite reduzir o custo total de execução;

- qualidade, devido ao maior controle na produção dos componentes em um ambiente de fábrica; a pré-fabricação permite sistematizar as atividades de produção, garantindo a qualidade independente do executante;

- previsibilidade, com a possibilidade de reduzir os riscos e eliminar os imprevistos de execução, já que o componente final é executado antes das atividades in loco; além de ter maior controle sobre as etapas de execução, pois elas se resumem na montagem desses componentes, não sendo influenciadas por eventos climáticos;

- produtividade, devido a concentração das atividades de produção em um mesmo local e pela montagem dos componentes no canteiro de obras, o que indica o trabalho especializado de cada profissional da execução;

- segurança, com a redução de exposição dos trabalhadores aos perigos de um canteiro de obras, como: trabalho em altura, proximidade com grandes equipamentos e a exposição a poluentes e altos níveis de ruído;

- coordenação, principalmente com a antecipação das tomadas de decisão, que demandam a escolha dos componentes ainda na etapa de projeto e resultam na busca precoce de soluções para as interferências entre as disciplinas de projeto;

- inovação, que é viabilizada pela sistematização dos processos produtivos e pela busca pela eficiência na execução e montagem dos componentes;

- reutilização, proporcionada pela natureza dos componentes, o que pode ser um fator essencial no caso de empreendimentos temporários ou que demandam alterações ou ampliações com certa frequência.

Segundo Blismas, Pasquire e Gibb (2006), os benefícios da construção industrializada têm relação direta com as características do projeto e o método de produção utilizado. A influência 
de diferentes fatores nas tomadas de decisão para a produção de um empreendimento requer que a análise sobre sua qualidade tenha um aspecto holístico. No entanto, é possível identificar algumas características comuns à construção industrializada que permitem definir suas vantagens.

Blismas, Pasquire e Gibb (2006) fizeram uma síntese sobre principais benefícios no uso da construção industrializada, sintetizados na Tabela 4. A maior parte desses benefícios não está relacionada ao custo direto de produção. A inserção da construção industrializada na produção dos empreendimentos modifica diversas questões do processo de produção, como a qualidade tanto do empreendimento quanto do processo produtivo.

Tabela 4 - Benefícios da construção industrializada pela percepção dos clientes

\begin{tabular}{|c|c|}
\hline Benefício & Descrição \\
\hline Tempo & $\begin{array}{l}\text { - menor tempo nas atividades do canteiro - velocidade de construção; } \\
\text { - velocidade na entrega do produto; } \\
\text { - menor tempo de comissionamento - verificações para entrega do empreendimento; } \\
\text { - confiabilidade na entrega, maior certeza sobre o planejamento e menor tempo de } \\
\text { gestão. }\end{array}$ \\
\hline Qualidade & $\begin{array}{l}\text { - maior qualidade - nas atividades de canteiro e nos componentes produzidos em } \\
\text { fábricas; } \\
\text { - componentes testados na fábrica; } \\
\text { - maior regularidade dos componentes - maior possibilidade de reprodução de soluções; } \\
\text { - maior controle de qualidade, regularidade nos padrões. }\end{array}$ \\
\hline Custo & $\begin{array}{l}\text { - menor custo; } \\
\text { - menor custo inicial; } \\
\text { - maior certeza sobre o planejamento, menores riscos; } \\
\text { - maior valor agregado; } \\
\text { - menores despesas, menores prejuízos nas atividades de canteiro e menor desperdício. }\end{array}$ \\
\hline Produtividade & $\begin{array}{l}\text { - menor correção de erros e defeitos de execução; } \\
\text { - maior qualidade nas interfaces entre componentes e sistemas; } \\
\text { - menor interrupções das atividades de canteiro; } \\
\text { - redução no uso de materiais que utilizam água na produção; } \\
\text { - remoção das operações complexas para o ambiente de fábrica; } \\
\text { - atividades de canteiro são independentes da produção na fábrica. }\end{array}$ \\
\hline Pessoas & $\begin{array}{l}\text { - menor quantidade de mão de obra no canteiro; } \\
\text { - mão de obra treinada para a produção; } \\
\text { - produção na fábrica independente dos requisitos para a produção no canteiro. }\end{array}$ \\
\hline Processo & $\begin{array}{l}\text { - planejamento centralizado; } \\
\text { - processo de construção simplificado; } \\
\text { - possibilidade de medir as características dos sistemas construtivos. }\end{array}$ \\
\hline
\end{tabular}

Fonte: BLISMAS; PASQUIRE; GIBB, 2006, tradução nossa.

No entanto, Blismas, Pasquire e Gibb (2006) destacam que o custo é o principal fator das análises comparativas durante o processo de escolha pelo sistema construtivo. Com isso, outros benefícios não são considerados nas avaliações dos agentes, apesar de influenciarem indiretamente no resultado do empreendimento. 
Pan, Gibb e Dainty (2012) indicam outros benefícios do uso da construção industrializada, como: redução do prazo de execução e dos erros; menores riscos de segurança durante a execução; redução e maior controle do impacto ambiental; e menor custo do empreendimento, considerando seu ciclo de vida. Os autores também indicam como vantagens o aumento na previsibilidade durante a produção e do desempenho da edificação.

De acordo com a ABDI (AGÊNCIA BRASILEIRA DE DESENVOLVIMENTO INDUSTRIAL, 2015), o uso da industrialização permite uma produção em maior quantidade, maior qualidade, maior controle e desempenho ambiental, em um menor tempo, se comparado a outros tipos de construção baseados em atividades in loco. Além disso, são definidas como vantagens da industrialização da construção: produção independente das condições climáticas, uso de mão de obra especializada, uso de matéria prima selecionada, maior controle de qualidade durante a execução, maior precisão geométrica dos componentes e maior controle dos custos.

De acordo com a pesquisa de Wong, Zwar e Gharaie (2017), alguns benefícios da industrialização atraem o setor a buscar esse tipo de construção:

- redução do prazo de execução, que é um dos benefícios mais citados pelos profissionais;

- redução no custo, principalmente para o contratante e o construtor, pois o tempo de atividade no canteiro é muito reduzido, além da redução no número de mão de obra e dos erros;

- aumento da qualidade, que está diretamente relacionado ao maior controle na produção dos componentes e na montagem dos elementos no canteiro; a produção em ambiente controlado reduz as alterações devido às variações climáticas e possibilita a realização de testes antes da montagem no local de destino, o que reduz a possibilidade de erros e posteriores retrabalhos;

- redução do uso de mão de obra, devido a simplificação da atividade de canteiro, que consiste na montagem dos componentes, o que leva a um aumento na produtividade; além disso, a pré-fabricação de elementos construtivos em ambiente de fábrica reduz a necessidade de diversas especialidades de mão de obra no canteiro;

- maior segurança, tanto no ambiente de produção, quanto no canteiro, principalmente pela redução do trabalho no canteiro e pela possibilidade de controlar o ambiente de fábrica, com grande parte das atividades utilizando ferramentas mecânicas; e 
- redução da produção de resíduos e de poluição, devido ao maior controle da produção em ambiente fabril, onde os resíduos podem ser mais facilmente separados e levados a destinação adequada, além de possibilitar o controle da emissão de ruído e poeira.

Apesar dos diversos benefícios identificados, existem algumas barreiras que dificultam a industrialização da construção civil.

Para Tam et al. (2007), os cinco principais empecilhos para a construção industrializada são:

- falta de flexibilidade para mudanças de projeto, o que impede que muitos clientes optem pelo uso da construção industrializada desde o início do processo de produção do empreendimento, com receio de alterações durante o desenvolvimento do projeto;

- falta de pesquisas, sobre questões como viabilidade e compatibilização dos sistemas, o que poderia dar mais segurança para as tomadas de decisão durante o processo;

- alto custo inicial de construção, o que pode ser consequência da rapidez durante a etapa de execução, em que os componentes pré-fabricados já devem estar disponíveis para a montagem;

- maior tempo de desenvolvimento do projeto, além do maior esforço gasto nessa atividade, já que todas as questões de projeto devem estar resolvidas antes do início da execução; e - utilização de métodos "convencionais" na produção do empreendimento, o que poderia impedir que alguns benefícios da construção industrializada possam ser alcançados.

A complexidade na inserção de sistemas construtivos industrializados e as incertezas geradas pelas mudanças organizacionais no método de execução do empreendimento, dificultam que os profissionais e clientes tenham uma visão sistêmica do processo. De acordo com uma pesquisa sobre como as empresas do setor da construção civil percebem a adoção de novas tecnologias no processo produtivo (KPMG, 2016), o custo e o risco da inserção das inovações superam os possíveis benefícios.

Apenas $8 \%$ das empresas entrevistadas são consideradas aquelas que estão na vanguarda da tecnologia, ou seja, inserem inovações ao longo de todo o processo. A maior parte das empresas, $69 \%$ delas, são mais conservadoras, o que indica que elas trabalham com métodos tradicionais ou aplicam novas tecnologias somente quando estas já estão consolidadas no mercado (KPMG, 2016).

No entanto, a indústria da construção possui particularidades que a diferencia das indústrias de bens de consumo e que influenciam na inserção das inovações. Forbes e Ahmed (2011) indicam algumas especificidades do processo de produção de uma edificação, como: relações de 
trabalho de curto prazo; produção voltada a um único produto e não a uma grande série; local de produção - canteiro - suscetível às variações climáticas; e maior tempo de produção.

Além do alto custo inicial e da falta de flexibilidade do projeto, Goh e Loosemore (2017) identificaram outras barreiras que dificultam a adoção de sistemas industrializados nos empreendimentos, como: falta de conhecimento tecnológico; limitação da capacidade da cadeia produtiva; aspectos culturais; falta de modelos ou soluções de negócio viáveis; distanciamento entre projeto e execução; medição dos benefícios a partir do custo final; dificuldades na logística e transporte dos componentes até o canteiro de obras; e falta de conhecimento técnico para trabalhar com novas tecnologias e sistemas construtivos.

Em uma pesquisa elaborada pelo Fails Management Institute (FMI) e BIMForum (HOOVER; TROMBITAS; COWLES, 2017), que aborda o uso de componentes pré-fabricados na construção civil, bem como as perspectivas dos profissionais e empresas sobre esse tipo de construção, foram identificados três principais obstáculos que impedem o maior uso da construção industrializada: cultura; falta de comprometimento pela mudança; e inadequação do processo de produção.

No caso do fator cultural, foi observado que muitos profissionais não são incentivados a mudar sua forma de trabalho, o que impede um aprimoramento contínuo da equipe. As mudanças muitas vezes podem trazer riscos, mas para que ela seja efetiva, os profissionais devem ter a liberdade de poder cometer erros sem serem penalizados por isso.

Outra barreira está relacionada ao receio que muitos profissionais e empresas têm ao inserir novos métodos de trabalho no processo de produção. O aprimoramento no uso da pré-fabricação requer um tempo de experiência com o sistema e suas particularidades. O fato de uma empresa não se comprometer totalmente com a mudança impede que os reais benefícios possam ser alcançados, o que leva à desistência nos primeiros problemas observados no processo.

A última barreira está diretamente ligada às especificidades do processo de produção na construção industrializada. O uso dos métodos tradicionais de produção, contratação e desenvolvimento do projeto podem impedir que a pré-fabricação seja utilizada da sua melhor maneira, trazendo mais desvantagens do que benefícios aos profissionais. Existe a necessidade de planejar o uso do sistema industrializado desde o início do processo, que deve considerar não só o material, mas toda a sequência de produção e montagem no canteiro de obras.

Percebe-se que para aumentar o uso da industrialização no setor da construção civil, é necessária uma mudança de percepção do processo de produção por parte dos agentes, tanto 
dos profissionais e empresas do setor, quanto dos clientes. Os benefícios relacionados ao uso da construção industrializada vão muito além do custo direto de produção. As melhorias organizacionais, aliadas a uso de sistemas pré-fabricados, possibilitam um aumento de qualidade, não só do empreendimento executado, mas de todo o processo, considerando desde as etapas iniciais de concepção do projeto.

\subsection{Especificidades do processo de produção na construção industrializada}

A produção de um empreendimento compreende um processo complexo, composto por etapas interdependentes, na qual incluem as atividades de projeto, produção dos componentes e execução (FABRICIO, 2002).

Considerando as características da construção industrializada descritas anteriormente, a visão sistêmica se faz ainda mais necessária. Para que os benefícios previstos por esse tipo de construção sejam alcançados, é necessário que o processo de produção esteja adequado às questões de utilização de componentes pré-fabricados; racionalização das atividades; mecanização; e automação do processo.

Uma das adequações do processo de produção às especificidades da industrialização diz respeito ao projeto. De acordo com Blismas, Pasquire e Gibb (2006), os benefícios do uso da construção industrializada são melhor alcançados quando o uso de elementos pré-fabricados é considerado desde o início do processo. O uso de componentes pré-fabricados requer a contratação de profissionais aptos a trabalhar com esse sistema, como no caso dos projetistas, calculistas e profissionais do canteiro de obras. Além disso, é necessário um maior planejamento desde a fabricação dos componentes, logística de transporte, depósito e montagem na obra.

Na pesquisa elaborada por Tam et al. (2007), a consideração pelo uso da construção industrializada nas primeiras etapas da produção foi considerada pelos agentes como a principal mudança necessária para a viabilidade desse sistema construtivo. O tipo de empreendimento, o método de construção e o desenho da forma interferem diretamente sobre o sistema construtivo adotado, o que indica a importância deste em relação às primeiras decisões do processo.

Ligny (2010), faz uma relação entre o uso da pré-fabricação e a complexidade do processo de produção. A pré-fabricação demanda um maior investimento nas etapas de planejamento e 
organização da produção, ou seja, as questões relacionadas à etapa de execução devem ser previstas ainda nas etapas de desenvolvimento do projeto.

Segundo Fabrício (2013), o projeto do empreendimento não deve constar apenas de disciplinas de arquitetura e engenharia, mas deve compreender todas as etapas, incluindo a produção dos componentes e a obra. As soluções de projeto devem orientar e otimizar as atividades de canteiro, aproximando o projeto da execução.

Fabrício (2013), ao abordar o conceito de industrialização flexível, indica que é necessário um projeto consistente para se alcançar os benefícios da industrialização. Com um projeto consistente, o autor se refere a um processo de desenvolvimento que especifique e simule o desempenho do produto ao longo de todo seu ciclo de vida.

Para Fabrício (2013), o projeto determina não só as características formais e especificações técnicas do empreendimento, mas também a gestão do uso e a manutenção do edifício. Com isso, o processo de produção integra todas as fases e especialidades de projeto, considerando uma abordagem mais ampla do empreendimento.

Dentre as questões analisadas sobre o sistema construtivo, deve ser considerada sua construtibilidade em relação ao tipo de empreendimento que está sendo produzido. Considerar a construtibilidade de um sistema industrializado representa integrar diversas questões relacionadas ao processo, desde as primeiras etapas. Segundo Fabrício (2002), a construtibilidade está relacionada tanto à utilização de inovações tecnológicas visando a racionalização da produção, quanto na integração das diferentes disciplinas de projeto e da etapa de execução.

A construtibilidade deve ser disciplinada e sistemática, o que possibilita que um método possa ser aplicado a diferentes processos, permitindo a comparação e avaliação sobre a eficiência deles. Pode-se definir algumas diretrizes em relação à análise da construtibilidade, como (KIFOKERIS; XENIDIS, 2017):

- todos os principais agentes devem participar das definições sobre a construtibilidade, ao longo de todo o processo;

- os agentes devem utilizar dos avanços tecnológicos a fim de facilitar a troca de informações e reduzir a fragmentação do processo;

- o contrato deve estar de acordo com os requisitos definidos para o empreendimento;

- o planejamento do processo e o método de execução devem ser definidos o quanto antes, de forma a garantir a eficiência na etapa de execução; 
- as soluções inovadoras devem ser incentivadas, visando resolver os problemas não previstos durante o desenvolvimento do projeto; e

- as soluções devem considerar a simplificação do processo.

As soluções de projeto nem sempre são adequadas a todo tipo de construção. A mudança do tipo de sistema construtivo em etapas avançadas de desenvolvimento do projeto pode demandar alterações de concepção, gerando retrabalho e, consequentemente, maiores custos e prazo de execução.

Na pesquisa elaborada pelo FMI/BIMForum (HOOVER; TROMBITAS; COWLES, 2017) apenas $21 \%$ dos entrevistados afirmaram planejar o processo de montagem dos sistemas industrializados desde as etapas de desenvolvimento do projeto. A maior parte dos profissionais $-56 \%$ - realiza essa atividade na etapa que antecede a execução, ou seja, no final do processo, onde o projeto já está definido.

Um esquema elaborado por Pan, Gibb e Dainty (2012) indica como ocorre o decréscimo da oportunidade em integrar o uso de componentes pré-fabricados ao longo do processo (Figura 3). A principal demanda do processo industrializado é estabelecer uma estratégia de produção, que considere o sistema construtivo desde as primeiras etapas de concepção e viabilidade do projeto. As soluções propostas para o projeto devem ser revistas ao longo do processo, podendo demandar adequações. No entanto, as características essenciais ao sistema construtivo já estariam presentes no projeto.

Figura 3 - Oportunidade de integrar a pré-fabricação ao longo do processo de produção

\begin{tabular}{|c|c|c|c|c|c|c|c|c|c|c|c|}
\hline \multirow{2}{*}{$\begin{array}{l}\text { Stages of } \\
\text { house building }\end{array}$} & \multicolumn{7}{|c|}{ Land acquisition } & \multicolumn{2}{|c|}{ Presite } & \multirow{2}{*}{$\begin{array}{l}\text { On- } \\
\text { site }\end{array}$} & \multirow[t]{2}{*}{ Postsite } \\
\hline & \multicolumn{2}{|c|}{ Opportunity } & \multicolumn{2}{|c|}{$\begin{array}{c}\text { Viability } \\
\text { appraisal }\end{array}$} & \multicolumn{3}{|c|}{ Proposals } & & & & \\
\hline $\begin{array}{l}\text { Phases of a } \\
\text { typical } \\
\text { construction } \\
\text { project }\end{array}$ & 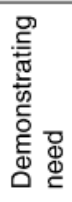 & 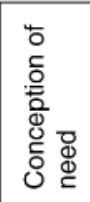 & 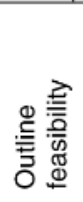 & 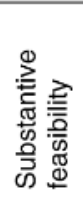 & 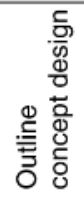 & 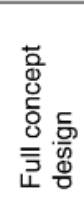 & 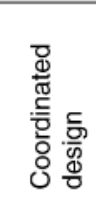 & 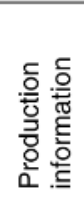 & 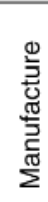 & 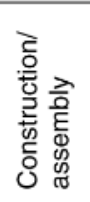 & 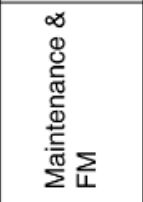 \\
\hline $\begin{array}{l}\text { Off-site reviews \& } \\
\text { integration }\end{array}$ & & $\begin{array}{r}\widehat{O} \text { Off-s } \\
\text { Revie }\end{array}$ & & & & & $\begin{array}{l}\text { Off-site } \\
\text { eview } 2 \\
\end{array}$ & $\widehat{\substack{\text { Off-sitte } \\
\text { Review }}}$ & & 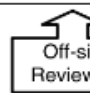 & $\begin{array}{c}\widehat{\text { Off-sitete }} \\
\text { Review }\end{array}$ \\
\hline & & $\begin{array}{l}\text { Best } \\
\text { off-sit }\end{array}$ & unit & & & & & & & & \\
\hline
\end{tabular}

Fonte: PAN; GIBB; DAINTY, 2012. 
A ABDI (AGÊNCIA BRASILEIRA DE DESENVOLVIMENTO INDUSTRIAL, 2015) afirma que a construção industrializada requer uma organização diferenciada do processo de produção, como a integração e antecipação das tomadas de decisão. A definição do tipo de tecnologia construtiva deve anteceder os projetos técnicos, pois ela estabelece diretrizes que vão nortear as soluções escolhidas. É necessário dar ênfase nas etapas de planejamento e monitoramento os processos; na modulação; e no detalhamento do projeto do para produção considerando fabricação; logística de transporte e armazenamento dos componentes; e montagem da estrutura.

O manual da ABDI (AGÊNCIA BRASILEIRA DE DESENVOLVIMENTO INDUSTRIAL, 2015) detalha como deve ocorrer o planejamento preliminar do processo de produção no caso da construção industrializada. A primeira questão a ser analisada é a viabilidade do uso de determinado sistema construtivo, considerando os aspectos técnicos e econômicos. As principais atividades da etapa de planejamento são:

- definição e caracterização do objeto a ser construído;

- análise do pré-projeto do componente, elemento ou sistema construtivo a ser contratado;

- análise da localidade onde o empreendimento será executado, considerando o terreno, topografia, logística para o transporte dos componentes, capacidade industrial para atender ao local e mão de obra disponível;

- análise da compatibilidade entre os critérios de desempenho requeridos para o empreendimento e os definidos pelo componente, elemento ou sistema construtivo a ser contratado; e

- análise dos custos, prazos, vantagens e desvantagens das opções construtivas analisadas.

Goh e Loosemore (2017) destacam o papel dos agentes subcontratados no caso da construção industrializada, que muitas vezes são responsáveis pelos diversos subsistemas do edifício. Ao considerar as informações desses agentes nas tomadas de decisão desde o início do processo, é possível desenvolver um projeto mais consistente e adaptado ao uso de componentes préfabricados. Quando a participação dos subcontratados ocorre somente no final do processo, ou seja, na etapa de execução, pode ser necessário realizar diversas modificações que não foram previstas em projeto, gerando retrabalho, maior custo e prazo ao processo.

Outra necessidade da produção industrializada é a avaliação contínua do processo. Considerando a busca pela eficiência na execução do empreendimento, é necessário avaliar os processos a partir de indicadores consistentes, que possam fornecer dados para aprimorar a própria produção e os próximos processos. 
Segundo Blismas, Pasquire e Gibb (2006) existe uma ausência ou precariedade de documentação do processo por parte dos agentes. As informações muitas vezes ficam dispersas entre os diferentes agentes, sem que exista um método que possa garantir a confiabilidade e padronização dos dados.

A documentação das características e resultados da produção, bem como das tomadas de decisão, possibilita aos profissionais e empresas avaliar o desempenho do processo como um todo ou de determinada atividade. Com isso, é possível estabelecer um banco de dados, que podem fornecer o histórico dos processos e indicar quais tomadas de decisão foram efetivas para a melhoria do desempenho, viabilizando o aperfeiçoamento do processo de produção (BLISMAS; PASQUIRE; GIBB, 2006).

Os dados da pesquisa do FMI/BIMForum (HOOVER; TROMBITAS; COWLES, 2017) indicam que muitos profissionais ou empresas não conseguem identificar os problemas relacionados aos empreendimentos, por não armazenar dados relativos à produção ou por não medir corretamente os indicadores de eficiência do processo.

Cerca de metade dos entrevistados monitoram a eficiência da construção industrializada a partir do indicador "unidade construída por horas trabalhadas". Segundo os pesquisadores (HOOVER; TROMBITAS; COWLES, 2017), esse dado pode não ser adequado, pois a préfabricação está baseada em um uso intensivo de mão de obra em um curto período de tempo, o que pode gerar resultados aquém do esperado.

Portanto, a construção industrializada requer uma mudança de paradigma em relação ao processo de produção do empreendimento. Questões relacionadas à integração, antecipação das tomadas de decisão, participação precoce dos principais agentes, avaliação contínua da produção e aproximação entre as etapas de projeto e execução, não só aprimoram o processo como podem garantir sua viabilidade econômica e sua construtibilidade.

Pode-se concluir que a industrialização não está necessariamente relacionada ao tipo de material, mas sim a questões como eficiência, racionalização, alta produtividade, redução de desperdício e uso de ferramentas em substituição ao trabalho manual. Essas características demandam um aprimoramento de todo o processo de produção, inclusive no tipo de sistemas construtivo utilizado, o que leva ao maior uso de componentes pré-fabricados na construção de uma edificação.

Entende-se que o efetivo estudo sobre os processos de produção que utilizam a construção industrializada deve considerar os dois aspectos da industrialização da construção: tecnológico 
e organizacional. Tanto a tecnologia como a forma de organização do processo de produção devem estar alinhados aos conceitos de industrialização, o que refletirá na maior qualidade do objeto construído. 


\section{INTEGRAÇÃO NA CONSTRUÇÃO CIVIL}

A integração na construção civil se mostra como um tema recorrente, nas publicações e pesquisas da área, como sendo uma solução para os problemas do processo produtivo, como fragmentação das etapas, falta de colaboração, baixa produtividade e baixa qualidade da edificação (LATHAN, 1994; EGAN, 2002; FORBES; AHMED, 2011; EASTMAN; et al., 2011; AMERICAN INSTITUTE OF ARCHITECTS, 2014; EL ASMAR; HANNA; LOH, 2015).

Murray e Langford (2003), a partir da análise de uma série de relatórios publicados pelo Governo Britânico sobre a construção civil, entre os anos de 1944 e 1998, identificaram três principais questões que têm impacto no aperfeiçoamento do setor: sistema contratual, industrialização da construção e integração do processo de produção. A necessidade de integrar o processo é citada desde o primeiro relatório, elaborado em 1944.

Os relatórios posteriores a 1998 também abordam o tema da integração. No relatório elaborado por Egan (2002), a integração é definida como o uso de todo o potencial de cada uma das especialidades, resultando em um processo transparente e facilmente compreendido tanto pelos agentes, quanto pelo cliente. No último relatório elaborado pelo Governo Britânico (HM GOVERNMENT, 2013), a integração ainda aparece como uma meta a ser alcançada.

Apesar das recomendações propostas, houve pouca mudança no método de produção. É evidente que o setor da construção civil apresentou diversos avanços, como a mecanização dos procedimentos construtivos, criação de novos materiais e desenvolvimento de tecnologias da informação. No entanto, Murray e Langford (2003) destacam que, em relação aos aspectos comportamentais e as interações entre os agentes, as mudanças se mostraram muito mais lentas, ou seja, os métodos de trabalho do processo de produção não acompanharam as evoluções tecnológicas da construção civil.

Muitas pesquisas buscam definir maneiras para tornar o processo de produção na construção civil mais integrado. Nam e Tatum (1992) definem que a integração é uma ótima oportunidade para incentivar a inovação nas construções. Esses autores dividem a integração a partir de três perspectivas:

- contratual, onde se busca estabelecer os mesmos objetivos nas relações de contrato entre os participantes, possibilitando criar um ambiente de confiança na equipe;

- organizacional, que indica a integração entre as disciplinas e os participantes do processo, mantendo um fluxo contínuo de colaboração desde o projeto até a execução; e 
- tecnolgia de processamento da informação, com a coordenação dos dados e informações de projeto e execução, mantendo um mesmo banco de dados do projeto para todos os membros da equipe.

Outros autores utilizaram a mesma definição da integração feita por Nam e Tatum (1992) em suas pesquisas (MITROPOULOS; TATUM, 2000; AZARI; KIM, 2015; LIU; SKIBNIEWSKI; WANG, 2016; PAPADONIKOLAKI; WAMELINK, 2017). Mitropoulos e Tatum (2000) acrescentaram que a falta de integração se deve principalmente à complexidade dos empreendimentos, que demandou um alto nível de especialização nas disciplinas da construção civil.

Baiden, Price e Dainty (2003) também subdividiram a integração a partir das áreas em que ela interfere no processo de produção da construção civil. De acordo com os autores, a integração pode ser definida como a aproximação de diferentes disciplinas, estabelecendo um processo produtivo coeso, contínuo e colaborativo, visando alcançar os objetivos da equipe de maneira clara e eficiente. Além disso, o termo integração é usado na construção civil para descrever a continuidade nas trocas de informações entre os diferentes participantes do processo de produção do empreendimento.

Segundo Baiden, Price e Dainty (2003), existem duas abordagens para a integração na construção civil: formas de contrato e método de produção. Em relação aos contratos, com a integração busca-se reduzir o número de interações realizadas entre os agentes, simplificando a contratação e determinando um objetivo comum a todos os participantes.

No caso dos métodos de produção, existem duas questões a serem investigadas. A primeira está relacionada a forma como são estabelecidas as atividades dentro do processo, ou seja, busca-se o envolvimento de todas as disciplinas ao longo da produção. A segunda questão compreende o fator humano, considerando a necessidade de integrar a equipe de forma a aperfeiçoar as trocas de informações entre os diferentes profissionais (BAIDEN; PRICE; DAINTY, 2003).

Alguns autores buscaram em outras indústrias, procedimentos para integrar o processo de produção na construção civil. Pode-se destacar o método da Engenharia Simultânea (Concurrent Engineering).

De acordo com Love, Gunasekaran e Li (1998), Engenharia Simultânea é uma abordagem holística do processo de produção, considerando o projeto, execução e contratação. Busca-se uma equipe multidisciplinar, que participa desde a etapa de concepção do produto até o entrega 
final, o que permite antecipar os principais problemas e estabelecer as melhores soluções de desenvolvimento do produto.

Por meio da Engenharia Simultânea, os projetistas conseguem incluir precocemente, no desenvolvimento do projeto, as questões de produção, como requisitos estruturais, funcionais e estéticos. Com isso, reduz-se a necessidade de alterações projetuais durante a etapa de execução (LOVE; GUNASEKARAN; LI, 1998).

Forbes e Ahmed (2011) destacaram a importância de incluir diferentes disciplinas durante a elaboração do projeto. As oportunidades para alterar as soluções projetuais caem progressivamente após o fim da etapa de desenvolvimento do projeto, pois as revisões se tornam cada vez mais complexas e, consequentemente causam maior impacto no custo e prazo do empreendimento (Figura 4).

Figura 4 - Relação entre o tempo e o impacto das modificações de projeto

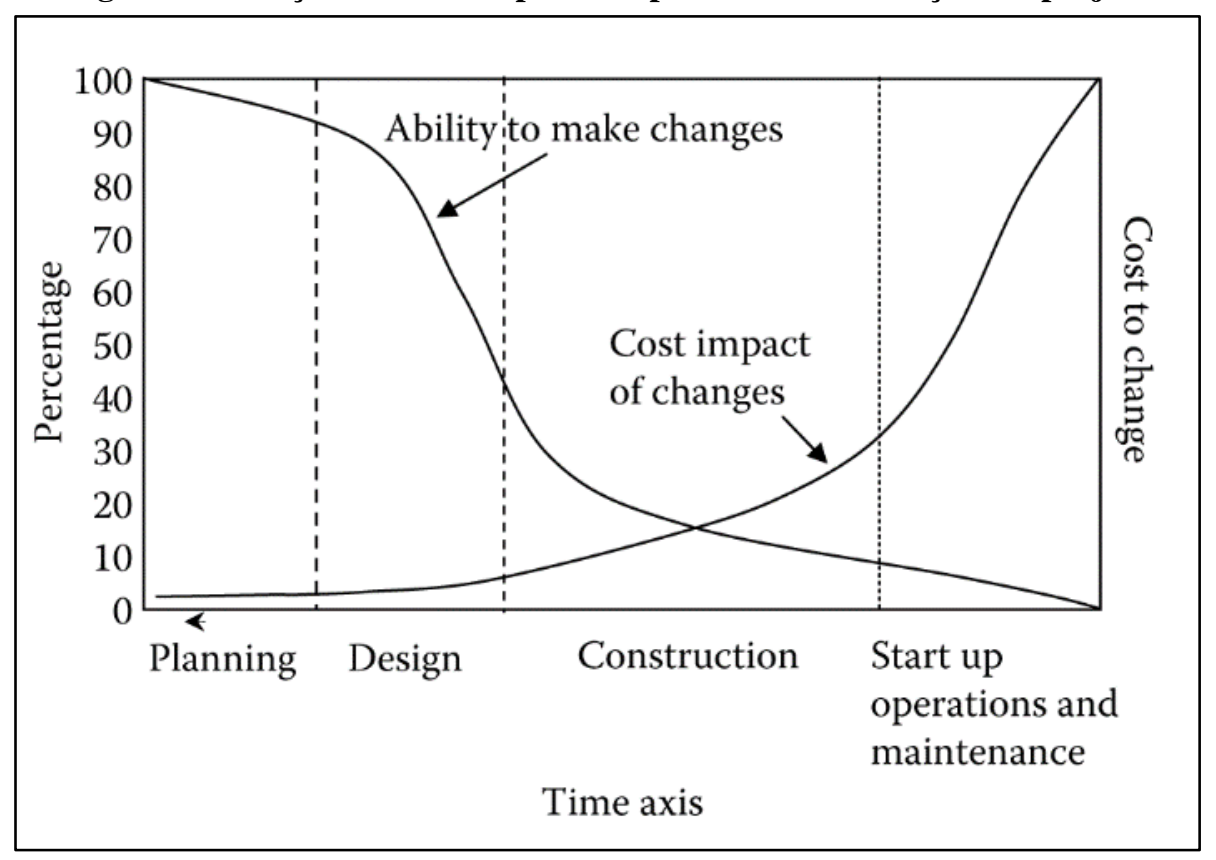

Fonte: FORBES; AHMED, 2011.

No entanto, Forbes e Ahmed (2011) indicaram que as especificidades da construção civil impedem que os métodos utilizados pelas demais indústrias sejam diretamente aplicados, como é o caso da Engenharia Simultânea. A diferença entre as relações de trabalho e o ciclo reduzido e não repetitivo de cada projeto são características que demandam um estudo particular para se alcançar a integração na construção civil. 
Azari e Kim (2015) destacam a ampla utilização do termo integração na literatura sobre os processos de produção na construção civil. A integração pode ser não só um meio para solucionar a fragmentação, mas também um catalizador para que melhores práticas funcionem. Nesse caso, destaca-se o papel da cooperação entre os profissionais, que pode levar a melhores soluções projetuais, devido aos benefícios do trabalho colaborativo.

Liu, Nederveen e Hertogh (2017) identificaram que, apesar de ser um setor interdisciplinar, é recorrente que muitos agentes da construção civil foquem apenas nos seus próprios interesses e busquem o melhor desempenho somente na sua área de atuação. A integração na construção civil se mostra essencial ao aperfeiçoamento do processo produtivo e do empreendimento final. Percebe-se que a fragmentação do processo de produção é um dos principais problemas encontrados na construção civil. O distanciamento entre as etapas de projeto e execução, a falta de comunicação e interação entre a equipe impedem que melhores soluções sejam dadas ao projeto. Perde-se em qualidade e eficiência, o que implica no aumento do prazo e custo de execução.

Além disso, autores como Nam e Tatum (1992) e Baiden, Price e Dainty (2003), indicam a importância de dividir as áreas de interferência da integração no processo de produção do empreendimento. Para compreender melhor como pode ser estabelecido um processo integrado e colaborativo, é preciso analisar o processo sob diferentes aspectos, como o sistema de contrato, as relações entre os participantes, o fator humano, o método de produção e a organização das atividades em cada etapa da produção do empreendimento.

Portanto, pode-se considerar a integração sob três perspectivas: contratual, organizacional e de tecnologia da informação.

A perspectiva contratual representa os métodos de produção do empreendimento (Project Delivery Methods), que são determinados pelos instrumentos contratuais. Os modelos de contrato especificam como os profissionais devem atuar para entregar o empreendimento ao cliente, detalhando a forma de interação entre eles e as responsabilidades de cada um na execução das atividades.

$\mathrm{Na}$ perspectiva organizacional, analisa-se o aspecto comportamental dos agentes, independentemente do modelo de contrato estabelecido. A forma com que as informações são transmitidas, as possibilidades de colaboração e formação da equipe permitem analisar a influência do fator humano no desempenho do processo de produção. 
A última perspectiva investigada aborda como a tecnologia da informação pode influenciar a integração do processo de produção. A atualização dos instrumentos utilizados na produção do empreendimento pode demandar mudanças no método de trabalho da equipe, como no caso do uso da Modelagem da Informação da Construção (BIM).

\subsection{Perspectiva contratual}

Existem diferentes formas de executar um empreendimento, podendo variar a sequência das etapas do processo; o momento de participação dos agentes; as responsabilidades de cada participante dentro do processo; os procedimentos de troca de informações; e o número e tipo de contrato estabelecido entre os participantes.

De acordo com Molenaar e Sobin (2009), o método de produção do empreendimento ou Project Delivery Method é o processo abrangente pelo qual os agentes prestam serviços de projeto e execução para entregar o empreendimento ao cliente.

Por se tratar de uma decisão anterior ao início do processo de produção e que influencia a qualidade final da edificação, é de extrema importância o procedimento de escolha desse método. Segundo Mostafavi e Karamouz (2010) a seleção do método é um problema único com múltiplas variáveis e que tem como objetivo atender aos interesses tanto do cliente quanto dos agentes contratados. No entanto, a tomada decisão é feita baseada em incertezas, ou seja, o método escolhido pode se mostrar inadequado ao tipo do empreendimento, ao final ou até durante sua execução.

De acordo com o relatório do CMAA (CONSTRUCTION MANAGEMENT ASSOCIATION OF AMERICA, 2012), que orienta os clientes na escolha do método de produção do empreendimento, nenhum deles é adequado a todos os tipos de empreendimento, pois cada método apresenta diferentes riscos e benefícios.

Algumas questões fundamentais influenciam na seleção do método, como: o nível de conhecimento técnico do cliente; a necessidade de controlar e fixar custo e prazo da produção; o nível de qualidade e controle sobre o projeto; e a avaliação dos riscos do empreendimento, tanto para o cliente quanto para os demais agentes. O cliente deve avaliar cuidadosamente os requisitos, necessidades, objetivos e potencialidades do empreendimento para selecionar o método que oferece as melhores oportunidades (CONSTRUCTION MANAGEMENT ASSOCIATION OF AMERICA, 2012). 
Os métodos de produção do empreendimento se apoiam em modelos de contrato, que determinam os direitos e deveres de cada agente sobre o processo produtivo. Segundo Mosey (2009), o contrato é um acordo voluntário entre duas ou mais partes que visa proteger os interesses dos participantes e garantir a execução do produto ou serviço em questão. Esse autor especifica três funções dos contratos:

- estabelecer os direitos, responsabilidades e procedimentos;

- identificar, atribuir e transferir os riscos; e

- atuar como uma ferramenta de planejamento do processo, a fim de evitar imprevistos durante a execução.

Ao analisar a integração a partir da perspectiva do sistema contratual, percebe-se que existe uma busca por reduzir o número de contratos, de forma a estabelecer os mesmos instrumentos para todos os agentes, mantendo como objetivo comum a busca pela qualidade do empreendimento. Dessa forma, os limites de atuação de cada profissional se tornam mais flexíveis, estabelecendo uma integração entre as diferentes disciplinas e favorecendo a colaboração entre a equipe (MURRAY; LANGFORD 2003).

Matthews e Howell (2005) definem uma forma de classificação dos contratos, entre transacionais ou relacionais.

Contratos transacionais são baseados na troca de bens ou serviço e, portanto, o foco está nas características e na qualidade dos produtos finais. Esses produtos são extremamente detalhados e os agentes são cobrados para que a entrega corresponda aos parâmetros definidos no contrato (RAHMAN; KUMARASWAMY, 2005).

Contratos relacionais são baseados nas relações entre os participantes do processo e têm como foco principal as formas de interação da equipe. Nele são estabelecidos princípios que favorecem a cooperação e confiança entre os agentes, visando reduzir a competitividade e os conflitos (COLLEDGE, 2005).

\subsubsection{Sistema contratual transacional}

O uso intensivo de contratos transacionais pela indústria da construção civil pode ser entendido pela necessidade de se obter maior controle sobre a produção do empreendimento. Segundo Rahman e Kumaraswamy (2005), os contratos transacionais são rígidos em suas cláusulas. 
Todos os elementos necessários para a entrega do produto ou serviço são definidos antes do início do processo de produção.

No entanto, a indústria da construção civil possui particularidades que trazem complexidade e incertezas ao processo. Novas questões sobre o empreendimento podem surgir ao longo do seu desenvolvimento, o que tornaria o contrato transacional inadequado ou incompleto.

Matthews e Howell (2005) identificaram quatro principais problemas do uso desses contratos nos processos de produção do empreendimento:

O primeiro problema é a omissão de melhores soluções para o empreendimento pelos especialistas. Isso ocorre principalmente pela contratação tardia dos profissionais responsáveis pela execução, que acontece somente quando o projeto já está finalizado. Esses agentes não participam do desenvolvimento do projeto e não têm a possibilidade de inserir informações relativas à sua disciplina.

Mesmo no caso em que os especialistas participam da etapa de desenvolvimento como consultores, essa omissão também ocorre, pois não existe nenhum vínculo formal com o cliente e nenhuma garantia de que esse agente será efetivamente contratado. Os especialistas ocultam as melhores soluções para serem usadas durante a etapa de licitação, como um diferencial para a contratação dos serviços.

O segundo problema é a falta de incentivo à cooperação e inovação. Como cada contrato é independente, os participantes tendem a focar somente nas etapas de sua responsabilidade. Além disso, os agentes não são incentivados a sugerir soluções inovadoras para o projeto, com risco de sofrerem penalidades pelo descumprimento de alguma cláusula contratual.

O terceiro problema identificado por Matthews e Howell (2005) é a complexidade da atividade de coordenação dos projetos. O grande número de contratos resulta em diversas interfaces que devem ser compatibilizadas. Isso pode se agravar no caso de existirem conflitos entre os objetivos de cada contrato, o que prejudicaria o processo como um todo.

O quarto problema identificado pelos autores é a pressão pela otimização dos resultados individuais em detrimento ao resultado global do empreendimento. Todos os agentes buscam a eficiência e o melhor desempenho do empreendimento; no entanto, sob pontos de vista diferentes, considerando apenas as atividades sob sua responsabilidade. Isso pode gerar conflitos entre os participantes, reduzindo a qualidade do empreendimento e a eficiência do processo. 
Cheung, Yiu e Chim (2006) destacam que os deveres e direitos de cada participante estabelecidos nos contratos incentiva a competitividade de uma forma danosa. Cada agente busca atender somente os seus interesses, o que pode não ser a melhor solução para o empreendimento como um todo. Isso passa a ser um agravante no caso de projetos complexos. Com maiores incertezas sobre as soluções de projeto, existe a tendência de os participantes aumentarem os valores de contrato para reduzir os riscos de projeto e execução.

Harper, Molenaar e Cannon (2016), também indicam o ambiente de conflito e competição favorecido pelos contratos transacionais. Os contratos são bilaterais, ou seja, o cliente estabelece relações de trabalho entre cada um dos profissionais, de maneira independente. Cada agente possui deveres relacionados a sua especificidade técnica, o que desconsidera a interdisciplinaridade do processo de produção.

Com a utilização de contratos bilaterais, existe a tendência de que as etapas do processo sigam uma execução linear, ou seja, em cada nova atividade, acrescentam-se informações e os desenhos são atualizados com maiores detalhes. Cada participante atua somente na atividade sob sua responsabilidade, sem considerar o impacto dela no processo como um todo.

Segundo El-Adaway, Abotaleb e Eteifa (2017), contratos transacionais podem ser adequados para empreendimentos menos complexos, que possuem curta duração, que não necessitam de muita interação e colaboração entre as disciplinas e que não apresentam possibilidade de novos trabalhos pela mesma equipe.

De acordo com Eastman et al. (2011), foram identificados três modelos de contrato transacionais mais utilizados pelo setor da construção civil: Design-Bid-Build (DBB) ou Método Tradicional; e dois modelos alternativos, que são variações do DBB.

Correspondem aos modelos alternativos: Design and Build (DB) ou Projeto-Construção; e o Construction Management at Risk (CMAR) ou Gestão da Construção por Administração com Risco para a Gestora (Figura 5).

Os modelos alternativos de contratação foram desenvolvidos com o intuito de aperfeiçoar os processos de produção e reduzir o ambiente de conflito entre os participantes. Apesar de utilizarem a contratação transacional, os métodos alternativos buscam reduzir o distanciamento entre as etapas de projeto e execução, ao propiciar a colaboração dos profissionais de execução nas atividades de desenvolvimento do projeto. 
Figura 5 - Modelos de contrato transacionais

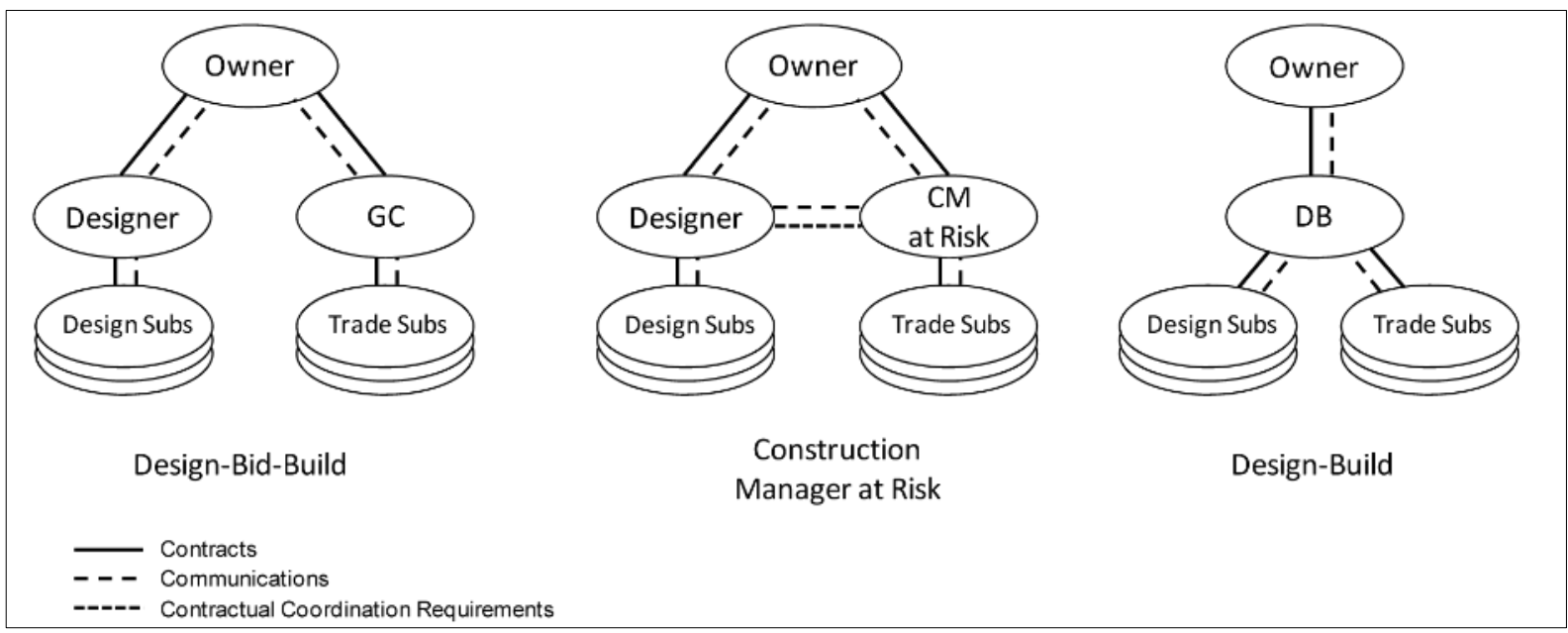

Fonte: MOLENAAR; SOBIN, 2009.

\subsubsection{Design-Bid-Build (DBB) ou Método Tradicional}

O método de produção tradicional, denominado Design-Bid-Build (DBB) ou Projeto-LicitaçãoConstrução, é o mais utilizado nos empreendimentos da construção civil nos Estados Unidos (Tabela 5). De acordo com um relatório do CMAA (2012), cerca de 60\% das edificações de multipavimentos desse país, são executadas seguindo o método $\mathrm{DBB}^{2}$. No entanto, essa mesma referência indica que houve um declínio desse método em relação aos demais.

A principal característica do DBB é a segregação das atividades de projeto e execução. Existem três etapas básicas no DBB, que dão nome ao método: projeto, licitação e execução. Inicialmente, é feito o desenvolvimento completo e detalhado do projeto (design) pelo projetista. A partir do projeto executivo, o cliente realiza a escolha do construtor por meio de uma concorrência (bid), utilizando como critério o melhor preço, melhor técnica, ou melhor técnica e preço. Finalmente, a empresa escolhida executa a obra (build) (HARPER, 2014).

Existem no mínimo dois contratos independentes: um entre o cliente e o projetista; e outro entre o cliente e o construtor (CONSTRUCTION MANAGEMENT ASSOCIATION OF AMERICA, 2009). Podem existir outros contratos, como no caso de uma empresa especializada ou de consultores. Esses agentes podem estabelecer o contrato diretamente com o cliente ou com o construtor, como um subcontratado deste.

\footnotetext{
2 Na pesquisa do CMAA (2012) foram considerados todos os principais métodos de produção dos empreendimentos e os demais resultados foram: Construction Management at Risk (CMAR) 25\%; Design-Build (DB) $15 \%$; e Integrated Project Delivery (IPD) $<1 \%$.
} 
Tabela 5 - Características do Design-Bid-Build (DBB) ou Método Tradicional

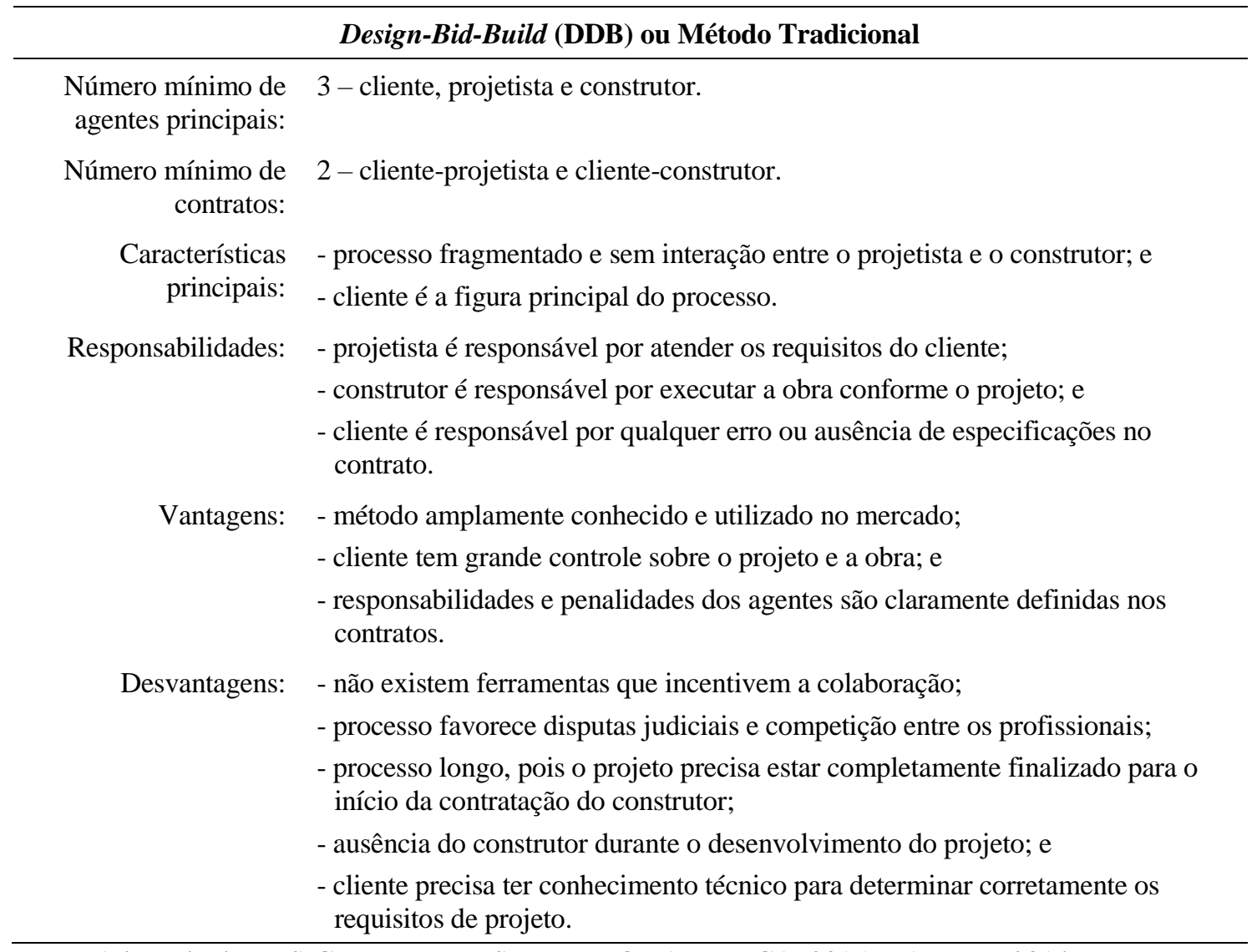

Fonte: Adaptado de DESIGN-BUILD INSTITUTE OF AMERICA, 2015; HARPER, 2014.

De acordo com Harper (2014), o cliente atua como a figura central do processo DBB, pois os contratos com os principais agentes são estabelecidos com ele. Além disso, ficam sob sua responsabilidade as atividades de definição da Requisição de Proposta (Request for Proposal RFP), licitação e aprovação de todas as decisões de projeto.

O AIA (AMERICAN INSTITUTE OF ARCHITECTS, 2007a) indica que o DBB é o modelo de contrato que menos oferece oportunidades para integrar o processo de produção. Como a participação dos agentes responsáveis pela obra ocorre somente após a finalização do projeto, é possível que existam diversos problemas de construtibilidade e compatibilização de disciplinas que só serão identificados na etapa de execução, resultando em atrasos, retrabalho e aumento de custo.

Costa et al. (2017) também indicam a dificuldade de estabelecer um processo integrado com o DBB. Existe uma linearidade na execução das atividades no DBB, o que considera cada etapa como sendo independente e isolada das demais. Cada participante é inserido no processo somente na atividade de sua responsabilidade. O contrato é o elemento que indica o momento 
em que cada participante entra no processo e passa a se responsabilizar pelas entregas, seguindo os requisitos estipulados no documento.

No DBB não existe nenhum vínculo entre os profissionais contratados, somente entre eles e o cliente. Os instrumentos contratuais não promovem a colaboração entre os agentes e não estimulam os profissionais a criarem alternativas que facilitem ou auxiliem a execução, o que poderia reduzir custos e prazos da obra e aumentar a qualidade final da edificação.

O processo de produção do DBB pode favorecer disputas judiciais, principalmente na etapa de aceite do empreendimento pelo cliente. Caso a edificação não atenda aos requisitos estabelecidos no contrato, o cliente solicita as modificações ao construtor. No entanto, dependendo do problema encontrado, o construtor busca responsabilizar os subcontratados ou os projetistas. Esse ambiente competitivo prejudica a qualidade do projeto e consequentemente o cliente (DESIGN-BUILD INSTITUTE OF AMERICA, 2015).

\subsubsection{Design and Build ou Projeto-Construção}

Design and Build (DB) ou Projeto-Construção se caracteriza pela presença de dois agentes principais: o cliente e uma associação entre o projetista e o construtor (Tabela 6). Essa associação pode ser um construtor que possui um setor de projetos próprio, ou um consórcio entre um construtor e um projetista (DESIGN-BUILD INSTITUTE OF AMERICA, 2014).

Existem duas características básicas desse método que representam um aperfeiçoamento em relação ao DBB. No DB é estabelecido um único contrato entre o cliente e o projetistaconstrutor, o que simplifica o diálogo sobre a produção do empreendimento (HARPER, 2014).

A outra característica é a aproximação entre as fases de projeto e execução. O DB facilita a interação e colaboração entre o projetista e o construtor. Ao trabalharem em uma mesma empresa ou associação, estabelece-se um ambiente colaborativo, onde ambos buscam as melhores soluções para o processo como um todo. Essa aproximação possibilita a redução de disputas e conflitos de interesse entre as etapas de projeto e execução (CONSTRUCTION MANAGEMENT ASSOCIATION OF AMERICA, 2012).

De acordo com Costa et al. (2017), o DB é um modelo de contratação que está sendo usado com mais frequência a nível internacional. O projetista e o construtor passam a compor uma equipe temporária, estabelecida para a produção de um empreendimento de maneira mais coordenada e integrada. 
Tabela 6 - Características do Design and Build (DB) ou Projeto-Construção

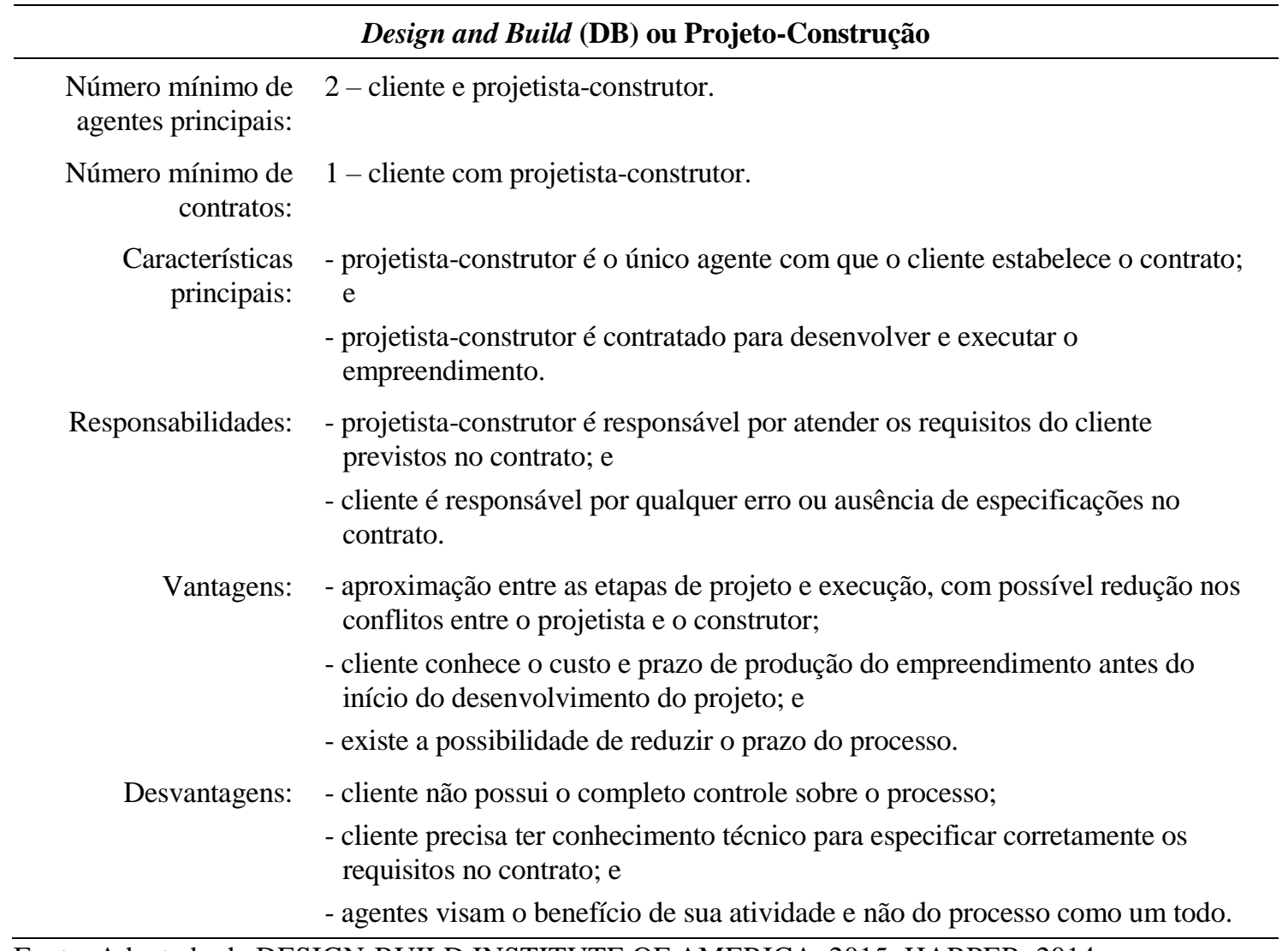
Fonte: Adaptado de DESIGN-BUILD INSTITUTE OF AMERICA, 2015; HARPER, 2014.

Com a participação do construtor nas etapas de planejamento e desenvolvimento do projeto, o projetista passa a ter um maior número de informações relativas à execução, resultando na antecipação das decisões no processo. Isso possibilita reduzir a necessidade de retrabalho devido às incoerências entre projeto e execução.

No entanto, a contratação dos especialistas de execução acontece da mesma forma que no DBB, ou seja, somente no final do processo. Como os especialistas têm conhecimento do projeto somente no momento de sua contratação, as soluções escolhidas pelos projetistas podem não ser adequadas ao método de trabalho desses agentes, resultando em retrabalho, aumento de prazo e custo.

O DB demanda um maior conhecimento técnico do cliente, se comparado ao DBB. Ao associar as atividades de projeto e execução em um único agente, o envolvimento e o controle do cliente no processo de produção são mais reduzidos. O cliente precisa estabelecer todos os requisitos e o escopo do empreendimento, antes do início do desenvolvimento do projeto, deixando claro no contrato quais os detalhes estéticos e funcionais requeridos (XIA; CHAN; MOLENAAR, 2012). 
A escolha do projetista-construtor também pode representar uma dificuldade no método $\mathrm{DB}$. $\mathrm{O}$ cliente fica responsável por selecionar uma construtora que tenha conhecimento suficiente para desenvolver um projeto adequado à RFP. No caso de uma associação, o projetista e o construtor devem interagir de maneira satisfatória e devem trabalhar em prol do projeto como um todo. Caso contrário, a disputa e os conflitos entre esses agentes podem prejudicar o processo de produção e impedir que a colaboração do construtor na etapa de desenvolvimento do projeto efetivamente aconteça.

\subsubsection{Construction Management at Risk (CMAR) ou Gestão da Construção por Administração com Risco para a Gestora}

Construction Management at Risk (CMAR) ou Gestão da Construção por Administração com Risco para a Gestora é um método de produção em que o cliente contrata um gestor de construção no início do processo como seu representante para coordenar a produção do empreendimento (NATIONAL ASSOCIATION OF STATE FACILITIES, 2007) (Tabela 7).

O relatório do National Association of State Facilities (NASFA) (2007), que fornece orientações para o uso do CMAR, define três características básicas desse processo:

- o projetista e o gestor de construção estabelecem contratos independentes diretamente com o cliente;

- o gestor de construção é selecionado de acordo com suas qualificações; e

- o gestor de construção estabelece os contratos com os especialistas da obra e é responsável pela qualidade e desempenho da execução.

A contratação do gestor de construção pode ocorrer antes do início do projeto, ainda na elaboração da RFP, ou com o projeto já em desenvolvimento. O AIA (AMERICAN INSTITUTE OF ARCHITECTS, 2019) possui dois modelos de contrato para o método CMAR. Em um deles, o gestor atua como o próprio construtor do empreendimento e no outro, o gestor de construção é um consultor independente, que gerencia todas as atividades ao longo do processo de produção. 
Tabela 7 - Características do Construction Management at Risk (CMAR) ou Gestão da Construção por Administração com Risco para a Gestora

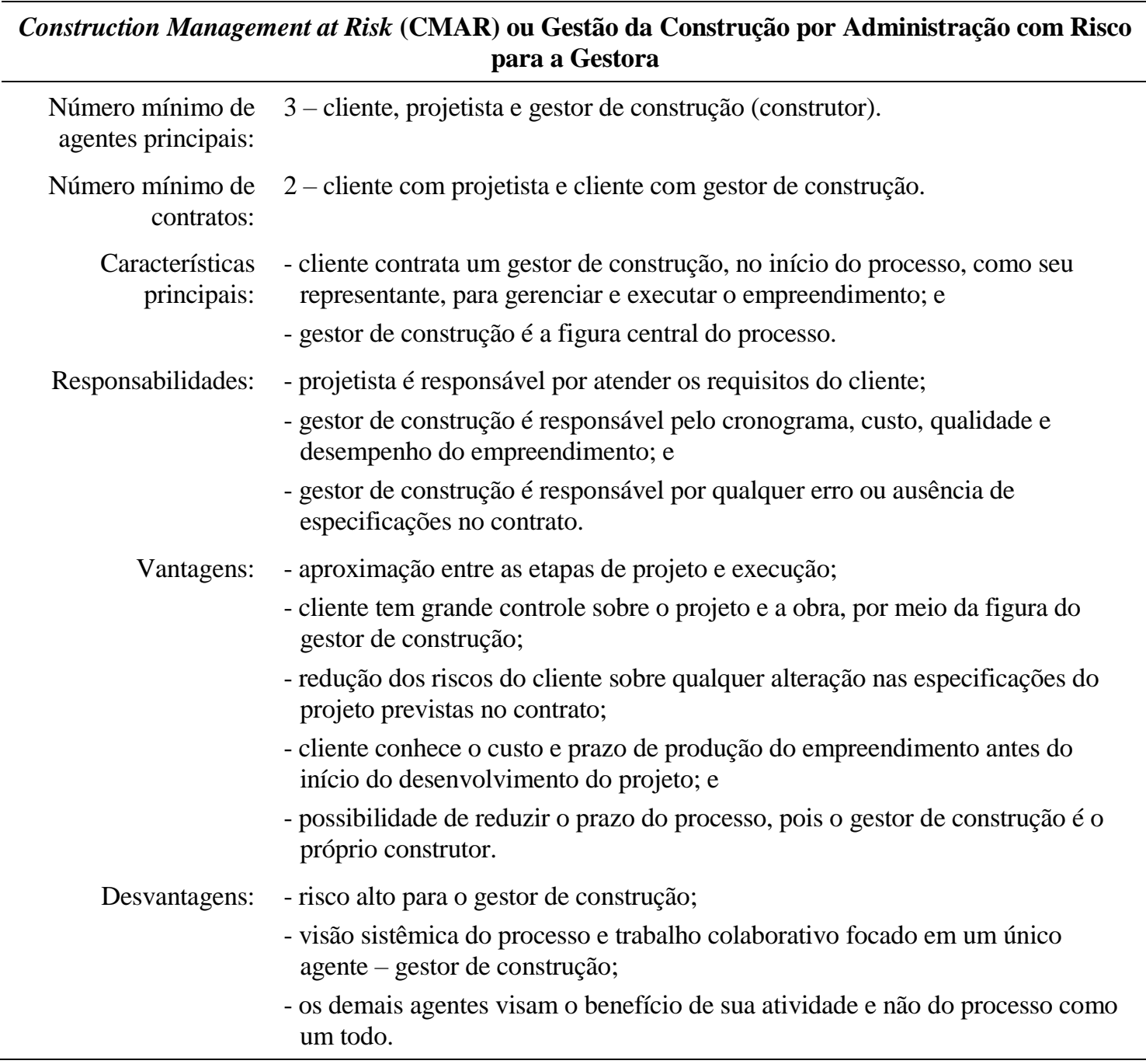

Fonte: Adaptado de DESIGN-BUILD INSTITUTE OF AMERICA, 2015; HARPER, 2014.

O termo at Risk, que denomina o método, indica que, após o a definição da RFP e do anteprojeto, o gestor de construção será responsável pela qualidade do processo de produção. Esse agente se responsabiliza pelo cronograma, orçamento, gestão do projeto, definição das técnicas construtivas e os subcontratos dos especialistas de execução (CONSTRUCTION MANAGEMENT ASSOCIATION OF AMERICA, 2012).

Segundo o NASFA (NATIONAL ASSOCIATION OF STATE FACILITIES, 2007), existe uma variação desse método, onde o gestor de construção não é responsável pelo desempenho do processo. Nesse caso, esse participante atua apenas como um consultor, que gerencia as etapas de projeto e execução. Essa variação é denominada Construction Management not at Risk (CM not-at-risk) ou Gestão da Construção por Administração sem Risco para a Gestora. 
Quando o gestor de construção assume o risco do empreendimento, ele tem um incentivo para buscar as melhores soluções para o projeto, desde as etapas de planejamento. O gestor busca antecipar o maior número de informações e, com isso, reduzir os riscos ao longo do processo.

No entanto, esse risco fica concentrado em um único agente. Como o sistema contratual estabelecido no CMAR é o mesmo que no DBB e DB, os produtos e serviços a serem entregues por cada um dos participantes estão claramente detalhados. O gestor de construção fica responsável por garantir que os agentes entreguem, não somente o que foi especificado, mas que tenham uma visão sistêmica do processo, considerando o impacto de suas atividades nas etapas posteriores. Caso existam divergências, o método do CMAR fica vulnerável a conflitos entre os participantes.

\subsubsection{Sistema contratual relacional}

No sistema contratual relacional, são definidos todos os elementos que irão nortear as relações entre os participantes, baseadas nos princípios de confiança e transparência nas trocas de informações (LAHDENPERÄ, 2012).

Ao contrário do que ocorre no sistema transacional, a troca de bens e serviços não é o fator mais importante, mas sim a relação entre os agentes e como ocorrem as interações entre eles. $\mathrm{O}$ contrato relacional altera o foco da produção, que passa a ser o empreendimento como um todo e não os objetivos individuais dos participantes (HARPER; MOLENAAR; CANNON, 2016).

De acordo com El-Adaway, Abotaleb e Eteifa (2017) os contratos relacionais ainda são pouco utilizados na construção civil. Os autores indicam que esses contratos consideram a importância da cooperação entre os participantes e a interação entre as disciplinas como os fatores principais para se alcançar os objetivos do empreendimento. Questões como confiança, transparência na troca de informações, cooperação e fluxo contínuo na execução das atividades representam as premissas dos contratos relacionais.

Existem alguns instrumentos comuns aos contratos relacionais que visam estabelecer um processo de produção integrado e colaborativo. Um deles é o contrato multilateral, que prevê a criação de uma pequena sociedade temporária entre os agentes. De acordo com Saunders e Mosey (2005), os principais agentes - construtor, projetista, consultores e especialistas subcontratados - assinam um único contrato com o cliente, de forma a garantir os mesmos termos e condições de trabalho. 
O contrato multilateral proporciona um ambiente de confiança na equipe, trazendo transparência nos termos contratuais e permitindo que todos os agentes tenham conhecimento sobre as atividades e responsabilidades dos demais. Além disso, um único contrato simplifica o processo e integra as diferentes especialidades, incentivando o comprometimento aos objetivos do empreendimento.

Outro instrumento é o compartilhamento de riscos e benefícios do processo de produção. Boukendour e Hughes (2014) destacam que a forma de remuneração dos participantes pode ser um empecilho para a colaboração, de forma que os participantes busquem sempre o maior lucro apenas de sua atividade.

Com o compartilhamento de riscos e benefícios é estabelecida uma meta de custo para o projeto. Os participantes trabalham colaborativamente para desenvolver as melhores soluções, visando reduzir o custo e prazo do projeto, mantendo a qualidade final. Com isso, o valor que foi economizado é repartido entre todos os participantes, proporcionalmente à responsabilidade de cada um no processo, independentemente de quem foi responsável pela melhor solução (BOUKENDOUR; HUGHES, 2014).

Existem diversos métodos de produção do empreendimento que utilizam o contrato relacional, variando conforme a localidade em que foram desenvolvidos, os instrumentos voltados à integração e os participantes do processo. Apesar das diferenças, todos os métodos visam incorporar os principais agentes desde as primeiras etapas do processo, por meio do trabalho colaborativo.

Lahdenperä (2012) destaca os principais contratos relacionais usados na construção civil: Project Partnering (PP); Project Alliancing (PA); e Integrated Project Delivery (IPD). Além desses, Mosey (2009) e Scheepbouwer e Humphries (2011) indicam o modelo Early Contractor Involvement (ECI).

\subsubsection{Project Partnering (PP) ou Projeto de Parceria}

O Project Partnering (PP), ou Projeto de Parceria, é considerado o primeiro método de produção do empreendimento a utilizar o sistema contratual relacional, o primeiro relato de seu uso foi em 1988 pelo departamento de engenharia do exército dos Estados Unidos (U.S. Army Corps of Engineers - USACE). O PP foi inicialmente desenvolvido como uma prática de gestão e, posteriormente, com a elaboração de novos instrumentos, caracterizou-se como um método próprio (LAHDENPERÄ, 2012). 
O Association of Consultant Architects (ACA) (MOSEY, 2010), que representa os arquitetos no setor privado da construção civil no Reino Unido, se refere ao PP como um método que busca aperfeiçoar o processo de produção do empreendimento por meio do esforço colaborativo da equipe. Com a aplicação do método, busca-se reduzir o custo e prazo de execução, aumentar a qualidade do empreendimento e atender aos princípios de sustentabilidade tanto do edifício quanto do processo de produção.

O Construction Industry Institute (CII) descreve o PP como um compromisso firmado entre dois ou mais agentes, que trabalham como uma única organização, ou seja, sem barreiras entre as diferentes empresas e profissionais, com o intuito de atingir objetivos específicos de negócio, maximizando a eficiência dos recursos de cada participante (Tabela 8) (CONSTRUCTION INDUSTRY INSTITUTE, 2018).

Tabela 8 - Características do Project Partnering (PP) ou Projeto de Parceria

\begin{tabular}{|c|c|}
\hline \multicolumn{2}{|r|}{ Project Partnering (PP) ou Projeto de Parceria } \\
\hline $\begin{array}{l}\text { Número mínimo de } \\
\text { agentes principais: }\end{array}$ & 3 - cliente, projetista, construtor. \\
\hline \multirow[t]{3}{*}{ Número de contratos: } & depende do modelo de contrato, podendo ser: \\
\hline & - 1 contrato multilateral entre os agentes principais (PPC2000); \\
\hline & - vários contratos bilaterais com uma cláusula de parceria (NEC). \\
\hline \multirow{6}{*}{$\begin{array}{l}\text { Características } \\
\text { principais: }\end{array}$} & - contrato multilateral opcional; \\
\hline & $\begin{array}{l}\text { - participação precoce dos agentes principais, com equipe formada como uma } \\
\text { organização temporária; }\end{array}$ \\
\hline & $\begin{array}{l}\text { - definição compartilhada dos objetivos e metas do empreendimento, bem como } \\
\text { do próprio contrato; }\end{array}$ \\
\hline & - compartilhamento dos riscos e benefícios; \\
\hline & - bonificações variáveis de acordo com indicadores de desempenho; e \\
\hline & - resolução de conflitos dentro da equipe. \\
\hline \multirow[t]{2}{*}{ Responsabilidades: } & - PP é liderado pelo cliente; e \\
\hline & $\begin{array}{l}\text { - com o contrato multilateral ou o compartilhamento dos riscos, todos os agentes } \\
\text { são responsáveis pelo empreendimento como um todo. }\end{array}$ \\
\hline \multirow[t]{3}{*}{ Vantagens: } & $\begin{array}{l}\text { - redução das barreiras entre os profissionais e empresas participantes, que } \\
\text { proporciona um alto nível de confiança e colaboração entre os participantes; }\end{array}$ \\
\hline & $\begin{array}{l}\text { - comprometimento de toda equipe no processo como um todo, tendo como } \\
\text { incentivos o compartilhamento dos riscos e benefícios e as bonificações } \\
\text { variáveis; e }\end{array}$ \\
\hline & - método já estabelecido no mercado e com estudos de caso. \\
\hline \multirow[t]{2}{*}{ Desvantagens: } & - barreiras de legislação para a inserção dos contratos multilaterais; e \\
\hline & $\begin{array}{l}\text { - dificuldade para manter o aprimoramento contínuo da equipe, devido à curta } \\
\text { duração dos processos e falta de continuidade nos relacionamentos entre os } \\
\text { profissionais e empresas. }\end{array}$ \\
\hline
\end{tabular}

Fonte: Adaptado de ASSOCIATION OF CONSULTANT ARCHITECTS, 2005; MOSEY, 2010; CONSTRUCTION INDUSTRY COUNCIL, 2010; GADDE; DUBOIS, 2010. 
O ACA (ASSOCIATION OF CONSULTANT ARCHITECTS, 2005) especifica os seguintes instrumentos presentes no PP:

- contrato multilateral, todos os principais especialistas assinam um único contrato, o que incentiva o trabalho colaborativo, com o comprometimento de toda a equipe aos objetivos do empreendimento; para os demais agentes, são estabelecidos contratos de associação, mantendo os princípios do PP;

- participação precoce e contínua de todos os agentes no processo, o que possibilita a integração do processo de projeto, do fornecimento de componentes/materiais e da execução;

- formação de um grupo principal, que é composto por um representante de cada um dos principais agentes e fica responsável pela coordenação do processo, antecipando os principais riscos do empreendimento;

- participação de um consultor de PP, que deve ser um profissional com experiência nesse método e que tem como responsabilidade orientar o processo de produção e documentar todas as relações entre os participantes, suas expectativas e dificuldades com o método;

- resolução de problemas sem conflitos, por meio do estabelecimento de uma hierarquia para a solução dos problemas, passando primeiro pelo diálogo entre os agentes envolvidos e depois entre estes e o grupo principal;

- compartilhamento dos riscos e benefícios do processo, que são valores incidentes sobre o lucro do empreendimento, além de bonificações variáveis conforme o desempenho das atividades;

- gestão e flexibilização na alocação dos riscos, que busca definir, reduzir e compartilhar os riscos do empreendimento, além de envolver toda a equipe na definição e alocação dos riscos;

- transparência das informações sobre o processo de produção, por meio da divulgação de um único documento de controle, onde todos os participantes inserem as atividades, seus respectivos responsáveis e o tempo de duração delas; esse documento deixa claro para toda a equipe quais são as etapas de produção do empreendimento e as alterações realizadas durante o processo;

- parceria com a cadeia de fornecedores, com transparência na troca de dados do projeto, incentivando a participação de todos os especialistas, mesmo aqueles que são subcontratados; e 
- inserção de ferramentas que incentivam o aprimoramento do processo de produção, como, foco no produto final, melhoria contínua dos processos, atendimento aos princípios de sustentabilidade, qualidade no local de trabalho e treinamento da equipe.

Eriksson (2010) indica que o PP não é adequado a todos os empreendimentos. O processo colaborativo e o contrato multilateral do PP são apropriados em empreendimentos de alta complexidade, com muitas incertezas e especificidades, além de metas de prazo e orçamento muito rígidas.

Existem dois modelos de contrato mais utilizados para o PP: Project Partnering Contract (PPC2000) e New Engineering Contract (NEC).

O modelo de contrato utilizado pelo ACA, denominado Project Partnering Contract (PPC2000), foi desenvolvido no ano de 2000 e, desde então, é revisto periodicamente, sendo que a última atualização foi realizada em 2013 (ASSOCIATION OF CONSULTANT ARCHITECTS, 2016). Segundo Saunders e Mosey (2005), as principais características que diferenciam o PPC2000 dos contratos transacionais são: integração da equipe, por meio do contrato multilateral; e abrangência de todo o processo, desde o planejamento até a entrega do empreendimento.

O nível de detalhe dos instrumentos previstos no PPC2000 depende dos objetivos da equipe para o empreendimento em questão. O ACA (ASSOCIATION OF CONSULTANT ARCHITECTS, 2005) recomenda que a definição desses instrumentos faça parte do processo do PP, de forma que todos os agentes participem da elaboração do contrato, garantindo o comprometimento de toda a equipe na busca dos melhores resultados.

Segundo El-Adaway, Abotaleb e Eteifa (2017), o PPC 2000 insere o trabalho colaborativo como o instrumento principal do contrato. Uma equipe com os principais participantes do processo de produção é responsável por definir e acompanhar as atividades de planejamento, desenvolvimento e entrega do projeto, além das decisões pelas aquisições relacionadas à execução.

Um guia sobre o PP desenvolvido pelo Construction Industry Council (CIC) de Hong Kong (CONSTRUCTION INDUSTRY COUNCIL, 2010) indica outro modelo de contrato aplicado aos processos de PP: New Engineering Contract (NEC). O NEC foi desenvolvido pelo Instituto de Engenheiros Civis do Reino Unido.

Segundo Gerrard (2005), o NEC não é um contrato multilateral. Nesse modelo, o cliente estabelece vários contratos bilaterais com cada agente e, por meio de uma cláusula de parceria, 
comum a todos os contratos, os participantes passam a ter uma responsabilidade maior sobre as etapas de outros agentes. Isso incentiva que a equipe trabalhe integrada, estabelecendo assim, a parceria prevista no PP.

O CIC (CONSTRUCTION INDUSTRY COUNCIL, 2010) indica que esse tipo de contrato pode ser útil aos empreendimentos públicos. Devido às restrições legislativas, muitos países não conseguem incluir o contrato multilateral no setor público. Ao inserir uma cláusula que vincula todos os participantes, o NEC possibilita integrar a equipe, mesmo mantendo vários contratos entre o cliente e os demais profissionais ou empresas responsáveis pela execução do empreendimento.

De acordo com El-Adaway, Abotaleb e Eteifa (2017), não existe um tipo de contrato melhor para ser aplicado o PP. Cada um deles, se aplicado corretamente, permite que se alcancem melhores resultados para o empreendimento e cada processo tem suas próprias características que vão indicar a melhor escolha do contrato.

Portanto, o PP é um método de produção amplamente difundido no mercado da construção civil e tem como principal fundamento a criação de uma organização entre os participantes, para que eles possam trabalhar em conjunto na produção do empreendimento. Ao aperfeiçoar o processo de trabalho da equipe, inserindo um ambiente colaborativo, o PP visa aumentar a eficiência do processo e a qualidade do produto, além de eliminar o ambiente competitivo e propenso a conflitos.

\subsubsection{Project Alliancing (PA) ou Aliança de Projeto}

O Project Alliancing (PA) ou Aliança de Projeto teve origem no início da década de 1990 no Reino Unido. Com o aperfeiçoamento do método, o PA teve grande aceitação em diversos países, mas foi na Austrália que ele ganhou maior visibilidade e, atualmente, o governo deste país utiliza o PA como um padrão de contratação dos empreendimentos públicos complexos (DEPARTMENT OF TREASURY AND FINANCE, 2010) (Tabela 9).

Segundo o Departamento do Tesouro e Finanças (Department of Treasury and Finance - DTF) do estado de Vitória na Austrália (DEPARTMENT OF TREASURY AND FINANCE, 2010), o PA é um método de produção em que todos os participantes trabalham colaborativamente, com o objetivo de alcançar as melhores soluções para o empreendimento. 
Tabela 9 - Características do Project Alliancing (PA) ou Aliança de Projeto

\begin{tabular}{|c|c|}
\hline \multicolumn{2}{|r|}{ Project Alliancing (PA) ou Aliança de Projeto } \\
\hline $\begin{array}{l}\text { Número mínimo de } \\
\text { agentes principais: }\end{array}$ & $\begin{array}{l}\text { Divididos em } 2 \text { grupos: cliente e não-cliente (NOPs), este último varia conforme } \\
\text { o empreendimento. }\end{array}$ \\
\hline Número de contratos: & 1 contrato multilateral entre os agentes principais. \\
\hline \multirow{7}{*}{$\begin{array}{l}\text { Características } \\
\text { principais: }\end{array}$} & - contrato multilateral obrigatório; \\
\hline & $\begin{array}{l}\text { - participação precoce dos agentes principais, equipe formada como uma } \\
\text { organização empresarial; }\end{array}$ \\
\hline & - definição compartilhada dos objetivos, metas e riscos do empreendimento; \\
\hline & $\begin{array}{l}\text { - compartilhamento dos riscos e benefícios, separando os riscos que devem ser } \\
\text { compartilhados e os que ficam sob responsabilidade de um único agente; }\end{array}$ \\
\hline & $\begin{array}{l}\text { - remuneração separada entre: custo direto dos serviços, lucro pré-estabelecido e } \\
\text { valor sobre o qual são compartilhados os riscos e benefícios; }\end{array}$ \\
\hline & - transparência na divulgação dos dados do processo; e \\
\hline & - compromisso contratual de não iniciar disputas judiciais. \\
\hline \multirow[t]{2}{*}{ Responsabilidades: } & - todos os agentes são responsáveis pelo empreendimento como um todo; e \\
\hline & $\begin{array}{l}\text { - cliente é o único agente que pode alterar o escopo do processo (RFP, custo e } \\
\text { prazo). }\end{array}$ \\
\hline \multirow[t]{5}{*}{ Vantagens: } & $\begin{array}{l}\text { - cooperação entre os agentes e comprometimento de toda equipe no processo, } \\
\text { tendo como incentivo o compartilhamento dos riscos e benefícios; }\end{array}$ \\
\hline & - método já estabelecido no mercado e com estudos de caso; \\
\hline & - redução das disputas judiciais entre os participantes; \\
\hline & - possibilidade de antecipar o início do processo; e \\
\hline & - incentivo à inovação. \\
\hline \multirow[t]{4}{*}{ Desvantagens: } & $\begin{array}{l}\text { - falta de habilidade e conhecimento técnico do cliente pode trazer problemas ao } \\
\text { processo; }\end{array}$ \\
\hline & $\begin{array}{l}\text { - com o compartilhamento de riscos, o cliente se responsabiliza por questões que } \\
\text { antes eram de responsabilidade exclusiva dos NOPs; }\end{array}$ \\
\hline & $\begin{array}{l}\text { - como a parcela de riscos é limitada, o custo para o cliente pode exceder o } \\
\text { planejado, caso o limite dessa parcela seja alcançado; e }\end{array}$ \\
\hline & - dificuldade para contratar o seguro. \\
\hline
\end{tabular}

Fonte: Adaptado de AUSTRALIAN GOVERNMENT, 2015a; DEPARTMENT OF TREASURY AND FINANCE, 2010.

A estrutura da equipe no PA se assemelha a uma organização empresarial, composta pelo cliente (Owner) e não-cliente (Non-owner Participants - NOPs) (DEPARTMENT OF TREASURY AND FINANCE, 2009) (Figura 6). 
Figura 6 - Estrutura típica da equipe no Project Alliancing

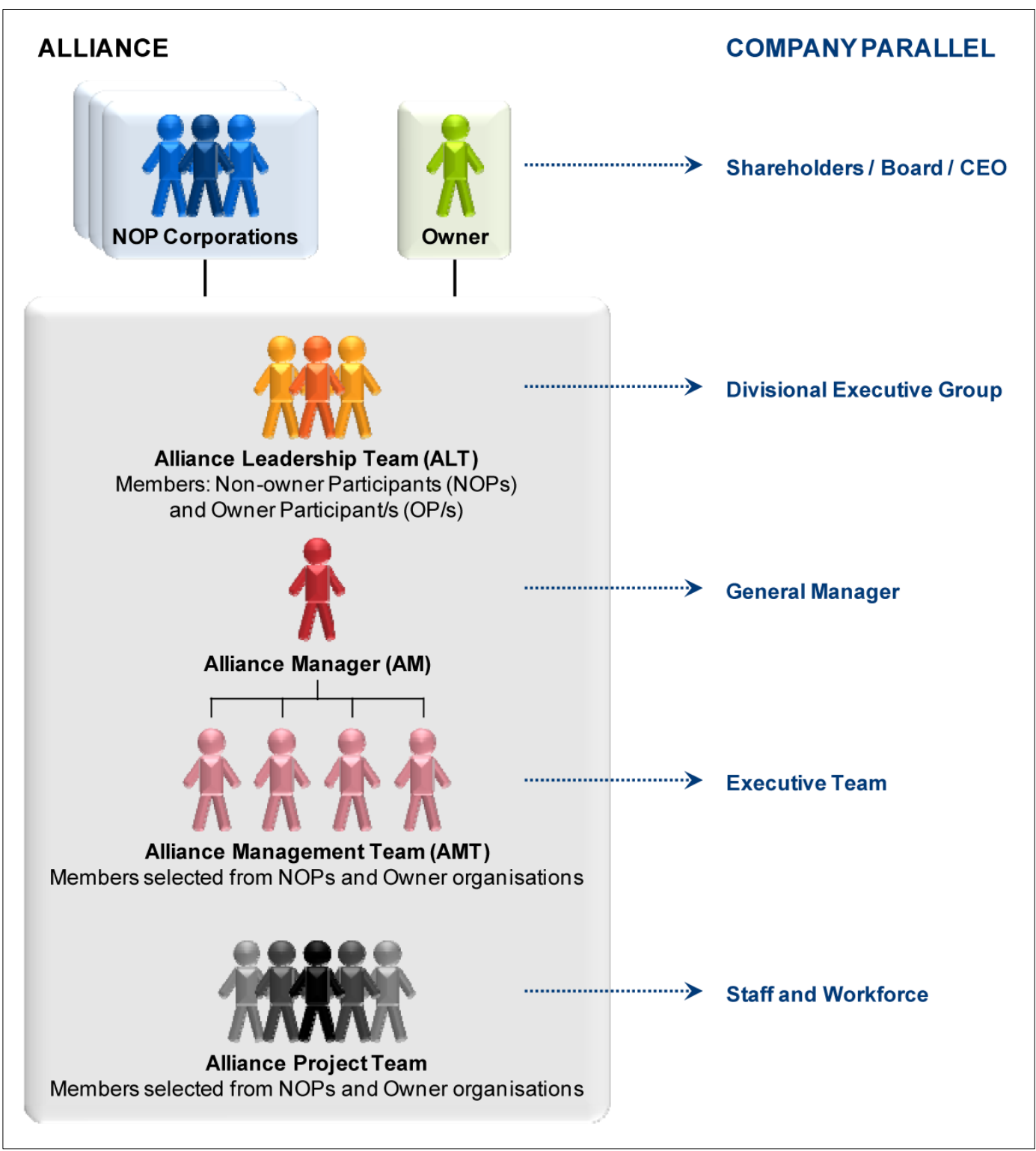

Fonte: DEPARTMENT OF TREASURY AND FINANCE, 2010.

O cliente é o agente que define a demanda, seleciona os participantes e estabelece o contrato do empreendimento. No PA podem atuar os consultores, denominados Owners Representatives (ORs), que possuem o conhecimento técnico necessário para auxiliar o cliente na definição dos objetivos, riscos e requisitos do processo, mas não fazem parte do contrato do PA (DEPARTMENT OF TREASURY AND FINANCE, 2009).

Os NOPs são responsáveis por planejar, projetar e executar o empreendimento seguindo o modelo de negócio estipulado no início do processo. Esses participantes não têm autonomia para alterar o escopo do projeto. Qualquer mudança no processo deve ser aprovada pelo cliente, 
que é o único agente com o direito de tomar decisões unilaterais no processo (DEPARTMENT OF TREASURY AND FINANCE, 2009).

O DTF (DEPARTMENT OF TREASURY AND FINANCE, 2010) lista os seguintes instrumentos que determinam o método do PA:

- contrato multilateral, em que participam o cliente e dois ou mais agentes, estabelecendo uma estrutura conjunta de gestão; esse instrumento permite que a equipe se assemelhe a uma pequena empresa criada temporariamente para a produção do empreendimento em questão; no entanto, o cliente é o único agente que pode tomar decisões unilateralmente, podendo modificar o escopo do projeto;

- compartilhamento de riscos e benefícios, esse instrumento incentiva a integração do processo; os participantes devem analisar previamente os riscos do empreendimento e diferenciar quais deles devem ser compartilhados e quais dependem apenas de um participante e, por isso, não devem ser compartilhados; além disso, a remuneração dos agentes deve ser dividida entre o custo direto dos serviços, um lucro pré-estabelecido e um valor sobre o qual devem ser compartilhados os riscos e benefícios;

- tomadas de decisão unânimes e baseadas no melhor para o empreendimento, os participantes devem ter como objetivo principal encontrar soluções que atendam o interesse coletivo, ao invés de favorecer apenas sua atividade; as decisões devem estar de acordo com os princípios do PA, ser aceitas por toda a equipe e estar alinhadas com as metas do empreendimento;

- compromisso por não iniciar disputas judiciais, esse instrumento incentiva a busca por soluções em conjunto, eliminado a cultura de procurar responsáveis pelos problemas; caso os participantes discordem em algum ponto, devem ser encontradas soluções para os conflitos dentro da equipe;

- princípios de boa fé e integridade, o que indica que os participantes devem se comprometer na cooperação junto aos demais para alcançar os objetivos propostos, considerar os interesses de todos nas tomadas de decisão e evitar ações que tragam benefício somente a sua atividade, prejudicando as demais; e

- transparência das informações do processo, os participantes devem se comprometer a divulgar todos os dados referentes às suas atividades, incluindo os custos dos serviços e produtos; esse instrumento incentiva a criação de um ambiente de confiança e o cliente passa a ter maior controle sobre o processo. 
Os benefícios na inserção do PA, de acordo com o departamento de infraestrutura do governo australiano (AUSTRALIAN GOVERNMENT, 2015a) são:

- aperfeiçoamento do desempenho, que pode resultar na redução de custo e maior qualidade ao empreendimento;

- incentivo à inovação, pois os participantes são incentivados a buscar melhores soluções para o projeto, sem, no entanto, sofrer com penalidades caso a escolha seja equivocada;

- cooperação ente os agentes da equipe, com a redução de conflitos, foco nas soluções, tomadas de decisão coletivas e gestão conjunto dos riscos;

- flexibilidade, para adaptar o processo às mudanças de escopo, riscos e oportunidades que surgem durante o processo de produção; e

- antecipação do início do processo, se comparado aos processos sequenciais, que necessitam do completo desenvolvimento do projeto para que as demais etapas tenham início.

Apesar desses benefícios, o PA pode não ser adequado a todos os tipos de empreendimentos. $\mathrm{O}$ departamento de infraestrutura do governo australiano (AUSTRALIAN GOVERNMENT, 2015a) define que alguns empreendimentos podem obter melhores resultados com o uso do PA: quando o custo de transferência dos riscos para o projetista e construtor é relativamente alto; existe urgência no início do processo de produção; e no caso em que todos os riscos não podem ser definidos nas etapas de planejamento.

Com o uso do PA, surgem alguns riscos diferentes daqueles especificados nos processos sequencias, que podem gerar problemas no processo e conflitos entre os participantes (AUSTRALIAN GOVERNMENT, 2015a):

- falta de habilidade e conhecimento do cliente, o que pode prejudicar o processo e impedir que os benefícios do PA possam ser efetivamente alcançados;

- meta de custo final baixa, caso não sejam avaliados todos os custos relativos aos produtos e serviços durante a contratação dos profissionais, o que pode resultar no aumento do custo final para o cliente;

- atribuição de custo, como os riscos do processo são compartilhados, os profissionais não devem adicionar os riscos individuais ao pagamento dos serviços;

- riscos para o cliente, com o compartilhamento dos riscos, os participantes têm suas responsabilidades individuais reduzidas, o que pode gerar menor comprometimento pelo desempenho do processo; 
- subcontratação, os profissionais e empresas podem subcontratar alguns serviços de sua responsabilidade, o que implica na participação de outros agentes, além do contrato do PA;

- alocação de risco, a parcela sob risco é limitada; caso a equipe tenha alcançado o limite, todos os riscos posteriores serão de responsabilidade do cliente;

- custos adicionais, os participantes são incentivados a não ultrapassar a meta de custo final especificada no início do processo; no entanto, o cliente pode solicitar modificações no escopo, alterando a meta de custo e prazo; e

- utilização de recursos legais, apesar de existir um acordo entre os participantes em abdicar dos processos judiciais na solução de conflitos, existem situações extremas em que os recursos legais podem ser aplicados no PA, como por exemplo, quando algum participante voluntariamente não cumpre com os objetivos especificados no contrato do PA;

Outra particularidade do método do PA se refere à contratação dos seguros. O principal elemento para avaliar a eficiência de um seguro é a abertura de alguma reclamação, ou seja, quando o seguro é acionado para cobrir algum risco do empreendimento. No entanto, de acordo com o governo da Austrália (AUSTRALIAN GOVERNMENT, 2015b), os processos públicos que utilizaram o método do PA não apresentam muitos relatos de acionamento das seguradoras. Apesar de esta característica ser positiva, não fica claro qual o verdadeiro papel dessas empresas no processo do PA e quais riscos estão sendo realmente segurados.

Cada processo de produção é diferente e possui riscos específicos, sendo que o seguro é uma das soluções para administrar esses riscos e trazer segurança tanto para o cliente quanto aos demais participantes. Porém, no PA não é desejável que todos os riscos sejam cobertos pelas seguradoras, pois a gestão de alguns deles pelos próprios participantes é fundamental para estabelecer o trabalho colaborativo e incentivar a busca por melhores soluções de projeto (AUSTRALIAN GOVERNMENT, 2015b).

Portanto, o PA é um método de produção do empreendimento que busca, por meio do trabalho colaborativo, aperfeiçoar o processo de produção, trazendo mais eficiência e qualidade ao empreendimento. A ampla utilização do PA na contratação dos empreendimentos públicos da Austrália fez com que o método se tornasse conhecido pela indústria da construção civil e permitiu que diversas publicações fossem elaboradas, visando orientar os participantes sobre os princípios e instrumentos do método. 


\subsubsection{Early Contractor Involvement (ECI) ou Participação Precoce do Construtor}

O Método de produção do empreendimento denominado Early Contractor Involvement (ECI), foi desenvolvido no final da década de 1990 e utilizado inicialmente pelo setor de infraestrutura urbana (MOLENAAR; et al., 2007). A denominação do método pode ser compreendida como Participação Precoce do Construtor.

De acordo com Mosey (2009), ECI é um método de produção do empreendimento baseado na participação precoce dos agentes responsáveis pela execução do empreendimento. Essa participação é estabelecida desde as primeiras atividades de planejamento, de forma que o construtor trabalha colaborativamente com o projetista nas definições do escopo do projeto (Tabela 10).

Tabela 10 - Características do Early Contractor Involvement (ECI) ou Participação Precoce do Construtor

\section{Early Contractor Involvement (ECI) ou Participação Precoce do Construtor}

Número mínimo de 3 -cliente, projetista, construtor.

agentes principais:

Número de contratos: depende do modelo de contrato, podendo ser:

- 1 contrato multilateral entre os agentes principais; ou

- vários contratos bilaterais com uma cláusula de parceria.

Características - processo de contratação dividido em no mínimo duas fases: planejamento e principais: desenvolvimento/execução;

- contrato multilateral opcional;

- participação precoce do construtor no planejamento e desenvolvimento do projeto;

- compartilhamento dos riscos e benefícios opcional;

- foco no processo de seleção dos agentes (licitação);

- não existe um padrão para os procedimentos do método, os instrumentos variam conforme o local e a instituição.

Responsabilidades: - depende do modelo adotado, podendo haver contrato multilateral ou bilateral; e compartilhamento dos riscos e benefícios ou alocação dos riscos de acordo com a atividade.

Vantagens: - simplificação do processo de licitação;

- todos os participantes conhecem precocemente todos os objetivos, metas e riscos do empreendimento, e realizam em conjunto a gestão dos riscos;

- possibilidade de contratar precocemente serviços da execução;

- maior precisão nas informações de orçamento e cronograma da execução; e

- possibilidade de inserir inovações.

Desvantagens: - falta de padronização do método;

- ausência do detalhamento dos instrumentos;

- ausência dos especialistas nas etapas de planejamento; e

- grande dependência do comprometimento da equipe para evitar conflitos. 
Os instrumentos do ECI especificados por Mosey (2009) são:

- contrato multilateral opcional, no ECI é possível estabelecer diferentes contratos bilaterais, com uma cláusula comum a todos eles que vincula as responsabilidades todos os participantes, ou um único contrato multilateral;

- contratação e orçamento dividido em no mínimo duas fases, sendo uma de pré-execução, que compreende todas as etapas de planejamento e projeto, e outra referente à execução, que inclui todo o detalhamento do projeto e a obra; o projetista e o construtor participam das duas fases do contrato; existem variações nas contratações de acordo com o país em que elas ocorrem, o que será detalhado posteriormente;

- participação precoce do projetista e do construtor, que trabalham colaborativamente desde as atividades de planejamento do empreendimento;

- gestão conjunta dos riscos; o que possibilita que os participantes conheçam previamente os riscos do empreendimento, e quais as responsabilidades sobre cada um deles; a participação dos projetistas, construtores e principais subcontratados na definição dos riscos possibilita eliminar custos desnecessários e antecipar informações sobre o processo; e

- transparência na troca de informações, sobre os custos, cronograma e alocação de riscos, o que incentiva o ambiente de confiança entre os participantes;

Segundo Mosey (2009), com a participação do construtor nas fases de planejamento e desenvolvimento do projeto, os projetistas possuem informações mais precisas sobre os processos construtivos, materiais e equipamentos, o que resulta em um orçamento e cronograma mais próximos da realidade. O cliente passa a ter maior controle sobre o custo e prazo de execução e o compartilhamento de informações passa a ser mais transparente.

No entanto, Mosey (2009) destaca que a participação precoce do construtor pode trazer alguns problemas ao processo, caso a equipe não trabalhe de forma integrada e colaborativa. Como muitos projetistas estão habituados a trabalhar com o processo sequencial, é possível que eles considerem que estão perdendo a liberdade de criação com a interferência do construtor na etapa de desenvolvimento do projeto, o que estabelece um ambiente competitivo e de conflitos no ECI.

Segundo Scheepbouwer e Humphries (2011), a estrutura dos contratos e os procedimentos do ECI variam conforme o país e as instituições em que ele é aplicado, com destaque a: Austrália, Nova Zelândia, Reino Unido e Estados Unidos. 
No caso da Austrália, o ECI é utilizado principalmente no setor de transportes e sua característica fundamental é a subdivisão do processo em duas fases. Na primeira fase, o cliente seleciona, por meio da melhor técnica, um projetista e um construtor associados para desenvolver um projeto preliminar. Na segunda fase, são contratados os demais agentes e são realizadas as seguintes atividades: detalhamento do projeto; aprovação pelos órgãos reguladores; elaboração do projeto para produção; contratação do seguro; execução da obra; e entrega do empreendimento (DEPARTMENT OF MAIN ROADS, 2009).

Existe apenas um contrato que abrange todo o processo e os mesmos agentes negociam com o cliente o valor para a finalização da produção do empreendimento. Caso os participantes não cheguem a um acordo, o cliente pode finalizar o contrato e iniciar outra licitação com a entrada de novos participantes. A situação ideal é que a mesma equipe participe do processo até o final, de forma que a execução do empreendimento mantenha os princípios de integração (DEPARTMENT OF MAIN ROADS, 2009).

No modelo de contrato da Nova Zelândia, o processo é subdividido em três partes, denominadas Separable Portions (SP) (NEW ZEALAND GOVERNMENT, 2015):

- SP1 - Investigação, que resulta no planejamento do empreendimento e na elaboração do projeto preliminar;

- SP2 - Desenvolvimento do Projeto, que inclui o desenvolvimento mais detalhado do projeto, negociação dos termos comerciais - incluindo o custo -, duração do contrato e planejamento para execução; e

- SP3 - Detalhamento do Projeto e Execução, que resulta na entrega do empreendimento para o cliente.

Antes do início de cada SP, o cliente estabelece, junto com os demais participantes, um valor fixo para a execução dos serviços. Outra especificidade desse tipo de contrato se refere à participação do cliente no processo, que acontece somente nas SP1 e SP2. A etapa de execução - SP3 - é semelhante ao processo sequencial DB, onde o cliente somente recebe o empreendimento no final do processo (SCHEEPBOUWER; HUMPHRIES, 2011).

O modelo britânico, identificado por Scheepbouwer e Humphries (2011), se caracteriza pela seleção dos participantes apenas pela técnica, com base na capacidade profissional e experiência. No momento da licitação, apenas os estudos de viabilidade estão finalizados, de forma que todo o planejamento e elaboração do projeto são realizados pela equipe contratada, com o cliente (Figura 7). 
Outra característica desse modelo é a inserção do instrumento de compartilhamento dos riscos e benefícios do processo. Inicialmente, os participantes desenvolvem o orçamento detalhado das atividades de forma conjunta e transparente. Após o aceite do cliente, o orçamento final passa a representar a meta de custo do empreendimento. Os riscos e benefícios compartilhados são determinados com base nessa meta, o que incentiva os participantes a buscar soluções que tragam eficiência à produção, podendo reduzir os custos de execução (SCHEEPBOUWER; HUMPHRIES, 2011).

Figura 7 - Processo de produção do Early Contractor Involvement - modelo britânico

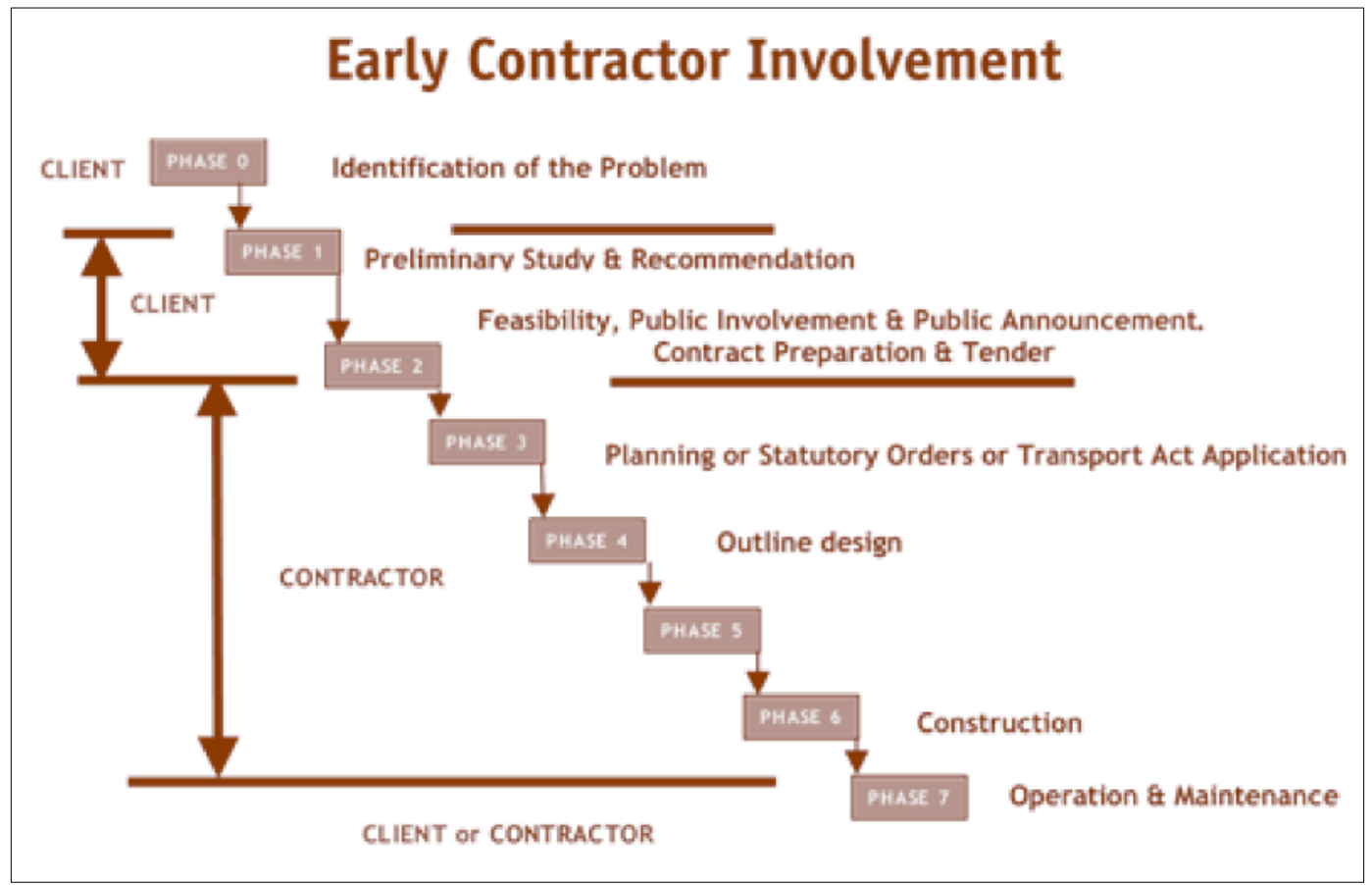

Fonte: DEWITT; et al., 2005.

O modelo dos Estados Unidos é utilizado pelo departamento de engenharia do exército (U.S. Army Corps of Engineers - USACE), que descreve o ECI como sendo uma variação do DBB. A principal diferença está na forma de licitação e contratação dos participantes responsáveis pela execução, que podem incluir as etapas de planejamento e desenvolvimento do empreendimento (US ARMY CORPS OF ENGINEERS, 2009).

Segundo Scheepbouwer e Humphries (2011), o método utilizado pelo USACE pode ser comparado também com o CMAR, pois o cliente estabelece dois contratos no início do processo, um com o projetista e outro com o construtor. O construtor neste caso atua como um gestor de construção, inserindo precocemente suas perspectivas sobre o sistema construtivo, gestão dos riscos e custo de execução dos serviços. Os autores concluem que a denominação de 
DBB ao método ECI pode ser uma forma do USACE conseguir alterar alguns procedimentos contratuais, sem infringir a legislação do país.

O procedimento do USACE, inferido por Scheepbouwer e Humphries (2011), vai ao encontro de uma das barreiras para a implantação do ECI nos processos de produção dos empreendimentos públicos. As normas para a contratação dos participantes são normalmente rígidas e impedem que o cliente adote novos métodos de produção.

O relatório do departamento de transportes do governo australiano (AUSTRALIAN GOVERNMENT, 2015c) descreve os seguintes benefícios na aplicação do ECI:

- os participantes conhecem previamente os objetivos, metas, escopo e riscos do processo, pois todos colaboraram no planejamento do empreendimento, além de ter a oportunidade de entender o processo como um todo e gerenciar os riscos de acordo com suas capacidades;

- a inserção de inovações no processo e a superação das metas de eficiência são incentivadas;

- os valores para cobrir os riscos somente são definidos após aprovação por todos os agentes;

- existe a possibilidade de realizar melhores negociações com os fornecedores, pois o processo possibilita adquirir ou contratar previamente serviços, materiais ou equipamentos que serão utilizados a longo prazo;

- os desperdícios durante a licitação são reduzidos, pois evita-se o retrabalho devido à inconsistências no projeto verificadas após a contratação dos construtores; e

- a equipe tem a oportunidade de utilizar todo seu potencial ao compartilhar diferentes perspectivas sobre o mesmo projeto.

Portanto, o método ECI está centrado no modo como os participantes são selecionados para executar o empreendimento. Todos os modelos de contratação descritos por Scheepbouwer e Humphries (2011) estabelecem os procedimentos de licitação para incluir precocemente o construtor no processo. No entanto, somente essa participação não garante a colaboração e integração da equipe, que fica vulnerável aos conflitos, o que pode refletir na eficiência e qualidade do processo de produção. 


\subsubsection{Integrated Project Delivery (IPD)}

O método Integrated Project Delivery (IPD) é relativamente recente, se comparado aos métodos anteriores. Segundo Lahdenperä (2012), o IPD surgiu em 2003 por iniciativa de uma empresa norte americana do ramo da construção civil.

De acordo com a definição do AIA (AMERICAN INSTITUTE OF ARCHITECTS, 2007a), o IPD é um método de produção do empreendimento que integra pessoas, sistemas, estruturas de negócio e práticas profissionais em um processo que colaborativamente aproveita as habilidades e percepções de todos os participantes (Tabela 11).

Tabela 11 - Características do Integrated Project Delivery (IPD)

\begin{tabular}{|c|c|}
\hline & Integrated Project Delivery (IPD) \\
\hline $\begin{array}{l}\text { Número mínimo de } \\
\text { agentes principais: }\end{array}$ & 3 - cliente, projetista e construtor. \\
\hline Número de contratos: & 1 contrato multilateral entre os agentes principais. \\
\hline \multirow{8}{*}{$\begin{array}{l}\text { Características } \\
\text { principais: }\end{array}$} & - contrato multilateral obrigatório; \\
\hline & $\begin{array}{l}\text { - participação precoce dos agentes principais, que se organizam como uma } \\
\text { pequena sociedade; }\end{array}$ \\
\hline & - definição compartilhada dos objetivos e metas do empreendimento; \\
\hline & - compartilhamento dos riscos e benefícios; \\
\hline & - custo dos serviços e materiais (variável), separado do lucro (fixo e sob risco); \\
\hline & - processo de aperfeiçoamento e aprendizagem contínuos; \\
\hline & - incentivo em alocar a equipe do empreendimento em um mesmo local; e \\
\hline & - resolução de conflitos dentro da equipe. \\
\hline \multirow[t]{8}{*}{ Responsabilidades: } & - todos os agentes são responsáveis pelo empreendimento como um todo; e \\
\hline & $\begin{array}{l}\text { - cliente é o único agente que pode alterar o escopo do processo (RFP, custo, } \\
\text { prazo). }\end{array}$ \\
\hline & $\begin{array}{l}\text { - tomadas de decisão compartilhadas, que permite o alto nível de confiança e } \\
\text { colaboração entre os participantes, e possibilita a redução de conflitos entre os } \\
\text { participantes; }\end{array}$ \\
\hline & $\begin{array}{l}\text { - comprometimento de toda equipe no processo como um todo, tendo como } \\
\text { incentivo o lucro final; }\end{array}$ \\
\hline & - possibilidade de reduzir o prazo de execução do processo; \\
\hline & - flexibilidade para a modificação do escopo do projeto; \\
\hline & - maior controle do processo pelo cliente; e \\
\hline & $\begin{array}{l}\text { - melhor qualidade do projeto, reduzindo a probabilidade de erros devido a } \\
\text { incompatibilidade de disciplinas e omissões de informações. }\end{array}$ \\
\hline \multirow[t]{4}{*}{ Desvantagens: } & - método novo e ainda não amplamente conhecido pelo mercado; \\
\hline & - poucos estudos de caso, com aplicações práticas do método; \\
\hline & - barreiras culturais e de legislação para a inserção de todos os instrumentos; e \\
\hline & - dificuldade para contratar o seguro. \\
\hline
\end{tabular}

Fonte: Adaptado de HARPER, 2014; AMERICAN INSTITUTE OF ARCHITECTS, 2007a, 2014. 
A integração se faz precocemente e em todas as fases do processo, envolvendo todos os profissionais da cadeia da construção civil. O objetivo do IPD é otimizar os resultados, aumentar o valor do empreendimento para o cliente, reduzir o desperdício e maximizar a eficiência ao longo de todo o processo (AMERICAN INSTITUTE OF ARCHITECTS, 2007a). Segundo o AIA (AMERICAN INSTITUTE OF ARCHITECTS, 2007a), a formação da equipe pode variar de acordo com as particularidades do empreendimento, mas estabelece como referência duas categorias: principal e suporte.

A equipe principal é formada essencialmente pelo cliente, construtor e projetista. Esses são os participantes que possuem grande envolvimento com o empreendimento durante todo processo. Os profissionais das demais especialidades fazem parte da equipe de suporte. Apesar do termo suporte, esses agentes são extremamente importantes no processo e são consultados pela equipe principal nas tomadas de decisão.

O AIA (AMERICAN INSTITUTE OF ARCHITECTS, 2014) estabeleceu os instrumentos que determinam como o IPD deve ser aplicado, de acordo com a área de interferência: estrutura do contrato, modelo de negócio e habilidades comportamentais dos participantes.

Os instrumentos que interferem na estrutura do contrato são:

- contrato multilateral, que inclui no mínimo o cliente, projetista e construtor, podendo inserir também todas as empresas e participantes vitais para a produção do empreendimento, como os gestores, especialistas de execução e consultores;

- participação precoce dos principais agentes, o que amplia o número de informações referentes ao empreendimento antes do desenvolvimento do projeto; possibilita que a atividade de coordenação possa ser realizada ao longo do processo; amplia as possibilidades de soluções para o projeto, ao inserir maior diversidade de perspectivas para um mesmo problema; e evita o retrabalho decorrente da transferência do projeto entre as diferentes disciplinas;

- controle do empreendimento e tomadas de decisão compartilhadas, esse instrumento garante que os participantes trabalhem como em uma pequena sociedade, pois todos os agentes são consultados nas tomadas de decisão do processo; isso reduz a probabilidade de erros na escolha das soluções, provocados pela resolução unilateral dos problemas;

- riscos e benefícios compartilhados e baseados nos resultados do empreendimento, esse instrumento garante que o modelo de negócio previsto para o IPD seja uma obrigação e não uma opção para os participantes, fazendo parte do contrato; esse instrumento também reduz as responsabilidades individuais de cada agente; e 
- determinação e validação compartilhada dos objetivos e metas do empreendimento, como essa etapa é realizada por todos os principais agentes, os objetivos e as metas não são tratadas como uma imposição, mas como um acordo e um incentivo para garantir qualidade ao processo.

Na categoria de modelo de negócio, os instrumentos são:

- separação entre lucro e custo, onde o lucro possui um valor fixo, e o pagamento pelos serviços prestados pelos agentes não possui limite; isso evita que os participantes acrescentem desnecessariamente tempo de serviço ou quantidade de material para aumentar o lucro final, além de incentivar a redução dos gastos como meta; evita-se também, que o participante insira um valor adicional ao custo do serviço para cobrir qualquer risco durante o processo;

- lucro atrelado aos resultados acordados para o empreendimento, esse instrumento garante que todos os participantes tenham como objetivo buscar as melhores soluções para o projeto como um todo, além de não estimular os comportamentos individualistas e egoístas em relação ao projeto; e

- direito limitado para modificar o escopo, as alterações que interferem no custo e prazo só podem ser feitas pelo cliente; os demais imprevistos são de responsabilidade dos participantes, como no caso de erros e omissões no projeto, erro de execução ou problemas de produtividade; caso exista algum problema durante o processo, os participantes devem trabalhar colaborativamente para resolvê-lo independente da causa.

Em relação às habilidades comportamentais dos participantes, o AIA (AMERICAN INSTITUTE OF ARCHITECTS, 2014) estabelece os seguintes instrumentos:

- otimização do todo e não das partes, esse instrumento estabelece que haja uma visão sistêmica do processo de produção; isso significa que todas as ações e decisões devem ser julgadas visando o benefício do empreendimento, em detrimento ao benefício de cada participante;

- transparência e respeito entre as relações dos participantes, esse instrumento incentiva o ambiente de confiança na equipe, trazendo segurança e, consequentemente, eficiência ao processo;

- integração (informações, pessoas e sistemas), esse instrumento possibilita combinar todas as capacidades individuais dos agentes, criando resultados melhores do que a simples soma entre as partes; a integração das informações facilita a troca de dados e estabelece um entendimento comum sobre o processo; a integração de pessoas representa a 
coordenação do processo e o estabelecimento de uma pequena sociedade entre os participantes; e a integração de sistemas permite aperfeiçoar todo o processo;

- aperfeiçoamento e aprendizado contínuos, onde as soluções propostas são testadas, modificadas e testadas novamente, visando o melhor resultado e incentivando a equipe a ultrapassar as metas estabelecidas;

- tecnologia apropriada, apesar do IPD não demandar nenhuma tecnologia específica, existe a necessidade de atualizar os processos de trabalho, particularmente na utilização do BIM; o BIM possibilita a colaboração e integração, além de permitir a simulação de diferentes soluções nas etapas iniciais do projeto; e

- colaboração, que representa o trabalho em conjunto para alcançar os melhores resultados para o empreendimento, elaborando e aperfeiçoando as ideias uns dos outros; essa colaboração é mais visível quando os participantes trabalham em uma mesma localidade e não somente realizam reuniões em conjunto.

Com o uso do IPD, o AIA (AMERICAN INSTITUTE OF ARCHITECTS, 2007a; 2014) indica os principais benefícios para a execução do empreendimento:

- flexibilidade, que representa a possibilidade de incluir ou modificar as demandas do empreendimento ao longo do processo de produção, sem prejudicar os requisitos de prazo, custo e qualidade definidos inicialmente pelo cliente;

- velocidade, que é o resultado da integração de toda a equipe desde o início do processo, pois a troca de informações ocorre com maior rapidez e os imprevistos relacionados a erros de incompatibilidade de disciplinas são reduzidos;

- redução de conflitos, viabilizada pelo contrato multilateral, compartilhamento dos riscos e benefícios do processo, e incentivo à ajuda mútua na resolução dos problemas; e

- maior controle sobre o processo, que resulta da transparência na troca de informações e da participação precoce de todos os agentes, possibilitando antecipar a identificação e resolução de problemas ao longo da produção do empreendimento.

O AIA (AMERICAN INSTITUTE OF ARCHITECTS, 2014), faz uma comparação por meio de diagramas do processo de produção de um método denominado tradicional e outro integrado (Figura 8). O processo tradicional pode ser inferido como o DBB, pois cada agente entra no processo apenas na atividade de sua responsabilidade, além de existir uma etapa específica para a concorrência dos agentes de execução após a finalização do projeto. O processo integrado representa o IPD, pois além de ter a participação precoce dos principais profissionais, os órgãos de regulação são considerados desde o desenvolvimento inicial do projeto. 
Figura 8 - Comparação do Integrated Project Delivery ao processo tradicional

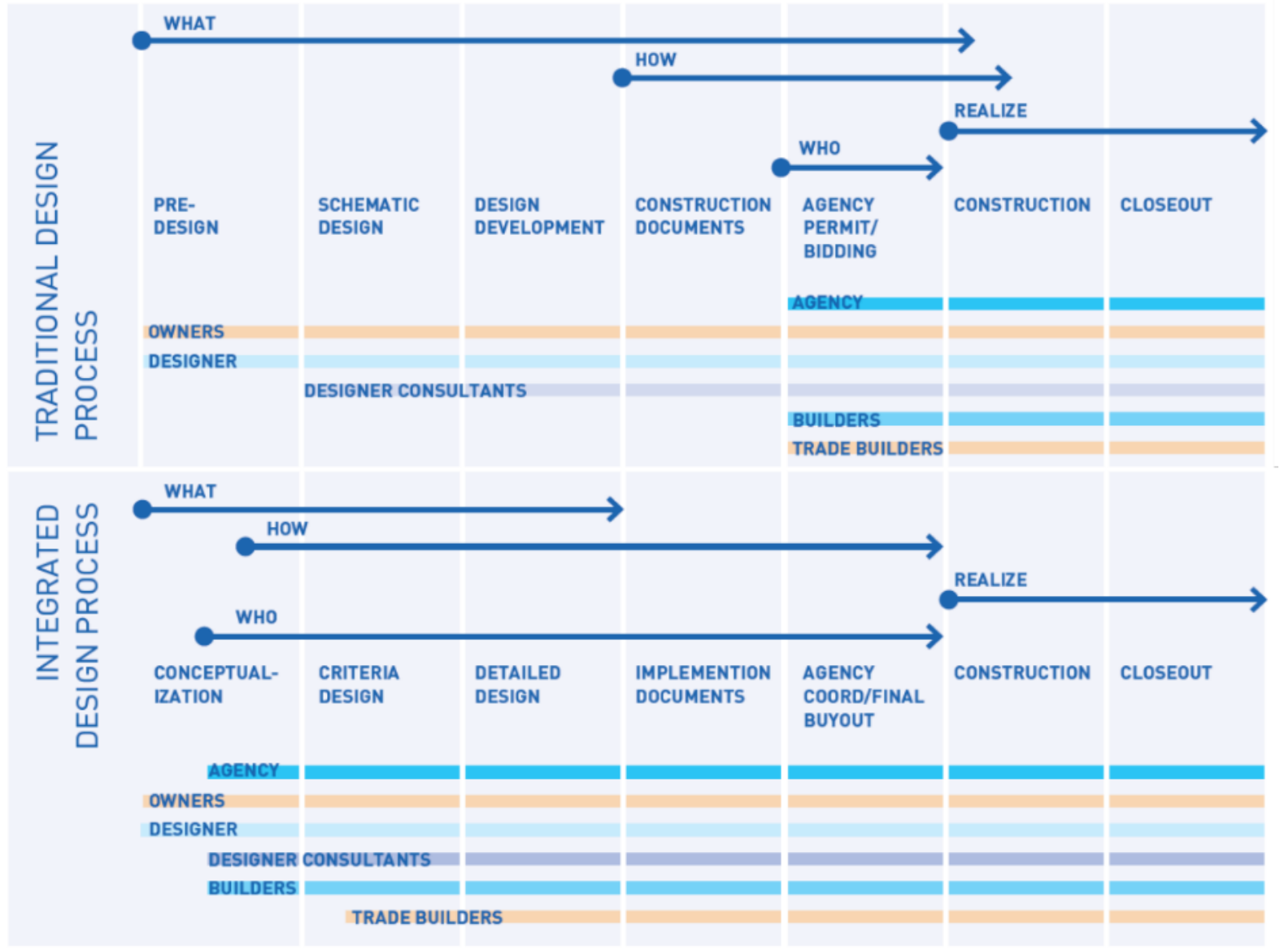

Fonte: AMERICAN INSTITUTE OF ARCHITECTS, 2014.

Por meio desses diagramas, é possível perceber outra vantagem do IPD, a antecipação das principais tomadas de decisão durante o processo. Dentre as tomadas de decisão, o AIA indica: $o$ que, que representa as características do empreendimento; como, que indica as técnicas e métodos de execução do empreendimento; e quem, que indica os participantes responsáveis pela execução. Com a participação precoce dos principais agentes é possível definir todos os critérios do empreendimento antes do início da execução (AMERICAN INSTITUTE OF ARCHITECTS, 2014).

Segundo El Asmar, Hanna e Loh (2013, 2015), o número de empreendimentos realizados sob o método do IPD ainda é muito limitado e está concentrado em algumas regiões dos Estados Unidos. 
Além dos poucos estudos de caso e a relativa incipiência do IPD, Harper (2014) indica outras desvantagens no uso do IPD:

- barreiras legais, que impedem a aplicação de alguns instrumentos essenciais, como o contrato multilateral e a abstenção dos processos judiciais para a resolução dos conflitos dentro da própria equipe;

- responsabilização conjunta sobre o processo, o que pode gerar conflitos na equipe, caso alguma empresa não trabalhe de acordo com os princípios do IPD;

- processo de contratação longo, o que pode resultar em um alto custo;

- necessidade de um alto nível de gestão, por parte de todos os participantes; e

- desconhecimento do método, por parte de muitos construtores, projetistas e empresas especialistas.

Post (2010) indica como uma outra desvantagem, a complexidade na contratação de um seguro para o empreendimento. Devido ao compartilhamento de riscos e do incentivo à resolução dos conflitos dentro da própria equipe, as seguradoras têm dificuldade em definir quais riscos devem ser cobertos.

El-Adaway, Abotaleb e Eteifa (2017) fazem uma análise dos incentivos financeiros dos dois modelos de contratos definidos pela AIA para o IPD: AIA C195 e AIA C191; ambos multilaterais.

No caso do AIA C195, é definido uma meta para o empreendimento que serve como base para o compartilhamento de riscos e benefícios. Os agentes que assinam o contrato podem receber valores adicionais caso o custo final seja menor que o custo definido como meta para o empreendimento. No entanto, caso o custo exceda o especificado, os profissionais recebem apenas o valor definido para o trabalho, sem nenhum valor adicional.

No modelo de contrato AIA C191, existe a diferenciação entre a equipe executiva, que desenvolve os projetos e executa a obra; e a equipe de gestão, que não tem poder para tomar decisões que vão impactar no custo e prazo do empreendimento. $\mathrm{O}$ valor adicional dividido entre a equipe é definido como a parcela de lucro do pagamento total, sendo referente aos melhores resultados em relação à meta estabelecida no início do processo ou por incentivos relacionados a alguma solução específica de projeto (EL-ADAWAY; ABOTALEB; ETEIFA, 2017).

Um estudo apresentado por Fischer et al. (2017) mostra a percepção de satisfação dos clientes em relação aos contratos transacionais e o relacional, representado pelo IPD. O IPD foi o que 
apresentou melhores resultados do que o esperado pelo cliente. O DBB foi o tipo de contrato que teve os piores resultados, ou seja, no final do processo o cliente avaliou o processo como típico, recebeu exatamente o que estava esperando.

Portanto, o IPD propõe uma mudança de paradigma nos processos de produção do empreendimento. Todos os elementos que compõe a produção da indústria da construção civil, como sistema contratual, processos de contratação, seguros, comunicação, participação dos agentes e tecnologia devem ser reestruturados e não apenas adaptados. Apesar do objetivo central do IPD, ou seja, a otimização do todo ao invés das partes, parecer simples e até óbvio em certo modo, os instrumentos para alcançá-lo indicam uma mudança profunda na forma de trabalhar dos agentes.

\subsubsection{Análise comparativa dos tipos de contrato relacional}

Os principais instrumentos voltados a integração presentes nos modelos de contrato relacional podem ser comparados de forma sintética, agrupados conforme sua área de interferência: estrutura do contrato; processo de produção; e tecnologia e local de trabalho (Tabela 12).

Em relação à estrutura do contrato, todos os métodos utilizam o compartilhamento dos riscos e benefícios como incentivo à integração da equipe. Existe uma variação em relação ao valor sobre o qual esse instrumento incidirá: sobre o lucro total, no caso do PP e IPD; ou um valor independente do lucro, no caso do PA.

Além desse instrumento, o método do PP disponibiliza outros benefícios financeiros associados às metas de desempenho. Somente no ECI, o compartilhamento de riscos e benefícios depende do modelo de contrato adotado, podendo o cliente escolher ou não inserir esse instrumento como uma cláusula do contrato.

O contrato multilateral é obrigatório apenas nos métodos PA e IPD, que o consideram um instrumento essencial para garantir o empenho da equipe no empreendimento como um todo. Nos demais métodos, é dada a opção ao cliente estabelecer vários contratos bilaterais com uma cláusula comum, que vincula as responsabilidades dos agentes.

No caso dos instrumentos que interferem no processo de produção, todos os métodos estabelecem a participação conjunta na especificação dos objetivos e metas do empreendimento. Esse instrumento é uma forma de garantir que os agentes se sintam como parte do processo e considerem as metas como um desafio profissional. 
Tabela 12 - Comparação entre os instrumentos para a integração dos métodos PP, PA, ECI e IPD

\begin{tabular}{|c|c|c|c|c|c|}
\hline $\begin{array}{c}\text { Área de } \\
\text { interferência }\end{array}$ & $\begin{array}{l}\text { Instrumentos para a } \\
\text { integração }\end{array}$ & $\begin{array}{l}\text { Project } \\
\text { Partnering } \\
\text { (PP) }\end{array}$ & $\begin{array}{l}\text { Project } \\
\text { Alliancing } \\
\text { (PA) }\end{array}$ & $\begin{array}{c}\text { Early } \\
\text { Contractor } \\
\text { Involvement } \\
\text { (ECI) } \\
\end{array}$ & $\begin{array}{c}\text { Integrated } \\
\text { Project } \\
\text { Delivery } \\
\text { (IPD) } \\
\end{array}$ \\
\hline \multirow{4}{*}{$\begin{array}{l}\text { Estrutura do } \\
\text { contrato }\end{array}$} & $\begin{array}{l}\text { Contrato multilateral } \\
\text { obrigatório }\end{array}$ & & $X$ & & $X$ \\
\hline & $\begin{array}{l}\text { Compartilhamento dos riscos e } \\
\text { benefícios }\end{array}$ & $X$ & $X$ & $X^{3}$ & $X$ \\
\hline & $\begin{array}{l}\text { Benefícios financeiros } \\
\text { variáveis de acordo com } \\
\text { indicadores de desempenho }\end{array}$ & $X$ & & & \\
\hline & $\begin{array}{l}\text { Abstenção em iniciar conflitos } \\
\text { judiciais }\end{array}$ & & $X$ & & \\
\hline \multirow{7}{*}{$\begin{array}{l}\text { Processo de } \\
\text { produçãao }\end{array}$} & $\begin{array}{l}\text { Participação precoce dos } \\
\text { agentes principais (projetista, } \\
\text { construtor e especialistas) }\end{array}$ & $X$ & $\mathrm{X}$ & & $X$ \\
\hline & $\begin{array}{l}\text { Participação precoce do } \\
\text { projetista e construtor }\end{array}$ & & & $X$ & \\
\hline & $\begin{array}{l}\text { Definição compartilhada dos } \\
\text { objetivos e metas do } \\
\text { empreendimento }\end{array}$ & $X$ & $X$ & $X$ & $X$ \\
\hline & $\begin{array}{l}\text { Tomadas de decisão } \\
\text { compartilhadas }\end{array}$ & $X$ & $X$ & & $X$ \\
\hline & $\begin{array}{l}\text { Ferramentas de aprimoramento } \\
\text { contínuo do processo de } \\
\text { produção }\end{array}$ & $X$ & & & $X$ \\
\hline & $\begin{array}{l}\text { Procedimentos para resolução } \\
\text { interna de conflitos }\end{array}$ & $X$ & $X$ & & $X$ \\
\hline & $\begin{array}{l}\text { Transparência na troca e } \\
\text { divulgação de informações do } \\
\text { processo }\end{array}$ & $X$ & $X$ & $X$ & $X$ \\
\hline \multirow{2}{*}{$\begin{array}{l}\text { Tecnologia } \\
\text { e local de trabalho }\end{array}$} & $\begin{array}{l}\text { Equipe deve trabalhar em um } \\
\text { mesmo local físico }\end{array}$ & & & & $X$ \\
\hline & $\begin{array}{l}\text { Incentivo ao uso de tecnologias } \\
\text { apropriadas ao processo } \\
\text { integrado (BIM) }\end{array}$ & & & & $X$ \\
\hline
\end{tabular}

Fonte: Elaborado pela autora.

Além disso, todos os métodos defendem que é essencial garantir a transparência na troca de informações e dados do processo. Esse instrumento proporciona um ambiente de confiança na equipe, o que incentiva o trabalho colaborativo.

\footnotetext{
${ }^{3}$ Instrumento previsto em alguns modelos de contrato e, portanto, não é obrigatório.
} 
A participação precoce dos agentes é especificada por todos os métodos, sendo que o ECI considera somente a inserção do projetista e do construtor nas etapas iniciais do processo. Os demais métodos consideram todos os principais participantes: cliente; projetista; construtor; principais subcontratados; e qualquer outro profissional essencial ao desenvolvimento do projeto, de acordo com as especificidades do empreendimento.

Apesar do PP ser o único método que insere no contrato uma cláusula de abstenção em iniciar processos judiciais, os métodos PA e IPD estabelecem regras para solucionar os conflitos dentro da equipe. Entre os procedimentos está uma hierarquia na comunicação dos conflitos e a participação de agentes específicos para mediar a decisão. Caso os participantes não estabeleçam um acordo, é permitido buscar judicialmente a resolução dos conflitos. O ECI é o único método que não indica procedimentos no caso de desentendimento entre os participantes. No IPD, além dos instrumentos relativos ao contrato e ao processo, são estabelecidos procedimentos em relação ao uso de tecnologia e ao local de trabalho da equipe. No caso da tecnologia, esse método indica que é necessário adequá-la ao processo de produção integrado, como é o caso do uso do BIM. Além disso, no IPD é indicado que a equipe trabalhe em um mesmo local, estabelecendo um escritório temporário para um determinado empreendimento, o que proporcionaria agilidade e maior qualidade ao trabalho colaborativo.

\subsection{Perspectiva organizacional}

Os modelos de contrato relacionais determinam diversos instrumentos visando a integração do processo de produção. No entanto, somente essa ferramenta pode não ser suficiente para garantir o trabalho colaborativo entre a equipe. $\mathrm{O}$ aspecto comportamental e organizacional dos profissionais é um fator essencial para possibilitar a integração na construção civil.

Alguns autores utilizam um conceito da teoria de jogos denominada "Dilema do Prisioneiro"4 para analisar as relações interdisciplinares em um processo de produção na construção civil (LAZAR, 2000; WONG, CHEUNG; HO, 2005; ERIKSSON, 2007; BAROUGHA; SHOUBIA; SKARDIB, 2012).

\footnotetext{
${ }^{4}$ Nessa teoria, dois prisioneiros são entrevistados pela polícia separadamente e ambos têm a opção de confessar o crime ou delatar o outro prisioneiro, recebendo em troca a redução de sua pena. Se apenas um delatar, este receberá a redução da sua pena e o outro receberá a pena completa; se ambos delatarem, os dois terão a pena reduzida; e se ambos confessarem, os dois serão libertados (BRAVETTI; PADILLA, 2018).
} 
Essa teoria analisa o comportamento humano frente a situações em que não existe um objetivo comum e os ganhos são dependentes de escolhas mútuas. Segundo Bravetti e Padilla (2018), a essência dessa teoria é que a cooperação mútua resulta em uma melhor alternativa do que o ambiente de conflito. No entanto, a cooperação não é uma opção segura, pois fica-se exposto a escolha do outro, que pode estar buscando apenas maximizar seus ganhos.

Ao relacionar essa teoria com os processos na construção civil, Eriksson (2007) destaca alguns fatores que podem influenciar positivamente para um resultado de cooperação entre os participantes:

- tempo de duração dos processos, com uma relação de trabalho longa ou com a possibilidades de se estabelecer novas parcerias de trabalho, a colaboração entre os agentes é facilitada; caso seja um trabalho único, os participantes tendem a buscar o melhor resultado em um curto prazo;

- montante do pagamento, com um valor maior referente ao resultado de cooperação é possível que os participantes vejam essa opção como a mais vantajosa, independentemente da escolha feita pelos demais;

- estratégia dos participantes, que indica como cada um reage dependendo da resposta do outro participante, por exemplo, um agente cooperativo pode se tornar competitivo caso o outro não trabalhe colaborativamente; $\mathrm{e}$

- ambiente de confiança, que favorece a colaboração entre os participantes.

Incertezas sobre o processo de produção podem resultar em comportamentos oportunistas entre os participantes do processo de produção. You et al. (2018) descreve esse comportamento como sendo aquele em que os participantes buscam se beneficiar ao enganar os demais agentes do processo. Os autores indicam dois tipos de incertezas que podem levar a esse comportamento: do ambiente e de comportamento.

O primeiro tipo se refere à instabilidade e imprevisibilidade em relação às alterações no escopo do projeto devido às influências externas, como eventos climáticos adversos e variação no preço dos insumos. O segundo tipo se refere às incertezas em relação ao comportamento dos demais participantes da equipe. Ao desconhecer a forma de trabalho dos outros participantes, é possível que algum agente busque aumentar seus ganhos às custas de prejudicar os demais e, consequentemente, o empreendimento (YOU; et al., 2018). 
Para se estabelecer um processo de produção integrado, e necessário considerar aspectos comportamentais que são independentes do tipo de contrato ou método de execução do empreendimento. Além dos aspectos comportamentais, destaca-se a presença do gestor de produção no processo, que tem a característica de transitar em todas as disciplinas e etapas, possibilitando a visão sistêmica do processo.

\subsubsection{Integração da equipe e trabalho colaborativo}

Existem diferentes procedimentos e ferramentas que incentivam a colaboração no ambiente de trabalho. Nam e Tatum (1992) identificaram que um alto nível de integração entre os participantes pode resultar em melhorias no empreendimento e melhores oportunidades para inovar nas soluções projetuais. De acordo com os autores, alguns instrumentos não definidos pelo contrato se mostraram mais eficientes para se alcançar a integração no processo de produção.

Dentre os instrumentos definidos por Nam e Tatum (1992) estão:

- liderança do cliente, que deve acontecer ao longo de todo o processo, o cliente não só deve receber as entregas de projeto e execução, como também participar das decisões e incentivar o trabalho em equipe;

- relações de longo prazo entre os participantes, mesmo que não seja oficializada por um contrato; ao estabelecerem um histórico de trabalho juntos, os profissionais ganham experiência e criam um método de trabalho em conjunto, o que é aprimorado a cada novo processo de produção do empreendimento;

- inserção de profissionais entusiastas da integração, que fazem parte da própria equipe de produção, mas que têm também a função de facilitar a cooperação interdisciplinar e o aprendizado contínuo da equipe; a escolha destes profissionais pode variar dependendo do tipo de empreendimento; e

- profissionalismo dos participantes, que leva a um ambiente de confiança na equipe, pois existe o comprometimento de cada participante a desenvolver o projeto e a execução buscando as melhores soluções.

Nam e Tatum (1992) destacaram que esses instrumentos não representam grandes alterações no processo de produção, mas refletem em muitas melhorias no resultado do empreendimento. 
É necessário que existam participantes que incentivem a integração e cooperação no processo, além do interesse do cliente para que isso aconteça.

De acordo com Mitropoulos e Tatum (2000), os instrumentos organizacionais que favorecem a integração estão relacionados ao incentivo do trabalho colaborativo e aos sistemas de gestão do processo de produção. Com a organização integrada da equipe, o papel de cada participante no processo passa a englobar o processo como um todo e não apenas a sua atividade de origem, conforme sintetizado nas Tabela 13 e Tabela 14.

Tabela 13 - Responsabilidades dos participantes em um processo não integrado

\begin{tabular}{|c|c|c|c|c|c|}
\hline Participante & Planejamento & Projeto & $\begin{array}{c}\text { Planejamento } \\
\text { da Execução e } \\
\text { Aquisições }\end{array}$ & Execução & Operação \\
\hline Cliente & $\begin{array}{l}\text { Definir o } \\
\text { escopo: } \\
\text { requisitos e } \\
\text { limites }\end{array}$ & - & - & - & - \\
\hline Projetista & - & $\begin{array}{c}\text { Selecionar } \\
\text { alternativas } \\
\text { para atender os } \\
\text { requisitos } \\
\text { funcionais do } \\
\text { cliente }\end{array}$ & - & - & - \\
\hline $\begin{array}{c}\text { Construtor e } \\
\text { subcontratados }\end{array}$ & - & - & $\begin{array}{l}\text { Selecionar } \\
\text { métodos para } \\
\text { atender aos } \\
\text { requisitos de } \\
\text { prazo e custo } \\
\text { do cliente }\end{array}$ & $\begin{array}{c}\text { Executar o } \\
\text { empreendimento }\end{array}$ & - \\
\hline Fornecedores & - & - & $\begin{array}{c}\text { Atender à } \\
\text { concorrência } \\
\text { dos } \\
\text { componentes }\end{array}$ & $\begin{array}{c}\text { Fabricação e } \\
\text { entrega }\end{array}$ & - \\
\hline Usuário & - & - & - & - & Operação/uso \\
\hline
\end{tabular}

Fonte: MITROPOULOS; TATUM, 2000. 
Tabela 14 - Responsabilidades dos participantes em um processo integrado

\begin{tabular}{|c|c|c|c|c|}
\hline Participante & Planejamento & $\begin{array}{c}\text { Projeto, } \\
\text { Planejamento da } \\
\text { Execução e } \\
\text { Aquisições } \\
\end{array}$ & Execução & Operação \\
\hline Cliente & $\begin{array}{l}\text { Definir o escopo: } \\
\text { requisitos e limites }\end{array}$ & $\begin{array}{c}\text { Fornecer diretrizes } \\
\text { claras de } \\
\text { necessidades e limites }\end{array}$ & $\begin{array}{c}\text { Solucionar os } \\
\text { problemas que não } \\
\text { foram antecipados }\end{array}$ & - \\
\hline Projetista & $\begin{array}{c}\text { Avaliar as alternativas } \\
\text { básicas }\end{array}$ & $\begin{array}{l}\text { Avaliar alternativas } \\
\text { para atender os } \\
\text { requisitos funcionais } \\
\text { do cliente } \\
\end{array}$ & $\begin{array}{l}\text { Solucionar os } \\
\text { problemas que não } \\
\text { foram antecipados }\end{array}$ & - \\
\hline $\begin{array}{c}\text { Construtor e } \\
\text { subcontratados }\end{array}$ & $\begin{array}{l}\text { Analisar os métodos de } \\
\text { execução básicos, inserir } \\
\text { informações sobre custo, } \\
\text { prazo e logística }\end{array}$ & $\begin{array}{l}\text { Avaliar alternativas } \\
\text { para os lites de custo, } \\
\text { prazo e logística }\end{array}$ & $\begin{array}{c}\text { Executar o } \\
\text { empreendimento }\end{array}$ & - \\
\hline Fornecedores & $\begin{array}{l}\text { Informações sobre } \\
\text { equipamentos e } \\
\text { componentes }\end{array}$ & $\begin{array}{l}\text { Avaliar alternativas } \\
\text { para fabricação e } \\
\text { atendimento ao prazo }\end{array}$ & Fabricação e entrega & - \\
\hline Usuário & $\begin{array}{c}\text { Informações sobre } \\
\text { necessidades e requisitos }\end{array}$ & $\begin{array}{l}\text { Avaliar alternativas } \\
\text { para operação e } \\
\text { manutenção }\end{array}$ & - & Operação/uso \\
\hline
\end{tabular}

Fonte: MITROPOULOS; TATUM, 2000.

Baiden e Price (2011) descrevem que apenas a formação de uma equipe não determina a integração da produção. Existem alguns fatores que são essenciais para favorecer o trabalho colaborativo: comunicação efetiva, determinação dos objetivos da equipe, monitoramento, feedback contínuo, ajuda mútua e coordenação.

Azari e Kim (2015) identificaram os principais fatores humanos que impactam na colaboração da equipe: responsabilidade, comprometimento, comunicação, convergência de objetivos, envolvimento apropriado ao projeto, atividades conjuntas, respeito mútuo e confiança.

A aproximação entre as disciplinas é considerada por Franz et al. (2016) como um dos fatores que incentivam a integração da equipe. Com a redução das barreiras formais entre os agentes, ou seja, considerando todos os participantes como parte de uma única organização, existe o incentivo do trabalho colaborativo, mesmo entre diferentes disciplinas. Os autores identificaram que a coesão da equipe de trabalho é um fator que influencia positivamente diferentes tipos de estruturas de produção, ou seja, diferentes sistemas contratuais e com o uso de diferentes ferramentas tecnológicas.

Portanto, pode-se considerar que existem algumas questões essenciais para se estabelecer a integração a partir da perspectiva organizacional: formação da equipe; comunicação; interdisciplinaridade; participação do cliente; relações de trabalho de longo prazo; e gestão do processo. 


\subsubsection{Formação da equipe}

A maior parte dos relatórios publicados pelo Governo Britânico, visando aumentar a eficiência na construção civil, considerou a influência da equipe do processo de produção do

empreendimento. É necessário que todos os participantes se sintam igualmente importantes para a equipe (MURRAY; LANGFORD, 2003). Um dos relatórios teve como tema central a formação da equipe, que foi considerada uma das decisões que mais influenciam no desenvolvimento do empreendimento (LATHAN, 1994).

O termo equipe corresponde a um grupo de pessoas que precisam colaborar entre si para executar uma tarefa. Cada equipe é formada por participantes que tem diferentes habilidades, que se complementam e possibilitam a execução do empreendimento, o que não poderia ser feito de forma independente por apenas um participante (BAIDEN; PRICE; DAINTY, 2003).

Para que a equipe trabalhe de maneira efetiva, é necessário que seja estabelecido um objetivo comum para todas as atividades. Além disso, é essencial considerar a presença de um agente coordenando essas atividades, permitindo estabelecer um ambiente de confiança e mantendo todos os participantes comprometidos a cumprir prazos, custos e qualidade definidos pelo cliente. $\mathrm{O}$ trabalho em equipe possibilita que melhores soluções sejam propostas, pois os problemas são analisados sob diferentes perspectivas, o que facilitaria a inserção de inovações no processo de produção (BAIDEN; PRICE; DAINTY, 2003).

Segundo Baiden, Price e Dainty (2003), não existe um modelo único para se formar uma equipe integrada. O mais importante é estabelecer uma equipe que tenha uma visão sistêmica do processo e se comprometa a trabalhar colaborativamente. Para isso é preciso que as informações da produção sejam compartilhadas por todos, ou seja, todos os participantes devem estar cientes de quais são os requisitos e os objetivos do cliente em relação ao empreendimento.

Baiden, Price e Dainty (2006) listam alguns indicadores para a integração da equipe:

- objetivo único para o empreendimento;

- ausência de barreiras formais entre os profissionais e empresas;

- trabalho em prol dos melhores resultados para todos, garantindo que todos os participantes se apoiem mutuamente e os êxitos do processo sejam compartilhados por todos;

- utilização de todas as habilidades para definir com maior acurácia as estimativas de custo e prazo de produção do empreendimento;

- informação compartilhada por todos, sem restrição a nenhum participante; 
- flexibilidade na composição da equipe, resultando em respostas mais rápidas e efetivas em caso de alterações nas especificações de projeto;

- criação de uma identidade própria e alocação dos profissionais em um mesmo ambiente;

- todos os participantes devem ter o direto de contribuir com soluções de projeto e são tratados com respeito; e

- existência de uma cultura de não culpar o outro (no blame culture).

Ibrahim, Costello e Wilkinson (2013) definem alguns indicadores para avaliar a integração de uma equipe, a partir da subdivisão em dois grupos:

- influenciados pelas relações pessoais: foco nos objetivos do empreendimento, confiança, respeito, comunicação, cultura de não culpa, comprometimento, equipe flexível e resiliente, entendimento conjunto das informações do processo, ausência de barreiras formais entre os profissionais, compartilhamento das informações e incentivo mútuo; e

- não influenciados pelas relações pessoais: alocação da equipe em um mesmo local, inovação e melhorias, sistemas de tecnologia de informação integrado, gestão efetiva, e atenção às necessidades do cliente.

A escolha dos profissionais para formar a equipe, deve considerar não só os objetivos comuns do empreendimento, mas também as necessidades individuais de cada disciplina. Deve-se identificar os participantes principais, ou seja, aqueles que têm maior influência sobre as decisões de produção e que participam ao longo de todo o processo. Além disso, deve-se especificar quais os interesses individuais e quais os impactos do processo de produção sobre esses interesses, de forma a aumentar o comprometimento do participante aos objetivos gerais do empreendimento, criando uma estratégia para cada disciplina (HERAVI; COFFEY; TRIGUNARSYAH, 2015).

A falta de integração da equipe resulta em um ambiente de produção hostil e competitivo, em que cada agente trabalha apenas visando seu próprio benefício. Isso faz com que a cada problema do processo, os participantes tentem minimizar sua responsabilidade sobre o erro e passem a culpar um outro agente, de forma que o que menos importa é a solução do problema (BAIDEN; PRICE; DAINTY, 2006). 
Baiden, Price e Dainty (2006) destacam alguns desafios para se estabelecer a integração na equipe:

- indicadores tradicionais de desempenho, que considera apenas o custo, prazo e qualidade, que são fatores muito simples para definir o real desempenho do processo; deveriam ser considerados também indicadores relacionados ao comportamento e cultura;

- cultura de produção do empreendimento, principalmente em relação à curta duração das relações de trabalho, o que prejudica o aprendizado contínuo dos profissionais e poderia resultar em processos de trabalho mais eficientes e de maior qualidade;

- necessidade de mudanças no comportamento, estabelecendo que cada profissional faz parte da equipe e não é somente um agente contratado para executar as atividades de sua disciplina;

- avaliação do processo, é necessário coletar dados referentes à execução de cada processo para que as futuras decisões sejam tomadas com segurança e baseadas na realidade.

\subsubsection{Comunicação}

A integração pela formação da equipe está diretamente relacionada à forma como é estabelecida a comunicação entre os participantes. A comunicação eficiente é um fator essencial para garantir um ambiente de confiança entre os participantes, de forma que todos tenham o conhecimento sobre os as regras e deveres do processo de produção (MURRAY; LANGFORD, 2003).

Emmitt e Gorse (2006) destacaram que muitas pesquisas sobre comunicação na construção civil estão baseadas em evidências informais e não utilizam dados seguros para definir o impacto de uma comunicação eficiente na qualidade do processo de produção.

Apesar dos grandes avanços no desenvolvimento na área da tecnologia de informação e comunicação (Information Communication Technologies - ICT), não existe um aperfeiçoamento efetivo da comunicação entre os membros da equipe. $\mathrm{O}$ uso de ferramentas de ICT não resulta diretamente em melhorias no desempenho do processo de produção, sendo necessário aperfeiçoar a relação interpessoal para que as informações sejam transmitidas de forma adequada a todos os agentes do processo (EMMITT; GORSE, 2006).

Segundo Emmitt e Gorse (2006), a forma de comunicação da equipe varia conforme as etapas do processo de produção. Nas atividades iniciais, as interações entre os participantes são menos 
formais e acontecem de forma menos estruturada. Durante a concepção do projeto, o nível de detalhe das informações é muito superficial, ou seja, as informações são imprecisas e podem mudar muito. Ao longo do desenvolvimento do projeto, existe um aprofundamento e maior consistência nas informações, o que possibilita estabelecer formas de comunicação mais estruturadas, criando regras para as trocas de mensagens entre os participantes.

De acordo com Emmitt e Gorse (2006), independentemente do tipo de comunicação - informal ou estruturada - é essencial que ela seja acessível e cooperativa. Isso faz com que se estabeleça um ambiente de confiança na equipe, evitando os conflitos e competitividade entre os participantes.

A comunicação entre a equipe de um processo de produção representa todos os envios e recebimentos de mensagens, considerando diversos meios: diálogos, meio virtual - email, sistemas de gestão ou telefonemas - além das trocas de documentos e arquivos de projeto. É essencial que os participantes tenham o mesmo entendimento sobre a mensagem transmitida, para que não haja dúvida sobre as atividades ou correções necessárias ao projeto e execução (OTTER; EMMITT, 2008).

A maior quantidade de instrumentos de comunicação leva ao maior entendimento entre os participantes. Dentre os instrumentos, Otter e Emmitt (2008) destacam quatro:

- possibilidade de feedback instantâneo;

- capacidade do transmissor da mensagem usar vários meios de interpretação, como linguagem corporal, tom de voz e inflexão;

- uso de linguagem natural; e

- foco pessoal no receptor.

A comunicação face a face entre os participantes é considerada por Otter e Emmitt (2008) o meio mais eficiente de transmissão das informações, principalmente na etapa inicial do processo de produção. Como na etapa de concepção do projeto, as informações e ideias ainda não estão muito claras e muitas das soluções estão implícitas na mente de cada participante, quanto maior o nível de interação entre o emissor e o receptor, mais eficiente será a comunicação.

A necessidade de proximidade entre os participantes para garantir a qualidade da comunicação também é identificada por Cheung, Yiu e Lam (2013) como um fator que aumenta o desempenho do processo de produção. Ao estabelecer encontros presenciais entre a equipe, 
podem ser identificados e definidos novas questões, problemas, ideias ou soluções, a partir de diferentes perspectivas dos agentes sobre o mesmo objeto.

Cheung, Yiu e Lam (2013) identificaram que quanto maior a distância entre o emissor e o receptor da mensagem, maior a possibilidade de distorção da informação transmitida, o que pode gerar conflitos pela não compreensão ou interpretação errada da mensagem.

Os autores (CHEUNG; YIU; LAM, 2013) listaram os principais problemas de comunicação dependendo do agente do processo:

- Comunicação com potenciais clientes: muitos clientes não têm conhecimento técnico sobre construção civil e isso dificulta a definição dos requisitos de projeto;

- Comunicação entre clientes e consultores: apesar dos consultores entenderem as necessidades e limitações dos clientes, eles não têm todas as informações para definir todas as possíveis soluções para o projeto, o que pode resultar em decisões inadequadas para o empreendimento;

- Comunicação entre a equipe de projeto: o curto prazo disponível para desenvolver o projeto resulta na falta de tempo necessário para melhor compreensão sobre os objetivos do empreendimento, de forma que os projetistas precisam definir soluções, sem que estas sejam melhor avaliadas no empreendimento;

- Comunicação relacionada ao contrato: principalmente pela falta de certeza sobre as expectativas individuais dos participantes em relação ao processo de produção como um todo;

- Comunicação entre a equipe de execução: que é semelhante à equipe de projeto, ou seja, a falta de tempo de planejamento leva à antecipação de soluções, sem que haja informações detalhadas sobre o processo.

\subsubsection{Interdisciplinaridade}

Ao pesquisar sobre a atividade do projetista, Dorst (1997) descreveu dois enfoques para o processo de projeto: racional e reflexivo (Figura 9). No método racional, a atividade de projeto consiste na resolução de um problema a partir do levantamento de todos os requisitos e suas variáveis. O processo de projeto é executado de forma objetiva, indicando uma sequência única e linear das atividades de análise, síntese, simulação e avaliação. 
Figura 9 - Métodos racional e reflexivo para execução do projeto

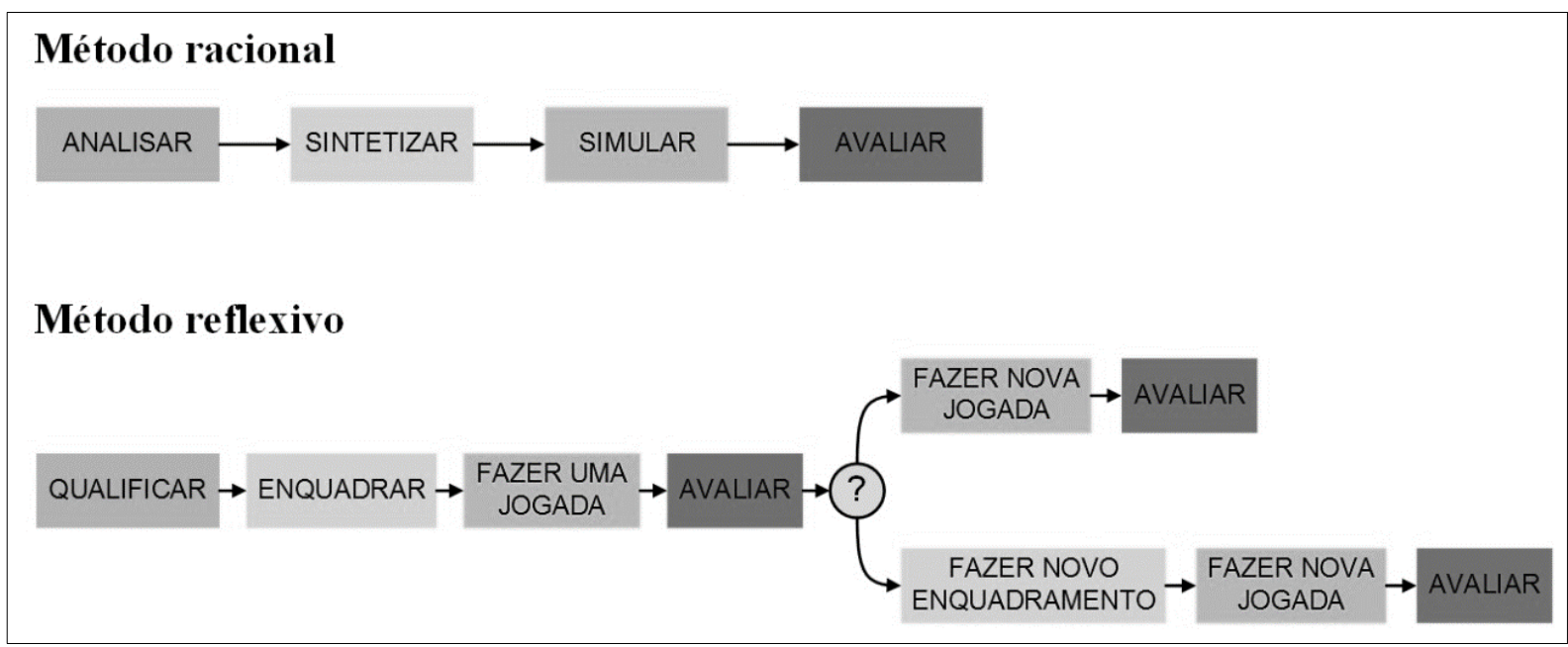

Fonte: Adaptado de DORST, 1997.

No método reflexivo, existe uma abordagem não linear e subjetiva do processo de projeto. Nesse método o projetista lista os fatores relevantes do problema e propõe algumas soluções, alternando entre as atividades de qualificar, enquadrar, fazer uma jogada e avaliar. Esse processo é repetido até que o profissional tenha base para evoluir na elaboração da solução definitiva.

Lawson (2006), afirma que existe uma grande divergência entre a descrição idealizada da sequência de execução do projeto, e a realidade do trabalho do projetista. Enquanto os diagramas adotam o enfoque racional, a atividade real de projeto segue o método reflexivo. Os projetistas realizam diversas proposições, como forma de ampliar o conhecimento sobre o problema para, finalmente, chegar a uma solução definitiva.

Isso ocorre devido à complexidade do projeto, pois existem muitas indefinições e diversas soluções para o mesmo problema. Além disso, existe a complexidade do processo de produção do empreendimento, que envolve um grande número de especialidades, aumentando ainda mais as variáveis e possibilidades de solução.

A complexidade de informações de um empreendimento demanda pela multidisciplinaridade nas tomadas de decisão. Cada disciplina exerce não só um papel no processo de produção, mas também interfere diretamente nas demais disciplinas. Isso faz com que, para se alcançar melhores resultados, as atividades não devem ser executadas de forma independente. A interdisciplinaridade do processo possibilita que sejam desenvolvidas as melhores soluções, aproximando as etapas de projeto e execução (AZARI; KIM, 2015). 
A necessidade de estabelecer barreiras claras entre as disciplinas é definida por Amstel et al. (2016) como uma forma de garantir que as entregas e os pagamentos de cada agente no processo de produção sejam bem definidos para o cliente. No entanto, para alcançar a integração do processo é necessário que essas barreiras sejam eliminadas ou reduzidas.

Dentre as técnicas que podem favorecer a interdisciplinaridade estão: divisão das atividades em tarefas independentes ou sub-tarefas, que possam ser executadas simultaneamente; definição de interfaces de interação entre as tarefas; e criação de equipes temporárias e específicas para determinada atividade (AMSTEL; et al., 2016).

\subsubsection{Participação do cliente}

Os clientes podem ser considerados como um dos principais participantes do processo, são eles que definem a demanda pelo empreendimento e dão o aval para definir como o processo de produção será estabelecido (LATHAM, 1994). Apesar disso, os clientes não são considerados como parte da equipe de produção em muitos estudos sobre o setor (ANUMBA; KAMARA; CUTTING-DECELLE, 2007).

Anumba, Kamara e Cutting-Decelle (2007) afirmam que a participação ativa do cliente no processo de produção é essencial para garantir o êxito na execução do empreendimento. Dependendo das características e interesse desse participante, ele pode ser um dos incentivadores para a integração do processo.

O cliente é responsável por definir os objetivos, requisitos, desejos e expectativas para o empreendimento. Essas características são essenciais para a garantir a qualidade do processo de produção, pois são as informações primárias que os projetistas recebem para desenvolver o projeto. Como em muitos casos o cliente não está familiarizado com questões técnicas da construção civil, é necessário que os profissionais traduzam os desejos abstratos dos clientes em requisitos práticos de execução (ANUMBA; KAMARA; CUTTING-DECELLE, 2007).

O guia do AIA para o contrato relacional Integrated Project Delivery (IPD) (AMERICAN INSTITUTE OF ARCHITECTS, 2007a) define que é necessário que o cliente exerça um papel ativo no processo de produção para garantir a integração. Além de definir os requisitos iniciais de produção, o cliente deve participar de todo o processo, monitorando e validando as tomadas de decisão, para que eventuais problemas possam ser corrigidos antecipadamente. 
As responsabilidades essenciais dos clientes de acordo com a AIA (AMERICAN INSTITUTE OF ARCHITECTS, 2007a) são:

- estabelecer os objetivos de acordo com a função, desempenho, prazo, custo requeridos;

- definir os marcos financeiros críticos do processo de produção;

- definir o sistema de contratação dos profissionais;

- selecionar e formar a equipe de trabalho;

- fornecer informações técnicas para o início do desenvolvimento do projeto, como levantamento topográfico e estudos de impacto sobre o terreno e a vizinhança;

- fornecer parâmetros para definir os riscos do empreendimento, medidas mitigadoras e contratação de seguros;

- estabelecer estrutura organizacional para as entregas, revisões, aprovação e tomadas de decisão;

- fornecer informações sobre requisitos legais que interferem no desenvolvimento do projeto.

Lu e Hao (2013) identificaram dois fatores que influenciam nas decisões do cliente no processo de produção: poder coercitivo e conhecimento técnico. O primeiro fator é definido como sendo o poder que o cliente tem de obrigar a execução das atividades por meio de punições e pelo controle dos pagamentos. Esse fator influencia negativamente o trabalho colaborativo da equipe pois cria-se um ambiente de desconfiança e insegurança entre os participantes.

O segundo fator indica a familiaridade que o cliente tem sobre as questões técnicas de execução do empreendimento. Quanto maior o nível de conhecimento técnico do cliente, mais confiança a equipe tem para desenvolver as soluções para o empreendimento. Nesse caso, fica mais claro para os projetistas e construtores os requisitos definidos pelo cliente, além de facilitar a comunicação entre eles (LU; HAO, 2013).

Visando estabelecer um processo de produção integrado, é necessário que o cliente defina antecipadamente os instrumentos para favorecer o trabalho colaborativo. Com a antecipação da participação dos principais agentes de produção, a definição dos requisitos para o empreendimento (RFP) passa a ser uma atividade conjunta da equipe. Os agentes devem definir também em conjunto as normas, regras e organização do processo de produção; as 
possibilidades de interações entre disciplinas; e a forma de resolução de conflitos dentro da equipe (SUPRAPTO; BAKKER; MOOI, 2015).

\subsubsection{Relações de trabalho de longo prazo}

No relatório elaborado por Egan (1998) para o Governo Britânico, as relações de trabalho de longo prazo são identificadas como um dos fatores essenciais para aumentar a eficiência e melhorar a qualidade dos empreendimentos. O autor considera não só os profissionais responsáveis pelo desenvolvimento e execução do empreendimento, mas também os fornecedores dos componentes dos edifícios.

Com a repetição da equipe para a produção de novos empreendimentos, cria-se uma organização de trabalho mais eficiente. A cada novo processo são revistos os problemas e as melhores práticas, de forma que os profissionais troquem conhecimentos e possam aperfeiçoar seus métodos de trabalho (EGAN, 1998).

Eriksson (2007) identificou que quanto mais longa é a relação de trabalho dos participantes, mais favorável é o ambiente para se estabelecer a colaboração entre os participantes. As relações de trabalho de longo prazo reduzem as incertezas sobre o comportamento dos participantes, ou seja, existe a tendência de que todos cooperem para alcançar da melhor forma os objetivos do empreendimento.

Outro benefício das relações de trabalho de longo prazo é a possibilidade de adaptação dos profissionais ao método de trabalho da equipe. Isso também é válido para os fornecedores dos componentes, que podem desenvolver melhores soluções técnicas para algum tipo de sistema construtivo utilizado em um certo grupo de empreendimentos de um mesmo cliente (GADDE; DUBOIS, 2010).

Gadde e Dubois (2010) identificaram que essa adaptação aumenta o desempenho do processo e possibilita a interdisciplinaridade do trabalho em equipe. Com o trabalho de longo prazo, as interações entre os participantes se tornam mais recorrentes e acontecem com maior proximidade. Isso faz com que as tomadas de decisão de uma determinada disciplina sempre levem em consideração os impactos nas demais, tornando o resultado muito mais adequado ao empreendimento como um todo.

Manter relações de trabalho de longo prazo pode ser um empecilho na construção civil, pois pode ter impacto direto no custo do empreendimento, ao reduzir a possibilidade de novas concorrências para a contratação dos profissionais. Além disso, o tempo para que sejam 
alcançados os benefícios dessa relação de trabalho pode ser longo (BYGBALLE; JAHRE; SW ÄRD, 2010).

A contratação de diferentes profissionais a cada novo projeto pode se dar por diferentes motivos, como a insatisfação com o resultado do trabalho, melhores propostas, redução no custo, ou até como forma de avaliar um novo profissional ou fornecedor (ERIKSSON, 2015).

No entanto, Bygaballe, Jahre e Swärd (2010) afirmam que muitos empreendimentos têm um tempo de produção longo, que já seria suficiente para aperfeiçoar o método de trabalho da equipe. Além disso, muitos profissionais de projeto especificam os mesmos sistemas construtivos para diferentes projetos, o que possibilita criar uma relação de trabalho de longo prazo, mesmo com processos de produção diferentes.

Eriksson (2015) afirma que para garantir um ambiente de aprendizado na equipe em apenas um processo de produção do empreendimento, é necessário que os principais agentes do processo de produção sejam contratados precocemente. $\mathrm{O}$ autor considera também a participação dos fornecedores, que podem aperfeiçoar a produção dos componentes para que estejam adequadas ao empreendimento na etapa de execução.

Forbes e Ahmed (2011) também indicam a dificuldade de contratar os mesmos profissionais para vários empreendimentos. No entanto, para que as relações de trabalho sejam longas, não é necessário que a equipe inteira seja a mesma. O importante é que os profissionais tenham trabalhado juntos de alguma forma, seja com consultorias ou em algum outro projeto.

Os autores (FORBES; AHMED, 2011) definem as seguintes vantagens para as relações de trabalho de longo prazo:

- execução do empreendimento com maior qualidade;

- redução no custo total do empreendimento;

- aumento das margens de lucro dos participantes;

- redução da competitividade e conflito entre os participantes;

- redução de erros e omissões, devido à melhoria de comunicação durante o projeto e execução; e

- redução nas solicitações de mudanças no projeto. 


\subsubsection{Gestão do processo de produção do empreendimento}

Dentre os profissionais que podem ser considerados como fundamentais para garantir a integração do processo de construção civil, pode-se considerar o gestor de produção. De acordo com Ceran e Dorman (1995) a gestão do processo de produção na construção civil é essencial para garantir a qualidade do empreendimento. Esse agente tem como princípio atuar no processo de forma abrangente, desde o início do desenvolvimento do projeto até a entrega da obra. Dentre suas responsabilidades estão: gestão da qualidade; controle do processo de produção, considerando custo, prazo e desempenho das soluções de projeto; planejamento e controle das atividades do processo; e organização da equipe.

Para que o processo de produção seja integrado, é essencial que o gestor esteja alinhado e tenha o interesse de estabelecer a integração e o trabalho colaborativo. Mitropoulos e Tatum (2000) indicam alguns instrumentos utilizados pelo gestor para a integração, a partir de três perspectivas - contratual, organizacional e tecnológica:

- contratual: definindo sistemas de contratação que incentivem a colaboração e especificando incentivos atrelados ao desempenho dos participantes;

- organizacional: com a criação de equipes multidisciplinares, parcerias com os fornecedores de materiais, para que eles participem no desenvolvimento do projeto, e métodos de trabalho como charrette, que se baseia no trabalho em grupo e por um tempo curto para a solução de determinados problemas do empreendimento; e

- tecnológica: por meio de ferramentas de tecnologia da informação como uma interface de comunicação e troca de informações entre os participantes.

A gestão do processo de construção é considerada como um dos fatores para o êxito na execução do empreendimento. No entanto é necessário que essa atividade seja efetiva, ou seja, que o gestor atenda a alguns requisitos como: comunicação adequada; instrumentos de controle do processo de produção; capacidade de fornecer feedbacks aos participantes; resolução de problemas; coordenação eficiente; capacidade de tomadas de decisão; monitoramento; organização da estrutura do processo de produção; controle do planejamento e prazo e de execução; e experiência prévia de gestão (CHAN; SCOTT; CHAN, 2004).

No entanto, Chan, Scott e Chan (2004) indicam que algumas decisões do cliente em relação ao processo de produção interferem na qualidade da gestão, como: a forma de organização da equipe, que vai influenciar no sistema de comunicação das informações; a estrutura organizacional e o sistema de contratação dos profissionais, que vai indicar a existência ou não 
de profissionais subcontratados e o limite de atuação do gestor; além da forma de controle dos riscos do empreendimento, como no caso da contratação de seguradoras.

A comunicação é considerada como uma das principais habilidades que um gestor deve ter. Com a necessidade de lidar com diversos profissionais, de diferentes disciplinas, o gestor de produção passa a representar uma liderança na equipe, além de responsabilizar-se pela adequação das diferentes interações das atividades de projeto e execução. Sem uma comunicação efetiva e baseada na confiança, não é possível estabelecer uma equipe focada nos objetivos gerais do empreendimento (EMMITT; GORSE, 2006).

Além do papel do gestor no processo de produção, Melhado (2005) destaca o coordenador de projeto, que possui como responsabilidade a operacionalização das diretrizes do projeto. A coordenação de projetos consiste em uma atividade que dá suporte ao desenvolvimento do projeto, possibilitando integrar todas as disciplinas envolvidas nessa etapa, coordenando as tomadas de decisão para garantir as melhores soluções projetuais para o empreendimento.

Segundo Melhado (2005), o coordenador de projetos se diferencia do gestor por sua abrangência no processo de produção. $O$ gestor tem uma atuação mais abrangente no processo, ele é o agente que define e controla a execução das diretrizes definidas para a produção do empreendimento, como questões de planejamento, prazo custo e formação das equipes. $\mathrm{O}$ coordenador de projetos tem uma responsabilidade menos abrangente, ou seja, sua atuação está limitada à dimensão do projeto.

De acordo com a Associação Brasileira dos Gestores e Coordenadores de Projetos - AGESC (2012), apesar de atuar na etapa de projeto, o coordenador deve compreender todo o processo, desde a elaboração do projeto até a entrega da obra. Ao favorecer a interatividade da equipe, o coordenador de projeto possibilita a integração dos objetivos de cada agente, visando a eficiência do processo e a melhoria da qualidade final do empreendimento.

Portanto, existem diversas características organizacionais que vão influenciar na integração do processo de produção. Todos os fatores citados neste capítulo - formação da equipe; comunicação; interdisciplinaridade; participação do cliente; relações de trabalho de longo prazo; e coordenação e gestão - visam possibilitar a interação entre os participantes, criando um ambiente de confiança e favorável ao trabalho colaborativo. 


\subsection{Perspectiva da tecnologia da informação}

Nam e Tatum (1992) ao abordarem o tema da integração, identificaram um aumento no interesse de integrar as informações geradas durante o desenvolvimento do empreendimento. Ao trabalharem diferentes disciplinas no processo de produção, é necessário que as informações sejam armazenadas e estejam disponíveis para todos os participantes.

Para integrar a produção na construção civil, é necessário atualizar os processos de trabalho, aliando os avanços da tecnologia à gestão das informações de projeto e execução. Ao aproximar as diferentes disciplinas e estabelecer o trabalho colaborativo da equipe, existe a necessidade de integrar em um único modelo computacional diversas informações de projeto, fabricação, execução e gestão da construção (AMERICAN INSTITUTE OF ARCHITECTS, 2007a).

Dentre os procedimentos voltados à integração e apoiados no uso da tecnologia da informação pode-se destacar a Modelagem da Informação da Construção (BIM). Eastman et al. (2011) afirma que o BIM representa uma ruptura no modelo tradicional do processo de produção sequencial e baseado na troca de desenhos bidimensionais do edifício. Com o uso do BIM é possível incorporar no modelo todos os componentes da edificação, não só como formas geométricas, mas com todas as propriedades deles. Isso facilita a interação entre os profissionais, que podem trabalhar simultaneamente com diversas informações de diferentes áreas de conhecimento.

\subsubsection{Modelagem da Informação da Construção (BIM)}

De acordo com Succar (2009), BIM é um conjunto de políticas, processos e tecnologias interativas que resultam em um método para gerenciar as informações do projeto e execução no formato digital, ao logo de todo o ciclo de vida do empreendimento. O BIM deve ser considerado como um sistema de integração da modelagem de produtos e processos e não apenas um conjunto de tecnologias.

Eastman et al. (2011) também abordam o BIM como um processo e não apenas uma mudança de tecnologia. Ao possibilitar o desenvolvimento de modelos virtuais que possuem informações detalhadas de cada elemento e que estes possuem regras de interação com os demais, altera-se toda a forma com que o empreendimento é desenvolvido.

É necessário rever as principais questões do processo de produção, como: a definição dos requisitos do cliente; a forma de análise das soluções projetuais; o trabalho colaborativo; a 
definição do planejamento e execução; e as atividades posteriores à entrega do edifício - uso e manutenção (EASTMAN; et al., 2011).

Eastman et al. (2011) lista os benefícios do BIM para o empreendimento e seus participantes de acordo com as etapas do processo de produção:

- pré-construção: com a maior precisão das informações geradas durante a concepção do empreendimento e as maiores possibilidades de realizar estudos sobre o modelo, a etapa de definição dos requisitos de projeto e as limitações do cliente se tornam mais eficazes, dando mais segurança para a etapa posterior de desenvolvimento do projeto; além na possibilidade de integração das diferentes disciplinas desde as primeiras etapas do processo;

- projeto: com a modelagem do objeto 3D, com todas suas informações técnicas, existe a antecipação e maior acurácia na visualização e compreensão do empreendimento; facilidade de identificar erros e sobreposições de objetos; redução dos erros pela automatização de geração de desenhos 2D; possibilidade de estabelecer uma plataforma de trabalho colaborativa e interdisciplinar; e antecipação e exatidão na geração das informações de projeto, como quantitativos, estimativa de custo e análises de conforto;

- construção e fabricação dos componentes: possibilidade de automatizar a fabricação dos componentes, com a transferência direta do modelo BIM para as máquinas, reduzindo os erros de desenhos; rapidez nas alterações de projeto solicitadas na etapa de execução; facilidade na identificação de erros de projeto antes do início da execução; integração das informações do planejamento de execução no modelo BIM; facilidade na inserção de técnicas de construção mais eficientes, como o Lean Construction; e maior precisão do modelo para a etapa de contratação dos profissionais de execução; e

- pós-construção: antecipação das decisões de uso e manutenção, com o detalhamento dos sistemas do edifício ainda na etapa de desenvolvimento do projeto; e maior precisão do modelo as-built, que pode ser usado para monitorar o edifício, controlando as necessidades de manutenção.

O relatório do Royal Institute of British Architects (2012) identificou que com o uso do BIM, a forma de trabalho na construção civil mudou, principalmente nas tarefas de geração, compartilhamento e integração das informações do processo de produção. Isso demanda por novos procedimentos de contratação, organização da equipe, além da elaboração de normas e regras para a execução do empreendimento. 
O National Institute of Building Sciences (2015a) instituição organizadora do buildingSmart, que é uma entidade internacional voltada ao fomento de padrões abertos de modelagem computacional (BUILDINGSMART, 2018b), define o BIM como uma representação digital das características físicas e funcionais de uma instalação. O BIM tem como finalidade compartilhar o conhecimento para fornecer as informações sobre determinada instalação. As informações geradas compõem uma base confiável para as tomadas de decisão ao longo do ciclo de vida do empreendimento.

O uso do BIM tem-se difundido em diversos países, de acordo com o relatório elaborado pela área de pesquisa e análise de dados do McGraw Hill Construction (2014). Os clientes do empreendimento indicaram uma percepção positiva do retorno de investimento (return of investment - ROI) com o uso do BIM. Apesar de não existir uma normatização para definir as métricas de análise, alguns fatores são comuns em diversos países, como: custo, lucro, produtividade, redução do retrabalho e das solicitação de alterações, maior satisfação dos clientes e aumento da colaboração entre a equipe.

Succar e Kassem (2015) destacam que os benefícios do BIM só podem ser amplamente alcançados quando existe a difusão do sistema, que representa o uso expressivo do BIM no setor da construção civil dentre todos os agentes da cadeia de produção - projetistas, construtores e fornecedores. Os autores identificaram três dinâmicas para a difusão do BIM:

- top-down, que é a forma coerciva, por meio da imposição de leis e regulamentos públicos;

- middle-out, com a adoção do BIM por grandes organizações ou grupos de empresas, que influencia o mercado e o setor público a também adotarem o BIM; e

- bottom-up, a partir do uso do BIM por um grupo significativo de pequenas empresas, que influenciam a adoção do BIM nos outros setores.

Para a inserção do BIM no processo de produção, é necessário não só alterar o tipo de tecnologia usado para a modelagem do projeto, mas estabelecer mudanças estruturais no trabalho da equipe. Sackey, Tuuli e Dainty (2015) abordaram o conceito de "sistema sociotécnico" (sociotecnical system - STS) para avaliar o uso do BIM na produção da construção civil.

O termo STS foi desenvolvido para descrever sistemas que possuem interações complexas entre pessoas, tecnologia e ambiente. Existem duas premissas desse sistema: quando algum processo envolve a participação de muitos atores, é necessário considerar a questão social além da técnica; e que o processo reflete o ambiente em que está inserido, o que interfere na validação das atividades (SACKEY; TUULI; DAINTY, 2015). 
No caso da construção civil, os autores (SACKEY; TUULI; DAINTY, 2015) argumentam que somente o uso do BIM não proporciona aumento da eficiência e trabalho colaborativo no processo. É necessário considerar as interações entre atividades, estrutura do processo, tecnologia e os participantes. Essas áreas são interdependentes e devem estar alinhadas com os objetivos da inserção do BIM no processo de produção.

Turk (2016) também considera a necessidade de se compreender o BIM não só pela tecnologia, mas a partir de três perspectivas:

- estrutural, que define como o BIM é organizado, quais partes ele possui e como elas funcionam em conjunto; para aperfeiçoar o uso colaborativo do modelo computacional do empreendimento, é necessário aperfeiçoar as ferramentas de coleta de dados do processo;

- funcional, que indica a maneira com que o BIM pode beneficiar o processo de produção; sendo necessário melhorar as ferramentas que possam utilizar os dados do modelo e fazer análises automatizadas, que poderão embasar as soluções definidas pelos projetistas; e

- comportamental, que representa a forma com que o BIM reflete o ambiente em que ele está inserido; sendo necessário adequar as características do processo de produção ao método de trabalho determinado pelo uso do BIM.

Percebe-se que para o uso adequado do BIM, devem ser consideradas características relacionadas a suas aplicações, nível de maturidade e método de trabalho da equipe. O BIM se mostra como uma alternativa para solucionar o problema da fragmentação do processo a partir das mudanças tecnológicas e seus objetivos estão alinhados ao conceito de integração definidos nas outras duas perspectivas da integração analisadas nesta pesquisa: contratual e organizacional.

\subsubsection{Trabalho colaborativo em BIM}

Grilo e Jardim-Goncalves (2010) destacam que o principal problema de interoperabilidade com o uso do BIM se refere à perspectiva organizacional. O desafio para se alcançar todos os benefícios do uso do BIM está relacionado à necessidade de mudanças no processo de produção. Deve-se adequar os procedimentos de trabalho para que o modelo computacional possa ser compartilhado e estabeleça a interdisciplinaridade das atividades. 
O BIM pode dar suporte ao trabalho colaborativo ao: possibilitar ao cliente definir os requisitos de projeto de forma mais confiável e correta; facilitar o desenvolvimento e análise do projeto; permitir que mais informações sejam usadas na atividade de gestão do empreendimento; e fornecer informações para as atividades de uso e operação do edifício (GRILO; JARDIMGONCALVES, 2010).

Eastman et al. (2011) identificou que uma das principais mudanças no processo de produção com o uso do BIM é a demanda pelo trabalho colaborativo devido à necessidade de se trabalhar como um modelo computacional compartilhado por diferentes profissionais, na etapa de desenvolvimento do projeto. Essa mudança requer que a equipe seja treinada e tenha as habilidades necessárias no uso dos softwares para possibilitar o trabalho colaborativo.

Um dos principais fatores que influenciam no trabalho colaborativo com o BIM é a comunicação. Ao disponibilizar diversas informações do empreendimento no modelo computacional, é necessário que exista uma comunicação eficiente entre os participantes. Essa comunicação pode ser direta entre os agentes, ou por meio da troca de informações de projeto contidas nos modelos do edifício (EASTMAN; et al., 2011).

Para alcançar a integração com o BIM é necessário que a equipe de trabalho tenha algumas habilidades que vão favorecer a colaboração. Succar, Sher e Williams (2013) dividem essas habilidades em três grupos:

- competências essenciais, que representam as características pessoais, como aquelas inerentes ao indivíduo, ou seja, que não podem ser adquiridas por treinamento; domínio da língua; qualificação acadêmica e técnica; e experiência profissional;

- competências de domínio, que representam as habilidades profissionais, como capacidade de criar estratégias de tomadas de decisão; habilidades de colaboração e gestão; conhecimento técnico das tecnologias de modelagem e sistemas de tecnologia da informação; além de conhecimentos administrativo, operacional, de pesquisa e desenvolvimento; e

- competências de execução, que representam as habilidades de uso de ferramentas computacionais.

O trabalho colaborativo pode ser favorecido pelo BIM, ao estabelecer procedimentos de troca de modelos computacionais em que cada disciplina insere informações referentes a sua especialidade. Quando uma equipe trabalha colaborativamente, é possível reduzir os conflitos e as incertezas por meio da troca de informações, objetivos e conhecimento sobre o projeto; 
coordenação transparente e eficaz do processo produtivo; e acesso livre aos dados do projeto por todos os participantes (LIU; NEDERVEEN; HERTOGH, 2017).

Liu, Nederveen e Hertogh (2017) identificaram três áreas de influência da colaboração por meio do uso do BIM: tecnologia, que está relacionada às funcionalidades dos softwares e a possibilidade de interoperabilidade dos modelos; processos, que representam a organização e regras das etapas e atividades de execução; e pessoas, que está relacionada às características e habilidades dos participantes (Figura 10).

Figura 10 - Códigos, conceitos e categorias do efeito da colaboração no uso do BIM

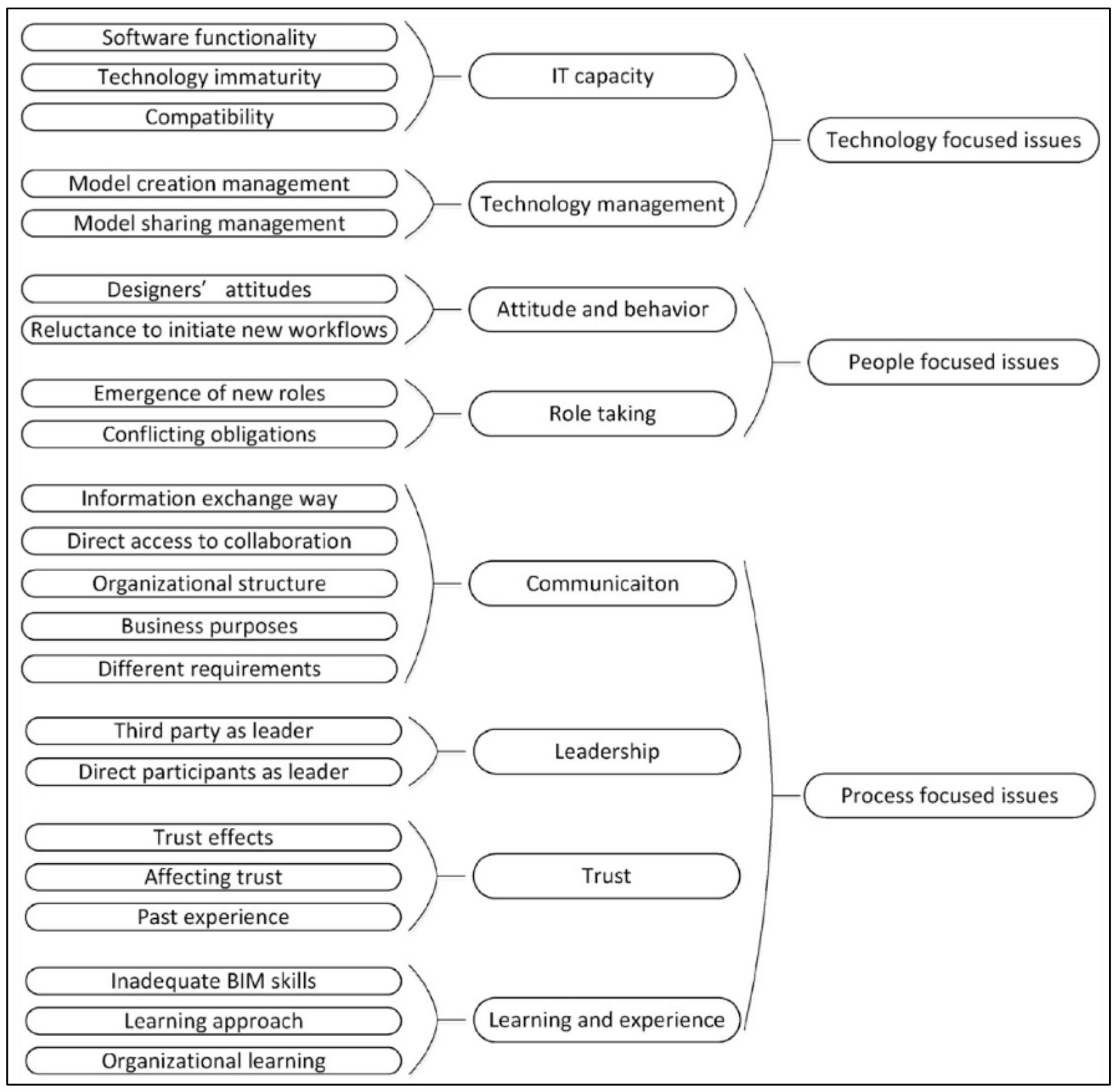

Fonte: LIU; NEDERVEEN; HERTOGH, 2017 
No caso da tecnologia, o uso integrado do BIM requer que o modelo seja compartilhado e utilizado por todas as disciplinas e etapas do processo de produção. Para isso é necessário que os profissionais consigam trabalhar com o mesmo arquivo ou parte dele, independentemente do software em que o modelo foi criado. Além disso, os profissionais devem estar cientes de qual o nível de detalhamento desejado para o projeto e quais informações devem ser compartilhadas, de forma que o compartilhamento do modelo seja compatível com o trabalho de toda a equipe.

Outra questão que impacta na área tecnológica da integração com o uso do BIM é a atividade de gestão do empreendimento, desde o projeto até a execução. Uma das ferramentas que facilitariam a colaboração é a "análise de interferências" (clash detection), que permite automatizar a identificação das inconformidades do projeto, como por exemplo a sobreposição espacial entre elementos dos diferentes sistemas - arquitetura, estrutura e instalações. Essa ferramenta permite uma análise mais confiável e precisa do modelo, antecipando a identificação dos problemas do projeto.

Em relação ao processo, a colaboração com o BIM tem influência sobre a comunicação, liderança e aprendizado. A comunicação pode ser facilitada e aprimorada com a integração das informações de projeto em um único modelo, de forma que todos os participantes tenham acesso aos dados de todas as disciplinas. Além disso, com o uso do BIM é necessário considerar diferentes aspectos do projeto desde o início de sua concepção, o que facilita a integração das etapas de projeto e execução, tornando o projeto mais completo e próximo a realidade.

A integração das informações, a troca de modelos computacionais e a interdisciplinaridade das atividades, demanda a presença de um líder que possa coordenar o trabalho colaborativo da equipe. No caso do BIM, podem existir participantes externos à equipe, como um consultor BIM, ou então, o próprio projetista ou o gestor, que são profissionais que possuem uma visão sistêmica do processo.

Ainda em relação ao processo, os autores (LIU; NEDERVEEN; HERTOGH, 2017) indicam que o BIM facilita e potencializa o aprendizado contínuo da equipe, seja pelo conhecimento sobre a tecnologia, ou pelas informações do processo. Como o BIM permite que diversas informações do processo sejam coletadas ao longo da produção do empreendimento, é possível organizar uma grande base de dados que permite a análise do processo sobre diferentes aspectos, como tempo de execução, desempenho dos componentes e quantidade de erros identificados. 
No caso das pessoas, a colaboração com BIM pode ser aprimorada com o uso das informações do processo para definição das responsabilidades e recompensas de cada participante. O cliente passa a ter mais controle sobre o processo e pode tomar decisões com mais embasamento. Além disso, com o uso do BIM, novas atividades são definidas o que leva a necessidade de participação de novos agentes, como no caso do gestor BIM ou coordenador BIM, e da especificação de novas habilidades para a contratação dos profissionais.

Çıdık, Boyd e Thurairajah (2017) também consideram a perspectiva humana como essencial para garantir os benefícios do BIM. Os autores definiram duas perspectivas para a inserção do BIM no processo de produção do empreendimento: objetivista ou centrada na tecnologia; e construtivista ou centrada nas pessoas.

O primeiro caso define que a tecnologia é o único responsável pelas melhorias do uso do BIM e a ausência de inovação no processo é exclusivamente resultado da má atuação dos profissionais. Essa perspectiva considera que as informações do modelo computacional representam informações objetivas e por isso devem possuir mesmo significado e as mesmas consequências no desenvolvimento de diferentes projetos. A perspectiva centrada na tecnologia é considerada pelos autores (ÇIDIK; BOYD; THURAIRAJAH, 2017) como simplista, pois considera a tecnologia da informação como o único impulsor das mudanças no processo e as pessoas apenas como usuários da tecnologia.

A perspectiva centrada nas pessoas considera que o fator social das interações humanas interfere diretamente no êxito dos benefícios do uso do BIM. Nesse caso, o fator humano determina o conhecimento intrínseco dos participantes, as possibilidades de solucionar problemas, a maneira de organizar tarefas e a capacidade de dar respostas rápidas aos imprevistos de produção, por meio da improvisação baseada em conhecimento tácito.

No entanto, os autores (ÇIDIK; BOYD; THURAIRAJAH, 2017) indicam que a capacidade de inovação e integração do processo com o BIM deve ser entendida como uma dinâmica em que se consideram as duas perspectivas. $\mathrm{O}$ uso da capacidade tecnológica junto com as questões sociais e do ambiente permite que se entenda o processo como um sistema complexo, em que o uso da tecnologia depende das habilidades pessoais e do trabalho colaborativo da equipe.

O uso do BIM tem sido veiculado como uma solução inovadora para o problema da fragmentação no setor da construção civil. No entanto, existem expectativas muito altas sobre a questão tecnológica, sem que sejam feitas adequações ao processo (ROWLINSON, 2017). 
Dentre os problemas de uma visão estreita sobre o uso do BIM, Rowlinson (2017) cita: foco na tecnologia e não na cultura de projeto; incerteza em relação aos valores que os diferentes serviços do BIM pode trazer para os clientes; ausência da avaliação de risco ao antecipar o esforço de desenvolvimento de projeto; falta de adequação do método de execução do empreendimento e do sistema contratual aos requisitos do BIM; uso de desenhos em 2D durante a execução do empreendimento, o que interrompe o fluxo de produção em BIM; e a segregação do desenvolvimento do projeto em disciplinas, impedindo o trabalho colaborativo e integrado.

\subsubsection{Nivel de maturidade BIM}

Os níveis de maturidade BIM representam o nível de integração sob a perspectiva da tecnologia da informação. Com maiores possibilidades de estabelecer o trabalho colaborativo com o uso do BIM, mais integrado pode ser considerado o processo.

Succar (2009) define três fases que são precedidas de um cenário denominado "Pre-BIM", que representa o desenvolvimento dos empreendimentos antes da disseminação do BIM; e um cenário futuro, que foi denominado "Integrated Project Delivery (IPD)", mas que em uma pesquisa posterior, o autor (SUCCAR; SHER; WILLIAMS, 2013) mudou esse termo para "Post-BIM", que indica a meta final para o uso do BIM (Figura 11).

\section{Figura 11 - Níveis de Maturidade do BIM por Succar}

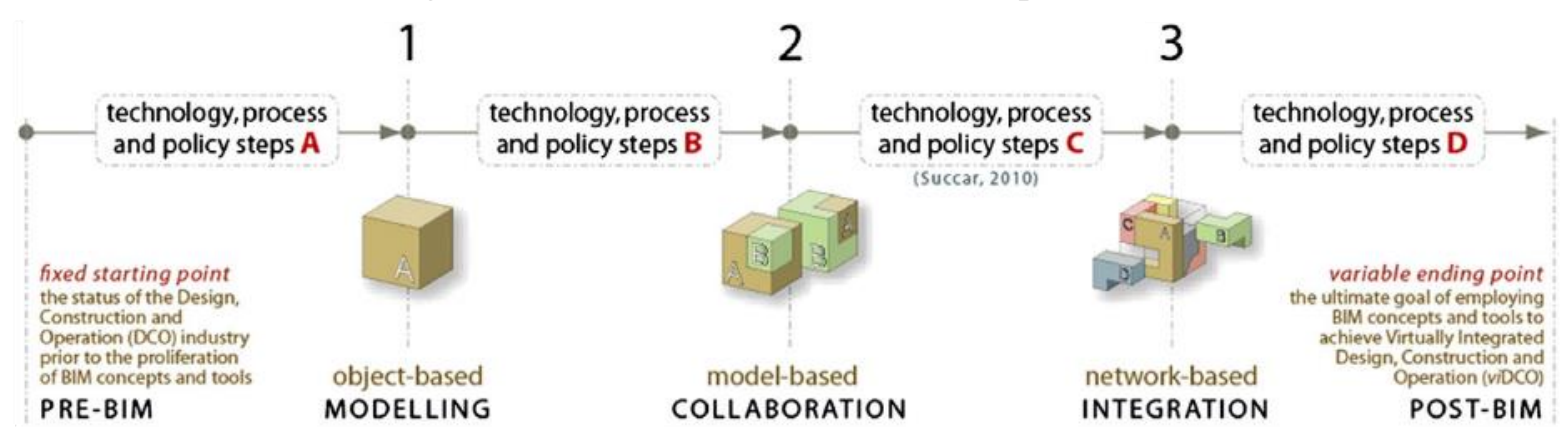

Fonte: SUCCAR; SHER; WILLIAMS, 2013.

Os níveis de maturidade definidos por Succar (2009) são:

- Pre-BIM, em que existe uma grande dependência da execução do processo de produção aos documentos e desenhos 2D do empreendimento; as análises sobre o projeto são realizadas a partir da visualização do modelo e não estão integradas à documentação dos componentes; e a colaboração não é uma atividade prioritário ao processo, mantendo uma execução linear das etapas de produção; 
- BIM fase 1 - modelagem orientada a objetos, que representa o uso do BIM por apenas uma disciplina de projeto, principalmente para automatizar e coordenar a geração de documentação 2D a partir do modelo computacional; nessa fase não existe a colaboração entre as disciplinas e a forma de comunicação da equipe é semelhante à fase Pre-BIM;

- BIM fase 2 - colaboração baseada em modelos, onde se inicia a colaboração entre diferentes disciplinas, por meio da troca dos modelos computacionais ou de parte deles; essa colaboração pode ocorrer em apenas uma etapa do processo de produção, como no desenvolvimento do projeto, ou entre etapas como projeto e execução;

- BIM fase 3 - integração baseada em rede, em que modelos computacionais integrados são desenvolvidos colaborativamente e compartilhados entre todo o processo de produção e entre todas as disciplinas; nessa fase é possível antecipar as análises sobre o projeto e o método de produção inclui questões como inteligência empresarial (business intelligence), conceitos Lean $^{5}$, princípios de sustentabilidade e custo referente ao ciclo de vida do empreendimento; e

- IPD - atualmente Pós-BIM (SUCCAR; SHER; WILLIAMS, 2013), que é uma meta para a completa utilização do BIM, mas que pode variar conforme a evolução do sistema; a fase final do BIM é possibilitar a integração de todas as etapas do processo - projeto, execução, fabricação, uso e operação - com a definição de um modelo $n D$, ou seja, um modelo com $n$ dimensões, que representam as variáveis para a análise do empreendimento.

A passagem para um novo nível de maturidade do BIM somente é possível quando se cumpre os requisitos de transição. Succar (2009) determinou diferentes passos para essa transição de acordo com os três campos do BIM:

- tecnologia, que são os requisitos técnicos para a evolução do uso do BIM, por meio da adequação dos softwares, hardwares e redes de colaboração, que possibilitam integrar o modelo em nível de disciplina, etapas de produção ou ciclo de vida do empreendimento;

- processo, que demandam alterações no método de execução do empreendimento, com a definição de líderes ou coordenadores do processo, trabalho colaborativo e habilidades dos profissionais contratados; e

\footnotetext{
${ }^{5}$ Inserção dos conceitos da Produção Enxuta - Lean Production - na construção civil (FORBES; AHMED, 2011)
} 
- políticas, definindo questões contratuais, regulamentação e treinamento dos profissionais para que os profissionais possam utilizar o BIM no processo de produção tendo um objetivo comum alinhado com o trabalho em equipe e os requisitos do empreendimento.

Ao considerar o BIM a partir da fase 3, Succar (2009) indica que o trabalho colaborativo não é uma característica intrínseca ao uso do BIM, mas sim resultado no aprofundamento do uso e disseminação do BIM entre todo o processo de produção do empreendimento.

A integração do processo é um reflexo da evolução do uso do BIM, que passa a fazer parte de todas as disciplinas e todas as etapas do processo. Para chegar à fase 3 , é necessário rever o método de execução do empreendimento, desde seu sistema contratual, alocação de riscos e fluxos de atividades. A tecnologia permite estabelecer a interdisciplinaridade da produção, por meio de modelos computacionais compartilhados por mais de um membro da equipe (SUCCAR, 2009).

Outra forma de definir o nível de uso dos instrumentos do BIM no processo de produção foi definido por Bew e Richards (apud ROYAL INSTITUTE OF BRITISH ARCHITECTS, 2012) (Figura 12).

Figura 12 - Nível de Maturidade BIM por Bew e Richards

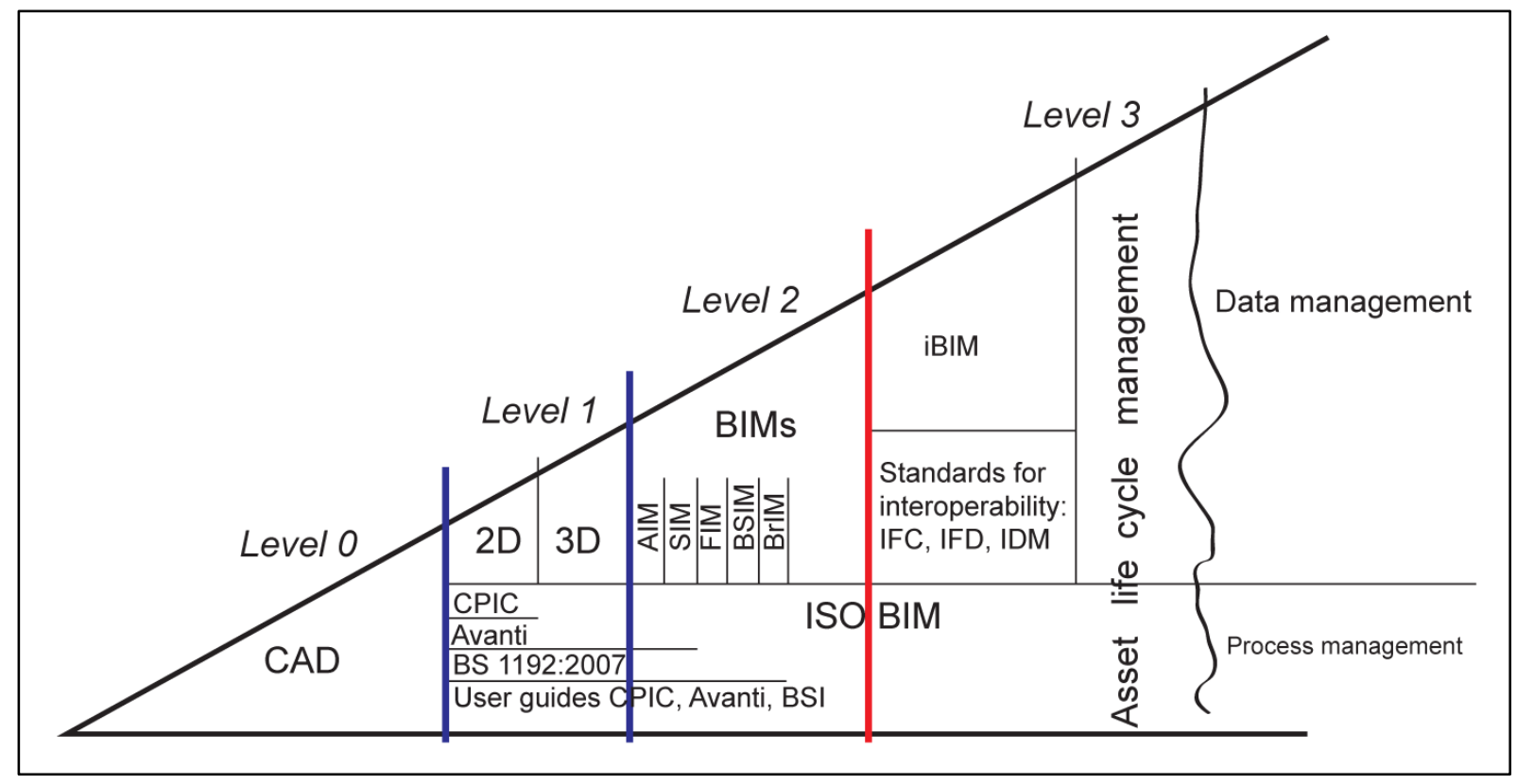

Fonte: ROYAL INSTITUTE OF BRITISH ARCHITECTS, 2012. 
Essa classificação é semelhante aos níveis de maturidade de Succar (2009), mas acrescenta como ocorrem a gestão do processo e dos dados em cada nível:

- Nível 0, em que as informações do projeto são desenvolvidas em arquivos 2D, que definem tanto a gestão de dados quanto a gestão do processo;

- Nível 1, em que apenas um dos profissionais utiliza a modelagem BIM, ou seja, durante o processo existe tanto o uso de arquivos 2D quanto BIM, nesse caso não existe a colaboração do modelo entre a equipe; nesse nível, existe a necessidade de sistematizar o processo de produção, além de estabelecer a gestão dos dados, considerando os dois modelos de arquivo - 2D e BIM para compreender o empreendimento;

- Nivel 2, onde todos os principais profissionais usam e compartilham o modelo BIM, mas cada um tem o domínio do seu arquivo; nesse caso, a gestão dos dados deve ser feita de acordo com as disciplinas - arquitetura, estrutura e instalações - já que não existe um único modelo BIM; a gestão do processo deve definir as regras de elaboração do modelo, de forma que o nível de detalhamento do modelo de cada disciplina possa ser compatibilizado no modelo completo do empreendimento; e

- Nível 3, que representa a principal mudança do processo para o uso de todos os instrumentos do BIM, por meio de um modelo único ou federado em que todos os profissionais desenvolvem seus projetos; nesse caso a gestão de dados deve prever o uso de formatos abertos, como o Industry Foundation Classes - IFC, de forma a garantir a interoperabilidade entre as disciplinas; a gestão do processo deve definir não só as regras de elaboração do modelo, mas também os direitos de cada agente sobre o modelo BIM.

\subsubsection{Guias de inserção do BIM nos processos de produção}

Existem diversos artigos, relatórios e guias indicando como o BIM deve ser inserido no processo de produção. Podem ser destacados cinco guias que direcionam a contratação e a definição do processo de produção com o BIM: Royal Institute of British Architects (RIBA) BIM Overlay, do Reino Unido; National BIM Standard - versão 3, dos Estados Unidos; BIM Handbook para o setor público, da União Europeia; Guia de Contratação BIM da Comissão de Normatização Técnica de Portugal; e a Coletânea de Guias BIM Agência Brasileira de Desenvolvimento Industrial (ABDI) e do Ministério da Indústria, Comércio Exterior e Serviços (MDIC), do Brasil. 
Royal Institute of British Architects (RIBA) - Reino Unido (2012/2013)

O RIBA elaborou um guia para orientar as alterações no Plan of Work de 2013 (ROYAL INSTITUTE OF BRITISH ARCHITECTS, 2013) com a inserção do BIM. O Plan of Work é um documento que visa orientar os agentes responsáveis pela produção do empreendimento para as etapas e atividades necessárias ao processo. Por meio do documento BIM Overlay (ROYAL INSTITUTE OF BRITISH ARCHITECTS, 2012), foram definidas em cada etapa do processo as principais atividades que envolvem o BIM.

As atividades BIM foram definidas considerando um nível de maturidade que requer a execução de modelos $3 \mathrm{D}$ com as informações de projeto por todos os principais participantes da equipe. Pode existir mais de um modelo BIM; no entanto, os profissionais precisam alinhar os objetivos e o nível de detalhamento do modelo, além de criar regras para as alterações das informações de projeto e sua interoperabilidade (ROYAL INSTITUTE OF BRITISH ARCHITECTS, 2012). Nesse guia, o BIM é usado ao longo de todo o processo:

- preparação, onde são definidos os usos e objetivos do BIM, com a especificação de qual dimensão será utilizada - 4D (tempo), 5D (custo), 6D (facility management), $n \mathrm{D}$; qual o ROI previsto para o cliente; definição da equipe integrada e as responsabilidades de cada participante; e a definição sobre a propriedade do modelo computacional;

- projeto, onde inicia-se o desenvolvimento do modelo BIM, desde as primeiras ideias conceituais, considerando as análises preliminares sobre o modelo, passando pelo compartilhamento das informações entre todas as disciplinas, definição dos elementos principais do modelo - como o sistema estrutural - e a exportação das informações para o desenvolvimento do planejamento de execução;

- pré-construção, em que são elaborados os modelos mais detalhados do empreendimento e são feitas as análises mais precisas sobre modelo, coordenação e compartilhamento do modelo com os responsáveis pela execução e fabricação dos componentes, além do maior detalhamento do planejamento de execução;

- construção, com a definição do modelo final de execução e se for o caso, uso do modelo para controlar o planejamento (4D - tempo) e controlar e atualizar os custos de execução (5D - custo);

- uso, principalmente em relação à manutenção e controle das instalações de edifício, por meio das informações do modelo BIM executado; e 
- pesquisa e desenvolvimento, com o uso das informações do modelo para acompanhar o desempenho dos componentes do edifício e para avaliar o processo de produção para aprimorara os projetos futuros.

National BIM Standard (NBIMS) - Estados Unidos (2015)

O guia elaborado pelo National Institute of Building Sciences (2015b) indica não só o uso do BIM ao longo do processo de produção do empreendimento, mas também informações mais técnicas sobre o uso e compartilhamento das informações do modelo BIM.

Em relação à inserção do BIM, esse guia define diretrizes para a elaboração do Guia de Planejamento e Execução BIM (BIM Project Execution Planning Guide). Esse documento tem como objetivo orientar e informar aos participantes do processo de produção como será utilizado o BIM, bem como os requisitos para o modelo computacional e as responsabilidades de cada participante.

O guia (NATIONAL INSTITUTE OF BUILDING SCIENCE, 2015b) define quatro passos essenciais para e elaboração do Guia de Planejamento e Execução BIM:

- identificar usos de BIM que possam agregar alto valor à produção do empreendimento, durante as fases de planejamento, projeto, construção e operação;

- criar um mapa de execução do processo, incluindo as atividades que evolvam o BIM;

- definir as entregas do modelo BIM, bem como a troca de informações entre as disciplinas;

- desenvolver toda documentação dos procedimento, como contratos, regras de comunicação, uso da tecnologia e controle de qualidade.

Não existe um modelo para a inserção do BIM para todos os tipos de projeto, mas a documentação dos requisitos e usos do BIM é importante para favorecer a comunicação e a relação de confiança entre os membros da equipe, de forma que todos estejam cientes dos objetivos do empreendimento. O Guia de Planejamento e Execução BIM deve incluir todos os participantes que possuem um papel importante no desenvolvimento do empreendimento (NATIONAL INSTITUTE OF BUILDING SCIENCE, 2015b).

Com a definição dos usos do BIM no processo, é necessário definir quais as características de cada atividade: elemento, fase, disciplina, nível de detalhamento - LOD (Tabela 15). 
Tabela 15 - Características das atividades no processo BIM

\begin{tabular}{ll}
\hline Característica & Descrição \\
\hline Componente & $\begin{array}{l}\text { Qual o sistema de instalação o componente será desenvolvido } \\
\text { com o BIM. }\end{array}$ \\
Fase & $\begin{array}{l}\text { Qual a etapa do processo de produção o componente será } \\
\text { desenvolvido usando o BIM. }\end{array}$ \\
Disciplina & $\begin{array}{l}\text { Qual a disciplina responsável pelo desenvolvimento em BIM } \\
\text { desse componente. }\end{array}$ \\
Nível de detalhamento - LOD & Qual o nível de detalhe o componente deve ser desenvolvido. \\
\hline Fonte: NATIONAL INSTITUTE OF BUILDING SCIENCE, 2015b, tradução nossa.
\end{tabular}

Todas as informações definidas no Guia de Planejamento e Execução BIM devem constar no contrato do empreendimento. O guia ainda define outras características específicas para o contrato com o uso do BIM:

- o RFP definido pelo cliente deve conter os requisitos BIM, bem como ferramentas de avaliação para os processos de licitação dos profissionais e empresas;

- a linguagem do contrato deve ser clara para todos os participantes, com a definição de todos os termos técnicos relacionados ao BIM, como no caso do LOD requerido para cada etapa;

- os objetivos do processo de produção do empreendimento deve estar claro em relação ao uso do BIM; e

- identificação dos requisitos técnicos para a elaboração do modelo computacional, como versão dos softwares e extensão dos arquivos.

\section{BIM Handbook para o setor público - União Europeia (2016)}

O guia elaborado pela União Europeia foi desenvolvido para nortear as contratações públicas em relação ao uso do BIM e teve a participação de entidades públicas, usuários de edificações públicas e o setor de infraestrutura de mais de 20 países europeus (EUBIM, 2017).

As recomendações desse guia estão voltadas para definir estratégias para a difusão do BIM entre os países da União Europeia a partir do incentivo público. Esse guia descreve sobre as razões de incentivo ao uso do BIM, os benefícios esperados com o uso do BIM, como o setor público pode colaborar para o avanço do setor, as vantagens do incentivo público para o uso do BIM, além das definições básicas do BIM para equalizar as informações a nível europeu. 
De acordo com a publicação (EUBIM, 2017), as políticas governamentais e a definição de métodos de contratação pública para a difusão do BIM são instrumentos importantes para fomentar o aumento de qualidade no setor da construção civil. O Poder Público pode ser um dos líderes da transformação do setor por meio da transformação digital.

Foram definidas quatro áreas de atuação das estratégias para a difusão do BIM: política, aspectos técnicos, processo e pessoas. Cada área foi descrita quanto às suas características mínimas para a transição ao uso do BIM indicando quais medidas devem ser tomadas pelo Poder Público dos países da União Europeia. Esse guia utiliza estudos de caso bem-sucedidos dos países em que o uso do BIM se mostra mais difundido, como Reino Unido e Alemanha.

Em relação à política, o guia defende que o desenvolvimento de um protocolo de uso do BIM e um modelo de contrato que inclui os procedimentos para o desenvolvimento do modelo e uso dos dados de projeto, contribuem para o trabalho colaborativo. Ao estabelecer regras e objetivos comuns aos participantes, as incertezas em relação ao uso do BIM são reduzidas, mantendo o foco no desenvolvimento colaborativo do modelo computacional.

No caso dos aspectos técnicos, o guia aborda a importância do uso de formatos abertos dos modelos computacionais (open BIM). O uso de formatos não proprietários permite a interoperabilidade no processo de produção do empreendimento, sem especificar qual o software deve ser usado pelos participantes. Isso permite a diversidade no mercado dos desenvolvedores de softwares, contribuindo para a concorrência, que pode incentivar a busca constante de melhorias nos sistemas que trabalham com o BIM.

O incentivo ao trabalho colaborativo é a principal característica abordada na área de processo. Por meio do compartilhamento do modelo computacional entre todas as disciplinas do processo, mantém-se o fluxo contínuo do desenvolvimento do projeto em BIM e seu uso na etapa de execução. Para garantir a qualidade na troca de informações, é necessário definir regras para o compartilhamento do modelo, especificar quais as áreas de atuação de cada participante, bem como um sistema de gestão das alterações do modelo.

Em relação às pessoas, esse guia defende que é necessário definir a responsabilidade sobre a gestão dos dados e informações do modelo computacional. Dependendo da dimensão e complexidade do projeto a atividade de gestão pode ser acumulada com alguma atividade de desenvolvimento, como no caso do projetista, ou então essa atividade deve ser delegada exclusivamente a um agente externo à produção do empreendimento. 
Guia de Contratação BIM - Portugal (2017)

O guia editado pelo Instituto Superior Técnico da Universidade de Lisboa (COSTA; et al. 2017) é um documento que define as boas práticas para o uso do BIM pelas empresas, instituições e profissionais da construção civil, considerando todo o ciclo de vida do empreendimento. Nessa publicação são estabelecidas diretrizes para a contratação adequada dos serviços BIM, que incluem as informações normalmente presentes nos processos de contratação tradicionais e acrescentam as condições específicas do BIM.

Em relação aos contratantes, o guia estabelece as condições necessárias ao melhor uso do BIM no processo de produção a partir de três requisitos: comerciais, de gestão e técnicos. Esses requisitos são as condições mínimas que os profissionais ou empresas precisam ter para trabalharem com um método que utiliza o BIM.

No caso dos requisitos comerciais, deve-se incluir as informações referentes aos objetivos do contratante em relação ao uso do BIM, incluindo um planejamento que compreenda as principais entregas do processo. Deve ser especificada a abrangência do uso do BIM em relação às disciplinas, de forma a identificar quais habilidades os profissionais dever ter e quais as informações devem constar nos modelos BIM. Além disso, deve ser especificado pelo contratante o direito de propriedade sobre o projeto BIM. O guia sugere que a propriedade seja específica do contratante, ou seja, os autores do projeto só podem utilizar o modelo, parte dele ou seus estudos no contexto do contrato, caso contrário será necessário uma autorização do contratante.

Em relação aos requisitos de gestão, o guia define algumas atribuições que devem constar na equipe de trabalho, podendo ser exclusivas de um participante ou compartilhadas com outras tarefas:

- entidade contratante, que é o cliente do empreendimento e responsável pela contratação dos profissionais ou empresas;

- gestor do empreendimento, que deve auxiliar o cliente na contratação, coordenação e gestão do processo de execução do empreendimento;

- coordenador de projeto, que pode ser o autor de um dos projetos, ou um profissional que é responsável pela integração da equipe, garantindo a compatibilidade entre as disciplinas e o atendimento aos requisitos técnicos e legais; 
- diretor de obra, profissional ligado ao construtor, que deve assegurar a execução da obra, seguindo o planejamento do projeto e cumprindo as exigências legais de execução;

- diretor de fiscalização de obra, profissional ligado ao cliente, que é responsável por monitorar o processo de execução da obra;

- gestor BIM do empreendimento, que é responsável por facilitar o desenvolvimento e compartilhamento de informações durante o desenvolvimento do modelo BIM, favorecendo a integração em todo ciclo de vida do empreendimento; e

- prestadores de serviço, que são os profissionais e empresas responsáveis pelo desenvolvimento e execução do empreendimento, cada prestador de serviço deve nomear uma equipe para realizar a gestão BIM das atividades de sua disciplina.

Como existe uma diversidade de disciplinas e profissionais, além dos gestores do processo BIM, o guia recomenda que seja estabelecida a integração do processo desde o início do desenvolvimento do projeto e que acompanha o processo até o final. O contratante deve definir a forma de interação entre os participantes para que o uso do BIM mantenha um fluxo contínuo durante a produção do empreendimento.

Os requisitos técnicos definidos pelo Guia de Contratação BIM, aborda as questões específicas de execução do modelo BIM. Deve ser definido pelo contratante os procedimentos técnicos e os requisitos mínimos para que o modelo BIM possa ser compartilhado, sem prejudicar a coleta e análise dos dados. Dentre os requisitos estão: softwares e plataformas; formatos de troca de informações; levantamento e cadastro das informações existentes; sistema de coordenadas e referências; sistema de classificação e critérios de modelação; nível de desenvolvimento da informação (LOD); tolerâncias de modelação; nomenclaturas das informações de modelagem; e necessidade de formação técnica dos profissionais.

\section{Coletânea de Guias BIM - Brasil (2017)}

O Governo brasileiro publicou recentemente um conjunto de guias para favorecer a disseminação do BIM no país, visando disponibilizar informações claras e precisas sobre a inserção do BIM no processo de produção e na elaboração dos contratos. Os guias, voltados a profissionais dos setores público e privado, está dividido em seis partes: Guia 1 - Processo de projeto BIM; Guia 2 - Classificação da informação no BIM; Guia 3 - BIM na quantificação, orçamentação, planejamento e gestão de serviços da construção; Guia 4 - Contratação e elaboração de projetos BIM na arquitetura e engenharia; Guia 5 - Avaliação de desempenho 
energético em projetos BIM; e Guia 6 - A implantação de processos BIM (AGÊNCIA BRASILEIRA DE DESENVOLVIMENTO INDUSTRIAL, 2017a).

Em relação às alterações do processo com o uso do BIM, o Guia 4 (AGÊNCIA BRASILEIRA DE DESENVOLVIMENTO INDUSTRIAL, 2017b) aborda a questão da contratação dos profissionais e a definição dos requisitos para que todos os participantes tenham as informações necessária para desenvolver o projeto. Nesse documento são definidos os procedimentos para a elaboração do Plano de Execução BIM, que tem como objetivo organizar os processos ao longo da produção do empreendimento e definir as responsabilidades e o método de comunicação entre a equipe de trabalho.

Dentre as informações do plano, o guia indica que o contratante deve definir:

- relação de participantes do projeto, indicando quais os profissionais de projeto e execução estão envolvidos no processo;

- funções do projeto, indicando a responsabilidade de cada participante para cada etapa e em relação a cada disciplina do processo;

- organograma do projeto, para definir o grau de interação entre os participantes;

- instrumentos para colaboração, com a definição das diretrizes para o desenvolvimento do projeto e o sistema de colaboração do modelo BIM;

- responsabilidades no desenvolvimento dos elementos, em relação a cada etapa do processo;

- responsabilidades no desenvolvimento dos espaços, com a definição dos requisitos mínimos de desempenho de cada espaço e os profissionais responsáveis pelo desenvolvimento desses ambientes; e

- serviços e produtos, definindo os produtos finais de cada etapa de desenvolvimento do empreendimento.

O Guia 5 (AGÊNCIA BRASILEIRA DE DESENVOLVIMENTO INDUSTRIAL, 2017c), descreve que toda organização que tem o interesse de inserir o BIM no seu processo de produção deve estabelecer estratégias para realizar a mudança. Deve-se definir primeiramente a situação atual da empresa em relação aos métodos de execução do empreendimento para depois estabelecer as metas desejadas com o uso do BIM. Para isso é importante ter indicadores que possam ser usados para avaliar as alterações técnica e de processo necessárias para a mudança e os impactos do BIM no processo. 


\subsection{Interdependência das perspectivas da integração}

Ao analisar as perspectivas de integração do processo de produção, percebe-se que existe uma interdependência entre elas. As características de cada uma reforçam a busca por um processo sistêmico, em que as atividades de desenvolvimento do empreendimento fazem parte de um fluxo de informação, que se inicia com o projeto e culmina na entrega efetiva da construção.

Os sistemas de contrato que buscam a integração têm como fundamento antecipar a entrada dos agentes no processo, vinculando suas responsabilidades e mantendo um objetivo comum a toda a equipe. Ao estabelecer a forma de trabalho dos agentes no processo de produção, os contratos relacionais abordam questões de organização da equipe, ou seja, buscando a integração também sob a perspectiva organizacional. O mesmo acontece com a integração pela tecnologia da informação, pois a colaboração por meio do modelo computacional requer uma aproximação entre os agentes que utilizam o BIM.

Para investigar como ocorre a interdependência das perspectivas da integração foram analisados dois procedimentos que indicam as melhores práticas para estabelecer um processo de produção integrado: Lean Project Delivery System (LPDS) e Integrated Design and Delivery Solutions (IDDS).

Os procedimentos integrados de produção do empreendimento se caracterizam por indicar estratégias para integrar a produção da construção civil. Esses procedimentos determinam alguns instrumentos, principalmente referentes à questão organizacional, além de considerar outras práticas, como sistemas de contrato, sistema de seleção dos participantes e influência da tecnologia da informação na construção civil.

\subsubsection{Lean Project Delivery System (LPDS)}

O Lean Project Delivery System (LPDS) foi criado em 2000 a partir da inserção dos conceitos da Produção Enxuta - Lean Production - na indústria da construção civil. Ballard (2000; 2008) lista os seguintes princípios essenciais do LPDS:

- participação precoce de todos os agentes, possibilitando o desenvolvimento conjunto do projeto, por meio da formação de equipes multidisciplinares;

- gestão contínua, o empreendimento é estruturado como um processo e não somente a soma de etapas; o controle do projeto tem impacto sobre a execução, antecipando as possíveis divergências entre o que foi planejado e o que foi executado; 
- metas de custo, buscando otimizar o processo não só com o aumento da produtividade, mas com o estabelecimento de um fluxo de trabalho baseado no planejamento;

- definição precoce do fluxo de materiais, por meio de redes de cooperação entre os agentes, de forma que a definição das necessidades é antecipada;

- redução e eliminação dos desperdícios, por meio da exclusão das atividades que não agregam valor, possibilitando um fluxo contínuo na execução das atividades; e

- retroalimentação, em todas as etapas do processo, possibilitando aprimorar o desenvolvimento das atividades.

O processo de produção proposto por Ballard (2000) é composto por cinco fases: definição do empreendimento; projeto Lean; fornecimento Lean; montagem Lean; e uso. Cada fase é definida por uma série de três atividades, que formam grupos que se sobrepõem. Essa sobreposição representa a interdependência entre as fases, que influenciam umas às outras e se beneficiam do trabalho colaborativo da equipe (Figura 13).

Figura 13 - Processo de produção pelo Lean Project Delivery System

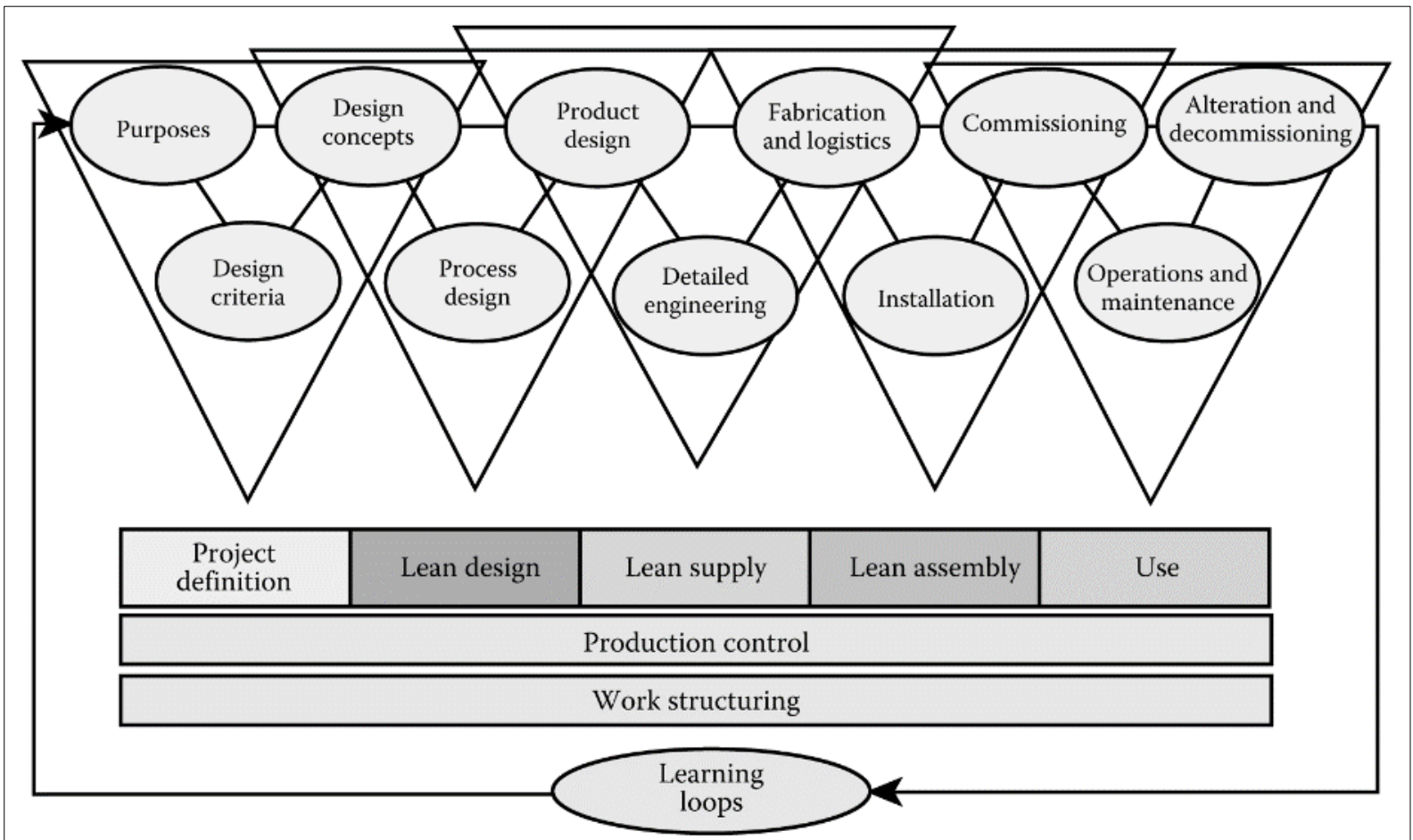

Fonte: FORBES; AHMED, 2011, tradução nossa.

Forbes e Ahmed (2011) detalharam cada uma dessas fases. Na definição do empreendimento, são desenvolvidas alternativas de projeto no nível conceitual, com a análise dos riscos, custo e planejamento. Essa fase é realizada por meio da colaboração de toda a equipe com o cliente e 
compreende as seguintes atividades: definição do objetivo do empreendimento, suas necessidades e valores; elaboração dos requisitos de projeto; e desenvolvimento do projeto conceitual.

A segunda fase, denominada projeto Lean, compreende o aprofundamento das informações do projeto conceitual, além do planejamento de execução do projeto e do projeto do produto. No LPDS o projeto é desenvolvido não apenas como um produto para a execução, mas também como um processo de execução. Nessa fase, questões de construtibilidade e geração de valor são avaliadas de maneira integrada pela equipe, que é composta por arquitetos, engenheiros, construtores, especialistas.

O fornecimento Lean compreende a terceira fase do processo e integra as atividades de projeto do produto; detalhamento da engenharia; e fabricação e logística. Nessa fase, todos os elementos necessários para a execução são definidos, bem como os momentos eles serão utilizados no canteiro. Com a aproximação entre projeto e execução, o LPDS permite que o fluxo planejado das atividades tenha informações coerentes com a realidade, o que possibilita vincular fluxo de produção com o fornecimento de materiais.

A fase de montagem Lean compreende a etapa de execução do empreendimento. Nela é realizada também a atividade de fornecimento de materiais, além das seguintes atividades: execução; e comissionamento, que garante que todos os sistemas instalados na edificação estejam funcionando de acordo com os requisitos do cliente.

A última fase do LPDS compreende o uso do empreendimento. Além da atividade de comissionamento, integram nessa fase a operação e manutenção, além das futuras atividades após a finalização do uso, como alteração, reforma ou demolição.

Após a entrega do empreendimento, Ballard (2008) propõe a retroalimentação do processo loop de aprendizagem - possibilitando aos participantes aperfeiçoar as soluções de projeto para os próximos empreendimentos. Além disso, é previsto o controle de produção e estruturação do trabalho, que proporcionam ao cliente e aos próprios agentes um maior controle sobre o processo.

O relatório elaborado para o Construction Industry Institute - CII (BALLARD; et al., 2007) determina cinco grandes áreas para a aplicação dos princípios do Lean na construção:

- foco no usuário, que inclui desenvolver o valor do empreendimento a partir dos requisitos do cliente, utilizando recursos e planejamento flexíveis; 
- cultura e pessoas, que inclui treinar toda a equipe, dar poder e autonomia aos participantes, garantir o comprometimento com a gestão, e trabalhar em conjunto com os fornecedores e subcontratados;

- organização e padronização do ambiente de trabalho, que considera inserir ferramentas para antecipar e evitar os erros, definir o processo de trabalho, elaborar planejamento de logística, transporte de material e estoque;

- eliminação do desperdício, que compreende suprimir a sobreposição de atividades e sincronizar os fluxos de atividades, que resultaria na elaboração confiável do planejamento de custo e prazo, e redução dos intervalos entre as atividades; e

- aperfeiçoamento contínuo e qualidade do edifício, que inclui utilizar métricas para avaliar o desempenho, criar uma resposta padrão aos problemas, e estabelecer um ambiente que desenvolva o senso de responsabilidade pela qualidade nos participantes.

Com o uso do LPDS, Forbes e Ahmed (2011) citam os seguintes benefícios ao processo de produção e ao empreendimento: redução no custo; poucos atrasos; menos incertezas; menor desperdício; edificações e sistemas mais eficientes; e maior satisfação do cliente. Os autores indicam que esse método possibilita o melhor aproveitamento dos recursos, principalmente, mão de obra e materiais. O LPDS pode aperfeiçoar principalmente a produção de empreendimentos complexos, que possuem muitas incertezas e prazos de execução muito rígidos.

Em relação ao sistema contratual, Forbes e Ahmed (2011) indicam que não existe um contrato específico para a aplicação dos conceitos do LPDS; no entanto, os princípios essenciais desse procedimento remetem ao tipo relacional. Para os autores, é necessário entender e aplicar os instrumentos básicos dos contratos relacionais para um bom resultado na inserção do LPDS. Alguns estudos de caso publicados por Forbes e Ahmed (2011) utilizaram o IPD como forma de contratação da equipe.

Em relação à integração da tecnologia da informação, Ballard (2000) indicou desde o primeiro documento sobre o LPDS a necessidade de se considerar a tecnologia para aperfeiçoar o processo de desenvolvimento do projeto. Com o avanço dos processos de modelagem computacional voltados à colaboração, Ballard (2008) passou a considerar que o uso da modelagem 3D possibilita estabelecer um trabalho colaborativo muito mais eficiente no LPDS. De acordo com Sacks et al. (2010), os procedimentos do LPDS são independentes do BIM, ou seja, as práticas do Lean podem ser aplicadas nos processos da construção sem o uso do BIM. No entanto, ao associar os princípios do Lean com as funcionalidades do BIM descritas na 
literatura, os autores identificaram 56 interações entre eles, o que indica que ambos procedimentos promovem mudanças no desenvolvimento da construção, considerando a gestão da informação, o que traz benefícios à produção do edifício.

Forbes e Ahmed (2011), também indicam que os procedimentos, que visam incluir a tecnologia da informação na integração do processo de produção, estão alinhados com os conceitos do LPDS. Dentre os procedimentos destaca-se o BIM, que possibilita aperfeiçoar o desenvolvimento do projeto:

- pela redução do desperdício e de atividades que não agregam valor ao empreendimento, por meio da automatização de alguns processos de projeto, como elaboração dos desenhos de representação do edifício e análises de desempenho;

- por permitir a colaboração de diferentes profissionais no desenvolvimento do modelo computacional;

- por facilitar a definição de uma meta de custo para o empreendimento, de forma mais precisa garantindo a confiabilidade nas informações geradas pelo modelo;

- pela facilidade na detecção de interferências entre as disciplinas, o que favorece o trabalho colaborativo; e

- por permitir o fluxo contínuo das informações, benefício que pode ser usado para favorecer o uso de sistemas construtivos pré-fabricados, pois o modelo computacional do componente pode ser compartilhado diretamente para o processo de fabricação, sem a necessidade de elaborar documentação digital ou impressa.

O tipo de sistema construtivo não é definido pelo LPDS; no entanto algumas características desse procedimento estão alinhadas com o uso da industrialização da construção. Segundo Forbes e Ahmed (2011), o uso da construção industrializada pode reduzir a fragmentação do processo de produção, não só pela pré-fabricação mas pela racionalização do processo de construção. Uma das oportunidades identificadas no LPDS é a organização do empreendimento como um sistema de produção, que pode ser facilitada pela pré-fabricação, modulação e a coordenação entre as atividades de desenvolvimento do projeto e fabricação dos componentes construtivos. 


\subsubsection{Integrated Design and Delivery Solutions (IDDS)}

O Integrated Design and Delivery Solutions (IDDS) foi criado pelo International Council for Research and Innovation in Building and Construction (CIB) no ano de 2004 e passou a compor um dos temas priortários desse grupo (OWEN, 2009).

O IDDS utiliza o trabalho colaborativo, o aprimoramento de habilidades pessoais, gestão do conhecimento, integração de dados e informações e sistemas de contrato transparentes com a gestão de riscos, para minimizar as ineficiências estruturais e de processo na construção civil. O objetivo do IDDS é aumentar o valor do empreendimento, durante o projeto, execução e operação, reduzindo custo e prazo de produção (OWEN, 2009).

O CIB (INTERNATIONAL COUNCIL FOR RESEARCH AND INNOVATION IN BUILDING AND CONSTRUCTION, 2013) destaca que, para a aplicação do IDDS, é necessário compreender o empreendimento a partir de uma visão sistêmica, desde a idealização do projeto até a demolição ou reabilitação do edifício para um novo uso. Ele também estabelece três áreas essenciais e interdependentes para a aplicação dos princípios do IDDS: processo, tecnologia e pessoas.

Segundo Owen (2009), a integração do processo de trabalho está dividida em três setores:

- integração do planejamento, onde são definidos os objetivos globais do empreendimento e não de cada uma das especialidades individualmente;

- integração do projeto, o que permite a elaboração de múltiplas alternativas de desenho e soluções, além da coordenação entre as diversas interfaces do projeto; e

- integração da cadeia de fornecedores, que permite a inclusão do conhecimento técnico dos fornecedores e especialistas ao longo do processo, considerando a definição do desempenho dos sistemas e as atividades de operação e manutenção.

Em relação à área tecnológica, Owen (2009) descreve que tecnologias adequadas e instrumentos para a colaboração e automação são essenciais para a viabilidade do processo integrado. Entre os instrumentos estão: interação entre as informações sobre a geometria do edifício, o canteiro de obras e as entregas dos componentes e materiais de construção; visualização 4D, que insere a variável do tempo no modelo virtual; prototipagem virtual; transparência, interoperabilidade e confiança na troca de dados; e automação da produção de componentes e da montagem na obra.

$\mathrm{Na}$ área que abrange as pessoas, o IDDS prevê que dentro da equipe alguns agentes são essenciais para que o trabalho integrado seja efetivo, como: líder técnico, líder de integração e 
os gestores de produção. Esses participantes são responsáveis por treinar e desenvolver as habilidades necessárias nos demais. Além disso é preciso definir nos contratos, procedimentos que favoreçam o ambiente colaborativo da equipe, mantendo objetivos comuns aos profissionais e a confiança na troca de informações.

Owen (2009), define quatro principais instrumentos para garantir a execução dos princípios estabelecidos nas três áreas essenciais:

- processo colaborativo, a colaboração deve ocorrer ao longo de todo processo de produção e entre todos os níveis de interação dos participantes;

- aperfeiçoamento de habilidades, não somente técnicas, mas habilidades que promovam o trabalho integrado da equipe, permitindo o compartilhamento de conhecimento entre as diferentes disciplinas;

- integração das informações e sistemas automáticos, que garantam trocas seguras de dados e informações do modelo virtual, sem dificultar o processo de produção; e

- gestão do conhecimento, dando acesso a todos os participantes às informações referentes aos procedimentos realizados na produção de um empreendimento, possibilitando a retroalimentação do processo e garantindo um processo contínuo de aprendizado.

Nederveen, Beheshti e Ridder (2010), indicaram as tendências de mudanças da indústria da construção civil, desde o processo sequencial até o IDDS (Tabela 16).

Tabela 16 - Tendência de mudança da indústria da construção

\begin{tabular}{ll}
\hline De: Projeto e processo de produção segmentados & Para: Integrated Design and Delivery Solutions \\
\hline Lucro de curto prazo & Serviços do mercado orientados na criação de valor \\
Cadeia de fornecedores segmentada & Cadeia de valor integrada \\
Envolvimento dos participantes (atores diretos) & Envolvimento de todos os participantes \\
Foco no controle do custo & Foco na produção de benefícios \\
Gestão de risco anterior ao processo & Gestão de risco durante o processo \\
Competição com base no preço e especificações fixas & Competição com base nos conceitos de inovação \\
Comportamento reativo e oportunista & Comportamento proativo e de aprendizagem \\
\hline
\end{tabular}

Fonte: NEDERVEEN; BEHESHTI; RIDDER, 2010, tradução nossa.

O CIB (INTERNATIONAL COUNCIL FOR RESEARCH AND INNOVATION IN BUILDING AND CONSTRUCTION, 2013) destaca que, com o IDDS, os processos de produção se tornam mais eficientes, ou seja, os tempos de espera entre as trocas de informações 
são eliminados e o trabalho colaborativo entre os participantes garantem uma maior qualidade ao desenvolvimento do projeto.

Owen et al. (2010) também indica os benefícios que podem ser alcançados com o IDDS: redução no prazo de produção, custo final e quantidade de materiais utilizados na execução; melhorias na qualidade e desempenho dos sistemas que compõem o empreendimento; otimização dos produtos, considerando os projetos e a própria edificação; e melhor reputação dos profissionais e empresas participantes do processo.

De acordo com Owen et al. (2010), o processo de produção integrado com o uso dos princípios do IDDS possibilita aumentar a eficiência da obra. Como questões de execução são consideradas desde o início de desenvolvimento do projeto, por meio da integração da cadeia de fornecedores e do trabalho colaborativo, é possível antecipar as soluções para a compatibilização dos sistemas prediais. Além disso, é possível analisar diversas alternativas para o planejamento da execução, de forma a escolher a que seja mais eficiente, reduzindo as perdas e desperdício de material durante a obra.

Portanto, percebe-se que tanto o LPDS quanto o IDDS abordam as três perspectivas da integração - contratual, organizacional e de tecnologia da informação. Os dois procedimentos indicam que é necessário rever todo o processo de produção para que a integração seja efetiva. As alterações em uma perspectiva indicam sua correlação nas demais, por exemplo o trabalho colaborativo e multidisciplinar está vinculado ao uso da integração da tecnologia da informação e, consequentemente, às formas de contrato estabelecidas no processo.

Além disso, os dois procedimentos indicam as vantagens da integração para a industrialização da construção. Isso ocorre de forma explícita no caso do LPDS, com a indicação pelo uso intensivo da pré-fabricação e de técnicas de racionalização; e de maneira indireta pelo IDDS, que considera a eficiência da execução como consequência da antecipação do planejamento e de questões construtivas, desde a elaboração do projeto. 


\section{ANÁLISE DAS PERSPECTIVAS DE INTEGRAÇÃO E SUAS INTERDEPENDÊNCIAS}

Para melhor compreender como ocorre a integração no processo de produção do empreendimento, foram elaborados diagramas para cada perspectiva de integração identificada nesta pesquisa: contratual, organizacional e de tecnologia da informação.

As características do processo de produção são descritas na literatura (EMMITT; GORSE, 2006; MOLENAAR; SOBIN, 2009; EASTMAN; et al., 2011; FORBES; AHMED, 2011; SCHEEPBOUWER; HUMPHRIES, 2011; LAHDENPERÄ, 2012; EL ASMAR; HANNA; LOH, 2015) geralmente na forma textual, o que torna difícil sua análise e comparação. Com a análise da integração a partir de uma ferramenta predominantemente visual, como é o caso dos diagramas, é possível identificar com mais facilidade as relações entre os participantes e as interações entre as disciplinas.

\subsection{Integração Contratual}

Os modelos de diagramas desenvolvidos pelo AIA (AMERICAN INSTITUTE OF ARCHITECTS, 2014) subdivide os tipos de contratação entre tradicional e integrado (Figura 8). O primeiro modelo pode ser inferido como o contrato transacional Design-Bid-Build (DBB), em que cada profissional participa apenas das atividades de sua responsabilidade e existe uma etapa específica para a licitação do construtor. O segundo modelo se assemelha às características do modelo relacional Integrated Project Delivery (IPD), que considera a participação precoce de todos os agentes, inclusive os órgãos de regulação.

Os diagramas do AIA (AMERICAN INSTITUTE OF ARCHITECTS, 2014) indicam as fases do processo de produção do empreendimento; o momento de participação de cada agente; e o início e fim das principais tomadas de decisão. O momento em que as principais decisões são tomadas, influencia na qualidade e eficiência do processo:

- o que, representa todas as características do empreendimento, ou seja, todos os requisitos físicos, funcionais e de desempenho, considerando desde as informações mais abrangentes, como o programa de necessidades, até os detalhes construtivos;

- como, que indica as técnicas e métodos de execução do empreendimento; e

- quem, que indica os participantes responsáveis pela execução. 
Os diagramas do AIA (AMERICAN INSTITUTE OF ARCHITECTS, 2014) representam situações extremas dos sistemas transacional e relacional. O caso transacional intitulado "Processo de Produção Tradicional" corresponde ao Design-Bid-Build (DBB) e o caso intitulado "Processo de Produção Integrado" corresponde ao Integrated Project Delivery (IPD). Usando como referência os diagrama do AIA, foram desenvolvidos diagramas para os outros tipos de contrato - Design and Build (DB) e Construction Management at Risk (CMAR), na categoria de transacional; e, Project Partnering (PP), Project Alliancing (PA) e Early Contractor Involvement (ECI), na categoria relacional (Figura 14).

Pode-se considerar três etapas principais do processo de produção do empreendimento, que estão representadas no diagrama de acordo com sua sequência de execução, sem considerar a escala do tempo:

- planejamento, onde são definidas todas as informações necessárias para desenvolver o produto e o estudo de viabilidade;

- desenvolvimento, que compreende todas as atividades que transformam os dados do planejamento em um produto executável, desde o estudo preliminar até o detalhamento do projeto, que possui todas as informações necessárias para iniciar a execução; e

- execução, que consiste na organização e execução da obra.

Considerou-se os seguintes agentes como os principais no processo de produção da construção civil:

- cliente, que é responsável pelo início do processo e é o agente que prioritariamente determina os requisitos e parâmetros para o empreendimento;

- projetista, que é o agente ou grupo de profissionais responsável por transformar a demanda do cliente em um projeto, desde o desenvolvimento do projeto arquitetônico até os projetos complementares, que representam os sistemas prediais; e

- construtor, que é responsável pela execução do empreendimento.

- órgãos reguladores, que representam os setores públicos que regulamentam a construção civil, como prefeituras, vigilância sanitária e corpo de bombeiros; e 
- especialistas da execução, que são profissionais ou empresas que atuam em uma área específica do empreendimento, como instalações elétricas, hidráulicas ou de arcondicionado.

Figura 14 - Comparação entre os contratos transacionais e relacionais

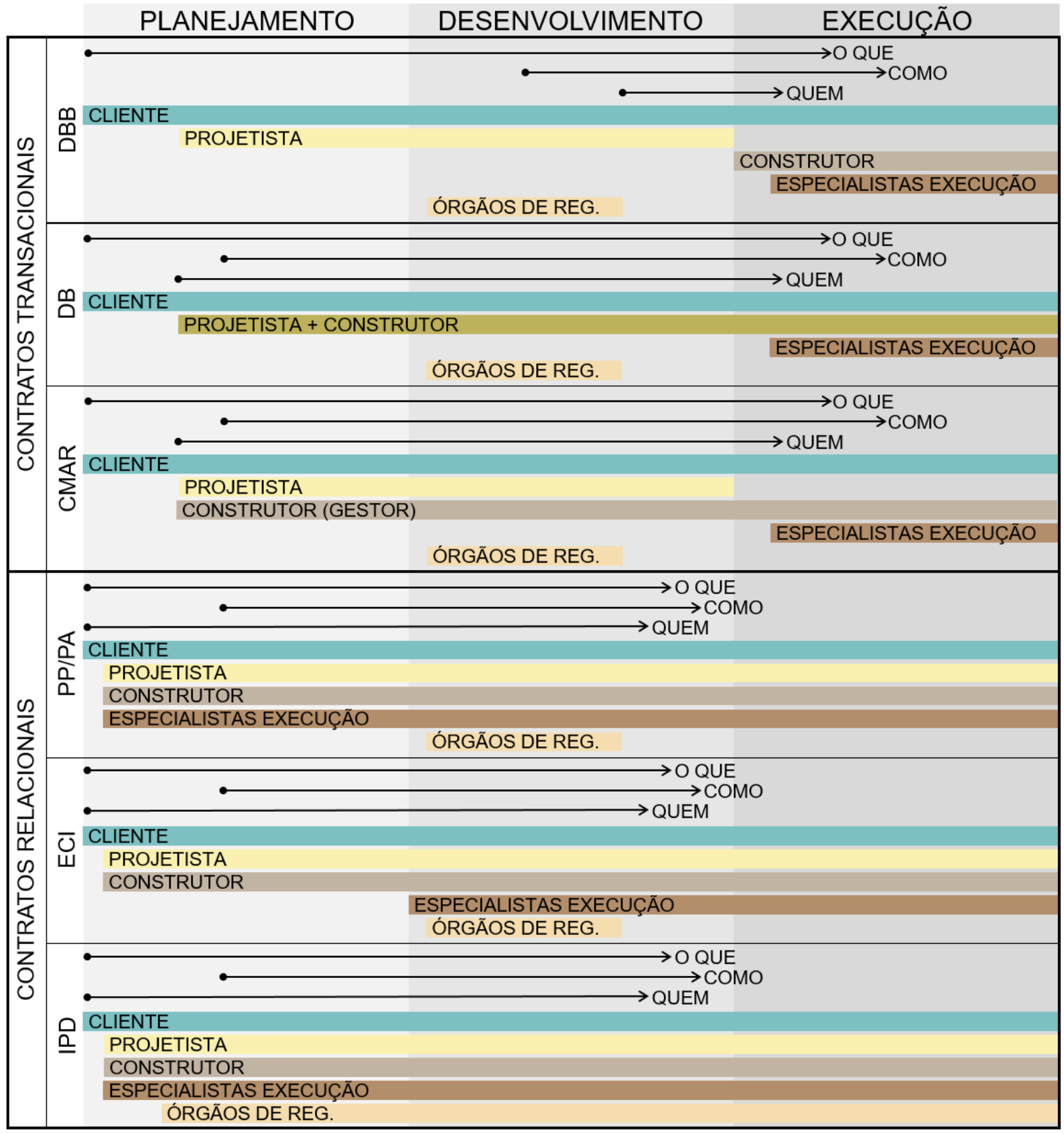

Fonte: Elaborado pela autora.

O gestor do processo foi considerado no caso em que o modelo de contrato indica a obrigatoriedade de sua presença no processo de produção, o que acontece no CMAR. Nos demais tipos de contrato esse agente pode ou não participar do processo, sendo que a decisão 
por sua contratação está definida pelo tipo de organização definido pelo cliente e não pelas regras de contratação estabelecidas pelos modelos de contrato.

A associação do projetista com o construtor no DB e a antecipação da participação do construtor, como um gestor do processo, no CMAR, possibilitam que as decisões de como e quem sejam antecipadas, o que indica que existe um trabalho colaborativo entre as disciplinas de projeto e execução. Isso indica que existe um nível de integração maior nos modelos de contrato DB e CMAR, se comparado ao DBB.

Em todos os contratos transacionais, os finais de todas as tomadas de decisão avançam sobre a etapa de execução, devido à inserção tardia dos especialistas de execução, em todos os métodos. No caso do DBB, isso ocorre também pela entrada tardia do construtor.

Os benefícios do DB e CMAR ao processo de produção são parciais, pois os especialistas de execução não são considerados nas etapas iniciais em nenhum dos casos. Somente a participação precoce do construtor não garante a definição de todas as tomadas de decisão antes do início da execução. Dessa forma, durante a etapa de execução da obra podem existir atividades relativas ao desenvolvimento do projeto, resultando no aumento de prazo e custo do empreendimento, com redução da qualidade do edifício.

Ao inserir precocemente todos os agentes do processo, inclusive os órgãos de regulação, o IPD estabelece um ambiente colaborativo em todos os níveis do projeto. Os modelos de contrato ECI, PP e PA - não consideram os órgãos de regulação como um agente da equipe do empreendimento, de forma que sua participação acontece como nos contratos transacionais, ou seja, apenas na atividade de aprovação do projeto.

Dentre os contratos relacionais, o ECI apresenta como diferença a entrada posterior dos especialistas de execução. Apesar de ser o último profissional a fazer parte da equipe do empreendimento, sua participação ocorre ainda na etapa de desenvolvimento de projeto, o que garante que as tomadas de decisão não aconteçam na execução da obra.

Faz-se necessário aumentar o nível de detalhamento do fluxo do processo de produção do empreendimento para compreender melhor as diferenças entre os tipos de contrato, sucessivamente, até que suas diferenças fiquem explicitadas. É necessário entender como cada agente interage em cada etapa do processo, ou seja, quais as suas responsabilidades e quais as possíveis interações entre as disciplinas.

Para isso, foi utilizada a notação do Business Process Model and Notation (BPMN) de forma a determinar a sequência das atividades, as responsabilidades dos agentes em cada etapa, os 
momentos em que são estabelecidos os contratos e as trocas de informação durante o processo. Algumas especificações foram adaptadas para o propósito desta pesquisa e os símbolos utilizados estão indicados na Figura 15. Em cada diagrama foram indicados os principais agentes ou grupo de profissionais que vão influenciar nas tomadas de decisão do processo (Figura 16).

Figura 15 - Legenda dos diagramas dos métodos de produção dos empreendimentos

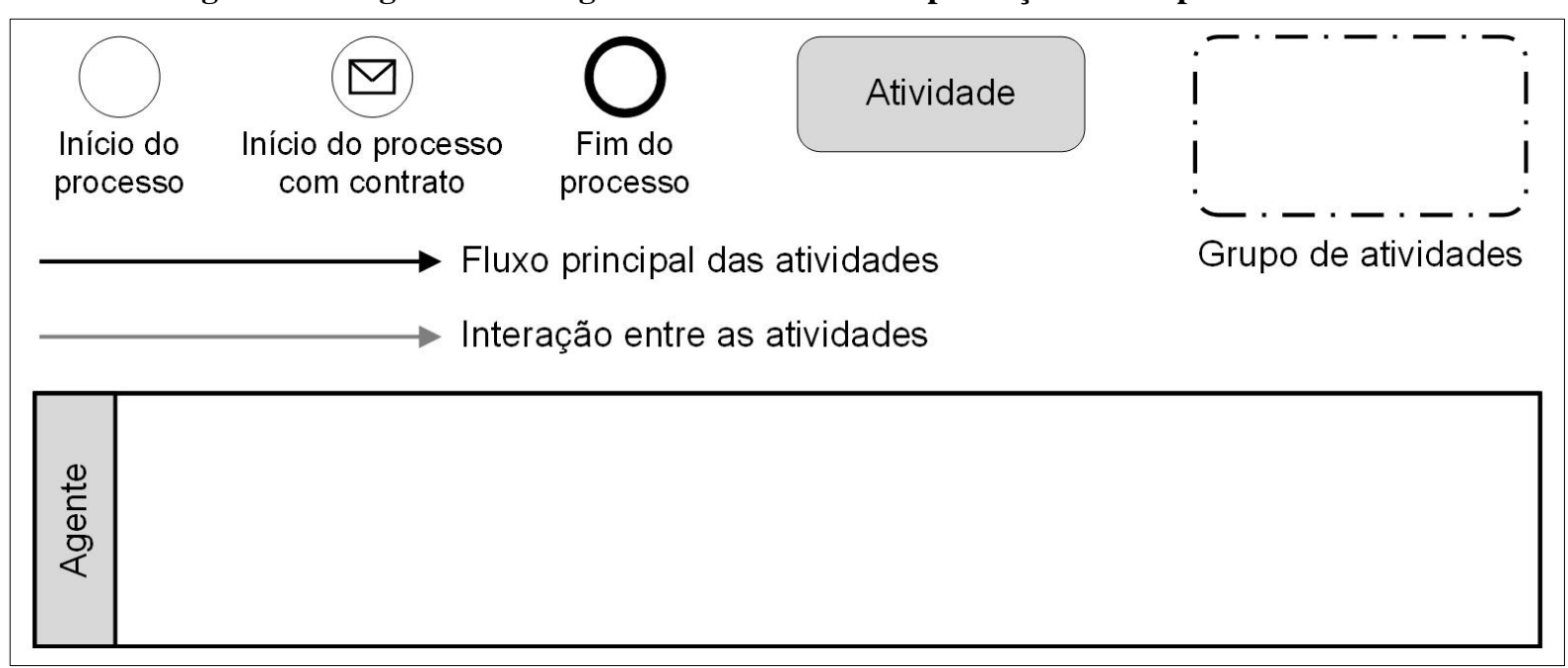

Fonte: Elaborado pela autora.

Figura 16 - Síntese do processo de produção utilizado na elaboração dos diagramas de integração contratual

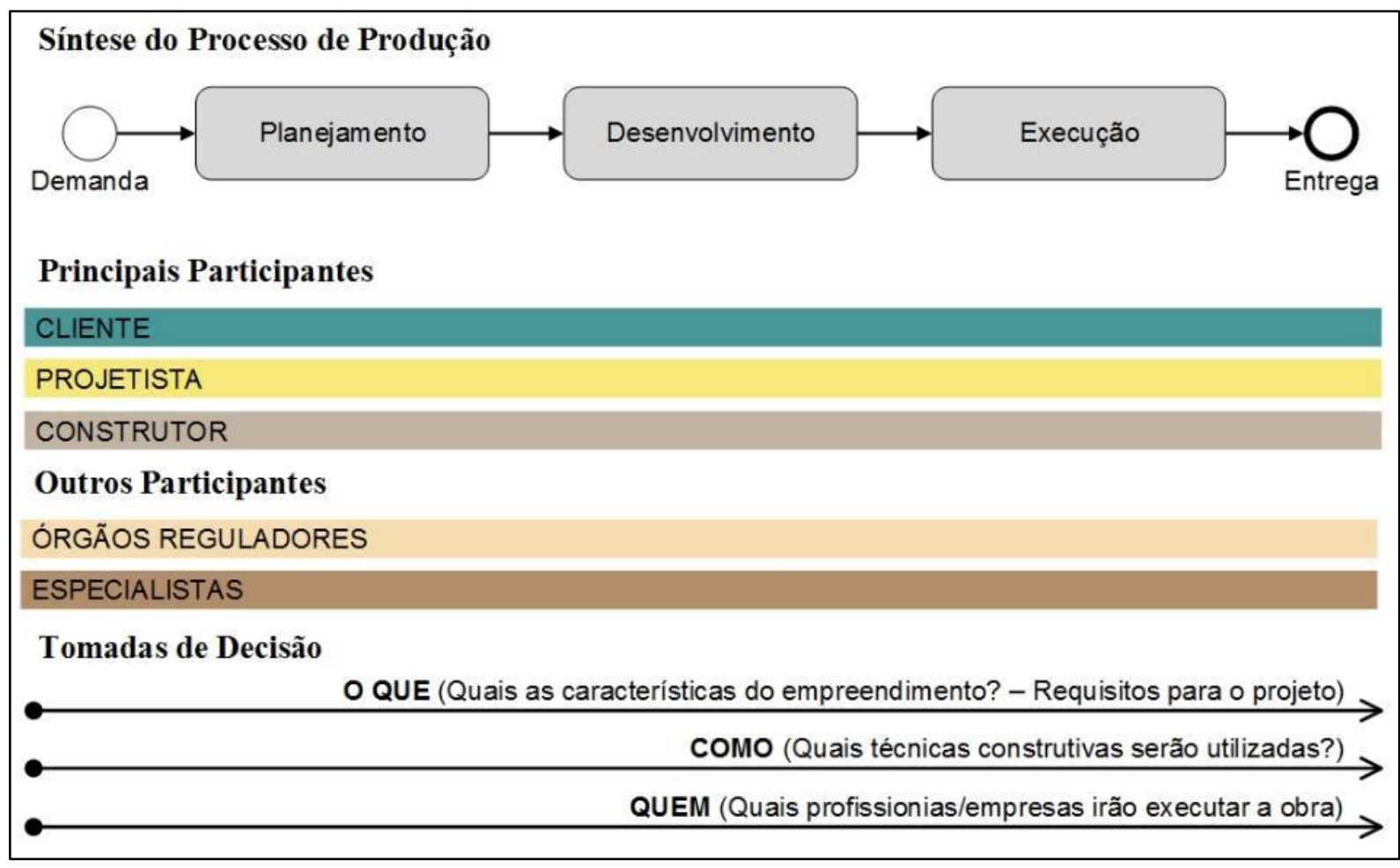

Fonte: Elaborado pela autora. 
Para esta pesquisa, considerou-se que o início do processo ocorre a partir da demanda do cliente e seu término com a entrega do empreendimento. Não foram consideradas as etapas posteriores à entrega, que consistem na gestão do empreendimento - uso, operação e manutenção - e encerramento das atividades - reforma, reabilitação ou demolição -, pois o foco dessa pesquisa é o processo de produção, ou seja, os métodos utilizados para transformar a demanda do cliente em uma edificação. Considera-se que as etapas posteriores à entrega possuem particularidades que as caracterizam como o início de um novo processo.

As colunas indicativas das etapas dos diagramas da Figura 14 foram substituídas por atividades na notação BPMN. Isto decorreu da necessidade de se explicitar o início, a sequência e o término dessas etapas, e também as interações entre os agentes. Além disso, foi necessário inserir a atividade sob responsabilidade dos órgãos de regulação - aprovação.

Esse detalhamento permitiu explicitar o momento de contratação de cada agente; a forma como é estabelecido cada contrato - bilateral ou multilateral; e as possibilidades de colaboração entre os profissionais.

\subsubsection{Primeiro nível de detalhamento dos contratos transacionais}

Ao considerar as etapas do processo de produção como atividades, foi possível identificar melhor as diferenças dos modelos de contrato e os motivos pelos quais ocorrem o início e o fim das tomadas de decisão. Cabe observar que apenas os elementos pertinentes à contratação e a interação entre os agentes estão indicados. Não são explicitados em detalhe as trocas de outros documentos, em especial os referentes ao projeto em si.

No diagrama da Figura 17, que representa o DBB, percebe-se que a segmentação no desenvolvimento do empreendimento acontece pela contratação dos agentes apenas nas atividades em que eles são responsáveis, que está explicitado nos eventos de "início do processo com contrato" e de "fim do processo" que regem o fluxo das atividades.

A entrada do projetista no processo tem início com o evento "Contrato Projeto" e o parecer dos órgãos de regulação tem início, posteriormente, com o recebimento do "Projeto Legal". A entrada dos responsáveis pela execução se dá após o final da participação dos projetistas e dos órgãos de regulação, sendo que o construtor entra no momento do "Contrato Execução" e os especialistas no "Contrato Especialistas", já com a execução em andamento, por meio da subcontratação por parte do construtor. 
Figura 17 - Diagrama com primeiro nível de detalhamento do Design-Bid-Build

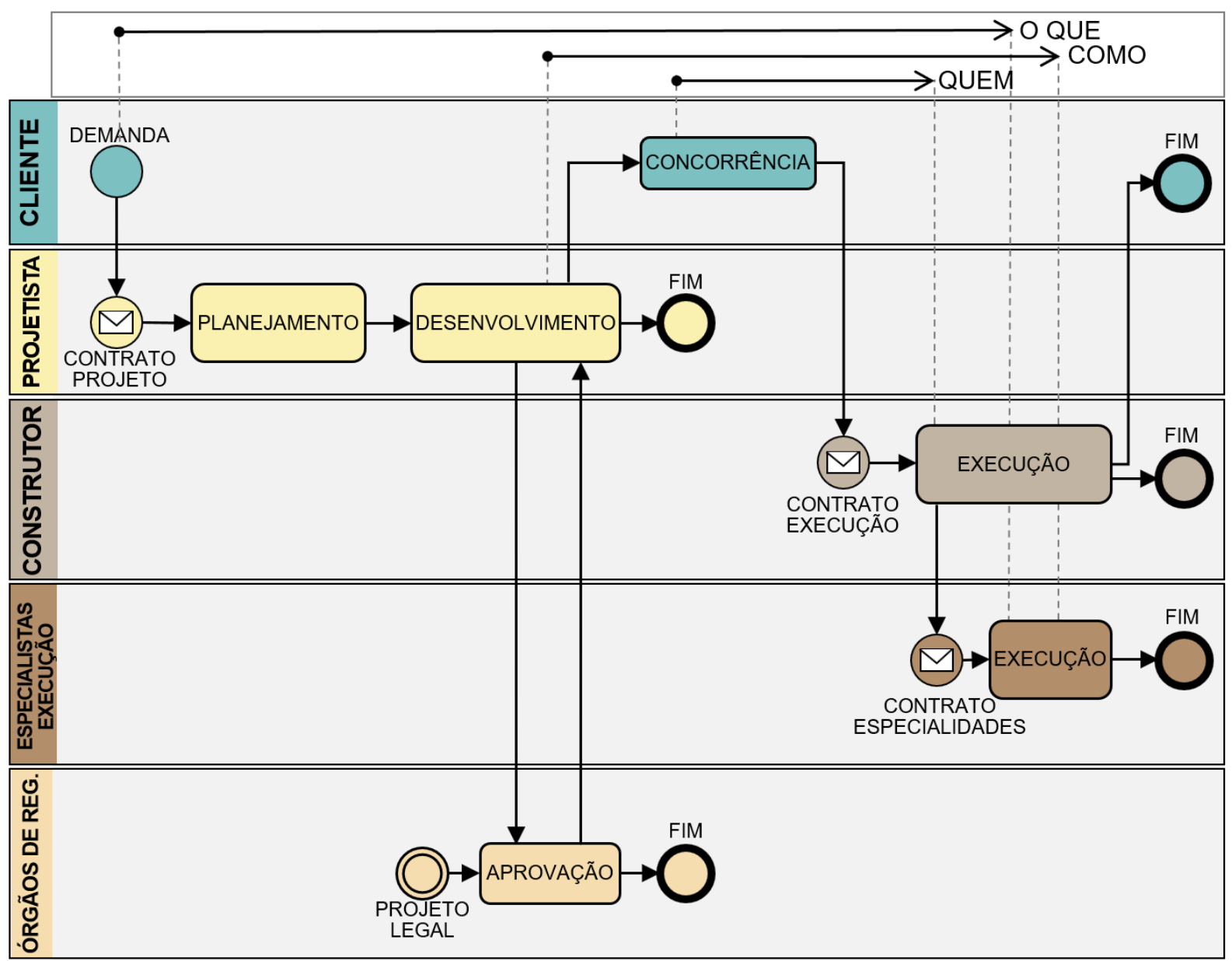

Fonte: Elaborado pela autora.

No caso do cliente, sua participação no processo não é contínua, mas sim dependente das entregas dos demais profissionais. O cliente fica responsável por estabelecer os contratos com o projetista e o construtor, além de realizar a concorrência para dar início à etapa de execução. A atividade de concorrência determina a transição entre as etapas de projeto e execução.

Como a participação do projetista e dos profissionais de execução não se sobrepõem, não existe possibilidade de colaboração entre esses agentes no DBB. Questões relacionadas à execução não são consideradas durante o planejamento e em grande parte da etapa de desenvolvimento. Como consequência, as decisões são tomadas tardiamente no processo.

No diagrama do DB (Figura 18) a associação entre o projetista e o construtor permite a aproximação entre as etapas de projeto e execução, a partir da colaboração ${ }^{6}$ recíproca entre o

\footnotetext{
${ }^{6}$ No diagrama da Figura 23, e subsequentes, tal colaboração é representada de forma simplificada. A borda pontilhada indica que "colaboração" não é uma atividade, mas sim uma indicação da participação de um agente (colaborador) concomitantemente a uma atividade sob a responsabilidade de outro agente (executor). A complexidade das interações, que possam ocorrer simultaneamente entre os agentes durante a colaboração, poderia
} 
projetista e o construtor. Tanto o projetista quanto o construtor participam do início ao fim do processo.

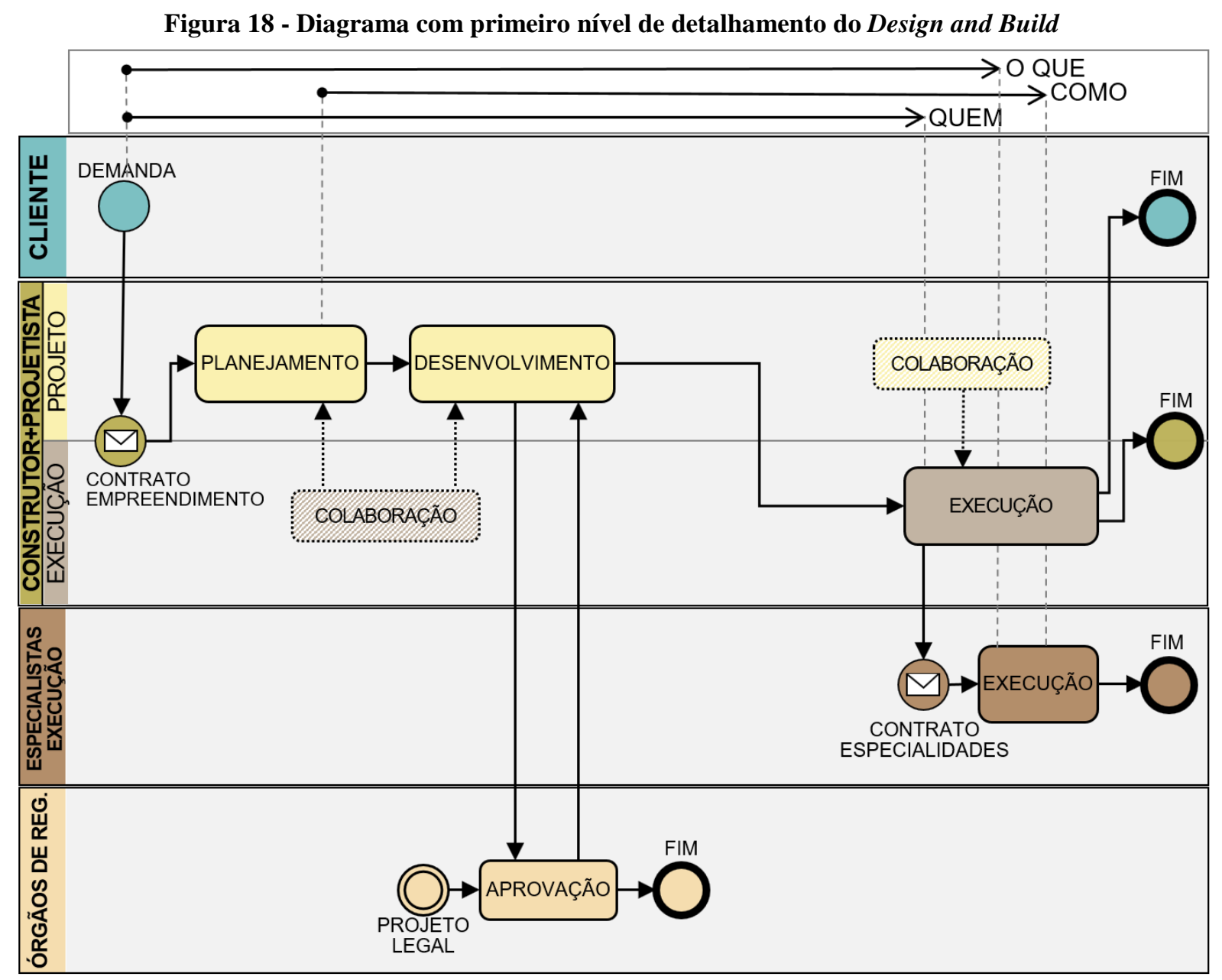

Fonte: Elaborado pela autora.

Um contrato único, identificado como "Contrato Empreendimento", estabelecido pelo cliente é o motivo da antecipação do início da decisão sobre quem executará o empreendimento. A atividade de colaboração do construtor justifica a antecipação sobre a decisão de quais métodos construtivos serão utilizados - como. No entanto, o cliente se distancia do desenvolvimento do processo, sendo que o início da sua participação acontece com a "Demanda", seguida da escolha e contratação do projetista-construtor, e tem fim com a entrega da obra pelo construtor. Isso indica que existe uma grande responsabilidade deste agente sobre a elaboração dos requisitos de projeto especificados no contrato.

ser representada por meio de trocas de mensagens e conversas entre os participantes, o que não contribuiria para a análise que se deseja fazer. 
A Figura 19 indica o diagrama do CMAR e ilustra a antecipação da participação do construtor, como um gestor, durante o planejamento e desenvolvimento do projeto. Apesar da participação do cliente nesse tipo de contrato ser semelhante ao DB, o papel de gestor do construtor indica que ele é o representante do cliente no processo, sendo que as tomadas de decisão são validadas em cada atividade.

Figura 19 - Diagrama com primeiro nível de detalhamento do Construction Management at Risk

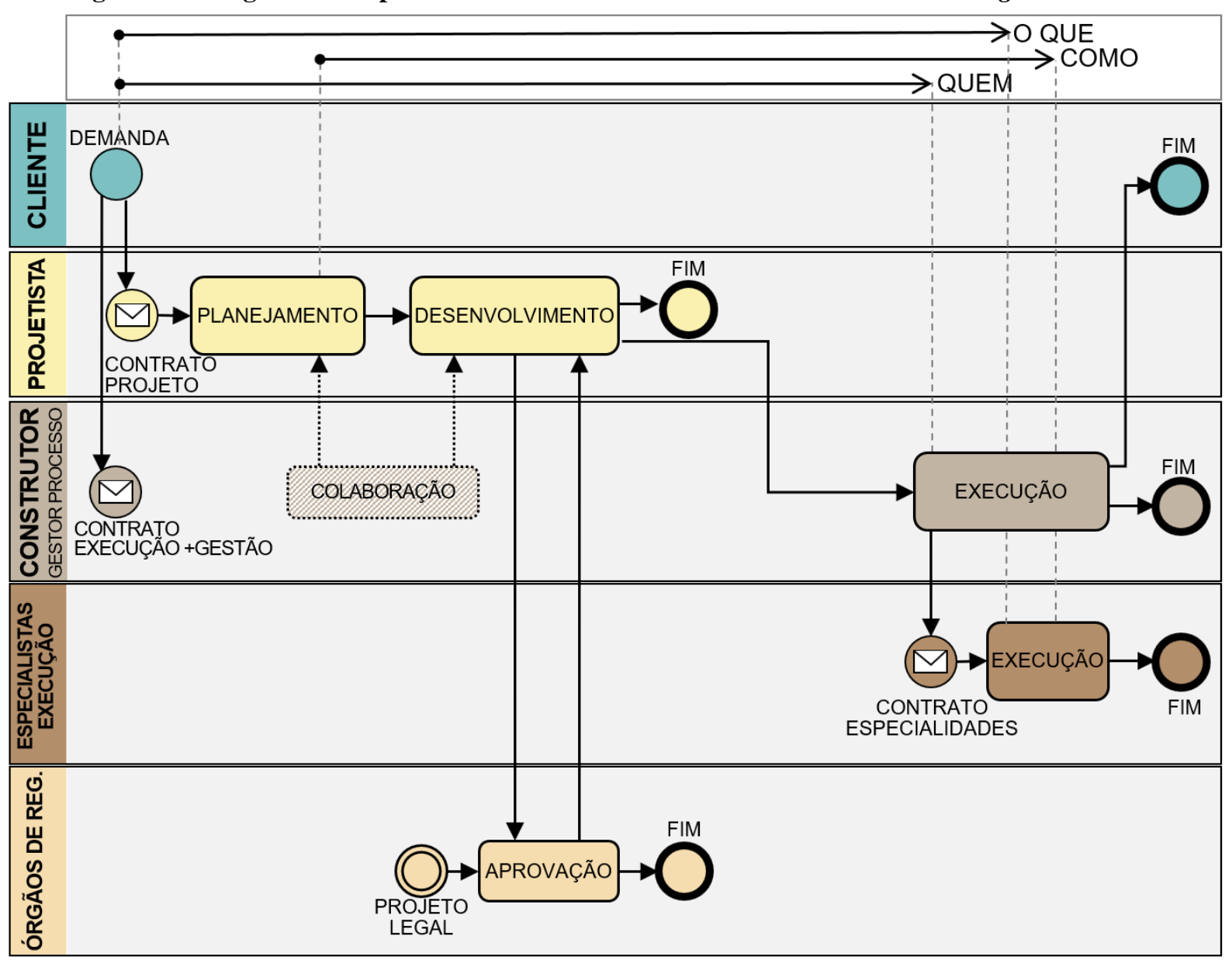

Fonte: Elaborado pela autora.

Assim como no DB, a contratação precoce do construtor, indicada por "Contrato Execução + Gestão", reflete na antecipação da decisão de quem vai executar a obra. Nesse tipo de contrato, também existe uma possibilidade de colaboração entre as atividades de projeto e execução, mas que ocorre de forma unilateral. O construtor participa da etapa de projeto, mas o projetista não participa da execução, sendo que a atividade de colaboração do construtor no planejamento e desenvolvimento do projeto indica o início da tomada de decisão de como será executado o empreendimento. 
Nos contratos transacionais estudados, os avanços introduzidos pelos modelos de contrato DB e CMAR, em relação ao DBB, são direcionados à aproximação entre as etapas de projeto e execução. No entanto, a colaboração entre os participantes é limitada, ou seja, não incluem os especialistas de execução nas etapas de planejamento e, no caso específico do CMAR, a colaboração acontece apenas do construtor nas atividades de projeto.

\subsubsection{Primeiro nível de detalhamento dos contratos relacionais}

O desdobramento do diagrama comum, derivado do modelo do AIA (AMERICAN INSTITUTE OF ARCHITECTS, 2014), segundo o critério para o primeiro nível de detalhamento, não indica haver diferenças entre os modelos PP e PA (Figura 20). Os principais agentes atuam do início ao fim do processo, a partir do "Contrato do Empreendimento", estabelecido com o cliente. Mesmo que cada etapa esteja associada a um agente definido, todos trabalham colaborativamente nas atividades, o que pode ser observado pela "Colaboração" comum a todos os profissionais.

A participação precoce dos principais agentes resulta na antecipação das tomadas de decisão, sendo que a decisão de como será executado o empreendimento tem início com a colaboração dos agentes de execução na atividade de planejamento do projeto. O fim de todas as tomadas de decisão ocorre após a participação dos órgãos de regulação no processo, ou seja, com a aprovação do projeto, todas as definições sobre o edifício são finalizadas pela equipe. 
Figura 20 - Diagrama com primeiro nível de detalhamento do Project Partnering e Project Alliancing

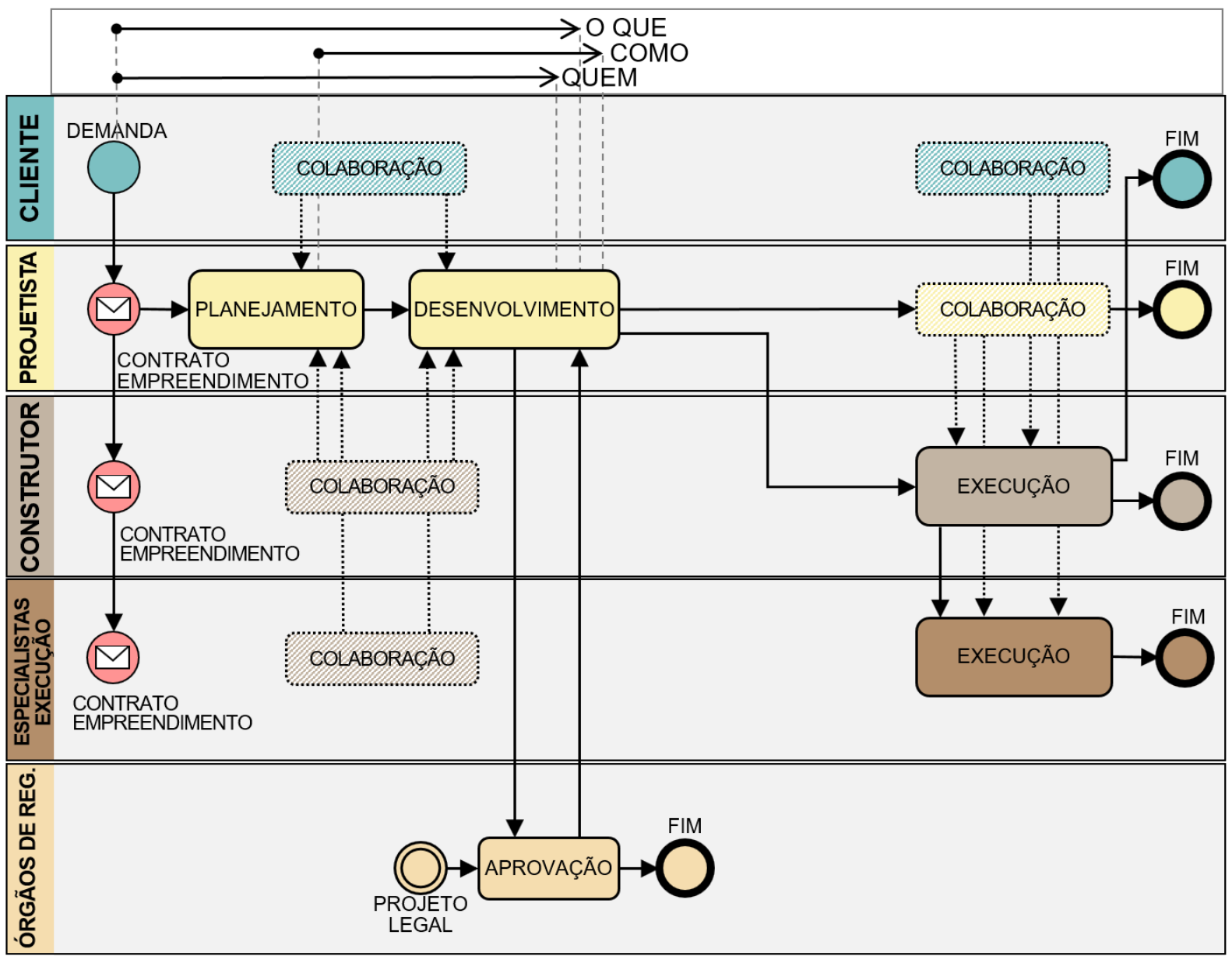

Fonte: Elaborado pela autora.

Com diagrama mais detalhado do contrato ECI (Figura 21) foi possível entender como a contratação em duas etapas interfere na participação dos especialistas de execução. Esses agentes entram no processo apenas ao final da atividade de planejamento, indicado pelo momento em que o cliente estabelece o "Contrato Empreendimento 2". Isso reflete na presença de menos atividades de colaboração dos especialistas de execução nas atividades de projeto, se comparado aos contratos PP e PA. No entanto, a antecipação das tomadas de decisão ocorre da mesma forma que no PP e PA, pois elas só terminam ao final das atividades dos órgãos de regulação. 
Figura 21 - Diagrama com primeiro nível de detalhamento do Early Contractor Involvement

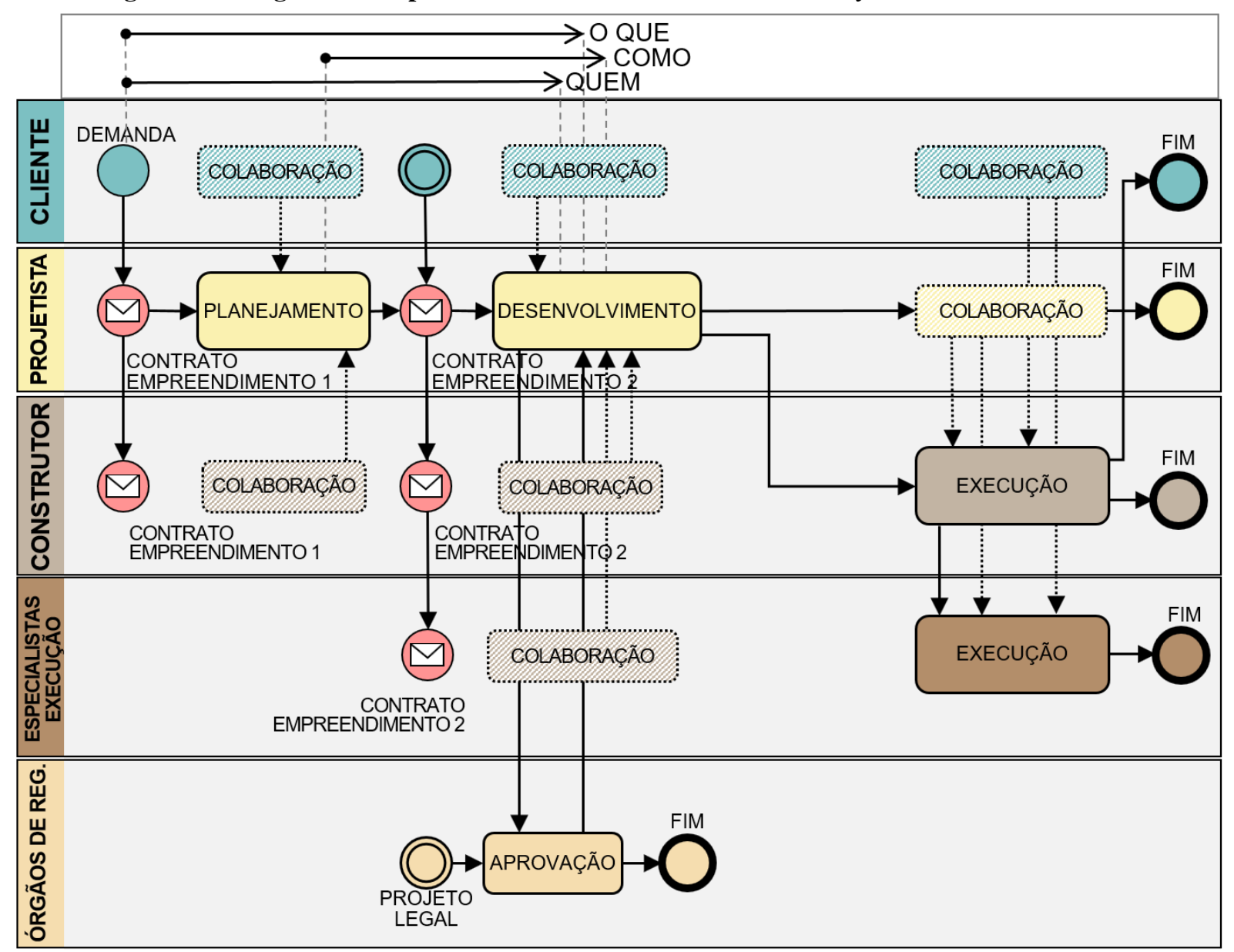

Fonte: Elaborado pela autora.

A diferença do modelo de contrato do IPD para os contratos relacionais PP e PA, como indicado no diagrama da Figura 22, é a participação precoce também dos órgãos de regulação. Esses agentes não fazem parte do contrato multilateral estabelecido entre todos os agentes, mas atuam em todas as etapas do processo, entrando no processo no momento em que é desenvolvido o planejamento do projeto.

Existe a presença da atividade de colaboração dos órgãos de regulação ao longo de todo o processo, tanto nas atividades de projeto quanto de execução. No entanto, as tomadas de decisão no IPD terminam como nos demais contratos relacionais, ou seja, após a aprovação do projeto. Em todos os contratos relacionais o cliente colabora ao longo do processo, validando todas as tomadas de decisão antes das entregas realizadas pelos profissionais, o que indica que esse agente tem maior controle sobre o processo. 
Figura 22 - Diagrama com primeiro nível de detalhamento do Integrated Project Delivery

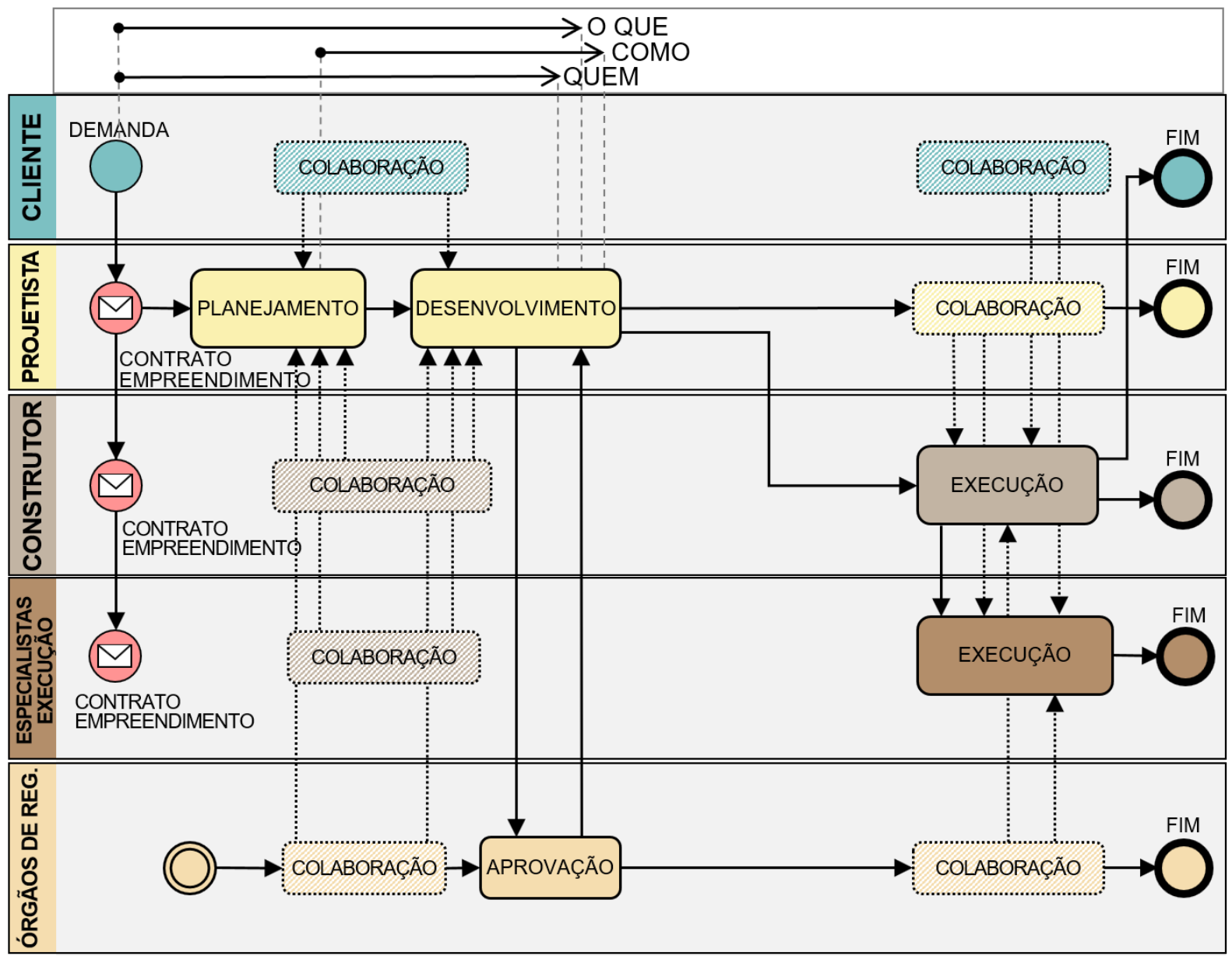

Fonte: Elaborado pela autora.

No presente nível de detalhamento as principais etapas da produção foram representadas como atividades na BPMN. Entretanto, cada etapa pode ser decomposta em suas principais atividades, sucessivamente, para melhor explicitar as diferenças relevantes entre os modelos de contratação. Faz-se necessário identificar as interdependências entre as atividades de cada etapa e como a presença ao não da colaboração impacta nas possibilidades de retrabalho pela entrada de um novo agente no processo.

\subsubsection{Segundo nível de detalhamento dos contratos transacionais}

Na Figura 23 está representado o diagrama mais detalhado do método de produção do empreendimento baseado no contrato DBB. Para dar início ao processo - "Demanda" - o cliente é o único agente responsável por elaborar os requisitos do projeto (Request for Proposal-RFP), que determina as características físicas, funcionais e de desempenho do empreendimento. Isso indica que esse agente precisa ter um conhecimento técnico suficiente para definir os termos 
sob os quais o empreendimento será desenvolvido, que vão impactar na qualidade do processo e do produto final.

A participação do projetista no processo é finalizada com a entrega do Projeto Executivo, que foi submetido à atividade de aprovação dos órgãos de regulação e é a base para a seleção dos construtores. A concorrência também fica sob responsabilidade única do cliente, o que reforça a responsabilidade desse agente sobre a qualidade da execução do empreendimento.

O contrato estabelecido entre o cliente e o construtor indica o início da execução, onde será realizada a análise técnica do projeto, por meio da atividade de planejamento e desenvolvimento do Projeto para Produção. Nessa atividade é realizada a seleção e contratação dos especialistas de execução.

Podem ser identificadas três possibilidades de retrabalho no diagrama do DBB, relacionadas a entrada de um novo agente no processo. Com a participação dos órgãos de regulação, é possível que sejam determinadas alterações no projeto que podem impactar no projeto conceitual, referente à etapa de planejamento. A entrada dos agentes de execução pode resultar na identificação de incompatibilidades dos projetos ao sistema construtivo definido na atividade das etapas de planejamento e desenvolvimento do projeto, o que resulta no retrabalho desde o projeto conceitual.

A entrada dos especialistas durante a atividade de execução da obra indica a possibilidade de retrabalho em todas as atividades anteriores a sua participação, ou seja, desde o projeto conceitual até o desenvolvimento do Projeto para Produção. Isso demonstra o motivo pelo qual o final das tomadas de decisão ocorre na etapa de execução, pois a possibilidade de retrabalho impede que o projeto do empreendimento seja considerado finalizado.

O DBB pode ser considerado como uma sucessão de atividades que se completam até a entrega do empreendimento. Considera-se que as atividades são autossuficientes, ou seja, cada atividade pode ser desenvolvida sem a participação dos demais agentes. No entanto, qualquer alteração do projeto durante esse processo, seja por solicitação do construtor ou dos especialistas, inviabiliza a execução sequencial das atividades, levando a retrabalhos. 
Figura 23 - Diagrama com segundo nível de detalhamento do Design-Bid-Build

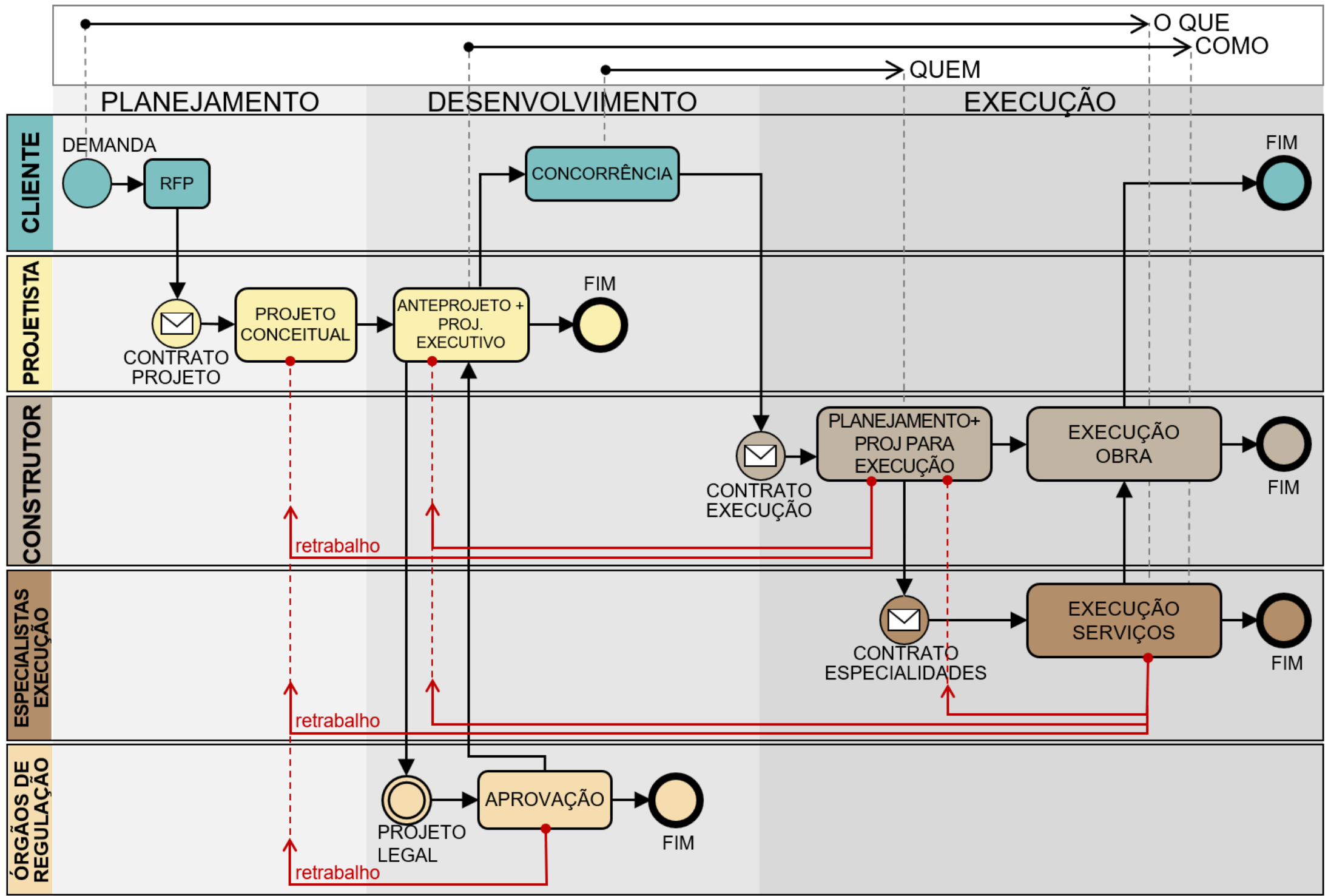

Fonte: Elaborado pela autora. 
Ao buscar reduzir a autossuficiência das atividades do processo de produção do empreendimento, os sistemas contratuais alternativos ao DBB - DB e CMAR - possuem atividades de colaboração que vão influenciar nas possibilidades de retrabalho do processo, reduzindo o distanciamento entre o projeto e execução.

O diagrama do DB com maior nível de detalhe (Figura 24) indica quais as atividades de responsabilidade do projetista e do construtor, associados em um mesmo agente. As atividades de colaboração indicam que o construtor insere informações relativas à sua área de atuação precocemente no processo, desde a elaboração do projeto conceitual, e o projetista participa das decisões durante a execução.

Como resultado, o Projeto Executivo possui todas as informações referentes ao processo construtivo do construtor, reduzindo as incompatibilidades no Projeto para Produção. Isso elimina a possibilidade de retrabalho na atividade de responsabilidade do construtor, que antecede a execução da obra.

No entanto, a colaboração está limitada às atividades do projetista-construtor, pois a contratação dos especialistas e a entrada dos órgãos de regulação acontecem da mesma forma que no DBB. Com isso, o DB possui duas possibilidades de retrabalho. A entrada dos órgãos de regulação pode demandar alterações de projeto específicas, impactando no Anteprojeto ou no Projeto Executivo; ou mesmo alterações que vão impactar no Projeto Conceitual.

O primeiro contato dos especialistas da execução com o projeto ocorre somente no momento de sua contratação, que acontece durante a atividade de execução da obra, permitindo que ocorram retrabalhos ao longo de todas as atividades anteriores. Isso determina o final das tomadas de decisão no processo, que ocorrem durante a execução dos serviços pelos especialistas. 
Figura 24 - Diagrama com segundo nível de detalhamento do Design and Build

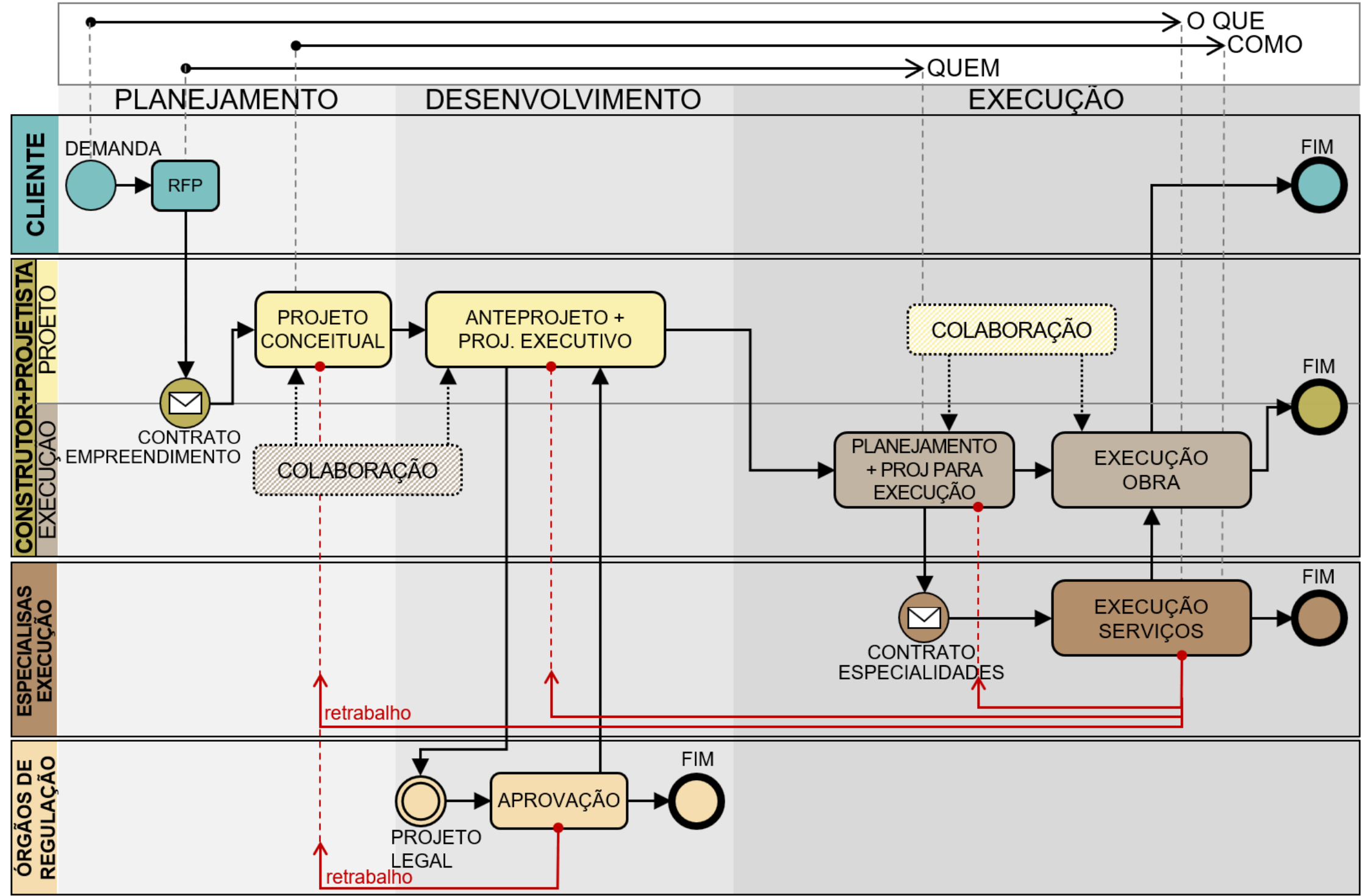

Fonte: Elaborado pela autora. 
O maior nível de detalhe do contrato CMAR (Figura 25) indica em quais atividades existe a colaboração do construtor, que também atua como o gestor do processo. A participação precoce desse agente, desde a elaboração do projeto conceitual, possibilita reduzir o distanciamento entre projeto e execução.

O cliente é responsável por elaborar o RFP, que vai ser usado como referência para realizar os dois principais contratos do processo: um com o construtor, referente à gestão e à execução; e outro com o projetista, referente ao desenvolvimento do projeto. Como o construtor-gestor é o primeiro agente a entrar no processo, ele pode indicar adequações do RFP definido pelo cliente, de forma que esteja mais adequado para a contratação do projetista.

Assim como DB, o construtor colabora durante o desenvolvimento do projeto conceitual, anteprojeto e projeto executivo. Isso indica a eliminação da possibilidade de retrabalho durante o planejamento e desenvolvimento do Projeto para Produção. No entanto, não existe a colaboração do projetista nas atividades do construtor.

As possibilidades de retrabalho no CMAR são semelhantes ao DB, ou seja, com a entrada dos órgãos de regulação e dos especialistas de execução. Modificações no projeto podem ser demandadas durante a execução, gerando aumento de prazo e custo do empreendimento, por isso as decisões de o que e como somente podem ser finalizadas com a análise do Projeto para Produção pelos especialistas de execução, durante a atividade sob sua responsabilidade. 
Figura 25 - Diagrama com segundo nível de detalhamento do Construction Management at Risk

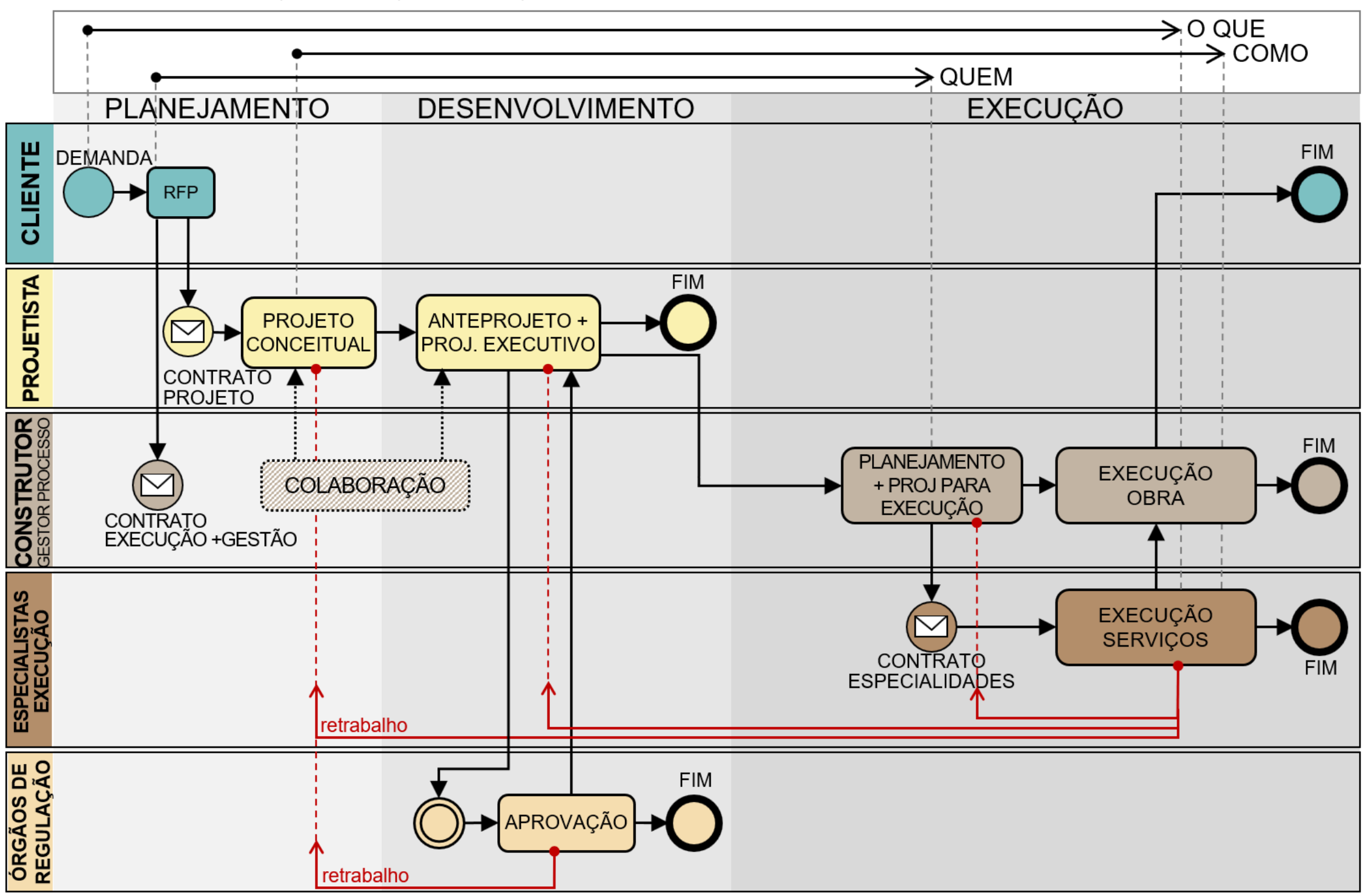

Fonte: Elaborado pela autora. 


\subsubsection{Segundo nível de detalhamento dos contratos relacionais}

O mesmo diagrama em um segundo nível de detalhamento ilustra os contratos PP e PA, pois as diferenças entre eles estão relacionadas a algumas cláusulas de contrato que não têm influência no fluxo das atividades, como o sistema de pagamento e a resolução de conflitos.

No processo do PP e PA (Figura 26) o contrato multilateral, indicado como "Contrato do Empreendimento" é estabelecido antes da elaboração RFP. A colaboração de toda a equipe na definição do RFP possibilita que os profissionais definam um produto com maior nível de detalhe e mais próximo daquele desejado pelo cliente. Evita-se alterações no escopo durante o processo, o que levaria a retrabalhos, e consequentemente, aumento do custo e prazo de execução.

Observa-se que, por meio da presença da colaboração, o cliente participa ativamente de todas as atividades do processo, devendo não só validar as decisões tomadas pela equipe, como também participar da escolha das soluções de projeto ou de questões da execução. Essa característica permite que o cliente tenha maior controle sobre o processo e tenha conhecimento dos caminhos tomados pelos agentes para transformar o RFP em um produto executável.

O final das tomadas de decisão do processo ocorre com a elaboração do Projeto Executivo, ou seja, após a atividade de aprovação dos órgãos de regulação. Nessa etapa do processo, todas as soluções e especificações do contrato foram finalizadas, de forma que pode ser finalizada a contratação de todos os serviços de execução que não fazem parte do contrato multilateral finalizando todas as questões sobre quem.

No entanto, como a atividade de aprovação do projeto ocorre de forma semelhante aos contratos transacionais, existe uma possibilidade de retrabalho pela entrada dos órgãos de regulação no processo. As alterações demandadas por esses agentes podem impactar no Projeto Conceitual, o que aumentaria o custo e prazo de produção do empreendimento. 
Figura 26 - Diagrama com segundo nível de detalhamento do Project Partnering e Project Aliancing

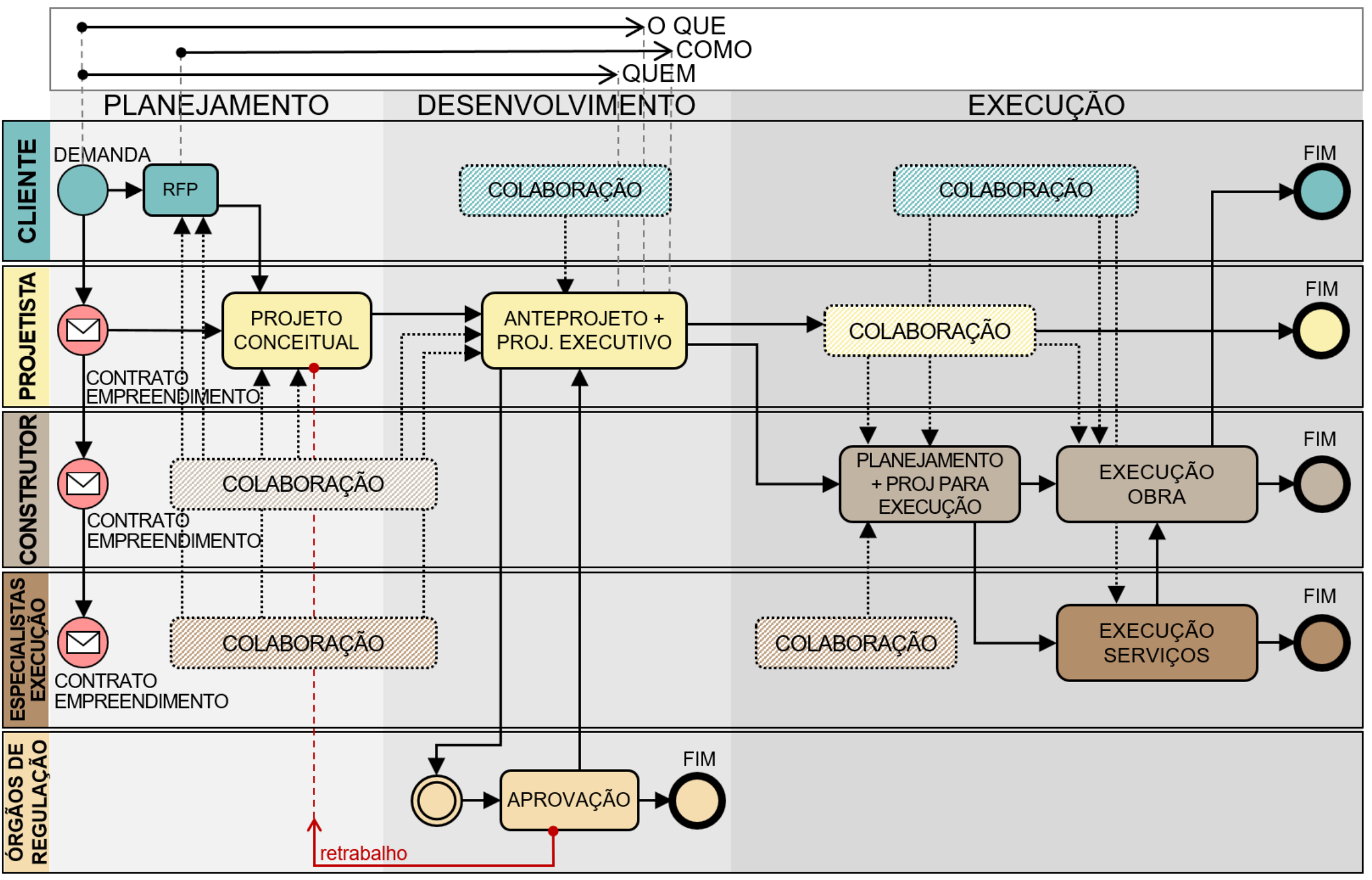

Fonte: Elaborado pela autora. 
A divisão do contrato em duas fases no ECI pode ser observada com mais detalhe no diagrama da Figura 27. Apesar de existir apenas um contrato multilateral, indicado como "Contrato do Empreendimento", a ausência dos especialistas de execução durante o desenvolvimento do projeto conceitual gera uma possibilidade de retrabalho. Mesmo que a participação desse agente ocorra ainda nas etapas de projeto, sua entrada possibilita que revisões sejam feitas para adequar o projeto conceitual aos seus métodos de construção.

No método do ECI, é permitido que os agentes possam optar em continuar ou não no processo. Caso eles não concordem com as condições oferecidas para desenvolver e executar o empreendimento, o cliente pode finalizar o contrato e estabelecer uma nova licitação para a segunda fase do contrato. Nesse caso, serão contratados novos profissionais que darão continuidade ao processo. No entanto, essa não é a melhor opção, pois inviabilizaria o processo integrado e o trabalho colaborativo ao longo de todo o processo.

No ECI, assim como no PP e PA, existe a possibilidade de retrabalho pela entrada dos órgãos de regulação, que poderia demandar alterações desde o Projeto Conceitual. 
Figura 27 - Diagrama com segundo nível de detalhamento do Early Constructor Involvement

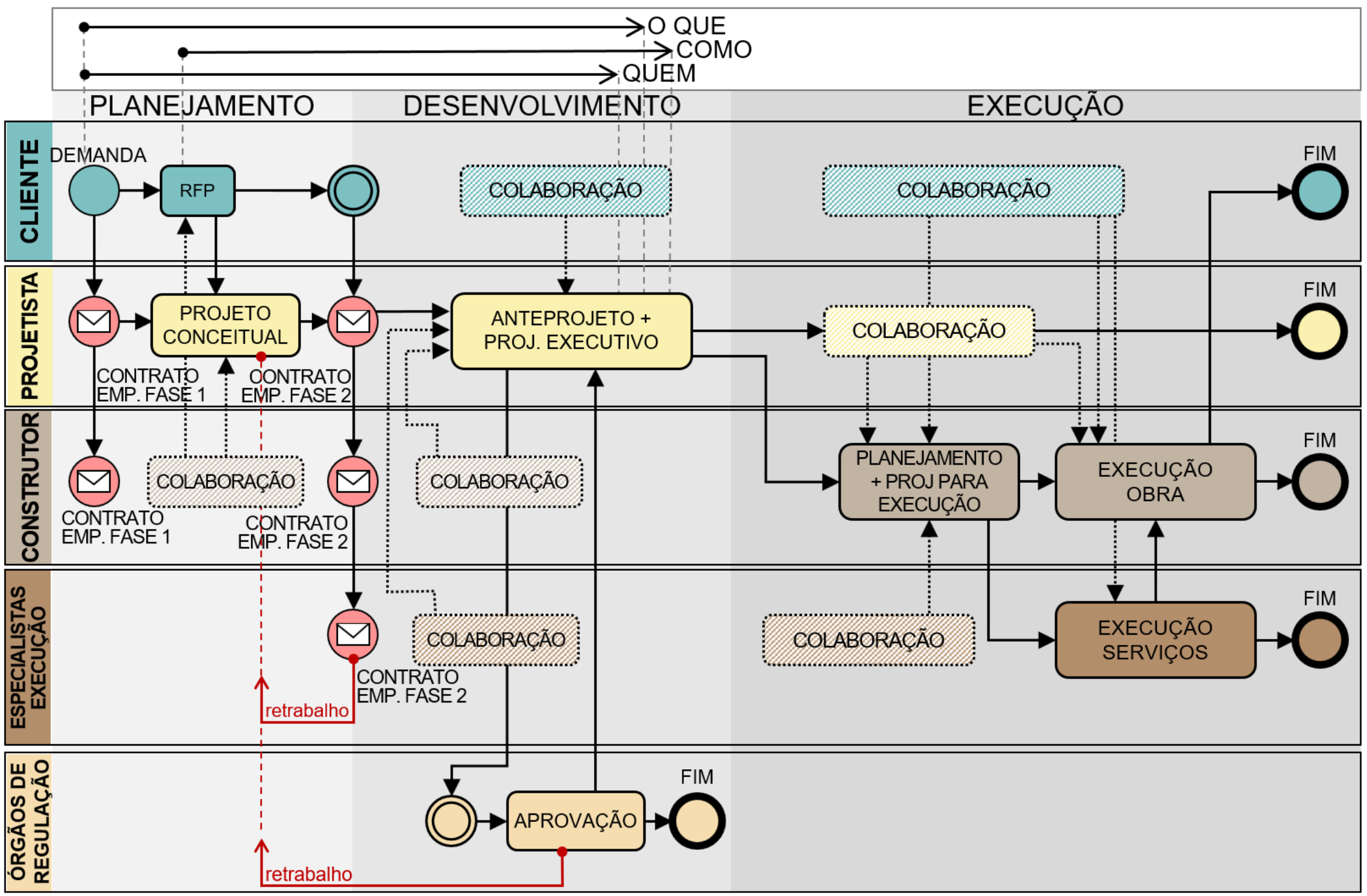

Fonte: Elaborado pela autora. 
A particularidade do IPD em relação aos demais contratos relacionais, reflete na ausência de possibilidades de retrabalho devido a entrada tardia de qualquer agente no processo, como pode ser observado no diagrama mais detalhado da Figura 28. Como os órgãos reguladores são considerados agentes atuantes no processo de produção, são verificadas e indicadas as alterações necessárias ao projeto para se adequar às normas e regulamentos vigentes, desde o projeto conceitual. Isso permite orientar as tomadas de decisão no processo e complementar o planejamento do empreendimento.

Essa participação é adequada no caso de empreendimentos complexos, que demandam uma análise individualizada do projeto para definir critérios de aprovação. Empreendimentos que causam grande impacto na infraestrutura viária, como shopping centers e hospitais, são exemplos que poderiam se beneficiar com a participação de representantes dos órgãos reguladores no processo de produção. Isso eliminaria a possibilidade de retrabalho devido a entrada de novos agentes no processo, ou seja, todos os participantes são responsáveis pelas tomadas de decisão desde o início do processo.

No entanto, o final das tomadas de decisão acontece como nos demais diagramas dos contratos relacionais, ou seja, após a atividade de aprovação do projeto. Apenas com a verificação do projeto protocolado nos órgãos de regulação é possível garantir a finalização do projeto executivo. 
Figura 28 - Diagrama com segundo nível de detalhamento do Integrated Project Delivery

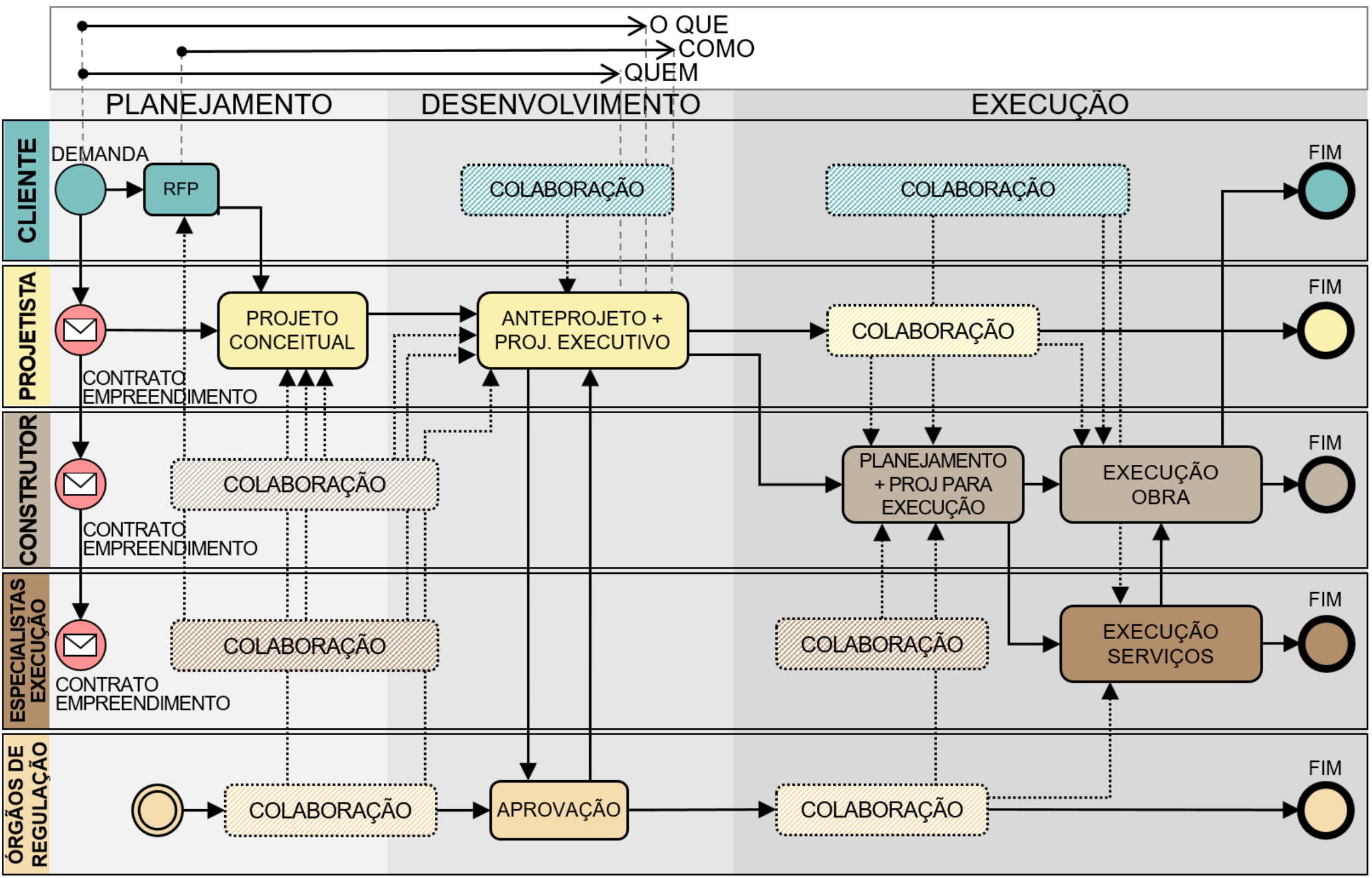

Fonte: Elaborado pela autora. 


\subsubsection{Níveis de Integração Contratual}

Na Figura 29 estão indicados os níveis de integração pela perspectiva contratual a partir dos modelos de contrato. Criou-se uma graduação dentro dos tipos de sistemas contratuais transacional e relacional - que varia conforme a presença de características que vão favorecer a integração na produção do empreendimento.

Figura 29 - Níveis de Integração Contratual

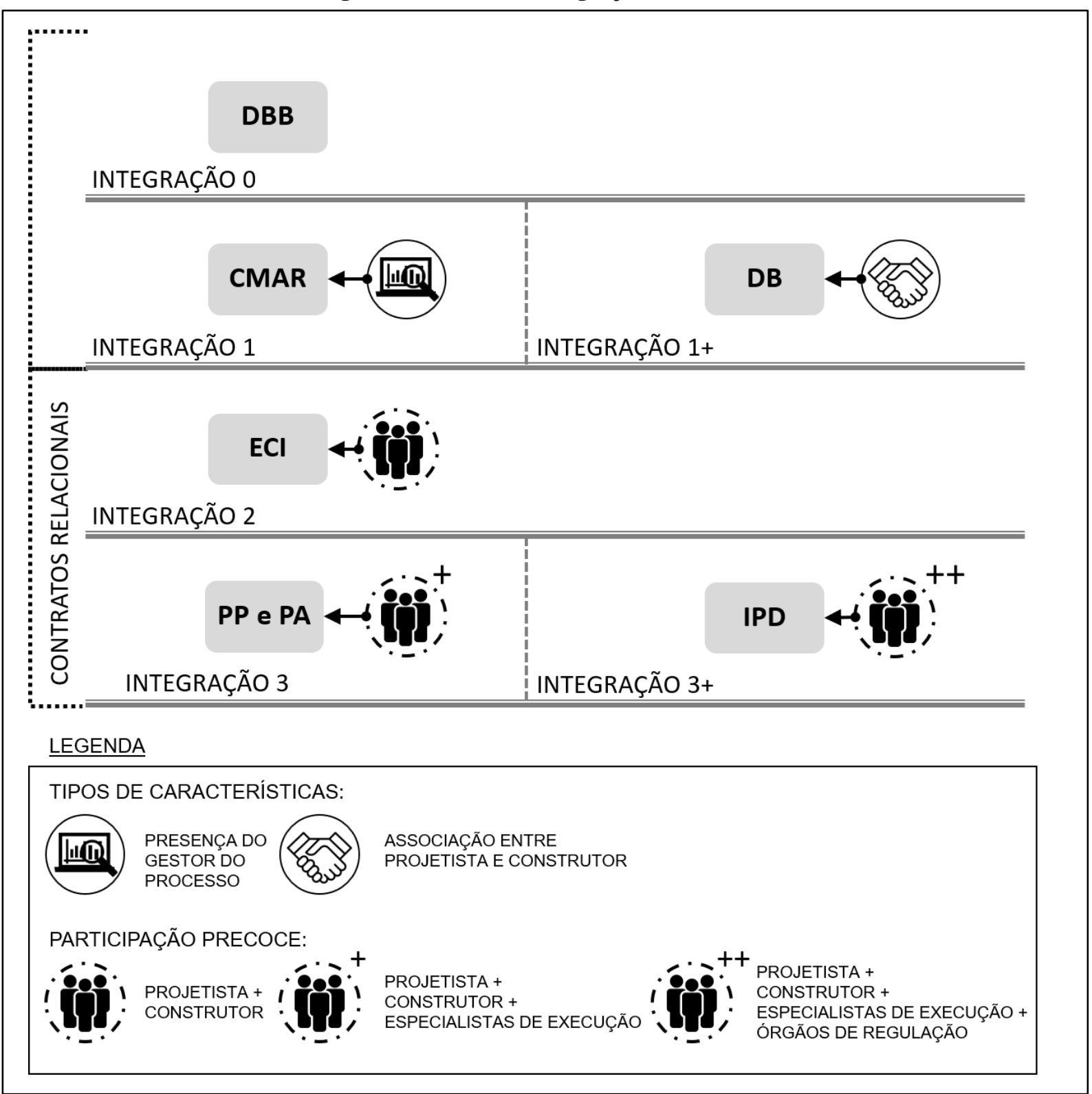

Fonte: Elaborado pela autora.

Dentre as características estão a associação do projetista e o construtor, no caso do DB, e a presença do gestor do processo, papel representado pelo próprio construtor, no CMAR. Esses 
dois modelos de contrato representam uma maior integração em relação ao DBB, pois estabelecem uma possibilidade de colaboração no processo.

Ambos - DB e CMAR - estão no mesmo nível de integração devido à antecipação das tomadas de decisão de como e quem. No entanto, o contrato DB possui um maior nível de integração se comparado ao CMAR, pois a colaboração entre as etapas de projeto e execução é recíproca, ou seja, ambos agentes, projetista e construtor, colaboram nas atividades dessas etapas.

Dentre os contratos relacionais, o grau de integração contratual varia conforme o número de agentes que participam precocemente do processo de produção. O ECI possui o menor nível de integração desse tipo de contrato, pois a ausência dos especialistas de execução possibilita mais retrabalhos ao processo. O PP e PA representam o mesmo nível de integração que o IPD, pois os principais agentes do processo são considerados desde as primeiras etapas de desenvolvimento do projeto conceitual. No entanto, o IPD representa o maior nível de integração por inserir os órgãos de regulação como colaboradores do desenvolvimento do empreendimento, o que representa a participação de todos os possíveis agentes que vão influenciar no processo de produção.

\subsection{Integração Organizacional}

Em relação à integração sob a perspectiva organizacional, verificou-se de que forma as interações entre os agentes influenciam na definição do trabalho colaborativo. Além dos principais agentes definidos na integração contratual - cliente, projetista, construtor e especialistas de execução - foram considerados os projetistas complementares e o gestor de produção.

Na perspectiva contratual, os projetistas complementares são considerados como parte da equipe de projetistas, pois na literatura sobre os sistemas contratuais, não existe diferença no momento de entrada desses agentes, em relação ao projetista de arquitetura. No caso do gestor, os modelos de contrato consideram ou não sua presença no processo, o que não influencia na forma de contratação dos demais agentes principais. Apenas no caso do Construction Management at Risk (CMAR), a presença do gestor é obrigatória para a formação da equipe e ele é representado pelo próprio construtor, que acumula as duas funções - execução da obra e gestão do processo. 
Percebeu-se que os diagramas elaborados por Molenaar e Sobin (2009) (Figura 2) foram desenvolvidos para indicar de forma simultânea o modelo de contratação e a forma mais comum de organização da produção. No entanto, ao considerar somente as possibilidades de organização da equipe, sem especificar os sistemas contratuais, percebeu-se que existem mais possibilidades de formatação da equipe, conforme a presença ou não do trabalho colaborativo no processo de produção.

Para explicitar as diferentes possibilidades de integração sob a perspectiva organizacional, foram identificados três cenários:

- processo de produção sem colaboração, em que cada agente tem como responsabilidade apenas sua atividade, sem nenhuma colaboração entre os participantes;

- processo colaborativo na etapa de projeto elou de obra, em que a colaboração entre os participantes ocorre apenas durante o desenvolvimento do projeto ou da obra, ou simultaneamente em ambos, mas sem a interação entre projeto e obra;

- colaboração ao longo de todo o processo, em que a colaboração entre os participantes ocorre no desenvolvimento do projeto e na execução da obra, com interações entre essas duas etapas;

Para cada um desses cenários, considerou-se a presença ou não de um gestor, que pode ser de projeto, de obra ou de todo o processo. Além disso foi considerado o tipo de contratação "chave na mão" ou turnkey, em que o cliente contrata uma associação entre o arquiteto e o construtor para desenvolver todo o empreendimento.

As interações entre os agentes pela perspectiva organizacional foram divididas em (Figura 30):

- entregas, que são os produtos finais de cada atividade sob responsabilidade dos profissionais, como projeto arquitetônico, projetos complementares e obra;

- colaboração, que corresponde à participação efetiva de dois ou mais profissionais no desenvolvimento de uma atividade, de forma que diferentes perspectivas são consideradas para a definição das soluções projetuais; pode existir a colaboração na etapa de projeto, execução ou do processo como um todo; e

- associação entre agentes, que representa a soma de atividades por um mesmo agente, de forma que o cliente estabelece um único contato com essa associação ao longo de todo o processo; 
Figura 30 - Legenda dos diagramas de Integração Organizacional

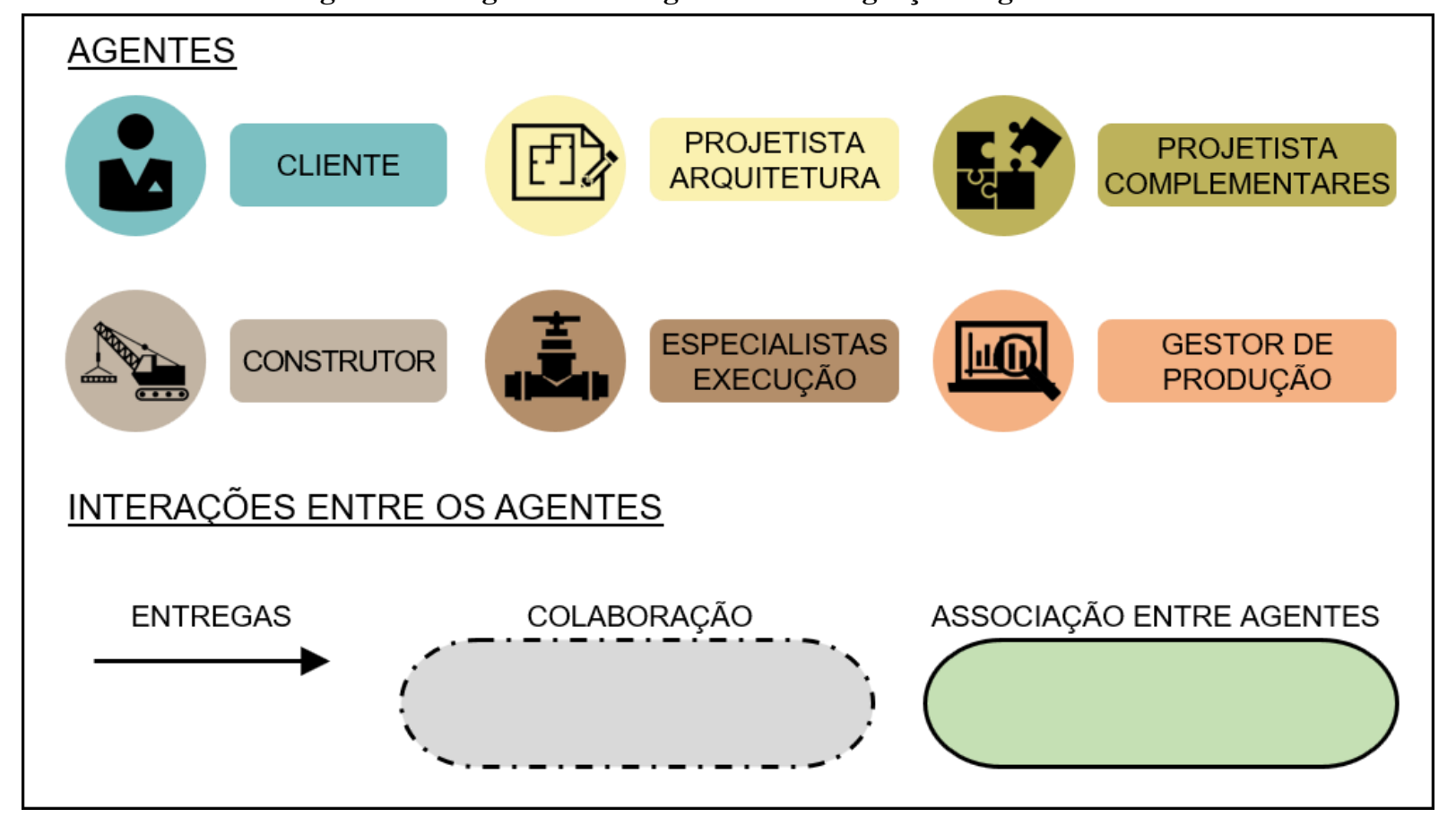

Fonte: Elaborado pela autora.

\subsubsection{Processo de produção sem colaboração}

Nas interações entre os participantes em um processo de produção segmentado, as atividades de cada profissional são bem definidas e correspondem apenas às entregas referentes à sua disciplina. Nesse caso, não existe nenhuma colaboração entre a equipe, apenas as entregas de cada atividade, que ao serem analisadas pelo agente receptor, podem surgir demandas por alterações ou correções.

A ausência do gestor no caso da Figura 31 faz com que o cliente seja o agente central do processo, pois é ele quem recebe as principais entregas - projeto e obra -; quem desenvolve e envia as informações para o início das atividades - RFP -; e realiza a seleção do construtor por meio de um processo de concorrência. 
Figura 31 - Interações de um processo segmentado sem gestor

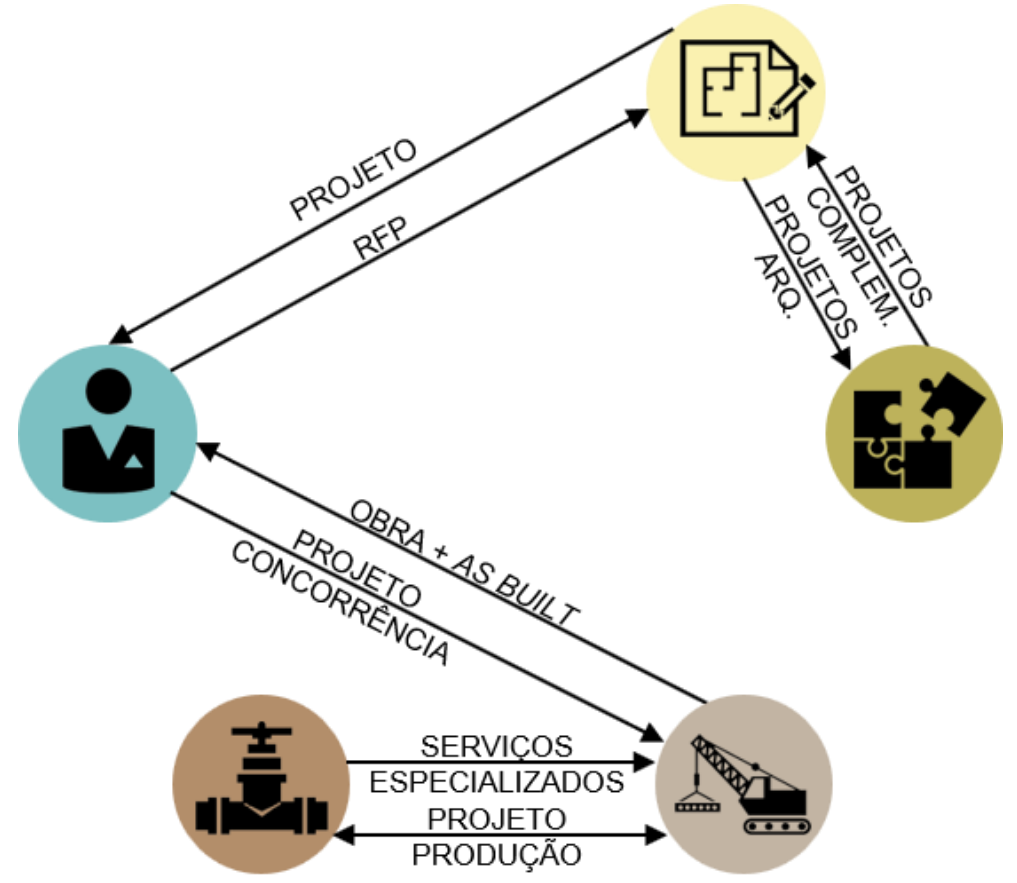

Fonte: Elaborado pela autora.

Quando o cliente não tem muito conhecimento e nem um quadro técnico próprio, esse modelo de interação dos agentes pode dificultar a comunicação entre a equipe. Os RFP podem não descrever adequadamente as demandas do cliente, de forma que, ao final de uma entrega, podem ser identificadas inadequações de projeto e obra. Isso pode resultar na necessidade de realizar modificações na edificação, gerando conflitos entre o cliente e a equipe, e entre os próprios profissionais.

Com a presença de um gestor (Figura 32), as entregas e as demandas para o início do projeto e obra passam a ser de responsabilidade desse profissional, como um representante do cliente. Existe uma maior facilidade na comunicação entre os agentes, pois o gestor é um profissional especializado e com conhecimento técnico, podendo especificar melhor os anseios do cliente para o empreendimento. Mesmo sem a presença da colaboração na etapa de projeto e execução, a presença do gestor, como um profissional que coordena toda a equipe, favorece o alinhamento dos objetivos de cada agente para o melhor desenvolvimento do empreendimento. 
Figura 32 - Interações de um processo segmentado com gestor

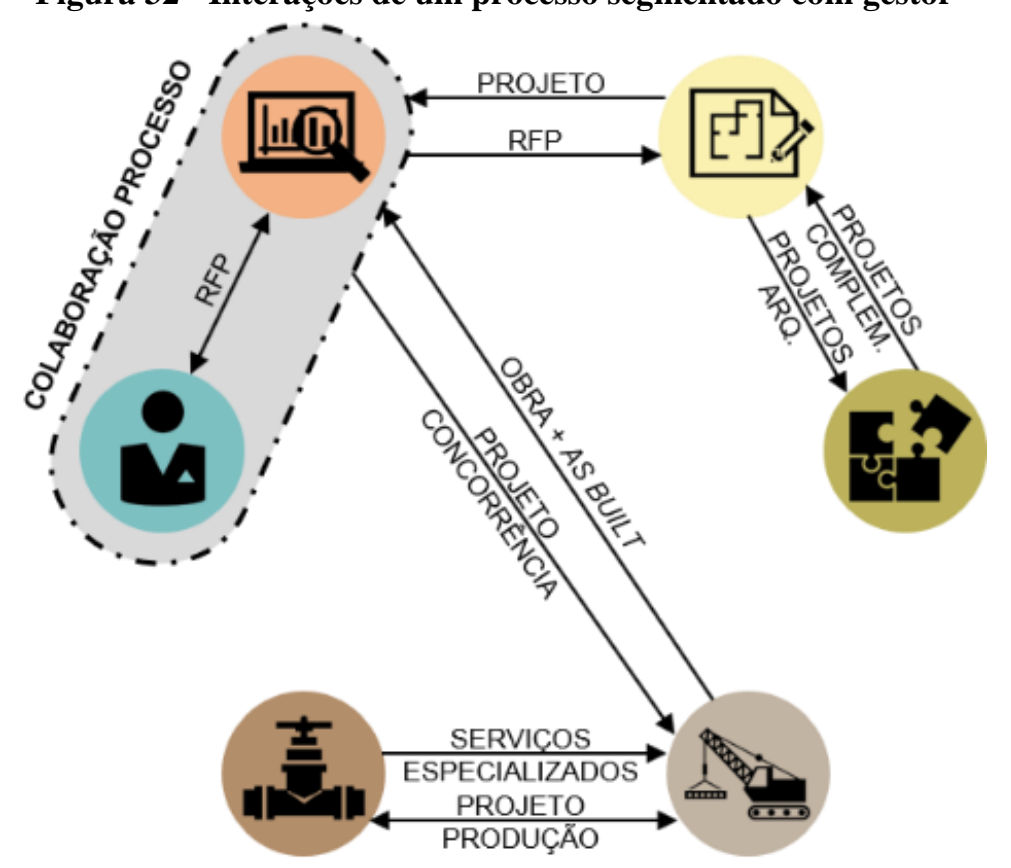

Fonte: Elaborado pela autora.

\subsubsection{Processo colaborativo na etapa de projeto e/ou de obra}

Nas interações de um processo de produção em que existe a colaboração durante a etapa de desenvolvimento do projeto, os projetistas complementares participam durante a elaboração do projeto pelos arquitetos. Desde a elaboração do projeto conceitual são incluídas questões referentes aos sistemas prediais, como elétrica, hidráulica e climatização.

Quando não existe a participação de um gestor no processo (Figura 33), a colaboração acontece apenas entre os agentes de projeto - arquitetura e complementares - tendo como base os requisitos definidos pelo cliente (RFP). Os problemas decorrentes da falta de conhecimento técnico do cliente ocorrem da mesma forma que no caso anterior - interações de um processo segmentado sem gestor. A diferença nesse caso é a presença da colaboração na etapa de projeto, o que possibilita antecipar as informações dos sistemas prediais desde o início do desenvolvimento do projeto arquitetônico, estabelecendo um trabalho colaborativo.

No caso da participação de um gestor na equipe (Figura 34), a colaboração se faz mais presente, pois existe um agente responsável por coordenar todo o processo, colaborando no desenvolvimento das atividades de projeto. Além de antecipar as questões dos projetos complementares no projeto de arquitetura, a presença do gestor possibilita validar o 
atendimento às demandas do cliente, mantendo a equipe de projeto - arquitetura e complementares - alinhada aos objetivos do empreendimento.

Figura 33 - Interações de um processo com colaboração na etapa

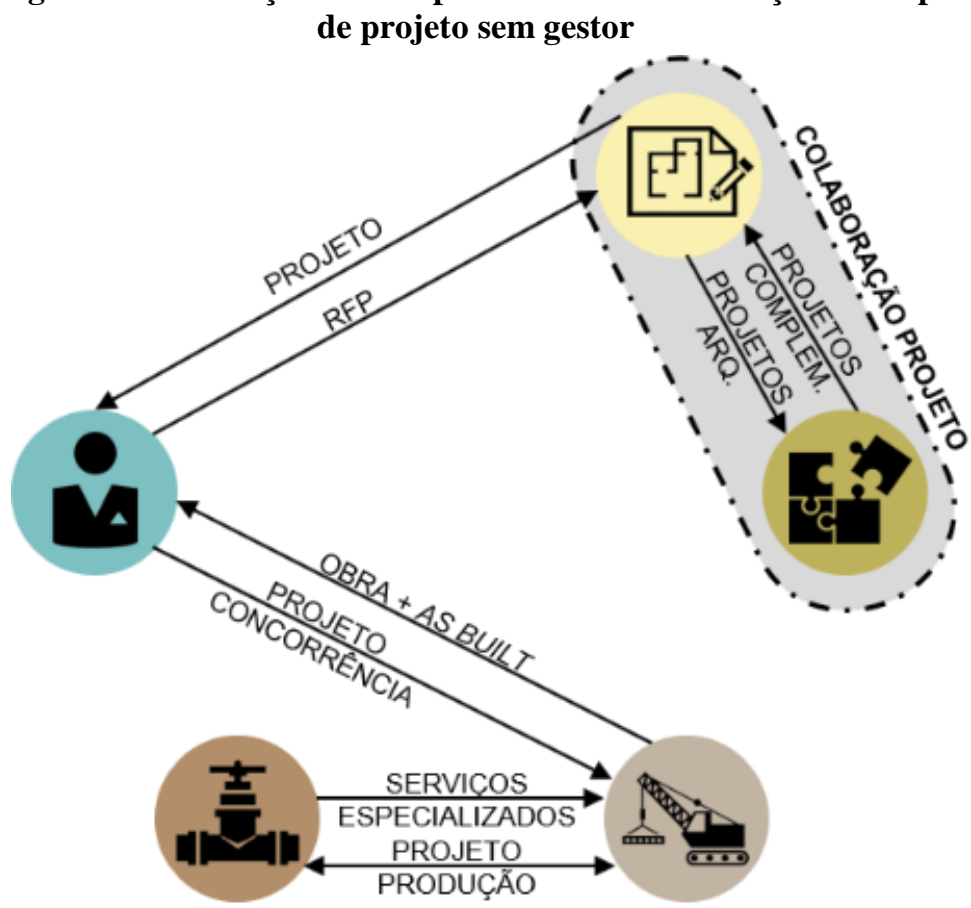

Fonte: Elaborado pela autora.

Figura 34 - Interações de um processo com colaboração na etapa

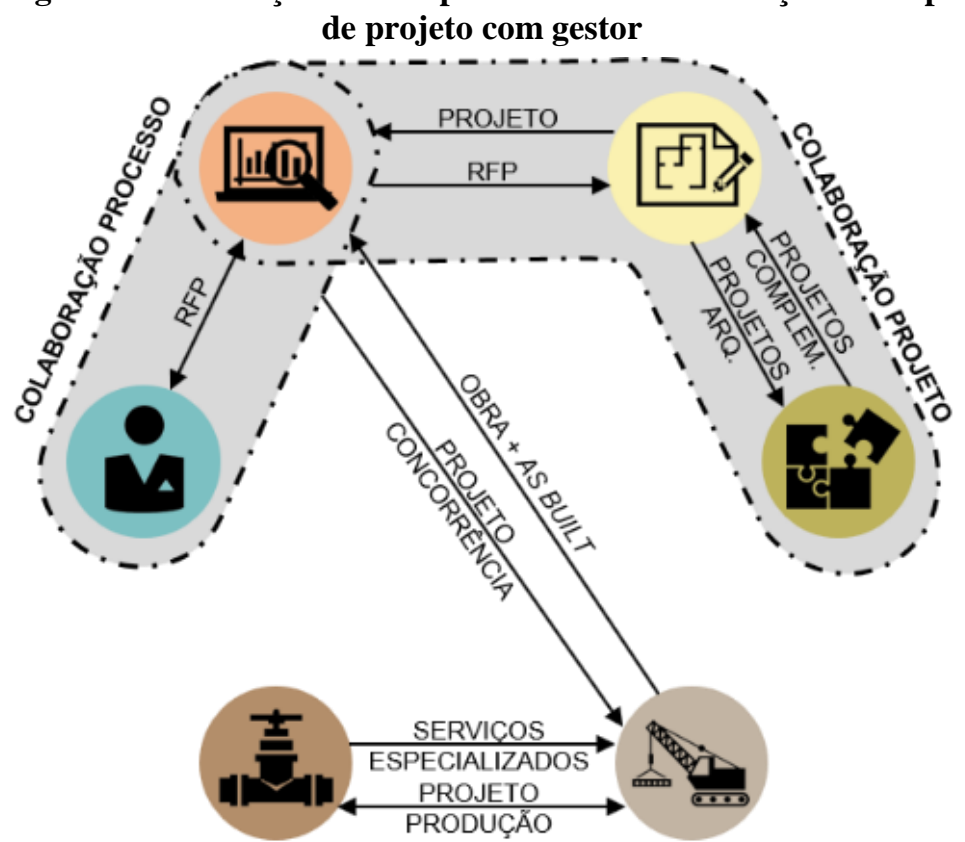

Fonte: Elaborado pela autora. 
As mesmas considerações dos dois casos anteriores podem ser feitas para a existência de colaboração na etapa de execução. Quando não existe a participação do gestor (Figura 35), a colaboração ocorre entre o construtor e os especialistas de execução, que participam desde o planejamento da obra e da análise técnica do projeto para a definição do projeto para produção. A colaboração na etapa de execução permite que as interferências entre os serviços especializados e a edificação como um todo sejam reduzidas, trazendo mais qualidade à obra.

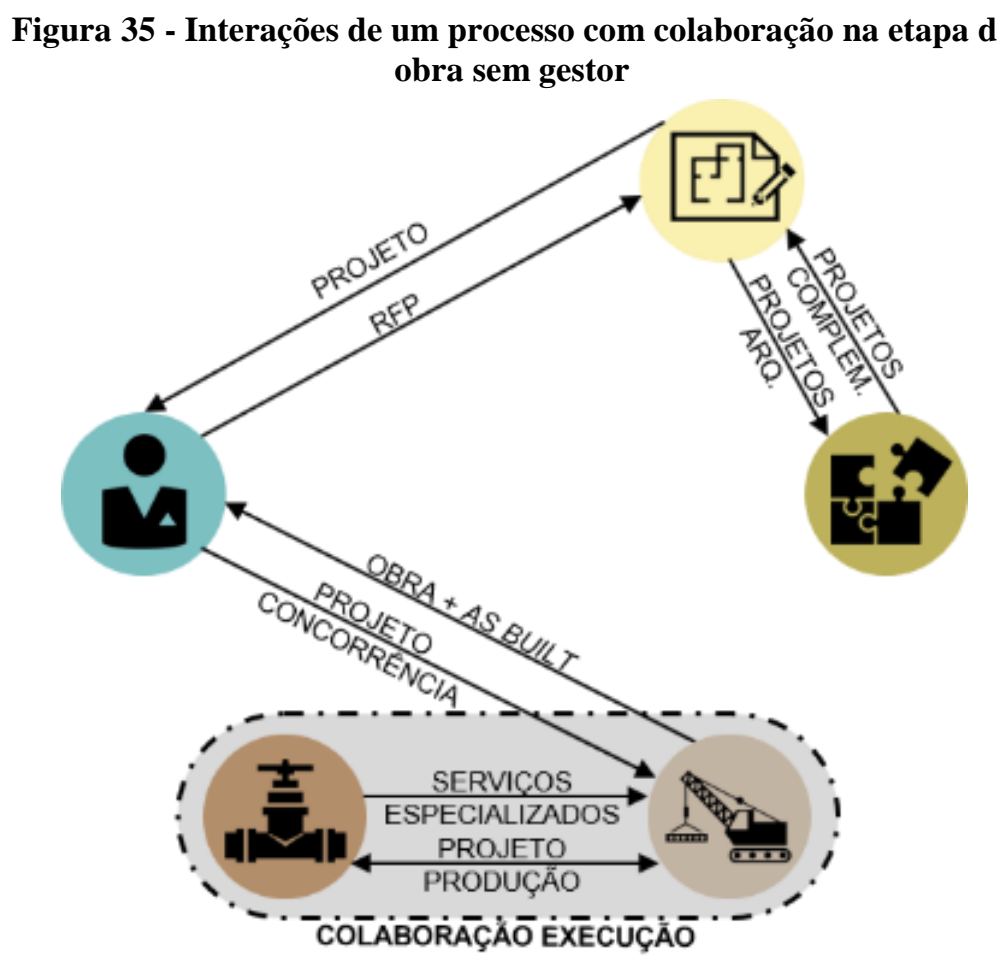

Fonte: Elaborado pela autora.

Com a entrada do gestor na equipe (Figura 36), a colaboração na etapa de execução é intensificada. A colaboração do gestor, como representante do cliente e como um agente que participa ao longo de todo o processo, permite que na etapa de execução sejam antecipadas as incompatibilidades dos serviços de obra em relação ao projeto, além de manter as atividades de execução alinhadas aos objetivos do cliente. 


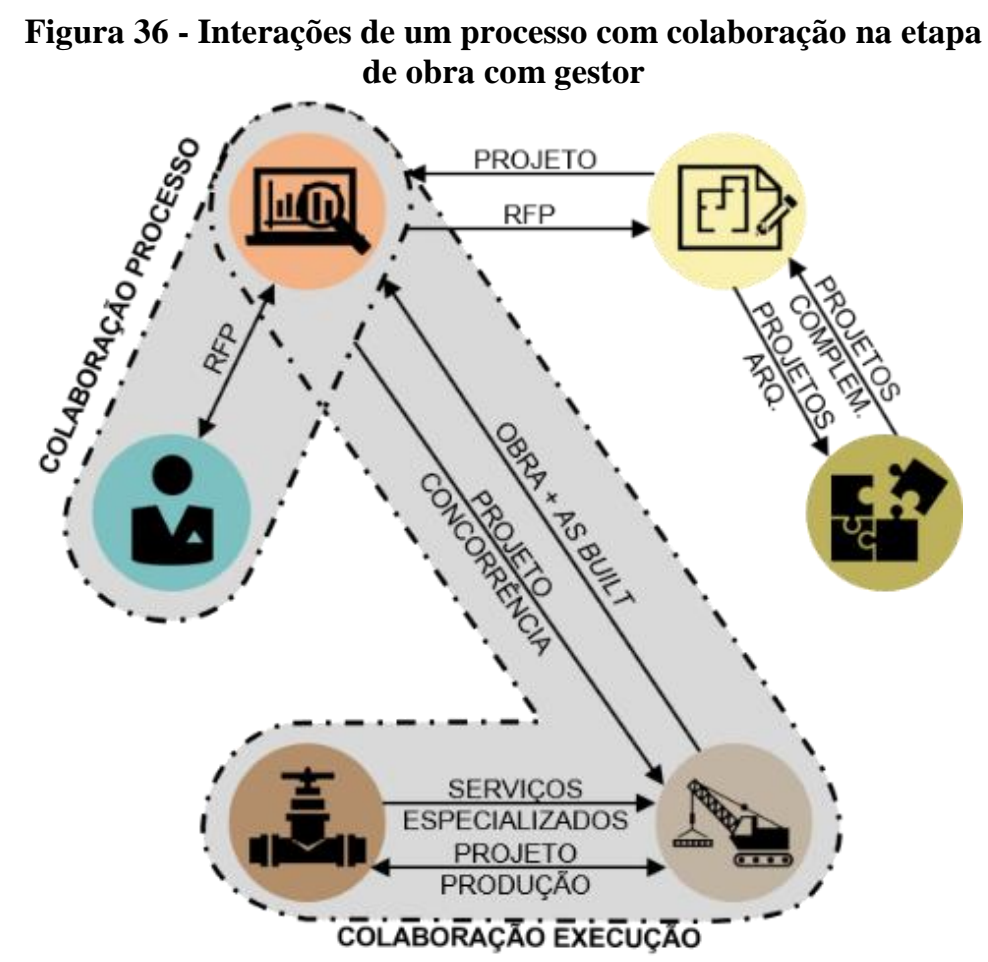

Fonte: Elaborado pela autora.

Existe ainda a possibilidade da presença da colaboração tanto na etapa de projeto quanto de execução, mas sem a interação entre elas, ou seja, os profissionais de projeto e execução não colaboram entre si. A Figura 37 indica esse tipo de colaboração sem a presença de um gestor.

Nesse caso, a colaboração entre os projetistas de arquitetura e complementares permite que o projeto entregue ao cliente tenha mais qualidade, pois todas as disciplinas foram consideradas desde a concepção da arquitetura do empreendimento. Além disso, a colaboração na etapa de execução possibilita a entrega de uma obra com mais qualidade e sem incompatibilidades entre os serviços especializados e o edifício como um todo.

No entanto, quando existe a presença do gestor (Figura 38), a continuidade do processo de produção é favorecida, com a aproximação das atividades de projeto e execução. Como esse profissional é responsável por coordenar todo o processo, considerações sobre a execução do empreendimento podem ser incluídas durante o desenvolvimento do projeto. Nesse caso, o gestor é o agente que se responsabiliza em manter todo o processo alinhado aos objetivos do cliente, colaborando nas atividades de projeto e execução. 
Figura 37 - Interações de um processo com colaboração na etapa de projeto e obra sem gestor

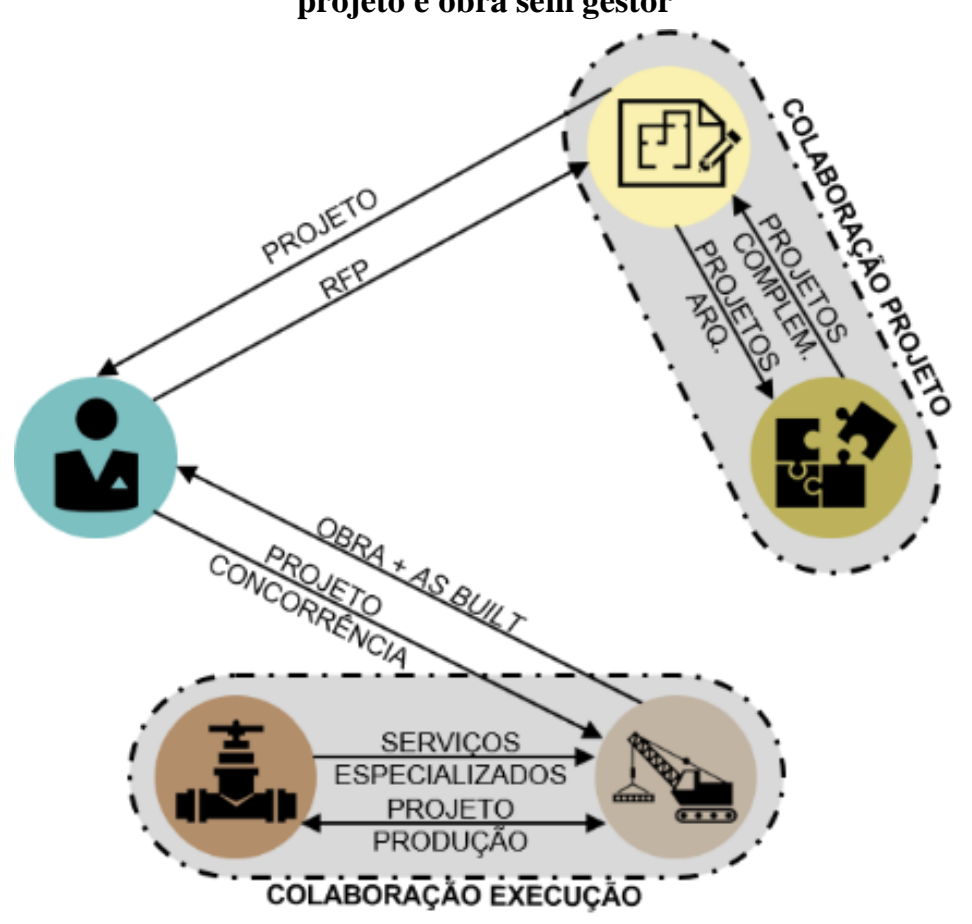

Fonte: Elaborado pela autora.

Figura 38 - Interações de um processo com colaboração na etapa de projeto e obra com gestor

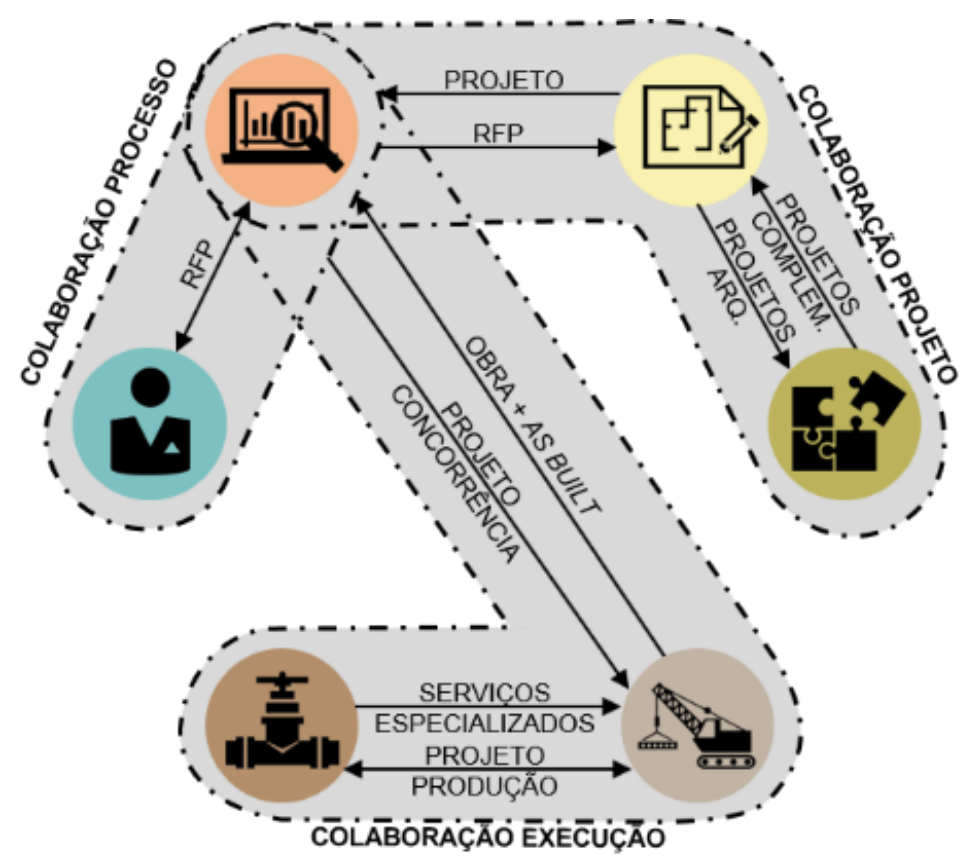

Fonte: Elaborado pela autora. 


\subsubsection{Colaboração ao longo de todo o processo}

Nas Figura 39 e Figura 40 estão representados os processos de produção em que existe a colaboração ao longo de toda a produção do empreendimento, com a interação entre todos os participantes.

Figura 39 - Interações de um processo com colaboração ao longo de todo o processo sem gestor

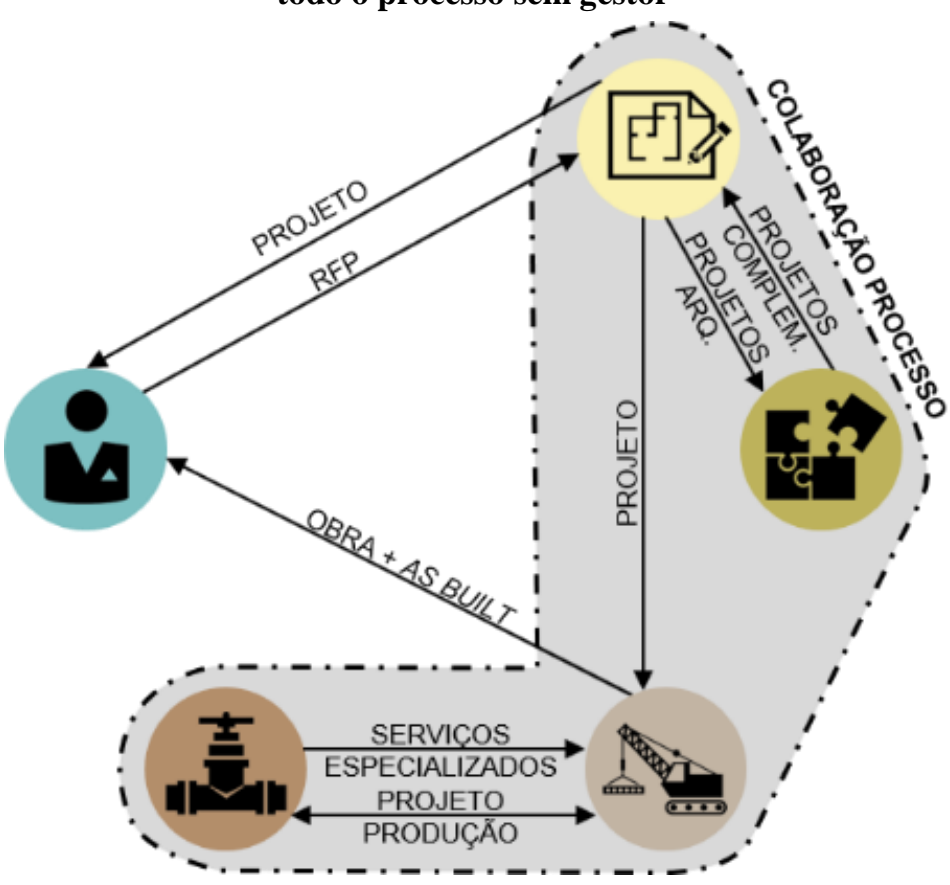

Fonte: Elaborado pela autora.

Figura 40 - Interações de um processo com colaboração ao longo

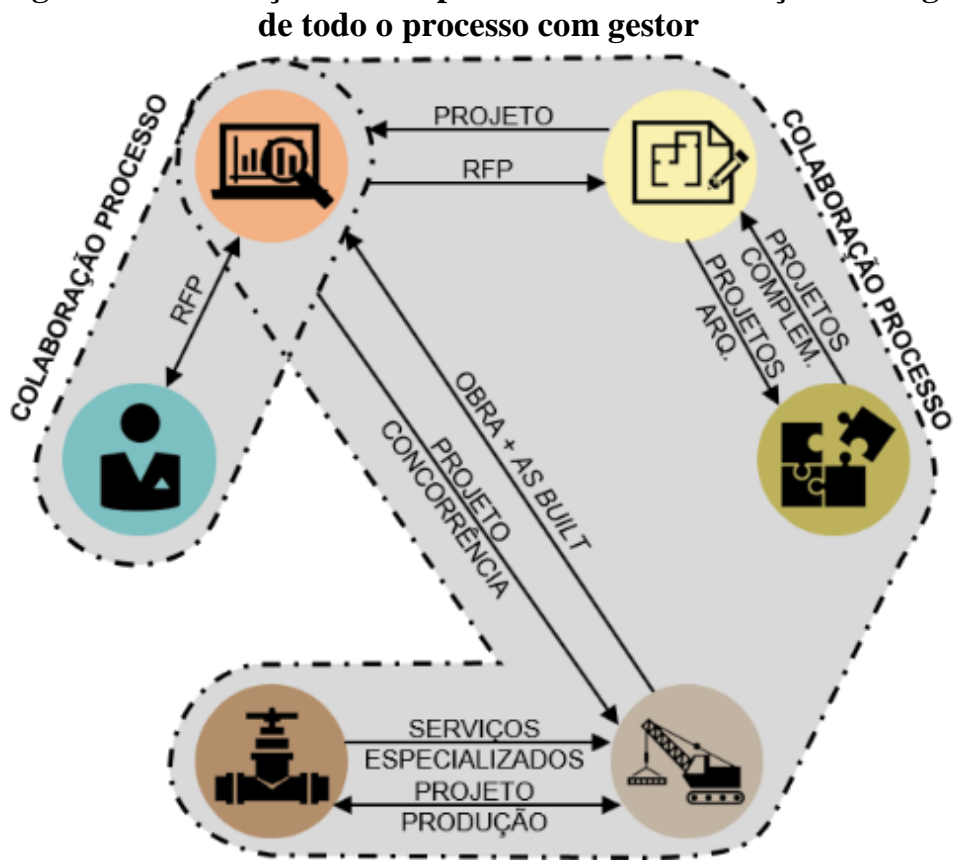

Fonte: Elaborado pela autora. 
Todos os profissionais colaboram com todas as outras disciplinas, de forma que ao final do desenvolvimento do projeto sejam reduzidas ou eliminadas as necessidades de modificações ou correções devido à incompatibilidade de informações.

Além disso, a colaboração entre toda a equipe facilita a análise técnica feita pelo construtor e os especialistas de execução antes do início da obra. Como esses profissionais tiveram participação desde a concepção do projeto arquitetônico, todas as informações sobre a execução já foram incluídas nas soluções projetuais, resultando em uma execução com mais qualidade e eficiência.

A colaboração ao longo de todo o processo e por todos os agentes, permite estabelecer uma equipe multidisciplinar desde o início da concepção do projeto, em que todos possam antecipar as informações de sua área de atuação. Nesse caso, o gestor não é o único agente responsável por estabelecer o trabalho colaborativo, mas sim o coordenador do processo que alinha os objetivos do cliente para o desenvolvimento do empreendimento.

\subsubsection{Processo “chave na mão” ou turnkey}

Existe a possibilidade de o cliente contratar em conjunto o desenvolvimento do projeto e a execução da obra, de forma a selecionar um único agente para todo o processo. Nesse tipo de contratação, denominada "chave na mão" ou turnkey, é realizada uma associação entre o projetista de arquitetura e o construtor da obra. Esses dois agentes trabalham colaborativamente desde o início do processo (FORBES; AHMED, 2011).

Os três modelos de processo descritos anteriormente - processo de produção sem colaboração; processo colaborativo na etapa de projeto ou de obra; e colaboração ao longo de todo o processo - podem acontecer nesse tipo de contratação. A diferença em relação aos modelos anteriores é que a associação entre o projetista de arquitetura e o construtor recebe o RFP do cliente, ou gestor, quando este participa do processo, e o arquiteto desenvolve colaborativamente o projeto com o construtor.

Como o construtor é selecionado no início do processo, não existe a etapa de concorrência. No entanto, o cliente é responsável por validar o projeto antes do início da etapa de execução, de forma a verificar se ele atende aos requisitos de desempenho e qualidade. Os demais agentes projetistas complementares e especialistas de execução - possuem as mesmas 
responsabilidades de um processo sem o turnkey, ou seja, desenvolvem os projetos de sistemas prediais e executam os serviços na obra, respectivamente.

O caso de um processo de produção sem colaboração está descrito na Figura 41, quando não há a participação de um gestor no processo e na Figura 42, quando este está presente. No processo com contratação turnkey, a colaboração entre o projetista de arquitetura e o construtor é obrigatória, já que ambos são contratados como uma única organização. Mesmo que sejam duas empresas ou profissionais independentes, é estabelecida a associação entre as duas disciplinas, que têm a responsabilidade mútua do desenvolvimento do projeto e da execução da obra.

Figura 41 - Interações de um processo turnkey segmentado sem

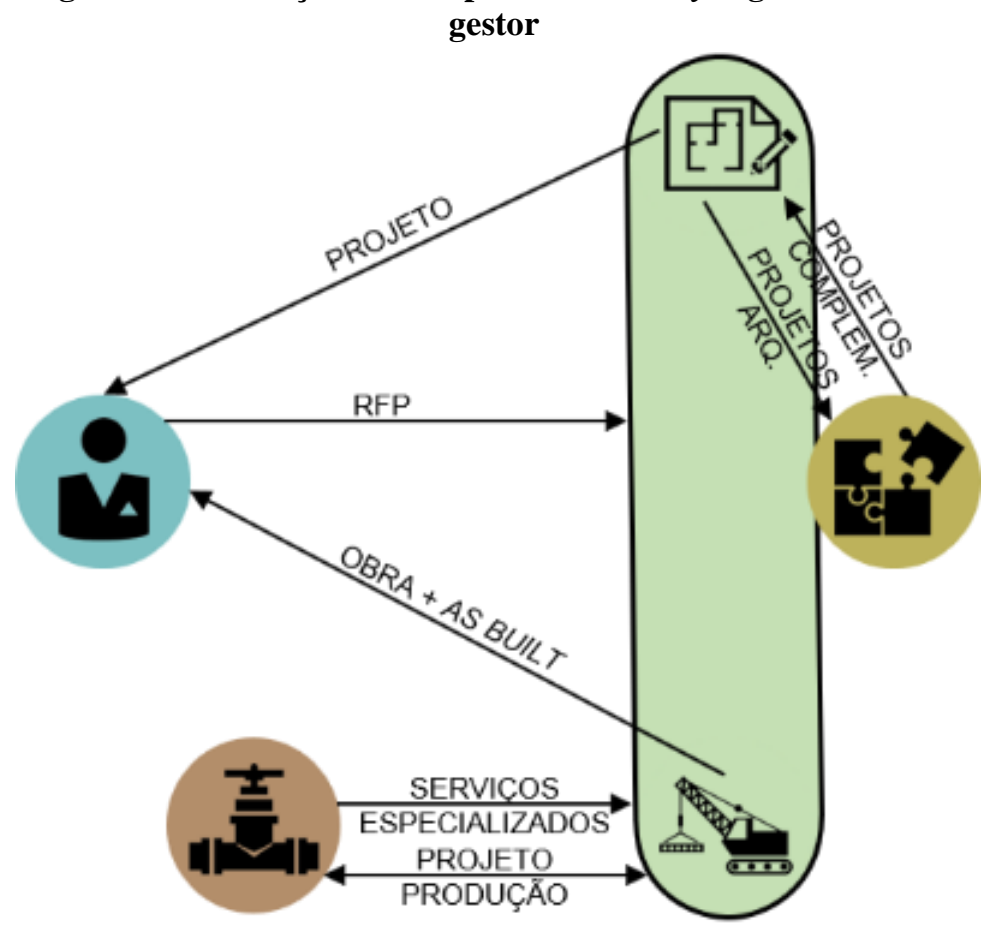

Fonte: Elaborado pela autora. 
Figura 42 - Interações de um processo turnkey segmentado com

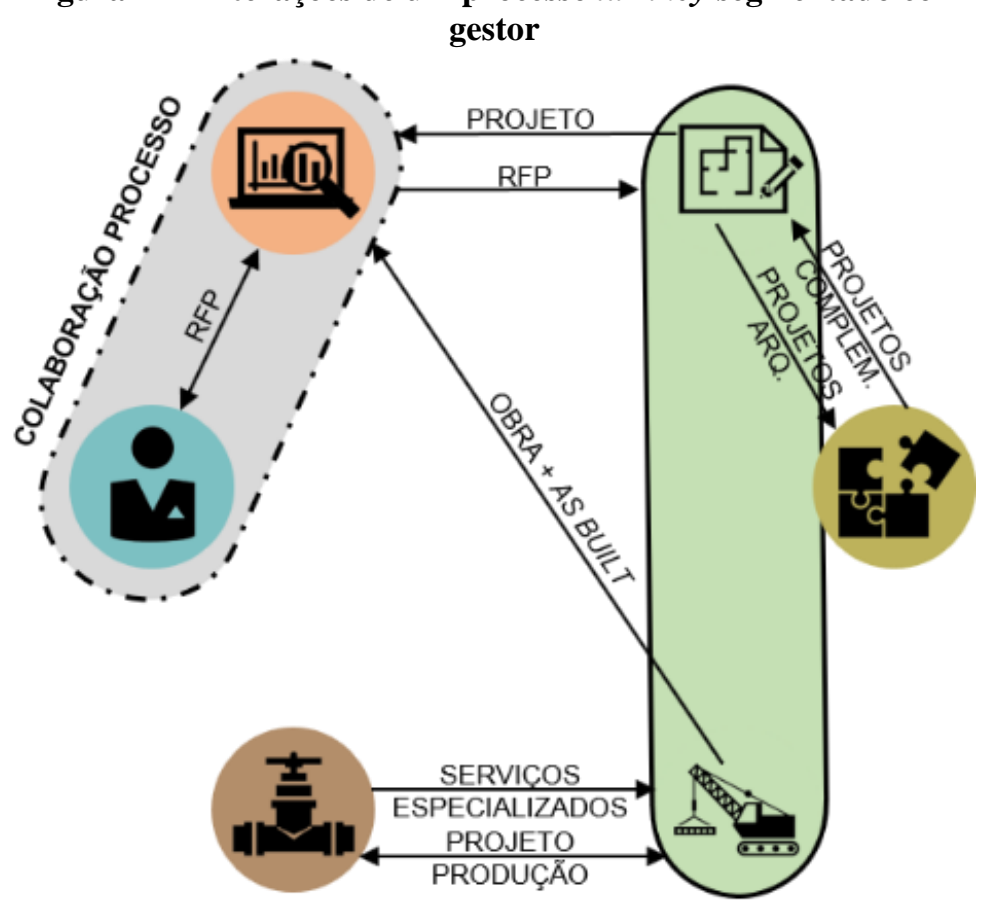

Fonte: Elaborado pela autora.

A colaboração entre os demais agentes, além do projetista de arquitetura e do construtor, pode acontecer no turnkey na etapa de projeto, em que os projetistas complementares participam da elaboração do projeto (Figura 43 e Figura 44), e na etapa de obra, em que os especialistas de execução participam do planejamento de obra e elaboração do projeto para produção com o construtor (Figura 45 e Figura 46).

Nesses casos, as possibilidades de colaboração são maiores do que em uma contratação separada do projetista de arquitetura e o construtor, pois no turnkey existe sempre a colaboração entre as disciplinas de projeto e execução. Ainda que a colaboração não aconteça entre todos os participantes, a aproximação entre as etapas de projeto e execução facilita a continuidade no desenvolvimento do processo, pois questões relacionadas à execução são levantadas e solucionadas ainda na etapa de projeto. 
Figura 43 - Interações de um processo turnkey com colaboração na etapa de projeto sem gestor

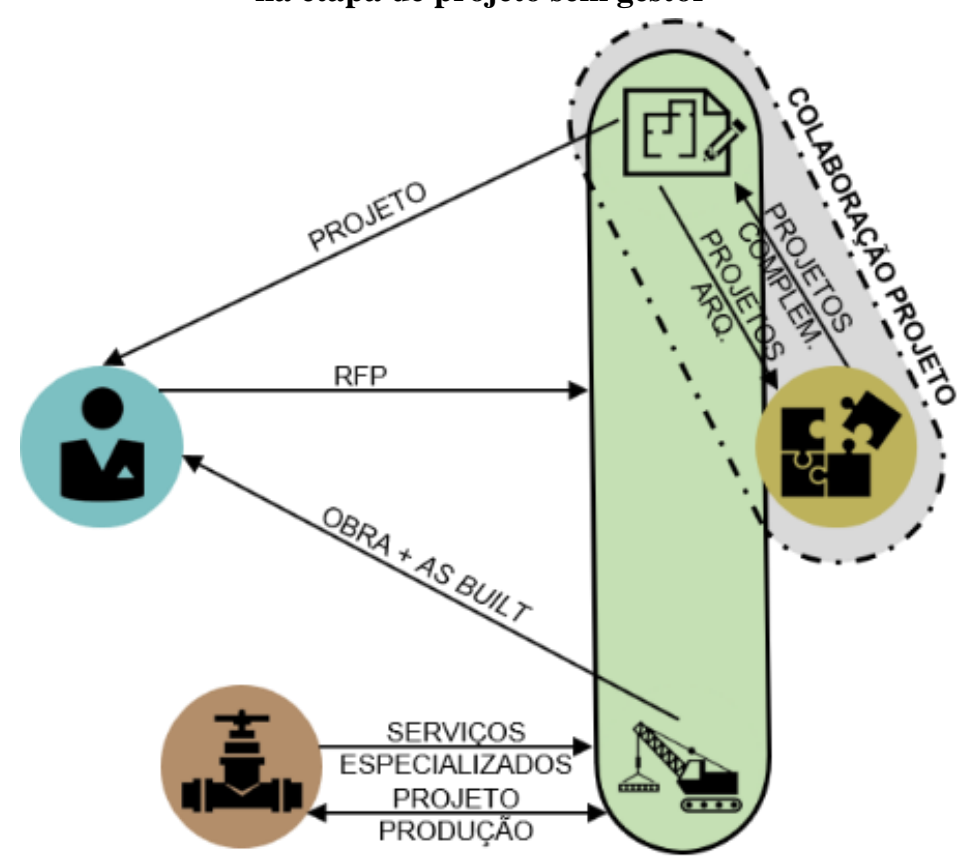

Fonte: Elaborado pela autora.

Figura 44 - Interações de um processo turnkey com colaboração

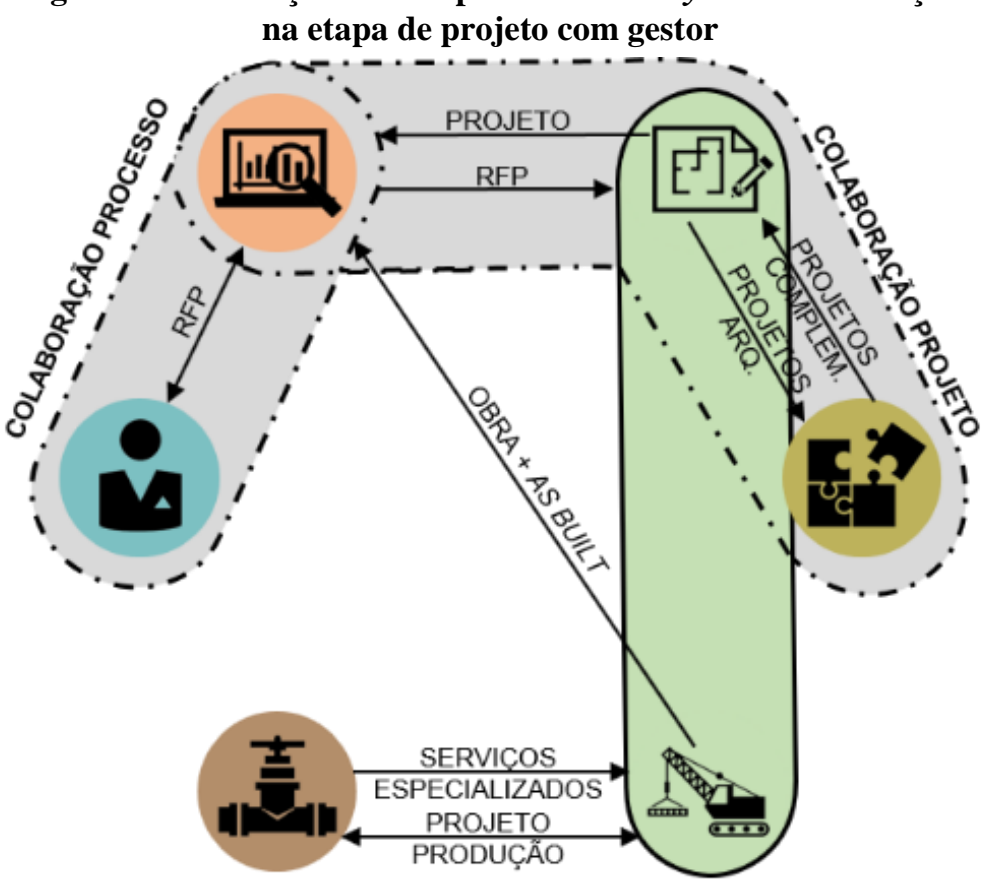

Fonte: Elaborado pela autora. 
Figura 45 - Interações de um processo turnkey com colaboração na etapa de obra sem gestor

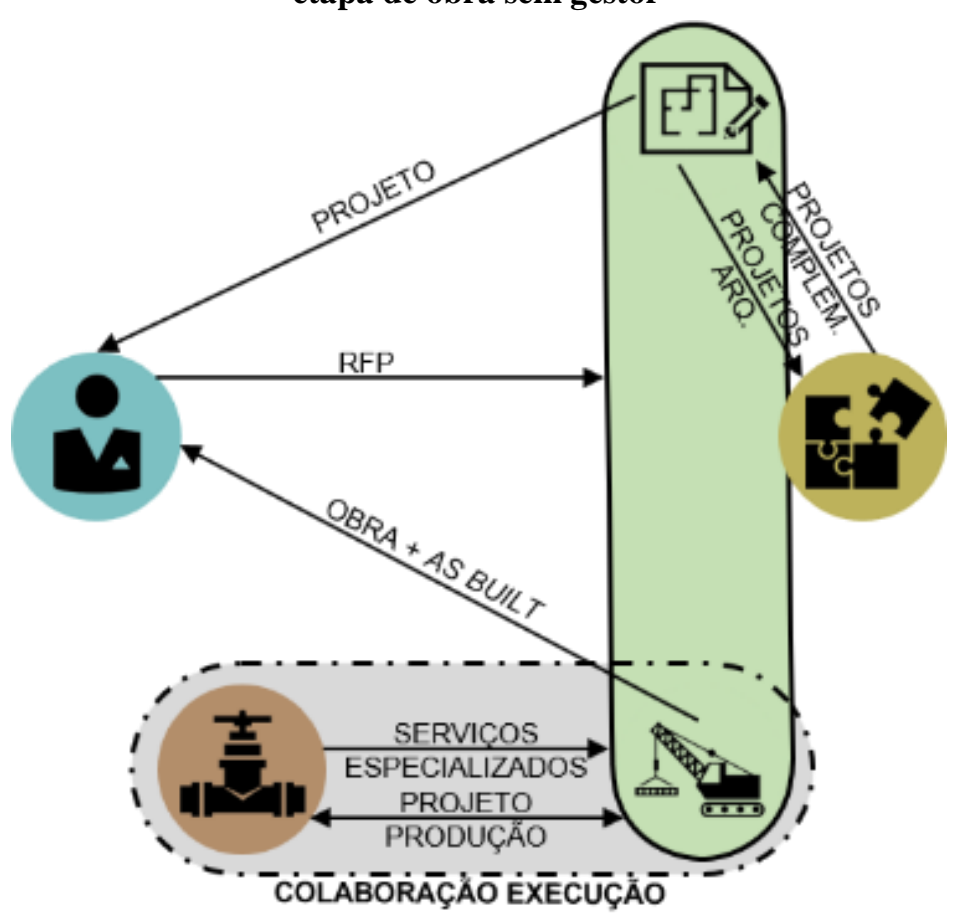

Fonte: Elaborado pela autora.

Figura 46 - Interações de um processo turnkey com colaboração na etapa de obra com gestor

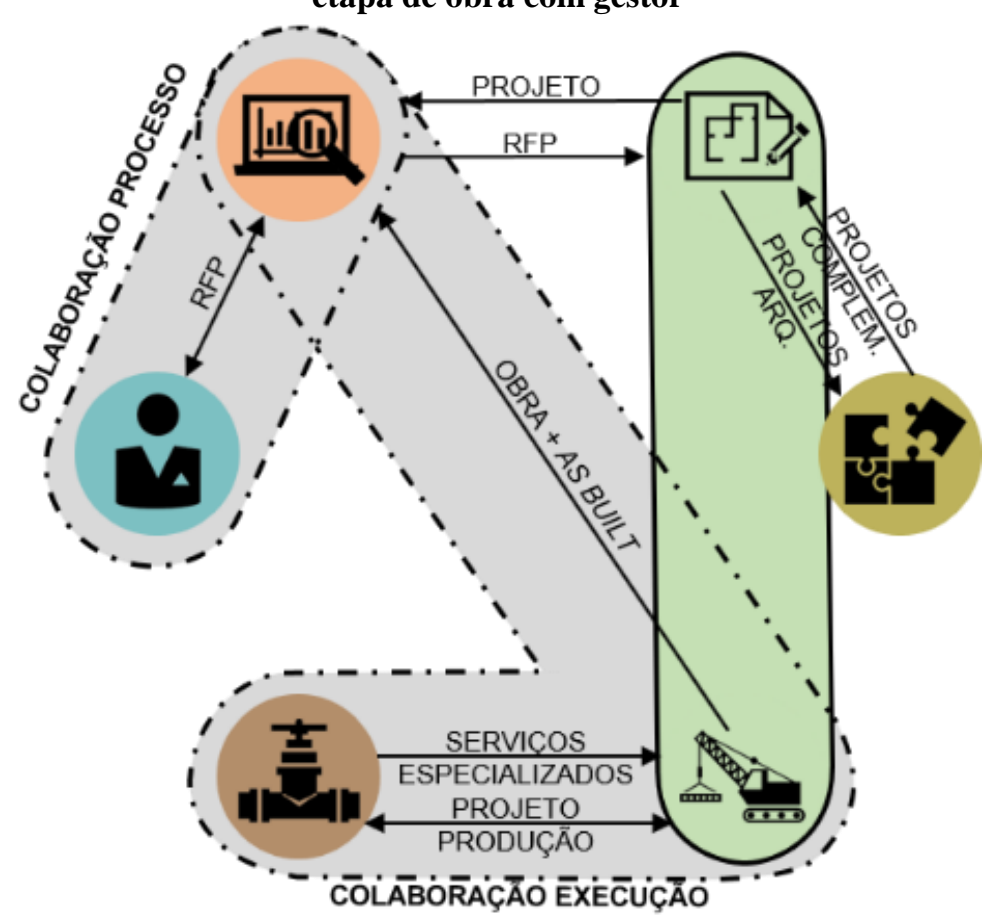

Fonte: Elaborado pela autora. 
A possibilidade de colaboração na etapa de projeto e de execução simultaneamente, representa no turnkey um processo com a colaboração ao longo de todo o processo (Figura 47 e Figura 48). Como a associação entre o projetista de arquitetura e o construtor está presente em todos os processos com turnkey, ela é responsável por garantir a aproximação entre as etapas de desenvolvimento do projeto e a execução. Dessa forma, existe a colaboração entre todos os profissionais do processo, desde as primeiras decisões do projeto, com base no RFP.

Figura 47 - Interações de um processo turnkey com colaboração ao longo de todo o processo sem gestor

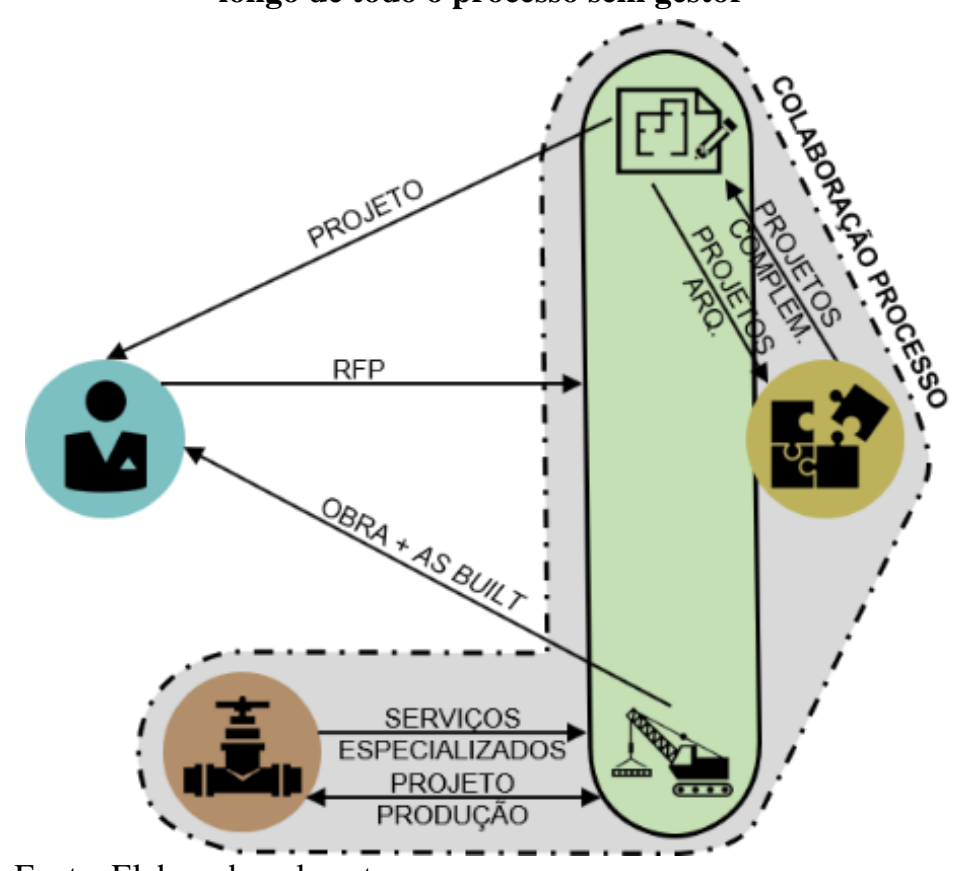

Fonte: Elaborado pela autora.

Figura 48 - Interações de um processo turnkey com colaboração ao longo de todo o processo com gestor

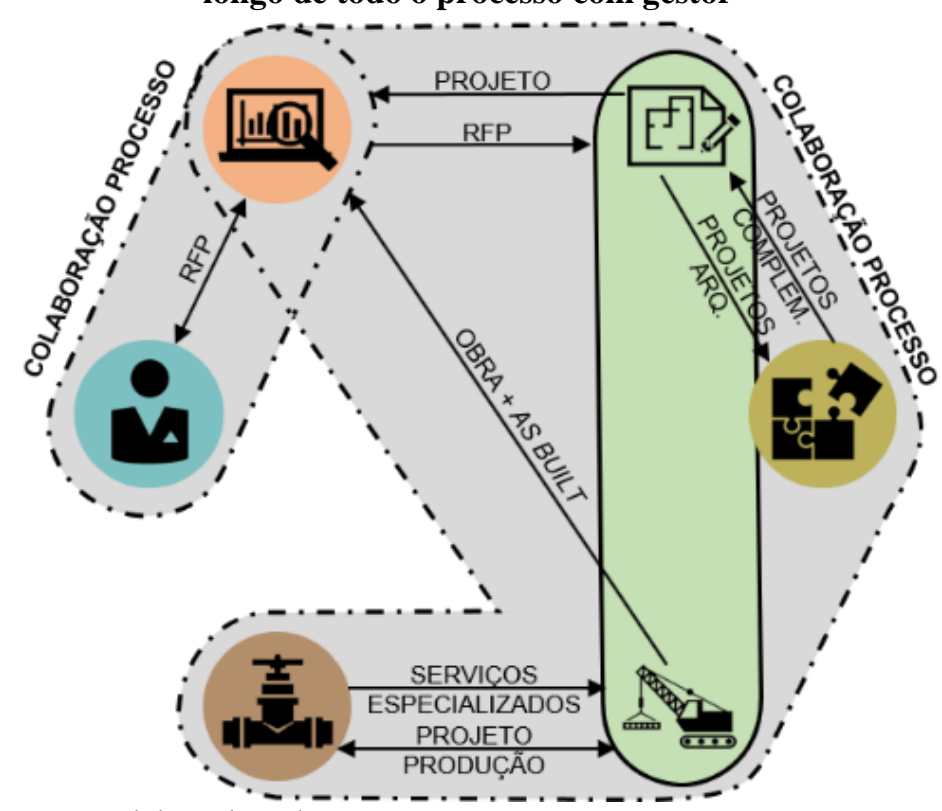

Fonte: Elaborado pela autora. 


\subsubsection{Níveis de Integração Organizacional}

A Figura 49 indica os níveis de integração dos modelos descritos para a integração organizacional, partindo do menos integrado - Integração 0 - para o mais integrado Integração 3++. Alguns modelos organizacionais podem ser identificados como derivações de outros modelos, a partir da inserção de algumas características ao processo de produção.

Dentre as características que alteram o modelo de interação da equipe estão:

- presença do gestor do processo;

- colaboração na etapa de projeto ou obra;

- colaboração entre todos os agentes; e

- associação entre o projetista de arquitetura e o construtor.

A cada inserção de uma ou mais dessas características ou com a combinação de dois modelos, altera-se o nível de colaboração. O nível de integração aumenta verticalmente, conforme aumenta o número de colaborações no processo, e horizontalmente, conforme diferentes combinações em um mesmo modelo o que favorece a integração organizacional (Tabela 17 Tabela 18).

Quanto maior o número de colaborações entre os participantes ou da inserção do gestor ou do modelo turnkey, mais integrado é o processo, pela perspectiva organizacional. Quando as atividades são realizadas independentemente pelas disciplinas, ou seja, sem a colaboração dos demais profissionais, existe a possibilidade de retrabalho pela incompatibilidade dos projetos e com a forma de trabalho dos responsáveis pela execução. Com a presença da colaboração na equipe, existe uma continuidade nas entregas de cada atividade, e o desenvolvimento do empreendimento acontece a partir da perspectiva de diferentes disciplinas da equipe. 
Figura 49 - Níveis de Integração Organizacional

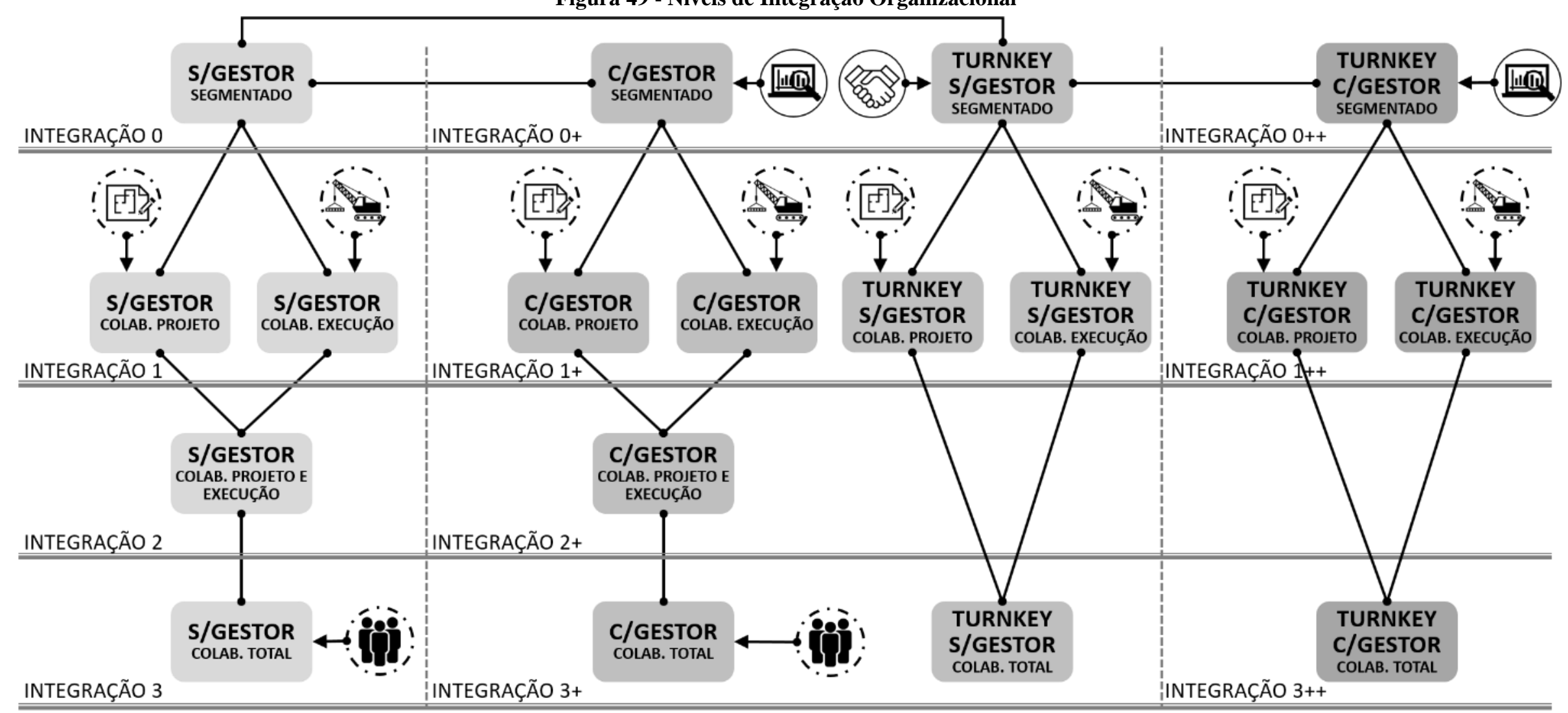

LEGENDA
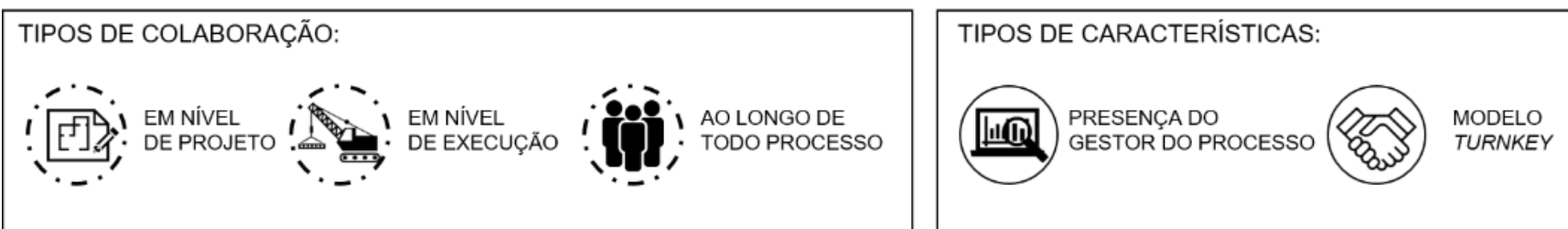
Tabela 17 - Descrição dos Níveis de Integração Vertical

\begin{tabular}{cl}
\hline $\begin{array}{c}\text { Nível de } \\
\text { Integração } \\
\text { Vertical }\end{array}$ & \multicolumn{1}{c}{ Descrição } \\
\hline $\mathbf{0}$ & processo em que não existe nenhum trabalho colaborativo. \\
$\mathbf{1}$ & $\begin{array}{l}\text { processo com a inserção de uma colaboração - na etapa de projeto } \\
\text { ou execução. }\end{array}$ \\
$\mathbf{2}$ & $\begin{array}{l}\text { combinação entre processos com colaboração na etapa de projeto } \\
\text { ou execução, sem a colaboração entre etapas. } \\
\text { processo com colaboração ao longo de todo o processo e entre } \\
\text { todos os profissionais. }\end{array}$ \\
\hline
\end{tabular}

Fonte: Elaborado pela autora.

Tabela 18 - Descrição dos Níveis de Integração Horizontal

\begin{tabular}{cl}
\hline $\begin{array}{c}\text { Nível de } \\
\text { Integração } \\
\text { Horizontal }\end{array}$ & \multicolumn{1}{c}{ Descrição } \\
\hline & $\begin{array}{l}\text { sem nenhuma característica adicional. } \\
\text { processo com a participação de um gestor ou da associação entre } \\
\text { projetista de arquitetura e construtor (modelo turnkey). } \\
\text { processo com a participação de um gestor e da associação entre } \\
\text { projetista de arquitetura e construtor (modelo turnkey). }\end{array}$ \\
++ &
\end{tabular}

Fonte: Elaborado pela autora.

\subsection{Integração pela Tecnologia de Informação}

A integração pela perspectiva da tecnologia da informação foi analisada de acordo com o nível de maturidade BIM definido por Succar (2009) e Bew e Richards (apud ROYAL INSTITUTE OF BRITISH ARCHITECTS, 2012).

- Nivel 0: desenvolvimento do projeto da forma convencional, com trocas de arquivos 2D, documentos digitais e documentos em papel;

- Nivel 1: uso do BIM em apenas uma disciplina, sem trocas de modelos BIM; o agente que trabalha com o BIM gera arquivos 2D, documentos digitais e documentos em papel, a partir do modelo BIM;

- Nível 2: colaboração e troca de modelos BIM por duas ou mais disciplinas, mas sem o uso em todo o processo; a troca dos modelos pode ocorrer dentro de uma mesma etapa ou entre etapas; 
- Nível 3: modelo BIM desenvolvido colaborativamente por todas as disciplinas e ao logo de todo o processo, os agentes trabalham em um modelo BIM único, ou um modelo federado.

As interações entre a equipe em relação ao nível de maturidade BIM podem ser analisadas de duas formas: em uma mesma etapa ou entre etapas. Dentre as etapas considera-se planejamento, desenvolvimento do projeto e execução.

No caso do nível de maturidade BIM dentro de uma mesma etapa, identifica-se a forma como cada agente trabalha no modelo - convencional ou BIM; qual o formato das entregas de cada atividade e, caso exista, como se dá a troca de informações do projeto e/ou o seu acesso.

No nível 0 (Figura 50), como os dois agentes trabalham da forma convencional, podem existir entregas de arquivos entre eles ou o acesso virtual ao arquivo de referência, por meio de arquivos 2D e documentos digitais ou impressos. No nível 1 (Figura 51), como apenas um agente usa o BIM, as trocas de arquivos ou o acesso remoto ocorre da mesma forma que o nível 0 , ou seja, com os mesmos formatos da forma convencional. No entanto, existe o aperfeiçoamento no desenvolvimento da atividade do agente que trabalha com o BIM.

No nível 2 (Figura 52), apesar dos dois agentes trabalharem com o BIM, cada um possui o domínio do seu modelo, sendo que esse pode ser compartilhado ou então acessado remotamente pelo outro agente. No nível 3 (Figura 53) considera-se o trabalho por meio de um único modelo BIM que é compartilhado pelos dois agentes, sem que seja necessário transmitir os arquivos do modelo computacional. Tanto no nível 2 como no 3, pode ser necessário transmitir alguns arquivos que não estejam no formato BIM, como no caso de documentos com informações sobre os componentes do projeto e desenhos para a execução da edificação no canteiro de obras. 
Figura 50 - BIM Nível 0 - Convencional

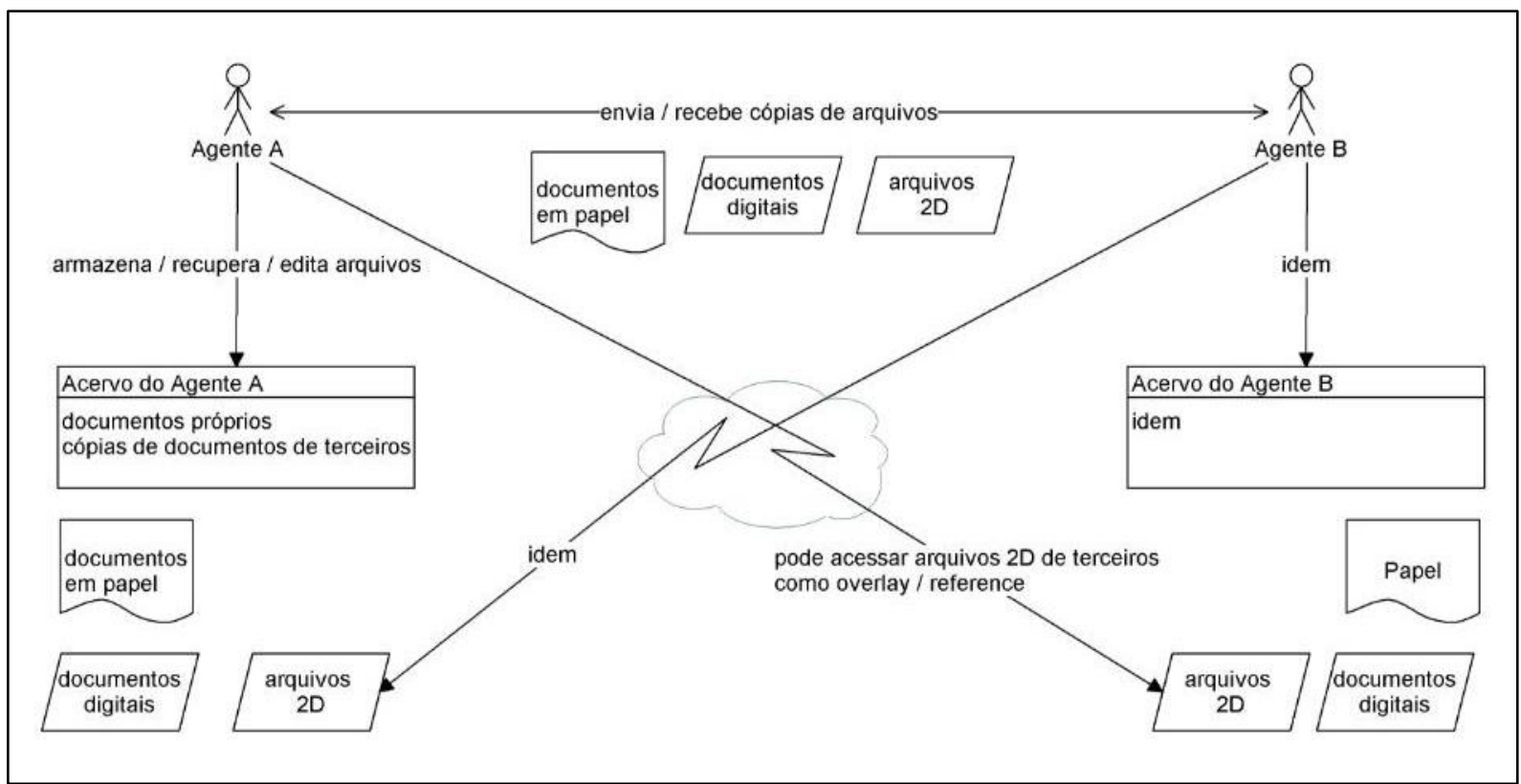

Fonte: Elaborado pela autora.

Figura 51 - BIM Nível 1 - BIM-Convencional

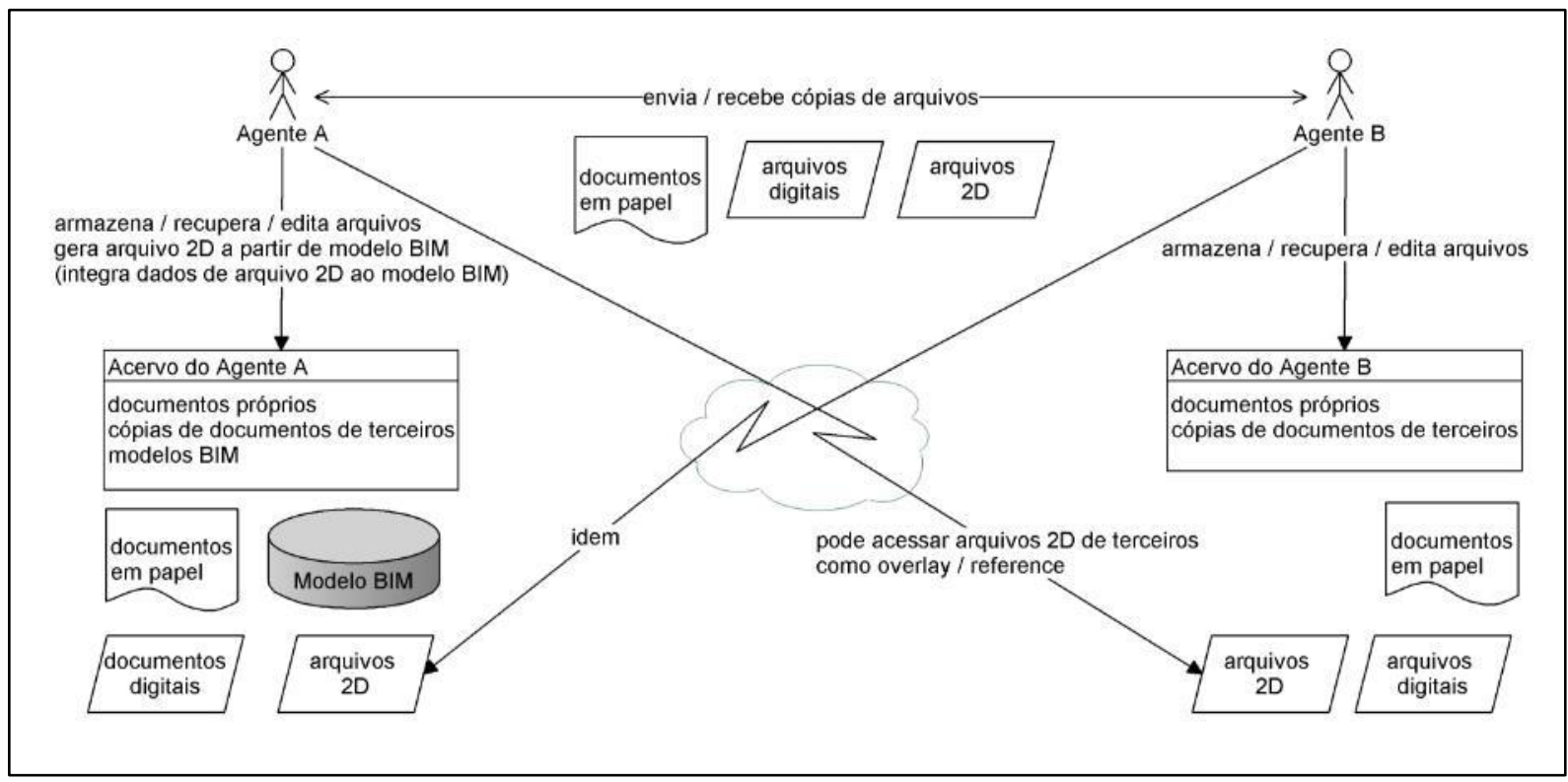

Fonte: Elaborado pela autora. 
Figura 52 - BIM Nível 2 - BIM-BIM

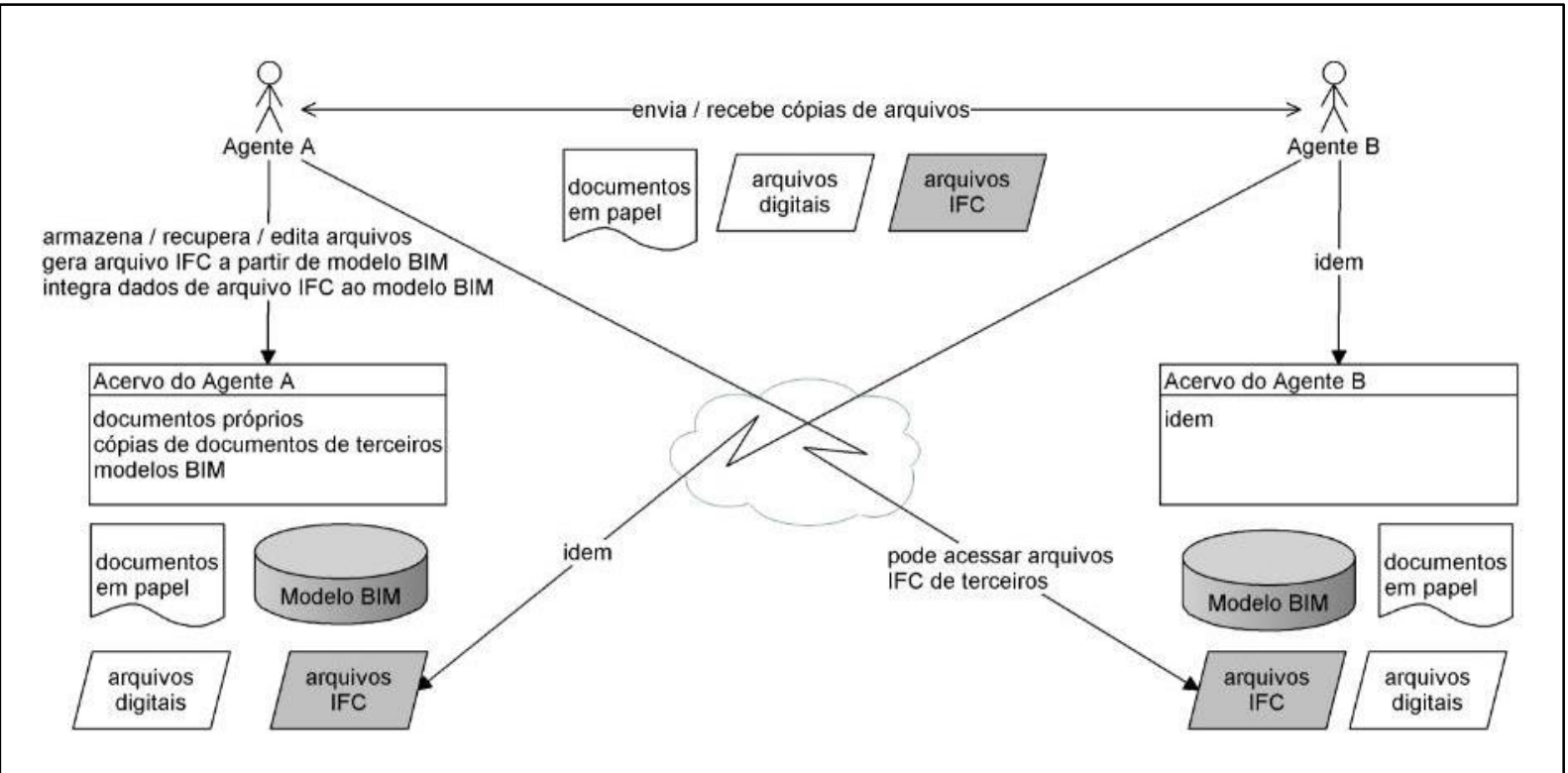

Fonte: Elaborado pela autora.

Figura 53 - BIM Nível 3 - BIM Modelo único ou federado

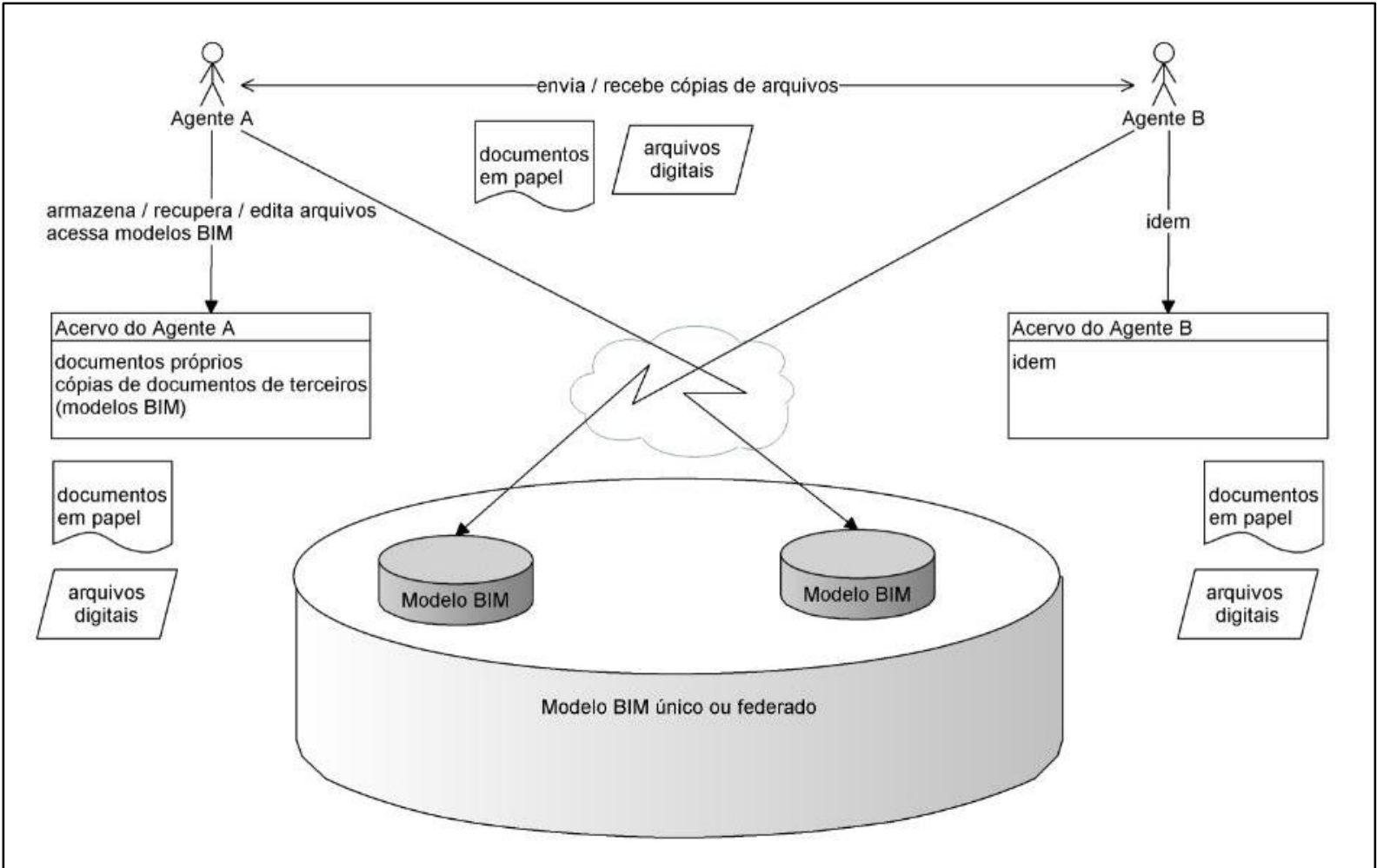

Fonte: Elaborado pela autora.

Considerando as integrações entre etapas, identifica-se quais as atividades necessárias para que o desenvolvimento do processo ocorra e qual o tipo de modelo é utilizado na transição entre as etapas. No nível 0 (Figura 54), em que não existe o uso do BIM, não existe nenhuma atividade 
necessária para que ocorra a troca de informações entre as etapas, sendo que ambas são realizadas com a utilização de arquivos $2 \mathrm{D}$, documentos digitais e impressos.

No Nível 1, existem duas possibilidades do uso do BIM: na etapa antecedente (Figura 55) ou na precedente (Figura 56). Na primeira, é necessário que a partir do modelo BIM sejam gerados arquivos $2 \mathrm{D}$ para que estes possam ser utilizados na etapa realizada na forma tradicional. $\mathrm{Na}$ segunda possibilidade - etapa precedente - é necessário gerar o modelo BIM a partir das informações desenvolvidas na forma convencional, ou seja, arquivos $2 \mathrm{D}$ e documentações digitais ou impressas. Em ambos os casos do nível 1, existe a falta de continuidade no fluxo de informações do processo, sendo necessário realizar atividades adicionais para solucionar o problema de incompatibilidade entre os processos - convencional e BIM.

O nível 2 e o nível 3 possuem a mesma representação (Figura 57), pois ambos os agentes responsáveis pela transição de etapas trabalham com o BIM. A diferença é que no nível 3, o uso do BIM acontece em todo o processo, ou seja, todas as etapas trabalham em um mesmo tipo de modelo, sem que seja necessário compatibilizar as informações - convencionais em BIM e BIM em convencional. Nesse caso existe a continuidade no fluxo de informações, o que favorece a integração pela tecnologia da informação. 
Figura 54 - BIM Nível 0 entre etapas

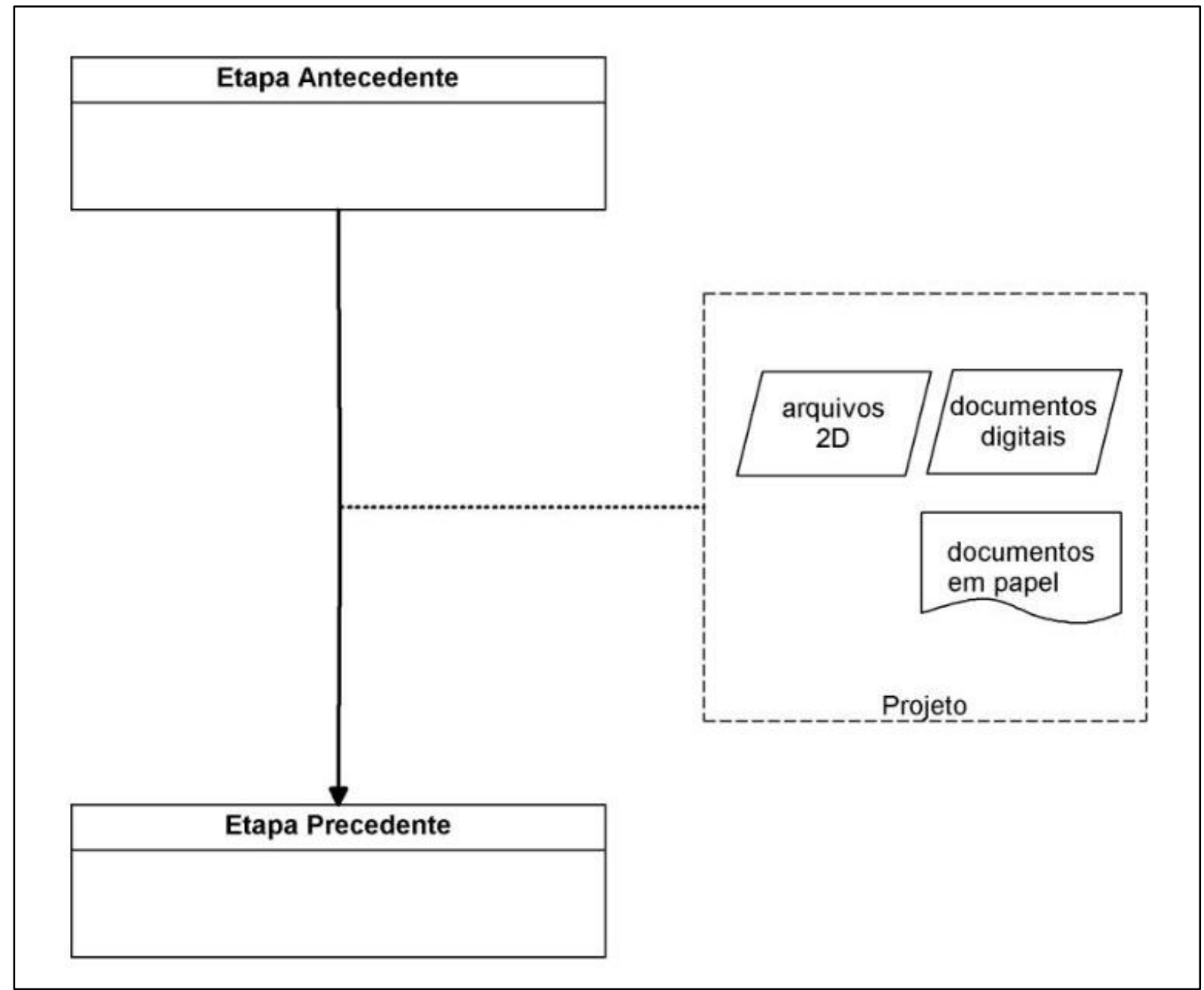

Fonte: Elaborado pela autora. 
Figura 55 - BIM Nível 1 entre etapas: BIM-Convencional

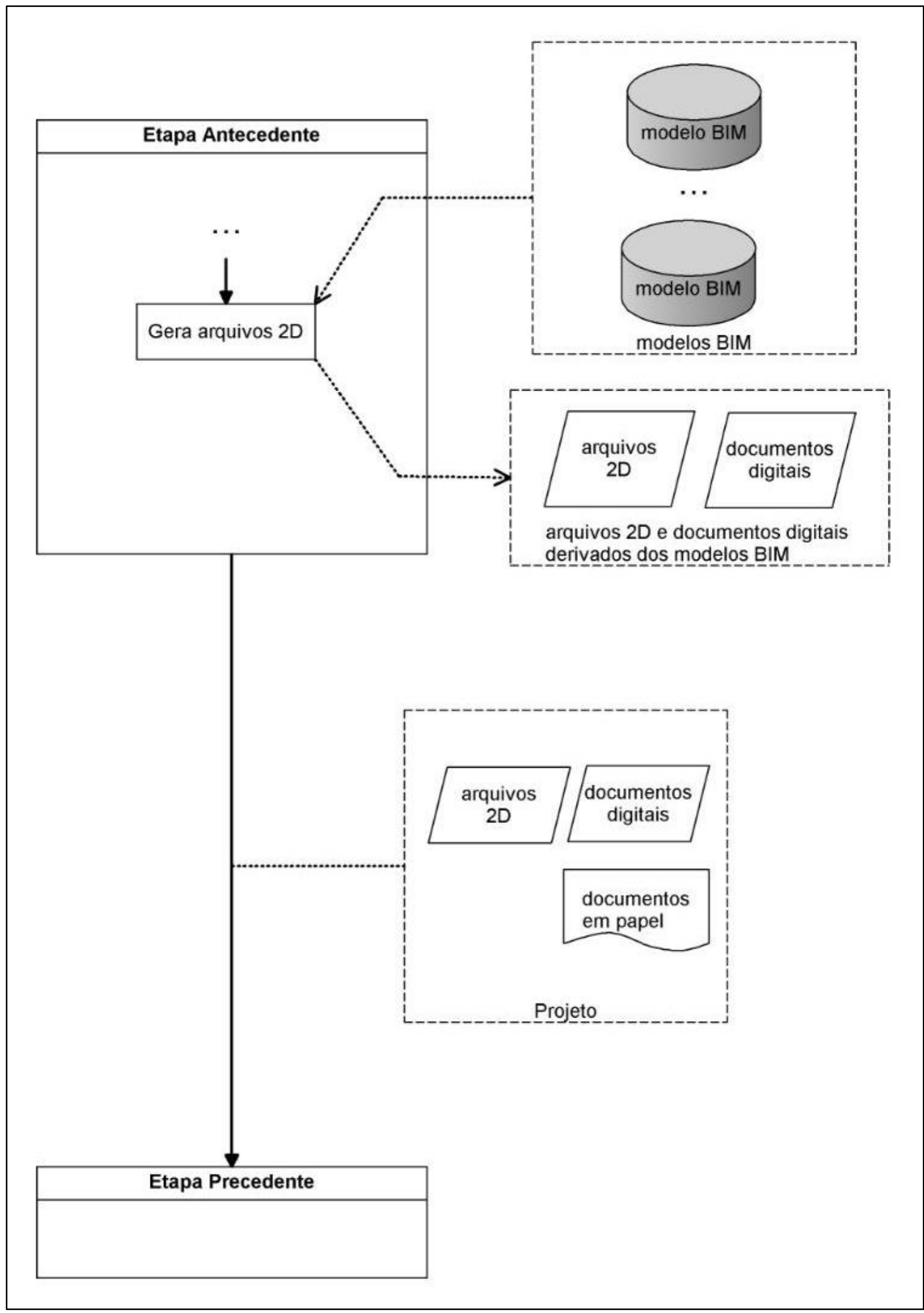

Fonte: Elaborado pela autora. 
Figura 56 - BIM Nível 1 entre etapas: Convencional-BIM

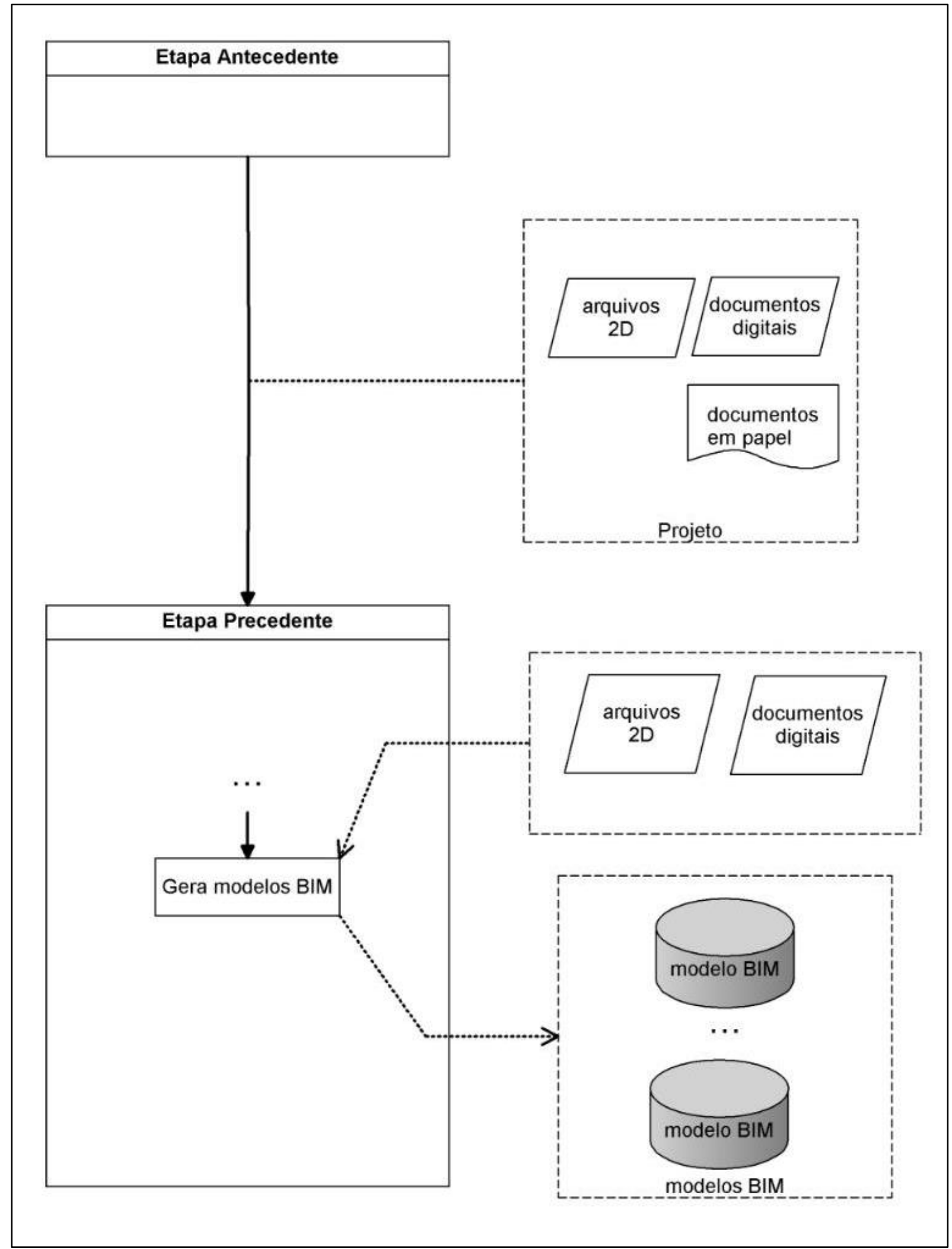

Fonte: Elaborado pela autora. 
Figura 57 - BIM Nível 2 e 3 entre etapas

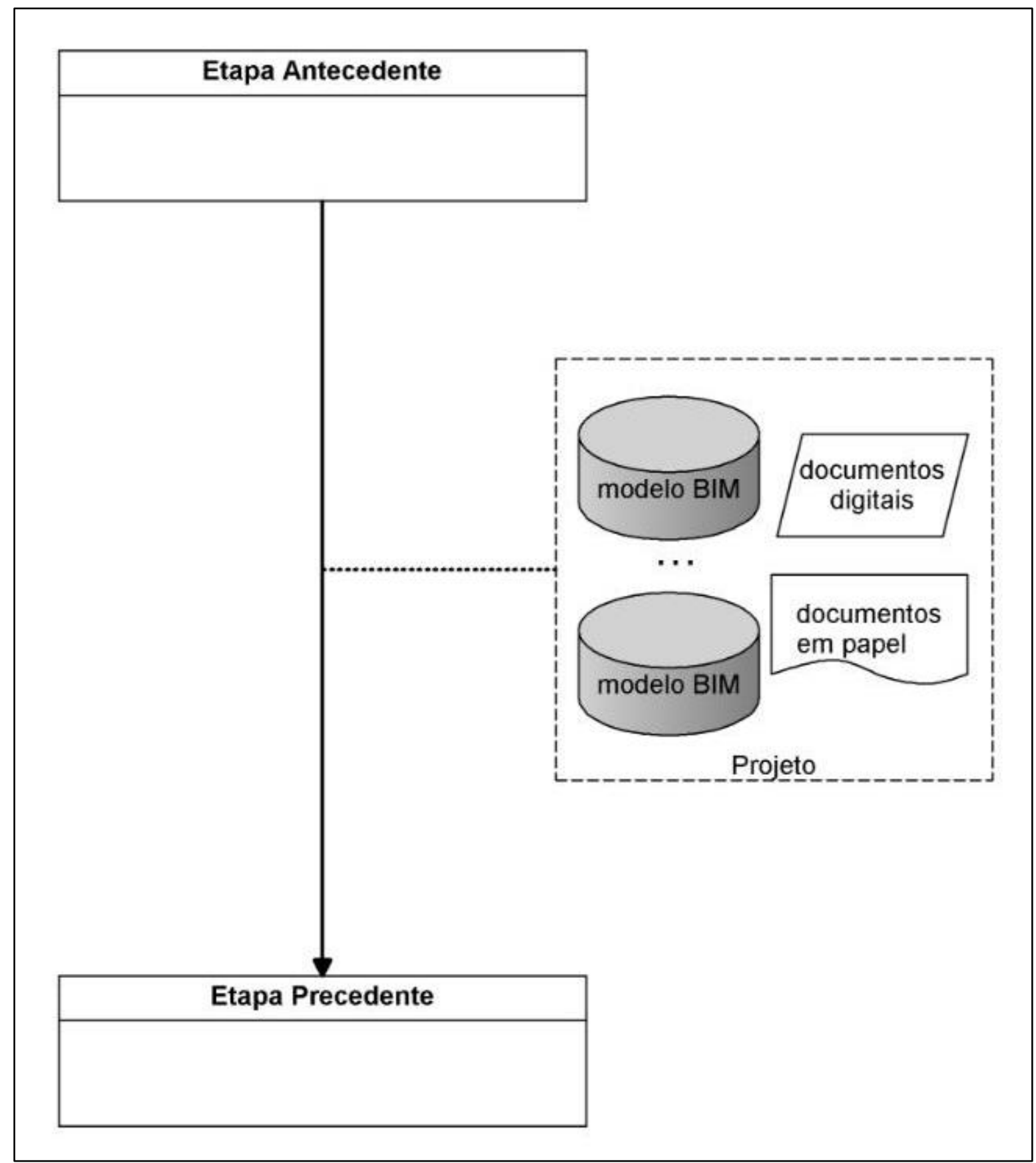

Fonte: Elaborado pela autora.

As relações de trabalho e desenvolvimento do modelo computacional da construção foram analisadas a partir das possibilidades do uso do BIM entre os agentes, que foram definidos de acordo com os profissionais dos diagramas da perspectiva organizacional - projetista de arquitetura, projetistas complementares, construtor, especialistas de execução e gestor do processo. Cada nível de maturidade BIM indica um tipo de relação de trabalho entre dois agentes: Convencional, BIM-Convencional, BIM-BIM, ou BIM em todo o processo (Figura $58)$. 
Figura 58 - Legenda dos diagramas de Integração pela Tecnologia da Informação

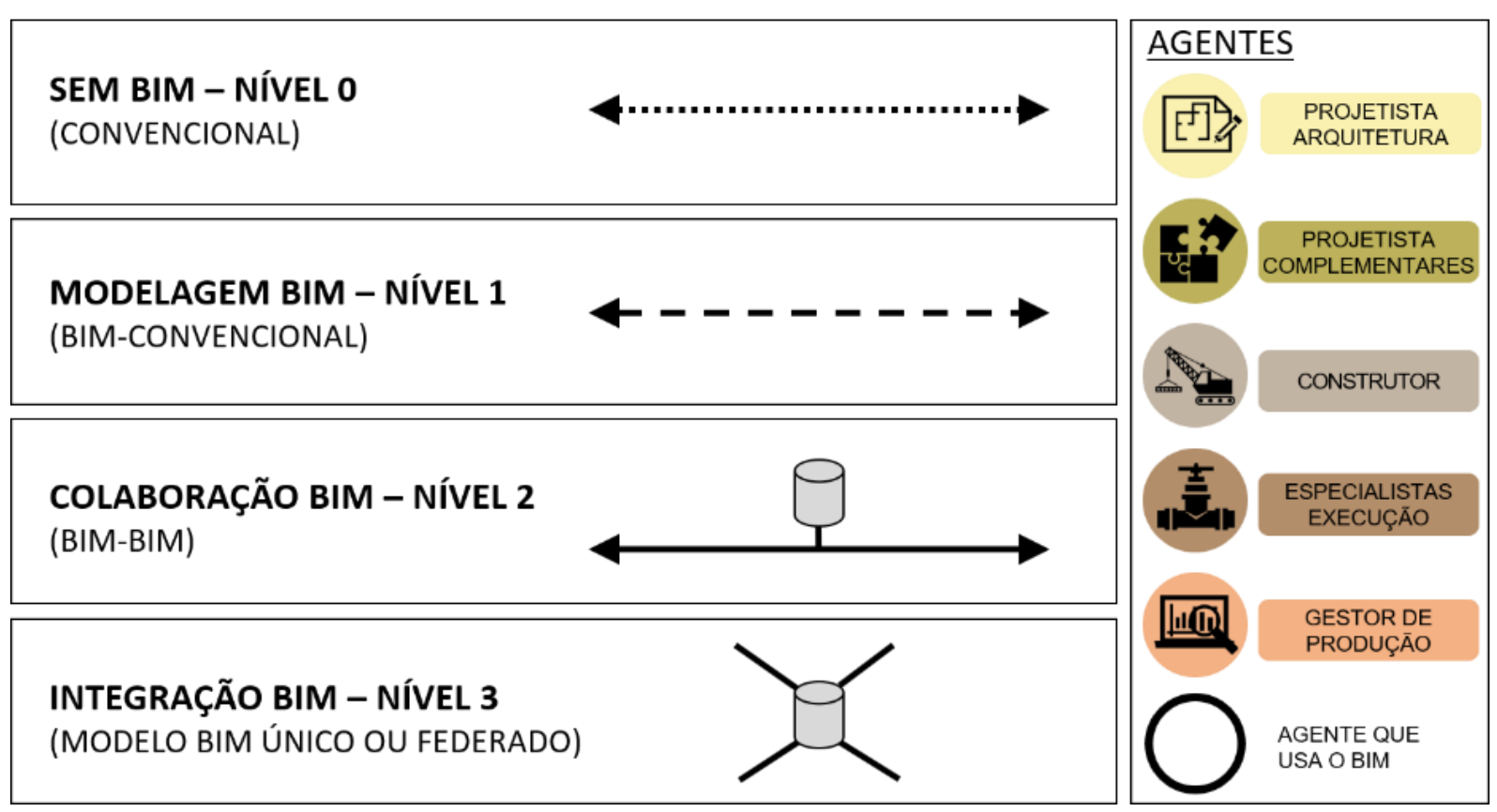

Fonte: Elaborado pela autora.

\subsubsection{BIM - Nível 0}

A Figura 59 indica um processo de produção em que não existe o uso do BIM por parte de nenhum agente. Nesse caso, o desenvolvimento e as trocas de informações do projeto consistem no conjunto de arquivos 2D, documentos digitais e documentos de papel. O nível 0 de maturidade BIM indica um processo de produção com um mínimo grau de integração pela perspectiva da tecnologia da informação, pois existe a possibilidade de colaboração por meio de arquivos digitais $2 \mathrm{D}$.

No entanto, pela perspectiva da tecnologia da informação, esse não é o modelo mais eficiente, pois, mesmo que exista a colaboração entre os agentes - integração contratual e/ou organizacional - o fluxo da informação durante o desenvolvimento do projeto não é contínuo, ou seja, a análise de dados, identificação de interferências entre disciplinas e elaboração de planilhas de quantitativos é realizada de maneira não automatizada. Isso pode levar a erros devido à interpretação visual de informações - ainda que os desenhos possam ser sobrepostos - e à necessidade de reinserção de dados e redesenho - ainda que em formato digital. 


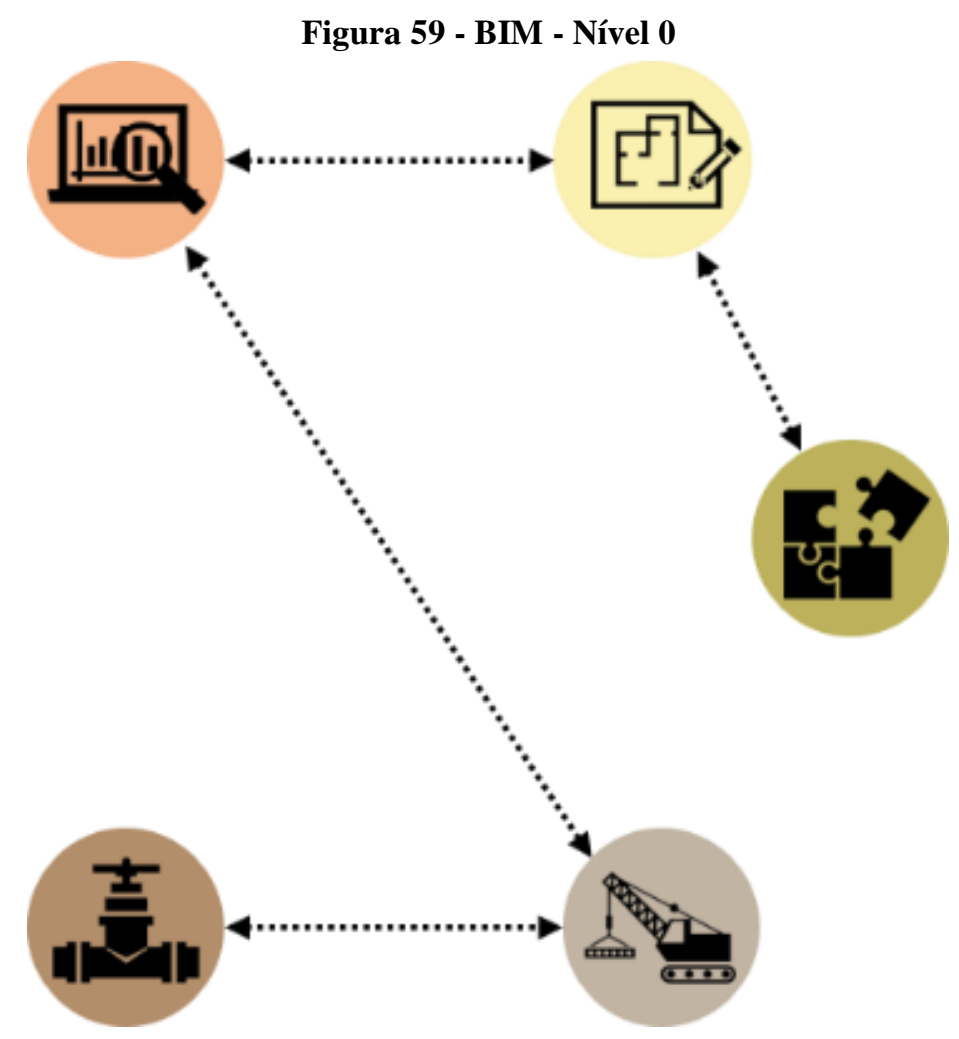

Fonte: Elaborado pela autora.

\subsubsection{BIM - Nível 1}

O nível de maturidade 1 indica que existe o uso do BIM no processo de produção dentro das atividades de apenas uma disciplina, podendo ser o projetista de arquitetura, construtor ou gestor. A falta do compartilhamento do modelo BIM faz com que seja necessário definir uma nova atividade ao processo, que visa passar as informações presentes nos arquivos $2 \mathrm{D}$ para o modelo BIM. Essa nova atividade pode causar o aumento do prazo de desenvolvimento do empreendimento e possibilitar que erros aconteçam na modificação do arquivo, além de impedir a continuidade no fluxo de informações.

No entanto, o uso não compartilhado do BIM, permite uma melhoria em relação ao nível 0, pois o desenvolvimento das atividades com o uso do BIM é aprimorado. Nesse caso, os demais agentes que não usaram o BIM no processo se beneficiam, de forma indireta, da modelagem BIM.

Quando se trata do uso pelo projetista de arquitetura (Figura 60), as análises sobre o modelo podem ser antecipadas e ocorrer de forma automatizada, garantindo que diferentes soluções 
sejam testadas desde a concepção do projeto. Como resultado, tem-se uma solução projetual mais confiável e próxima da realidade de execução.

No caso do construtor (Figura 61), podem ser propostas análises conjuntas do planejamento de execução, custo e acompanhamento das atividades de obra. Além disso, os modelos BIM podem ser usados para as atividades posteriores à entrega da obra, de uso e operação do edifício, facilitando e automatizando as tomadas de decisão para a manutenção dos sistemas prediais.

Quando o BIM é usado apenas na disciplina de gestão do processo (Figura 62), as atividades de compatibilização, quando de responsabilidade desse agente, podem ser automatizadas, garantindo maior confiabilidade e eliminando as possibilidades de interferência entre disciplinas. Além disso, esse agente pode usar o modelo BIM para as etapas de planejamento e acompanhamento do processo de produção - projeto e execução.

Existe ainda a possibilidade de uso do BIM pelo projetista de arquitetura e o construtor de forma isolada, ou seja, sem o compartilhamento do modelo BIM entre etapas (Figura 63). Nesse caso é possível aprimorar as duas atividades - projeto e execução. No entanto, não existe a continuidade no fluxo de informações, prejudicando a integração da tecnologia da informação. Mesmo nesse caso, existe a necessidade de realizar uma atividade exclusiva para transmitir as informações desenvolvidas em arquivos 2D para o modelo BIM, já que o projetista de arquitetura não compartilha esse modelo no final da sua atividade. 
Figura 60 - BIM - Nível 1 - projetista arquitetura

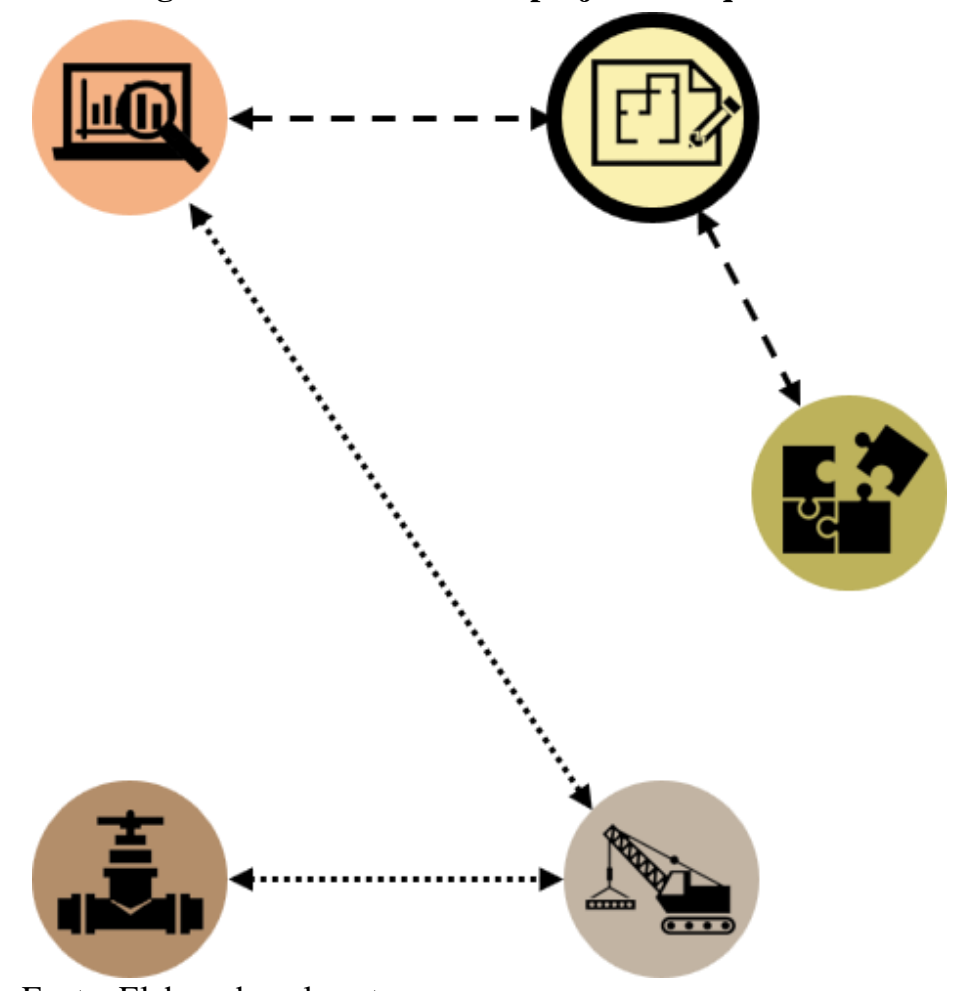

Fonte: Elaborado pela autora.

Figura 61 - BIM - Nível 1 - construtor

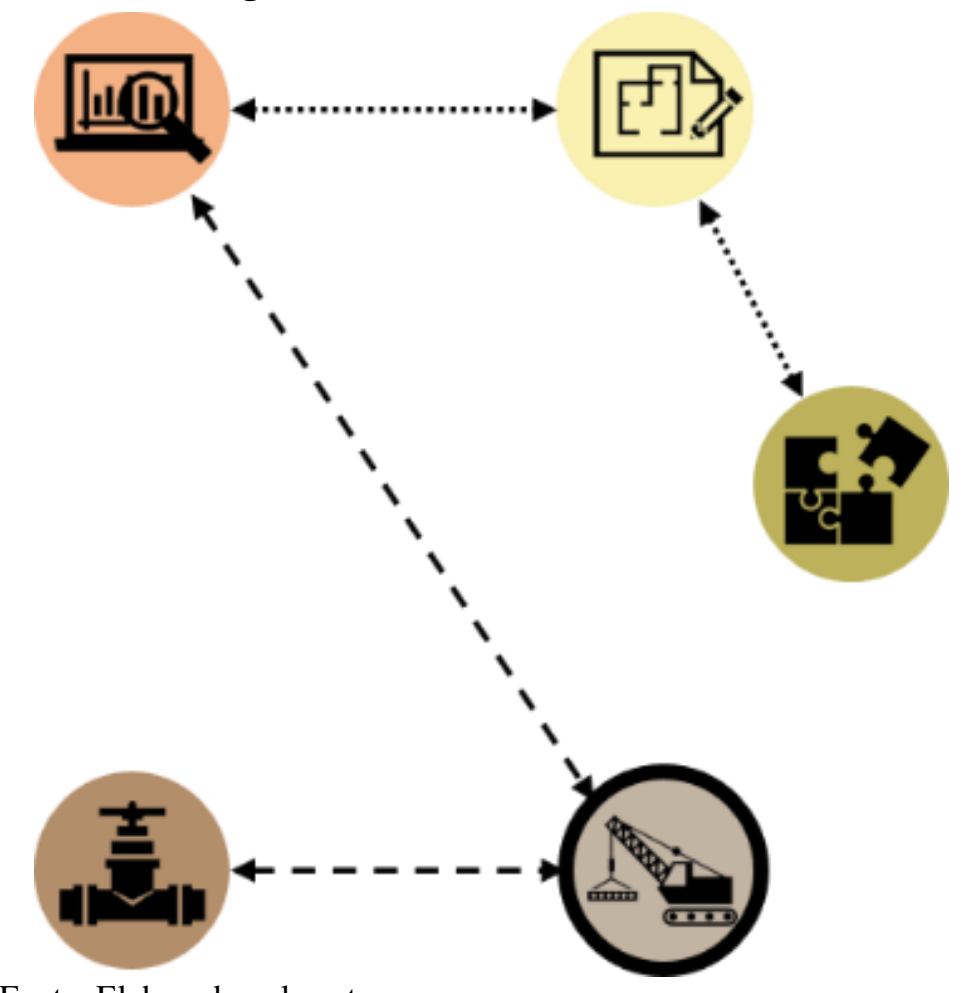

Fonte: Elaborado pela autora. 
Figura 62 - BIM - Nível 1 - gestor

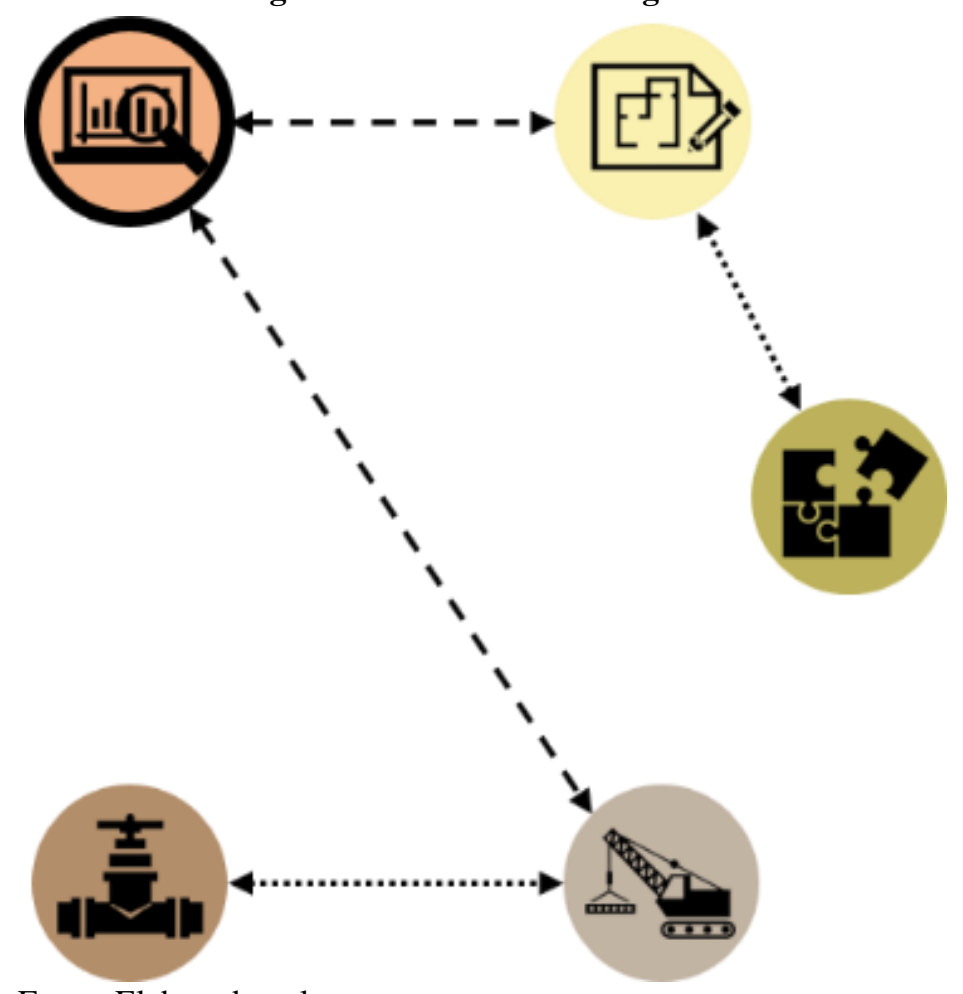

Fonte: Elaborado pela autora.

Figura 63 - BIM - Nível 1 - projetista arquitetura e construtor

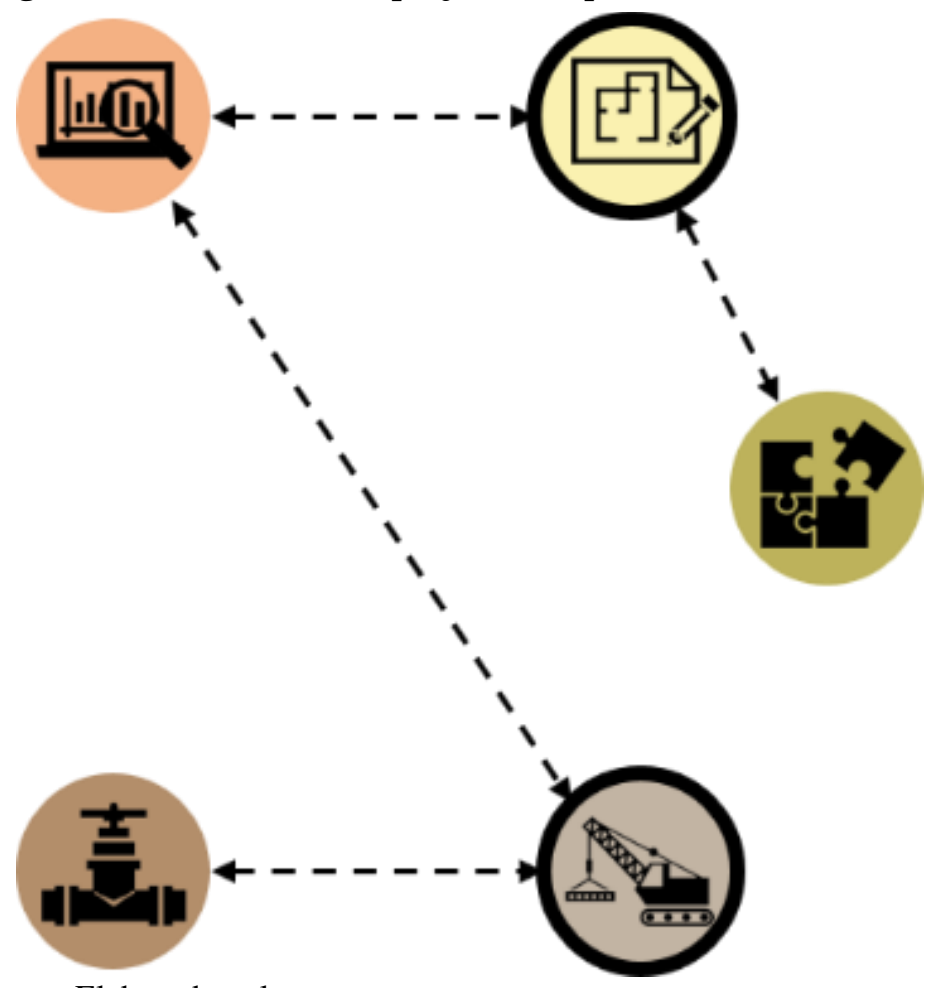

Fonte: Elaborado pela autora. 


\subsubsection{BIM - Nível 2}

O nível 2 do uso do BIM no processo de produção do empreendimento indica que existe a troca de modelos BIM e a colaboração em parte do processo e entre no mínimo dois agentes. Isso pode ocorrer na etapa de projeto, execução, ou em ambas, com ou sem a participação do gestor. Quando o BIM é usado na etapa de projeto, o compartilhamento do modelo pode ocorrer sem considerar toda a etapa, no caso do uso do BIM entre o projetista de arquitetura e o gestor (Figura 64), ou considerando toda a etapa de projeto, sem a participação do gestor (Figura 65) ou com a participação desse agente (Figura 66).

Esse último modelo de processo de produção, com o compartilhamento do modelo BIM por todos os agentes que participam da etapa de projeto, permite a continuidade do fluxo de informações desde o projeto conceitual até a entrega do projeto final. Isso permite que diversas análises sobre o modelo sejam antecipadas, além de possibilitar o uso do BIM na identificação das interferências entre disciplinas.

Figura 64 - BIM - Nível 2 entre projetista arquitetura e gestor

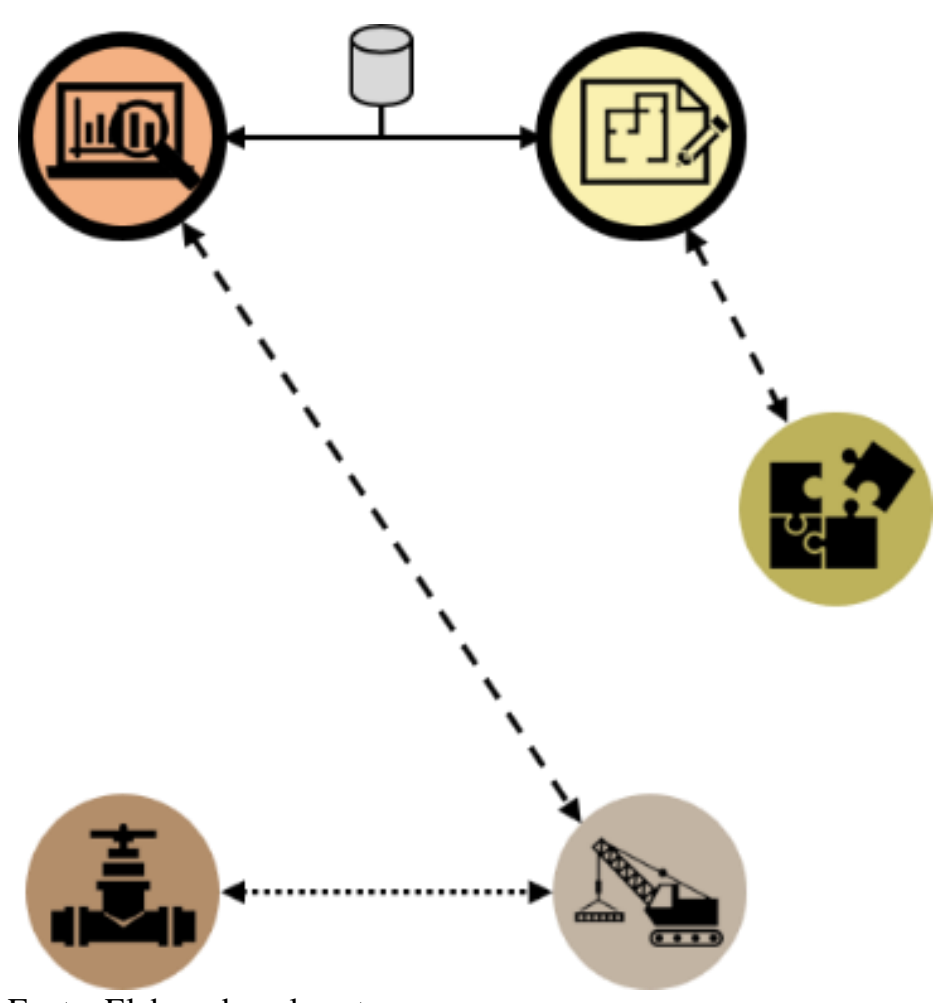

Fonte: Elaborado pela autora. 
Figura 65 - BIM - Nível 2 na etapa de projeto

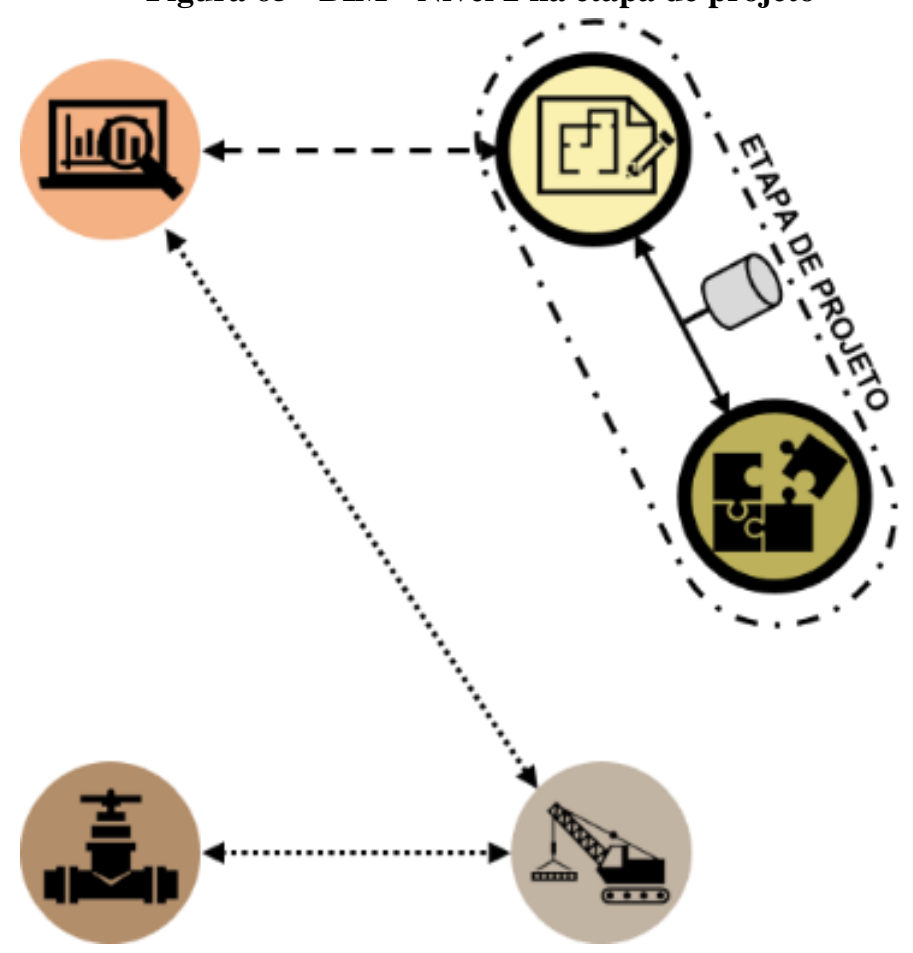

Fonte: Elaborado pela autora.

Figura 66 - BIM - Nível 2 na etapa de projeto com o gestor ETAPA DE PROJETO

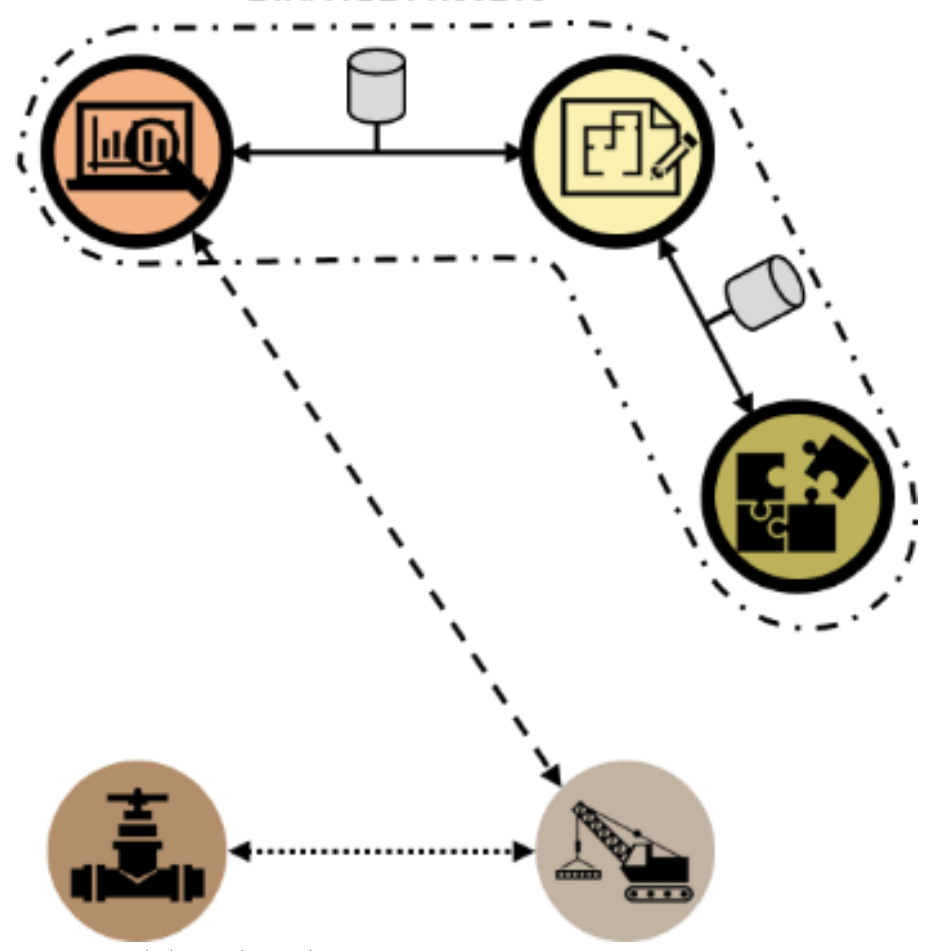

Fonte: Elaborado pela autora. 
As mesmas combinações dos diagramas anteriores podem ser feitas considerando o uso do BIM na etapa de execução: entre o construtor e o gestor (Figura 67), ou considerando toda a etapa de execução, sem a participação do gestor (Figura 68) ou com a participação desse agente (Figura 69). O último modelo, que inclui o gestor no compartilhamento do modelo BIM, permite que diversas atividades de execução sejam automatizadas, gerando análises de planejamento de obra, logística de equipamentos e materiais no canteiro de obras e reduzindo as interferências relacionadas às incompatibilidades de disciplinas.

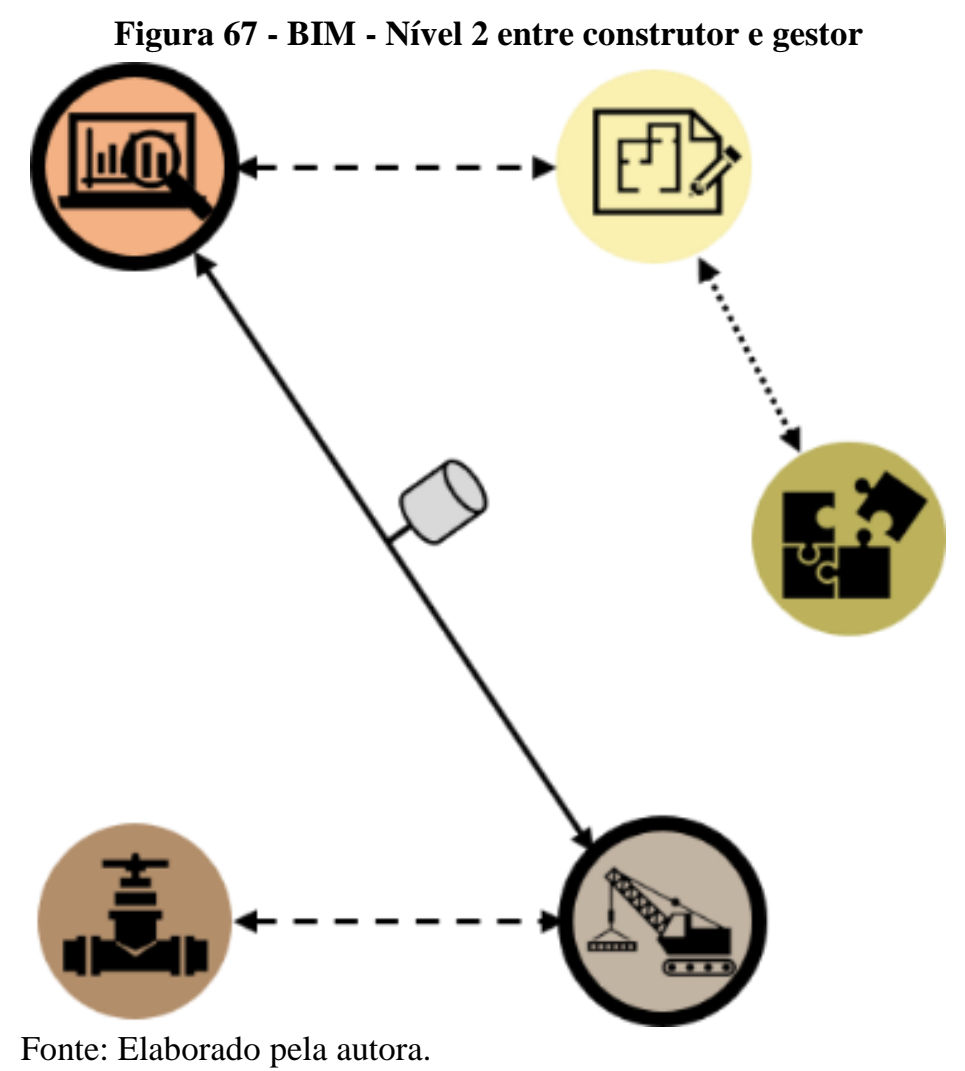


Figura 68 - BIM - Nível 2 na etapa de execução

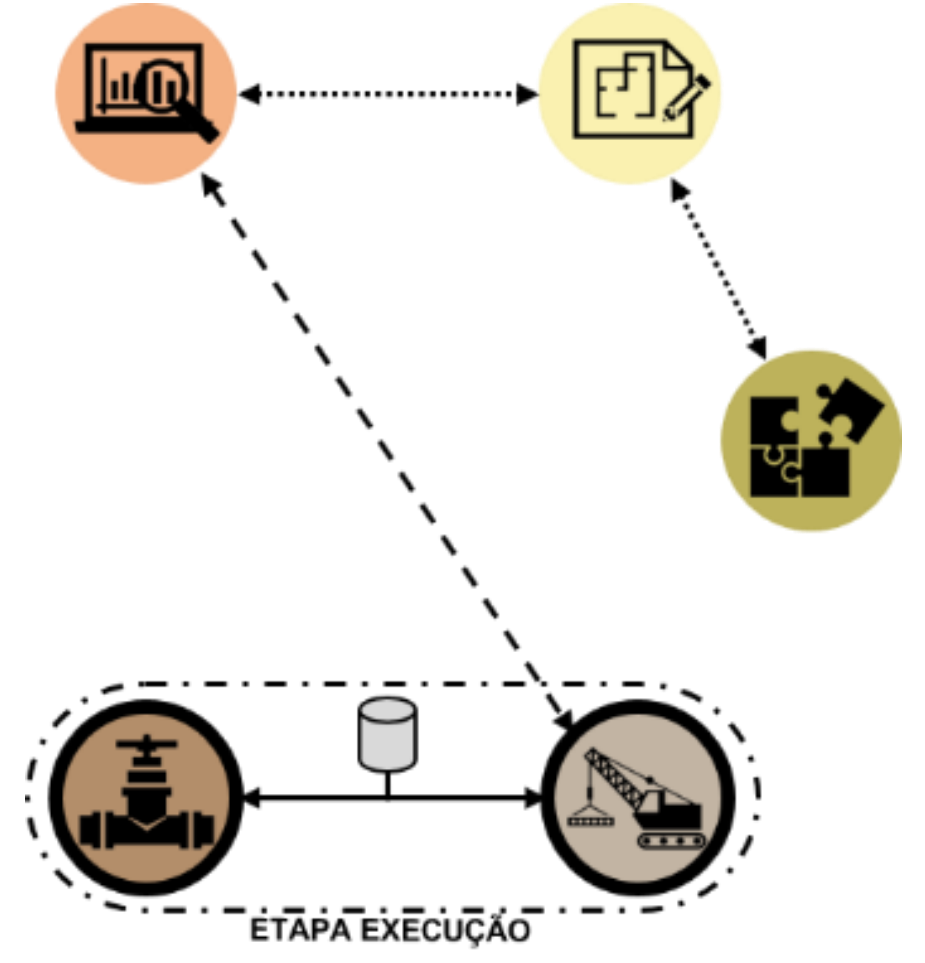

Fonte: Elaborado pela autora.

Figura 69 - BIM - Nível 2 na etapa de execução com o gestor

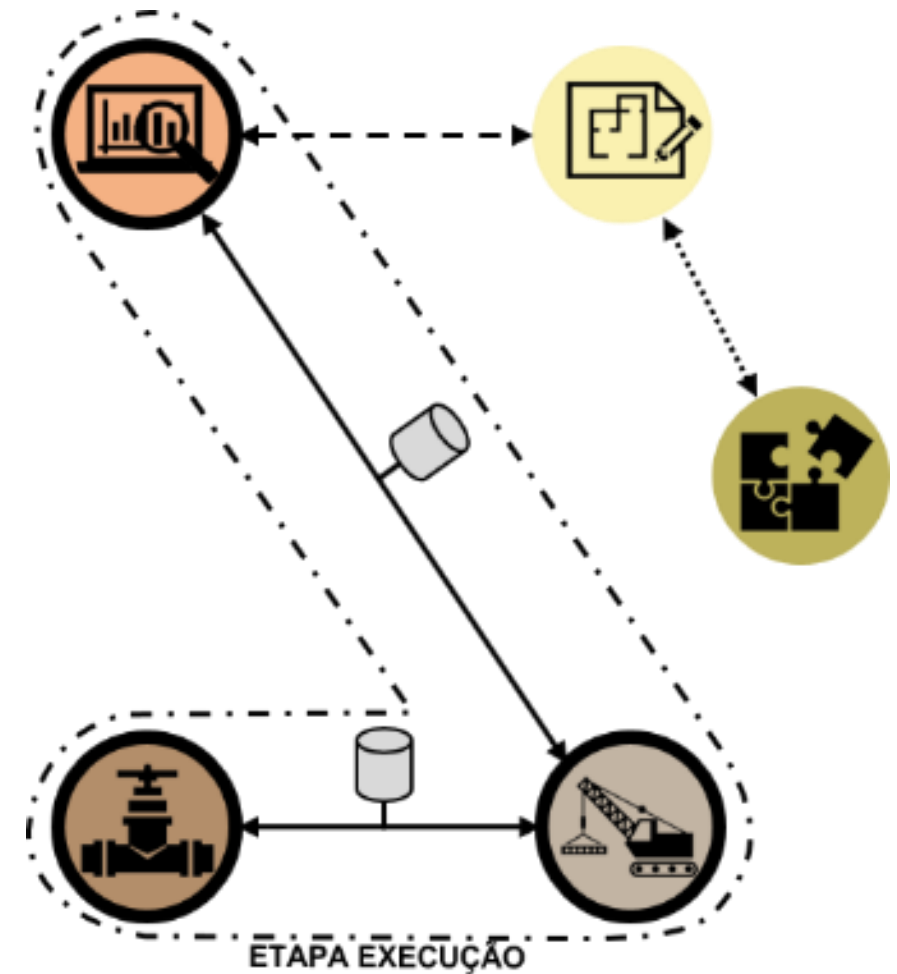

Fonte: Elaborado pela autora. 
Existe ainda a possibilidade do uso do BIM em mais de uma etapa do de produção do empreendimento, sem que exista o compartilhamento do modelo a nível do processo como um todo. A Figura 70 indica o uso do BIM no desenvolvimento do projeto e na execução da obra de forma isolada, ou seja, não existe o compartilhamento do modelo entre etapas e nem o uso do BIM pelo gestor.

Nesse caso, apesar de haver o aprimoramento do desenvolvimento de cada etapa, não existe uma continuidade no fluxo de informações do processo. Além disso, existe a necessidade de o construtor realizar uma atividade exclusiva para inserir as informações do arquivo 2D para um novo modelo BIM, já que o projetista de arquitetura não fornece o modelo computacional BIM usado na etapa de sua responsabilidade.

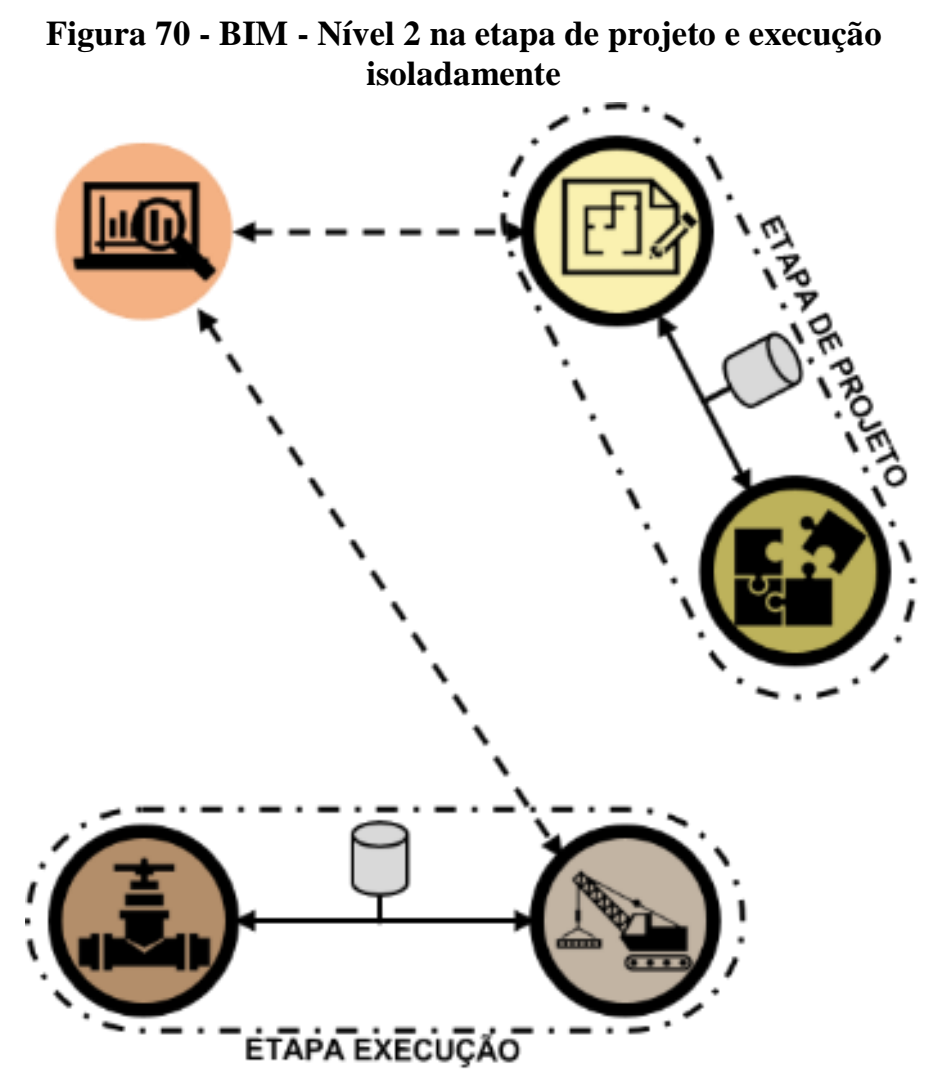

Fonte: Elaborado pela autora.

Quando existe a participação do gestor no desenvolvimento e compartilhamento do modelo BIM, ele é o agente responsável por manter o fluxo de informações entre as etapas. No entanto, existe a possibilidade do não uso do BIM pelos especialistas de execução (Figura 71) e pelos projetistas complementares (Figura 72). A ausência de todos os agentes no uso do BIM impede que o processo mantenha o fluxo de informações ao longo de todo o processo. 
No nível 2, existe um aperfeiçoamento no fluxo de trocas de modelos BIM, se comparado ao nível 1, pois duas ou mais disciplinas se beneficiam da execução mais precisa e completa do projeto, possibilitando analisar precocemente a eficiência das soluções projetuais. No entanto, o uso do BIM ainda é restrito a algumas atividades do processo. Dependendo do nível de restrição ou da ausência da continuidade do fluxo de informações dos modelos BIM entre as etapas, a integração da tecnologia de informação é prejudicada.

Figura 71 - BIM - Nível 2 entre projeto e construtor com gestor

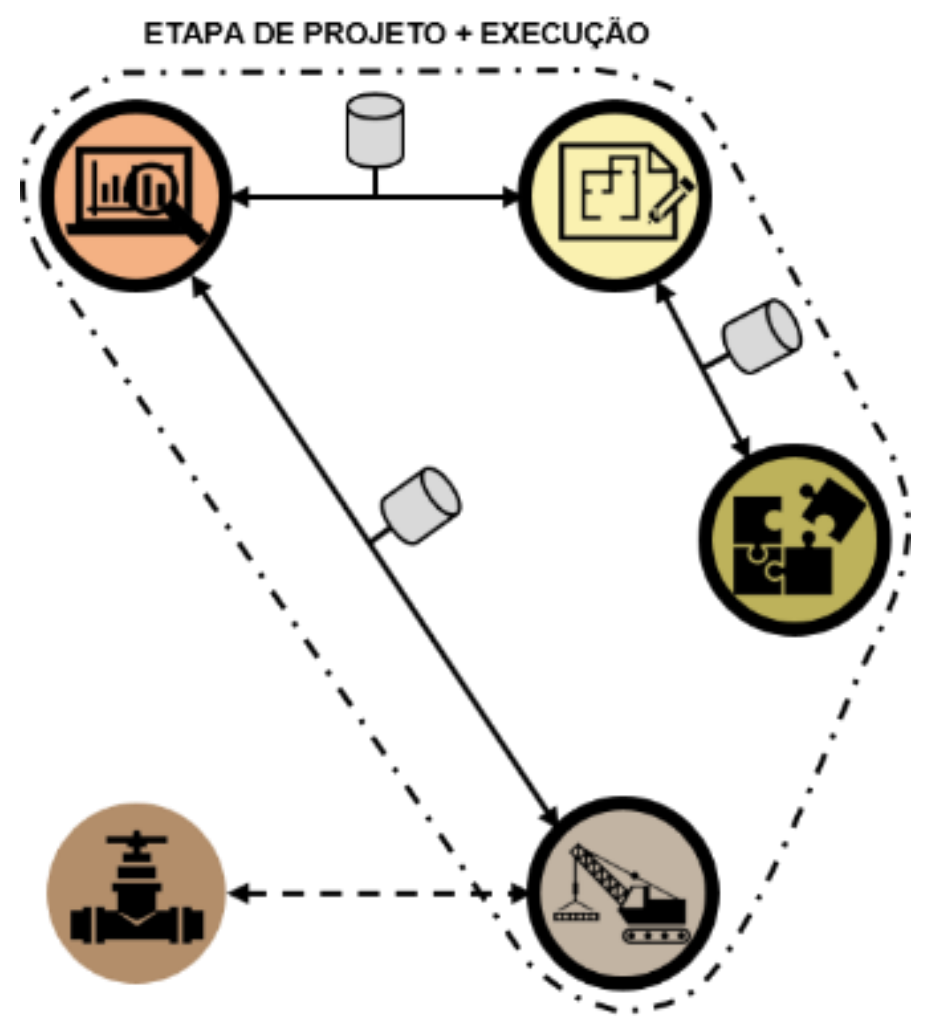

Fonte: Elaborado pela autora. 
Figura 72 - BIM - Nível 2 - entre execução e arquiteto com gestor

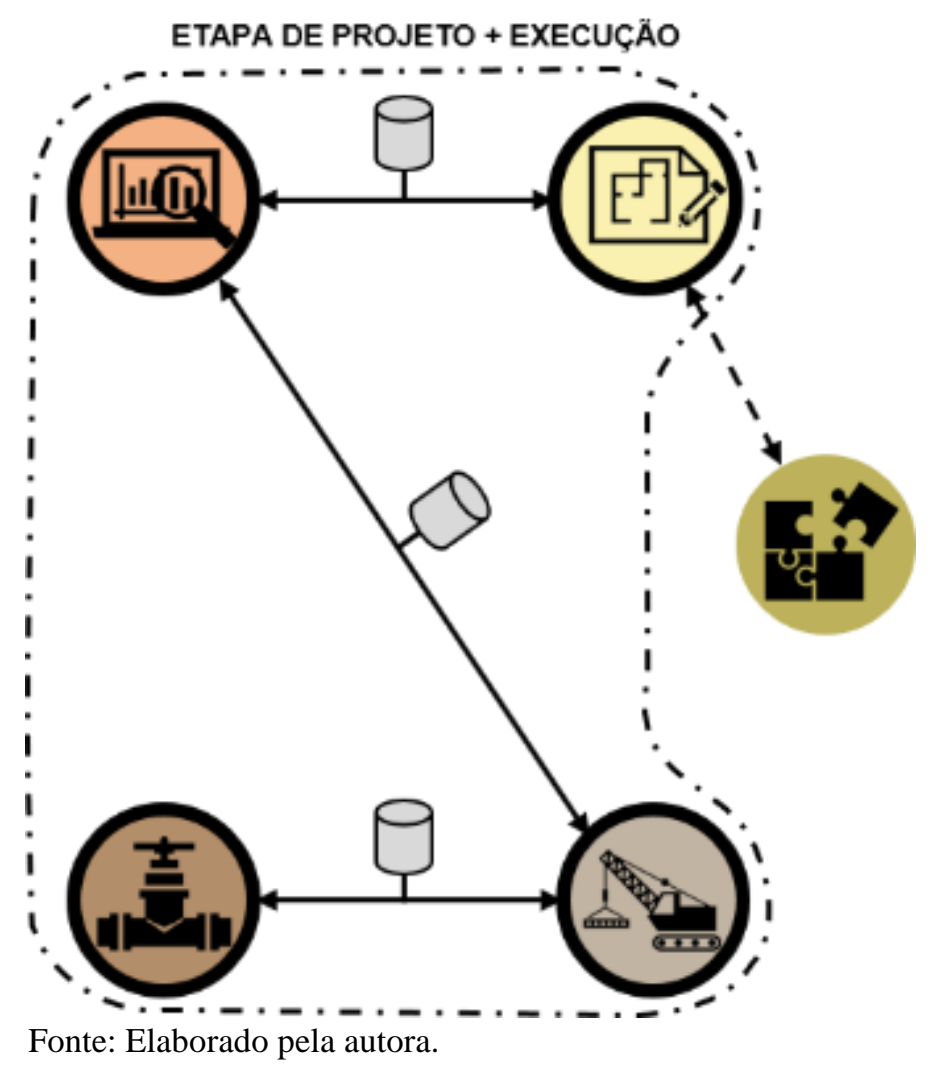

\subsubsection{BIM - Nível 3}

A Figura 73 indica um processo de produção com o nível 3 de maturidade no uso do BIM, ou seja, com o acesso compartilhado, por todos os agentes, a um único modelo ou a um modelo federado, mantendo a continuidade do fluxo de informações ao longo de todo o processo. Isso aumenta as possibilidades de análises desde a etapa de concepção do projeto, resultando em um projeto com mais qualidade, com informações confiáveis e adequadas às necessidades da etapa de execução. 
Figura 73 - BIM - Nível 3 - ao longo de todo o processo

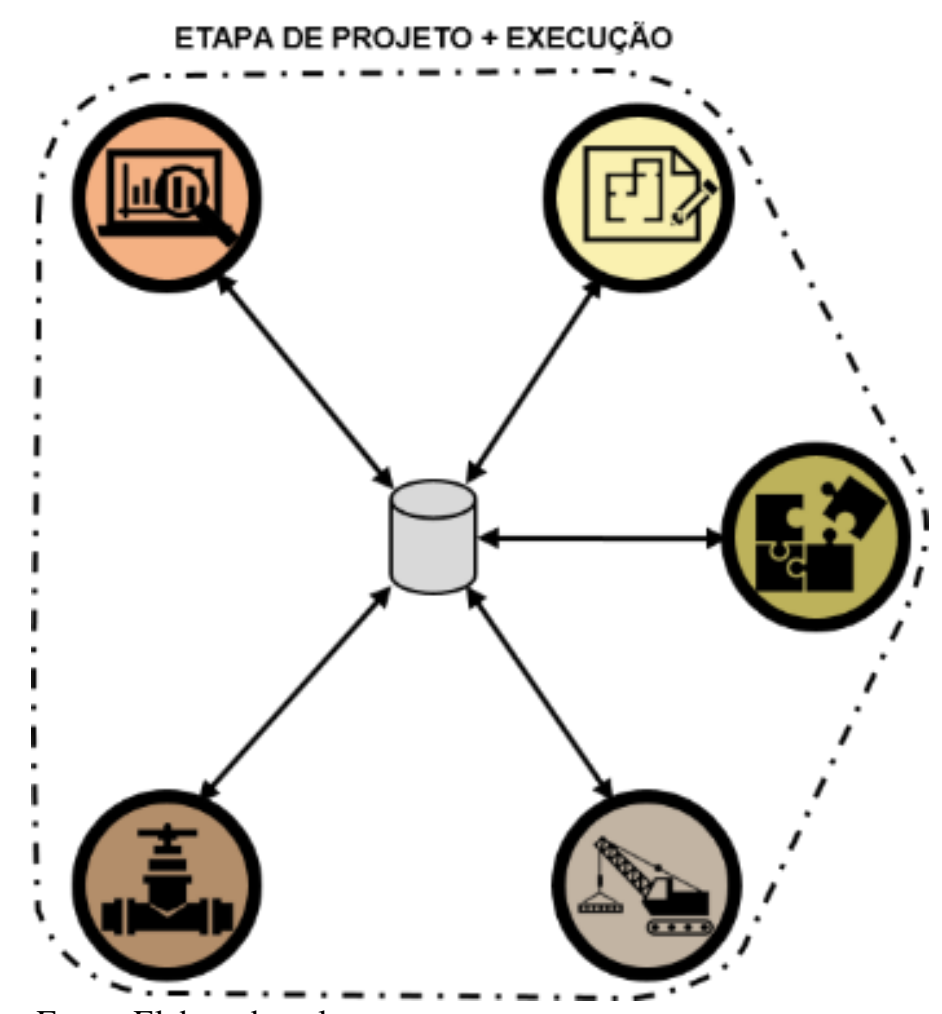

Fonte: Elaborado pela autora.

\subsubsection{Níveis de Integração pela Tecnologia da Informação}

A Figura 74 representa os níveis de integração dos modelos definidos para a perspectiva de tecnologia da informação. Percebe-se que em um mesmo nível de maturidade BIM podem existir diferentes níveis de integração, indicados pelo símbolo “+”, de acordo com o número de agentes que trabalham e/ou compartilham o modelo BIM, além da participação do gestor e da continuidade do fluxo de informações entre etapas do processo.

Quanto mais disciplinas utilizam o BIM, mais integrado pode ser considerado o processo em relação à tecnologia da informação. Além disso, a presença do gestor no compartilhamento e uso do modelo BIM, indica uma maior integração do processo, pois esse agente é responsável por dar continuidade entre as etapas de projeto e execução. Mesmo quando não existe o uso do BIM entre etapas, a presença do gestor indica um maior nível de integração. 
Figura 74 - Níveis de Integração pela Tecnologia da Informação

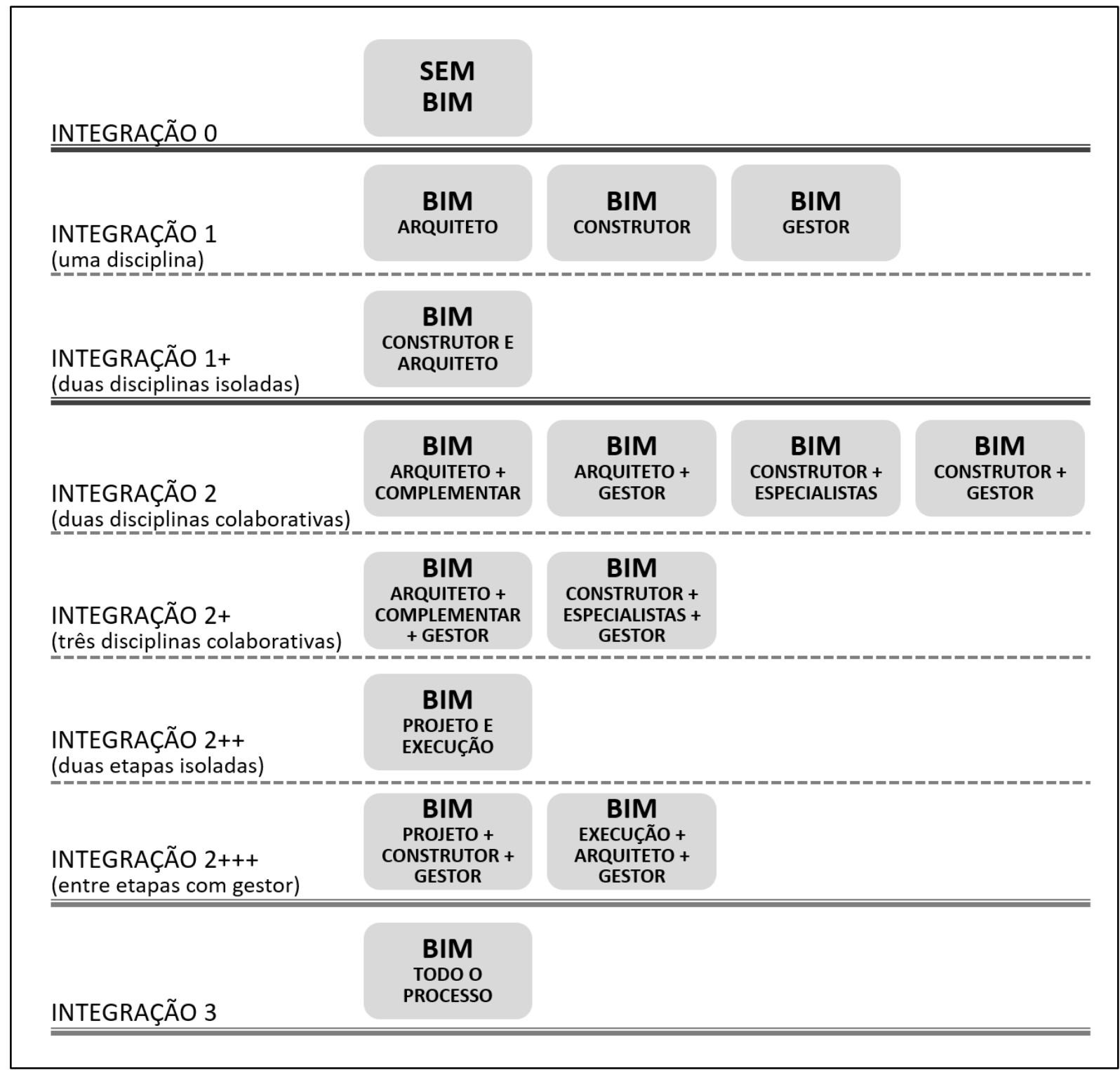

Fonte: Elaborado pela autora.

\subsection{Correlação entre as perspectivas contratual, organizacional e de tecnologia da informação}

As três perspectivas de integração podem ser analisadas de forma conjunta, de acordo com o nível de integração de cada uma e a relação entre elas. Percebe-se que, conforme o nível de integração de uma perspectiva aumenta, mais restritiva se tornam as combinações nas demais áreas analisadas (Figura 75). 
Figura 75 - Correlação entre as perspectivas de integração

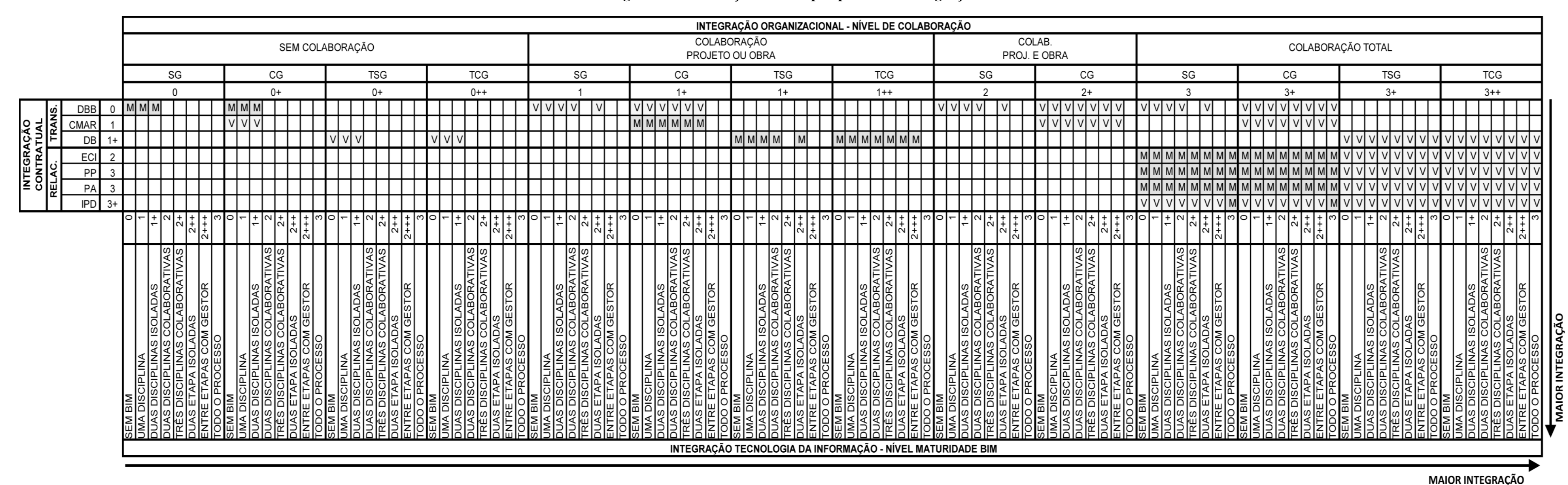

LEGENDA

M Modelo Ideal VIV Variacăo do Modelo

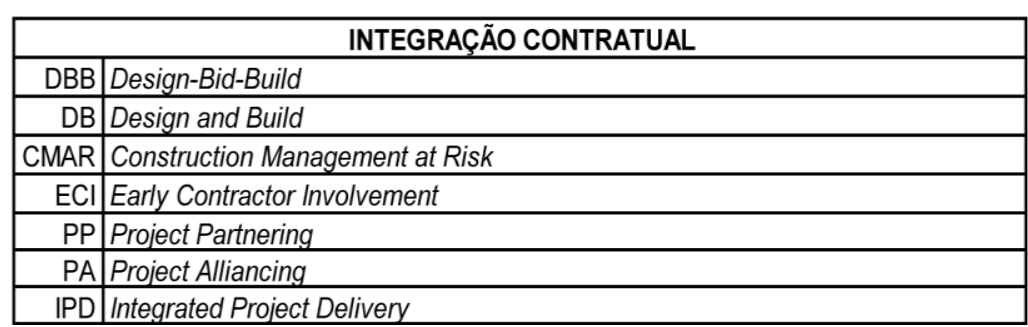

INTEGRAÇÄO ORGANIZACIONAL

\begin{tabular}{|l|l|l|l}
\hline SG & sem gestor \\
\hline CG & . \\
\hline
\end{tabular}

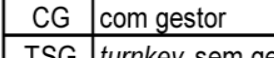

\begin{tabular}{|c|c|}
\hline TSG & turnkey sem gestor \\
\hline TCG & turnkey com gestor \\
\hline
\end{tabular}

ECl Early Contractor Involvement

Fonte: Elaborado pela autora. 
Os modelos de contrato estão ordenados de acordo com o nível de integração, ou seja, partindo do menos integrado - DBB - para o mais integrado - IPD. Foram considerados os modelos ideais descritos na literatura para cada tipo de integração ou as variações para esses modelos dependendo das escolhas feitas para estabelecer o processo de produção.

Por exemplo, o modelo de contrato DBB ideal não indica nenhuma possibilidade de colaboração entre os profissionais. No entanto, dependendo da forma de organização da equipe, pode haver o trabalho colaborativo em alguma etapa do processo.

No caso dos contratos relacionais, o modelo ideal é indicado pela integração em todas as perspectivas, o que permitiria estabelecer o trabalho colaborativo de forma mais completa, agregando o uso do BIM nas relações de desenvolvimento dos projetos. Ao apresentar o IPD, o AIA (AMERICAN INSTITUTE OF ARCHITECTS, 2007a) afirma que os princípios do BIM estão alinhados com os objetivos do sistema de contrato, além disso o IPD é capaz de impulsionar a eficiência do BIM.

No entanto, a literatura que descreve os contratos relacionais não indica a obrigatoriedade do uso do BIM nos processos. Alguns dos sistemas contratuais relacionais existem antes mesmo do surgimento do BIM. A ausência do uso do BIM nos contratos relacionais está representada como uma variação do modelo no quadro de correlação entre as perspectivas de integração.

A partir dos modelos de contrato relacionais - ECI, PP, PA e IPD - só é possível estabelecer equipes de trabalho colaborativas ao longo de todo o processo. Esses sistemas contratuais têm como princípio a participação precoce dos agentes, para que as tomadas de decisão sejam antecipadas no processo, permitindo que o projeto já esteja definido no início da etapa de execução.

Nos contratos relacionais, é possível estabelecer processos com ou sem gestor, ou por meio do turnkey. No entanto, é necessário que não só o arquiteto e o construtor participem precocemente de todo o processo, mas também os demais participantes. O AIA (AMERICAN INSTITUTE OF ARCHITECTS, 2007a) indica outras modificações necessárias ao processo para utilizar o modelo turnkey no IPD, como a participação efetiva do cliente ao longo de todo o processo, não só na validação das entregas, e a flexibilização na forma de pagamento dos agentes, pois é necessário que os riscos e benefícios do processo sejam compartilhados pelos principais participantes.

Nos modelos de organização da equipe sem colaboração só é possível atingir o nível 1 ou 1+ de integração pela tecnologia da informação, ou seja, com o seu uso em apenas uma das 
disciplinas do processo, ou em duas de forma isolada. A partir do aumento da colaboração - no projeto e/ou obra - é possível chegar ao nível 2, 2+, 2++ ou 2+++ do uso do BIM, em que existe a troca dos modelos e desenvolvimento compartilhado do projeto por mais de uma disciplina. Somente com a colaboração ao longo de todo o processo, pode-se alcançar o nível 3 de integração da tecnologia de informação. Nesses casos, o BIM é usado por todas as disciplinas e existe a colaboração entre todas elas, antecipando a participação dos agentes no processo de produção. 


\section{ESTUDOS DE CASO}

Cada estudo de caso foi analisado conforme as três perspectivas de integração - contratual, organizacional e de tecnologia da informação. Posteriormente foi feita uma comparação dos níveis de integração de todos os estudos de caso.

Para uma primeira abordagem, foi considerado o caso de um processo de produção com um alto nível de industrialização - industrialização fechada - representado pelos empreendimentos de João Filgueiras Lima, o Lelé, e Jean Prouvé - intitulado EC-0. Como as informações do EC0 são originadas da literatura existente, não foi possível elaborar diagramas para esse caso, mas foram feitas descrições e inferências sobre os procedimentos adotados por Lelé e Prouvé.

Posteriormente foram analisados quatro estudos de caso que utilizam a construção industrializada aberta:

- Estudo de Caso 1 (EC-1): a reforma e ampliação de um aeroporto público brasileiro, com o uso do modelo turnkey para a execução do empreendimento;

- Estudo de Caso 2 (EC-2): uma série de empreendimentos comerciais de uma franquia de locação de espaços de depósito, que tem como característica um modelo padrão de projeto e relações de trabalho de longo prazo com os profissionais;

- Estudo de Caso 3 (EC-3): um edifício institucional privado voltado a exposições de arte, que teve a participação de um gestor, mas sem o uso do BIM; e

- Estudo de Caso 4 (EC-4): uma biblioteca de uma escola particular, que teve a participação de um gestor e usou o BIM na etapa de projeto.

\subsection{Caso da literatura (EC-0) - Industrialização de ciclo fechado (Lelé e Prouvé)}

O EC-0 representa o maior nível de industrialização em comparação com os demais, pois utilizou a industrialização de ciclo fechado, de forma que os arquitetos detinham o total controle sobre o processo - planejamento, projeto, fabricação dos componentes e montagem do edifício. Essa característica foi fundamental para alcançar um alto nível de integração do processo de produção sob as perspectivas contratual e organizacional.

Apesar dos empreendimentos de Lelé e Prouvé terem sido elaborados há bastante tempo, década de 1990 e 1950 respectivamente, foi possível identificar na literatura os processos de trabalho 
dos arquitetos e como eles estão relacionados à integração na construção civil. A análise do EC0 possibilitou acrescentar algumas considerações sobre a interdependência das três perspectivas de integração - contratual, organizacional e de tecnologia da informação - e o nível de industrialização do processo de produção (OLIVEIRA; GIACAGLIA, 2018).

Tendo como referência a série de hospitais desenvolvidos pelo Centro de Tecnologia da Rede Sarah (CTRS), fábrica gerenciada por Lelé, e a série de unidades habitacionais pré-fabricadas desenvolvidas por Jean Prouvé, pode-se perceber algumas semelhanças entre os dois processos de produção.

Com um alto nível de industrialização, ambos usaram sistemas industrializados de ciclo fechado, ou seja, as fábricas dos arquitetos detinham todo o domínio técnico sobre os elementos construtivos e, desde o projeto conceitual, foram definidos os procedimentos de fabricação e montagem dos componentes no canteiro de obras. Dessa forma, as edificações foram executadas usando peças exclusivamente elaboradas por essas fábricas.

Esse tipo de industrialização refletiu no alto nível de integração contratual e organizacional do processo. Em relação ao sistema de contrato, os arquitetos estabeleceram relações de trabalho de longo prazo, por meio de uma equipe multidisciplinar contratada para desenvolver o processo de produção da série de empreendimentos e não de um projeto específico.

Apesar dos modelos de contrato estabelecidos por Lelé e Prouvé não estarem muito claros na literatura, pode-se considerar que havia um alto nível de integração contratual, resultando na participação precoce de todos os profissionais da equipe, que estavam associados em um contrato com objetivos comuns para os empreendimentos. Além disso, os contratos de longo prazo garantiram o comprometimento de todos em relação ao trabalho colaborativo.

A construção industrializada de ciclo fechado, associada à contratação de longo prazo, possibilitou um alto nível de integração organizacional. Além de desenvolverem o projeto, Lelé e Prouvé também tinham como responsabilidade a gestão do processo, considerando a produção dos edifícios como um processo contínuo, incluindo todas as questões de execução desde as primeiras soluções projetuais. A visão sistêmica de ambos arquitetos favoreceu a integração organizacional, mantendo toda a equipe comprometida em manter o trabalho colaborativo.

Lelé e Prouvé conseguiram inovar no desenho dos componentes pré-fabricados, alcançando um alto nível de desempenho e qualidade construtiva das peças, mesmo sem a integração de tecnologia da informação. Os processos de ambos ocorreram em um período em que não havia o BIM, o que indica que não havia a integração sob a perspectiva de tecnologia da informação. 
No entanto, as características da industrialização de ciclo fechado utilizada por ambos profissionais foi o que possibilitou o alto nível de integração do processo. Como uma mesma equipe de profissionais trabalhou em uma série de edificações, tendo o controle sobre todo o processo, foi possível manter o desenvolvimento colaborativo das atividades, em que todos estivessem buscando o melhor para o empreendimento e não apenas para sua disciplina.

Além disso, uma série de edificações desenvolvidas por uma mesma equipe e utilizando o mesmo tipo de sistema construtivo, permitiu o aprimoramento contínuo do processo. Cada problema ou erro identificado durante a produção foi corrigido no próximo empreendimento, criando uma nova solução projetual e tornando o processo cada vez mais eficiente.

Como exemplo destaca-se o aprimoramento dos elementos de ventilação da cobertura desenvolvido por Lelé (sheds). Segundo Lukiantchuki, Caixeta e Fabricio (2015), as soluções dadas aos empreendimentos hospitalares indicam a evolução da solução projetual, que foi aperfeiçoada em relação ao ângulo dos componentes, de forma a permitir a passagem de ar, sem a entrada de luz solar direta nos ambientes.

\subsection{Estudo de Caso 1 (EC-1) - Contratação turnkey}

O EC-1 trata-se de um caso de industrialização aberta e contratação turnkey de reforma e ampliação de um aeroporto público brasileiro. No ano de 2017, teve início o processo de produção, a partir da elaboração dos estudos de viabilidade pelo cliente para entrada no processo licitatório. Por meio de uma concessão pública, o cliente assinou, em julho de 2017, um contrato com a Agência Nacional de Aviação Civil (ANAC), se responsabilizando pela ampliação, manutenção e exploração da infraestrutura aeroportuária. No ano de 2018, foram iniciadas as obras no aeroporto, que têm previsão de término no primeiro semestre de 2020.

A coleta de dados desse estudo de caso foi feita na etapa de finalização do desenvolvimento do Projeto Executivo, ou seja, o projetista de arquitetura e os projetistas complementares estavam realizando os últimos ajustes no projeto após a compatibilização das disciplinas. Nessa etapa já havia sido definido todo o processo de produção do empreendimento, inclusive a forma de contratação da sua execução.

No empreendimento do EC-1 foi utilizado sistemas construtivos pré-fabricados na maior parte dos componentes da obra. Por ser uma obra de reforma e ampliação, a existência de uma edificação em uso criou a demanda de uma obra rápida, organizada e sem muita interferência 
das atividades de execução no entorno do canteiro de obras. Dessa forma, foi escolhida a estrutura metálica para a nova edificação, e o fechamento em drywall e light steel frame tanto para a parte nova como a parte a reformar.

\subsubsection{Integração Contratual}

O processo de produção do EC-1 (Figura 76) teve início com o desenvolvimento do projeto conceitual pelo próprio setor técnico do cliente, que é uma empresa com sede na Europa, que trabalha com a gestão de aeroportos em todo o mundo. Portanto, trata-se de um cliente com quadro técnico próprio e com um histórico de desenvolvimento de processos de produção de aeroportos.

Os requisitos do projeto (RFP) tiveram como base o programa de necessidades definidos pela ANAC no processo de licitação. Esses requisitos indicaram questões técnicas e genéricas do empreendimento, como: tipologia dos ambientes, área mínima, número de passageiros que devem ser atendidos e nível de desempenho das instalações; sem uma definição de desenho arquitetônico nem a especificação do sistema construtivo.

Apesar de ser uma obra pública, o cliente teve a liberdade para definir o tipo de contratação e os requisitos para selecionar os agentes. O cliente realizou um contrato em duas etapas: uma para o anteprojeto e outra para o desenvolvimento do projeto executivo e a execução da obra.

Na primeira etapa do contrato, o cliente selecionou um escritório de projetos de engenharia e sistemas prediais - projetistas complementares - para elaborar o anteprojeto. Esse escritório subcontratou um escritório de arquitetura para desenvolver o projeto arquitetônico, atividade que ocorreu com a colaboração dos projetistas complementares. Com a entrega do anteprojeto, teve fim o contrato dos dois escritórios e o cliente realizou uma concorrência para selecionar os demais agentes do processo.

Na segunda etapa do contrato, o cliente selecionou uma construtora que ficou responsável pelo desenvolvimento do projeto executivo e execução da obra. Por meio de um orçamento feito com base no anteprojeto, foi negociado um preço fechado para ambos os serviços. Como a construtora selecionada não tinha um setor técnico de projetos, ela subcontratou a mesma empresa de engenharia, que subcontratou o mesmo escritório de arquitetura do primeiro contrato. 
Figura 76 - Diagrama de contratação do EC-1

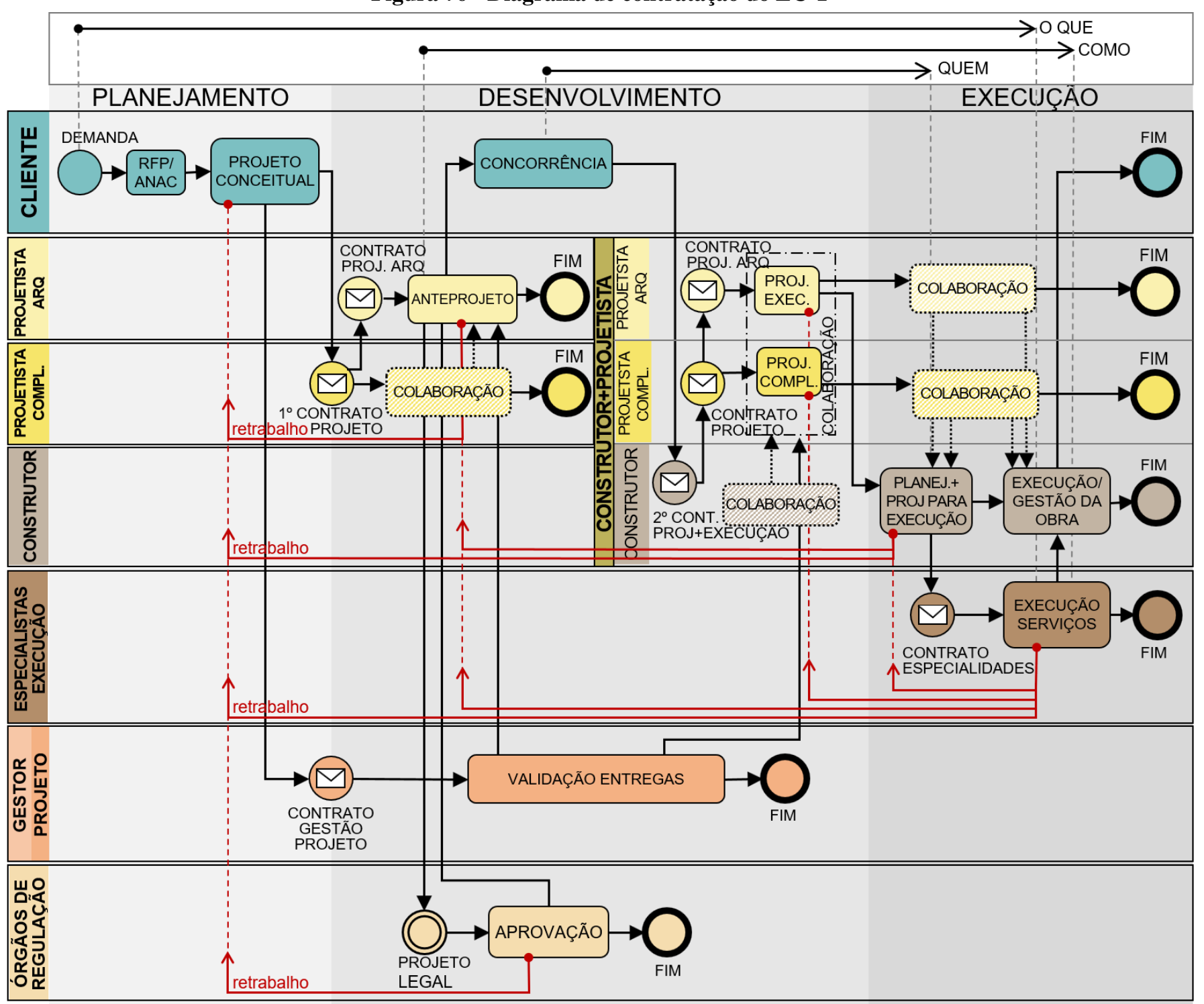

Fonte: Elaborado pela autora. 
A escolha pela recontratação dos mesmos profissionais foi da construtora, que deu prioridade para os projetistas que já haviam participado da etapa anterior, visando manter a continuidade do processo. Isso não foi uma exigência do cliente, sendo que poderia entrar no processo um novo projetista de arquitetura, além dos complementares.

Nesse processo de produção, existiu a presença da gestão dividida em duas disciplinas: projeto e execução. $\mathrm{O}$ gestor de projeto foi um profissional contratado pelo cliente no momento em que foi estabelecido o primeiro contrato de projeto. Esse agente colaborou em todas as atividades de desenvolvimento do projeto.

O papel de gestão da obra é de responsabilidade da própria construtora, que também é responsável pelo planejamento, elaboração dos projetos para produção e subcontratação dos especialistas de execução. Na etapa de execução, os projetistas - arquitetura e complementares - colaboram com o desenvolvimento dos projetos para execução, além de acompanharem as obras e realizar as modificações no projeto, quando necessário.

No diagrama do EC-1, percebe-se que, desde demanda do cliente até a entrega do anteprojeto, o processo se assemelha às etapas iniciais de uma contratação Design-Bid-Build (DBB), com a participação de um gestor de projeto. A segunda contratação, que vai da concorrência ao fim do processo, se assemelha à contratação Design and Build (DB), ou seja, o cliente estabelece um único contrato para o desenvolvimento do projeto e entrega da obra.

No entanto, o segundo contrato é feito diretamente com uma construtora, que não tem um setor de projetos próprio e precisa subcontratar os profissionais de projeto. A forma de contratação escolhida para esse processo de produção faz com que o cliente se distancie das tomadas de decisão do processo. O cliente não tem poder de decisão sobre a escolha do escritório de arquitetura que desenvolverá o projeto. Mesmo tendo o anteprojeto já definido, é possível que alterações significativas sejam feitas ao longo do processo, o que pode gerar conflitos no momento de entrega da obra.

As tomadas de decisão no processo do EC-1 se estendem até a etapa de execução, devido à possibilidade de retrabalho pela entrada tardia dos especialistas de execução. Isso indica que alterações de projeto podem ocorrer no final do processo, potencialmente aumentando custo, prazo e podendo criar inadequações nas soluções projetuais. Como os especialistas de execução só serão contratados pela construtora quando o empreendimento estiver na etapa de obra, não é possível indicar se houve ou não o retrabalho pela entrada dos especialistas de execução. 
As outras possibilidades de retrabalho no EC-1 são referentes à entrada do construtor, na segunda etapa do contrato, e dos órgãos de regulação. No caso do construtor, foi necessário rever alguns detalhes de escolha do sistema construtivo, realizados no anteprojeto, no entanto, as alterações foram pontuais e não provocaram aumento de prazo no processo de execução. $\mathrm{O}$ mesmo ocorreu no processo de aprovação, onde as modificações necessárias não causaram alterações no projeto conceitual.

As gestões independentes, uma por etapa - projeto e execução - não favoreceram a continuidade do processo. Como o gestor de projetos teve como responsabilidade apenas validar as entregas dos agentes, não existiu a colaboração, relativa às questões de execução na primeira etapa do contrato. Isso resultou nas revisões dos detalhes dos sistemas construtivos no projeto executivo, após a entrada do construtor, o que poderia ser evitado ou atenuado com a colaboração do gestor no desenvolvimento do anteprojeto.

A presença da "colaboração" dos projetistas complementares e do construtor no processo de produção do EC-1 favoreceu o uso da construção industrializada. Como a atividade de desenvolvimento do anteprojeto foi realizada com a participação dos projetistas complementares, foram consideradas as especificidades dos sistemas pré-fabricados, principalmente com a participação do calculista da estrutura metálica que foi utilizada na edificação nova. Isso permitiu antecipar as compatibilizações desse sistema construtivo com os demais sistemas do edifício.

Além disso, a participação do construtor, na etapa de Projeto Executivo, permitiu que questões operacionais de execução da obra fossem detalhadas antecipadamente com os projetistas, como por exemplo a subdivisão da obra em etapas. Caso não houvesse o trabalho colaborativo no EC1, muitas questões específicas de execução dos sistemas industrializados poderiam ser identificadas tardiamente no processo, levando a retrabalhos e atrasos na elaboração do projeto e da obra.

\subsubsection{Integração Organizacional}

No desenvolvimento do empreendimento do EC-1 (Figura 77) foi feita uma contratação no modelo turnkey, ou seja, o cliente contratou um único agente para desenvolver o projeto executivo e a obra. Isso fez com que existisse pelo menos uma possibilidade de colaboração nas relações entre as etapas - projeto e obra. Apesar da presença de um gestor para a etapa de 
projeto, não houve a colaboração entre esse agente e os profissionais de projeto - arquitetura e complementares.

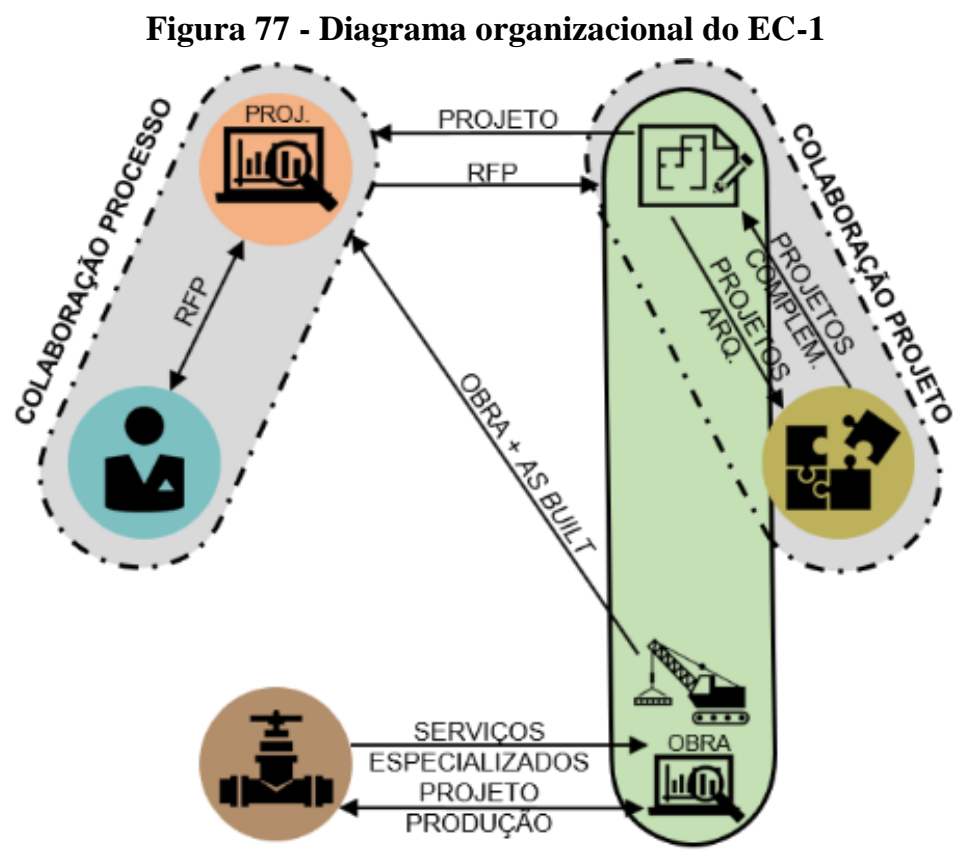

Fonte: Elaborado pela autora.

Como o contrato turnkey foi estabelecido com uma construtora que não tem um setor de projetos e, consequentemente, subcontratou os profissionais dessa disciplina, existiu uma hierarquia nas tomadas de decisão. Cada agente precisou validar a solução projetual com o agente com quem mantém o contrato, ou seja, a solução projetual elaborada pelo escritório de arquitetura foi validada primeiro pelo escritório de engenharia, que posteriormente elaborou os projetos complementares e validou suas soluções com o construtor. Portanto, as alterações solicitadas pelo construtor foram realizadas em um projeto com um alto nível de desenvolvimento, o que dificultou o trabalho colaborativo, sendo identificado diversos retrabalhos na etapa de projeto.

Um exemplo de retrabalho ocorreu devido ao atraso na entrega do levantamento detalhado da edificação existente. Para a elaboração do anteprojeto, foi utilizado o levantamento fornecido pela ANAC, que continha o projeto como construído (as built) do aeroporto. No entanto, como o edifício havia sofrido modificações ao longo do tempo, esse levantamento estava desatualizado, sendo que o cliente contratou uma empresa para entregar o projeto "como construído" atualizado, durante o desenvolvimento do anteprojeto. 
Com o atraso dessa entrega, que ocorreu somente durante o desenvolvimento do Projeto Executivo, foi necessário adequar as soluções projetuais com base no novo levantamento. Isso foi realizado primeiro pelos arquitetos, depois pelos projetistas complementares, e por último teve a validação do construtor. No entanto, antes da validação do construtor foi necessário realizar ajustes no projeto, primeiro pelo escritório de engenharia e depois o de arquitetura.

Outra questão que prejudicou a colaboração no EC-1 foi em relação a responsabilidade dada ao gestor de projeto. Esse agente ficou responsável por garantir que as entregas fossem feitas com as informações necessárias e no tempo especificado no planejamento, não tendo uma efetiva participação no desenvolvimento do projeto. As entregas dos projetos foram feitas diretamente dos profissionais do escritório de arquitetura para o escritório de engenharia e destes para o construtor, de forma que o gestor somente validou a existência dessa entrega.

\subsubsection{Integração pela Tecnologia de Informação}

A integração sob a perspectiva da tecnologia da informação está representada no diagrama da Figura 78. O BIM foi utilizado no processo de produção do EC-1 apenas pelos profissionais de projeto - arquitetura e complementares -, com trocas de arquivos por meio de uma plataforma online de gestão de arquivos.

Figura 78 - Diagrama do uso do BIM do EC-1

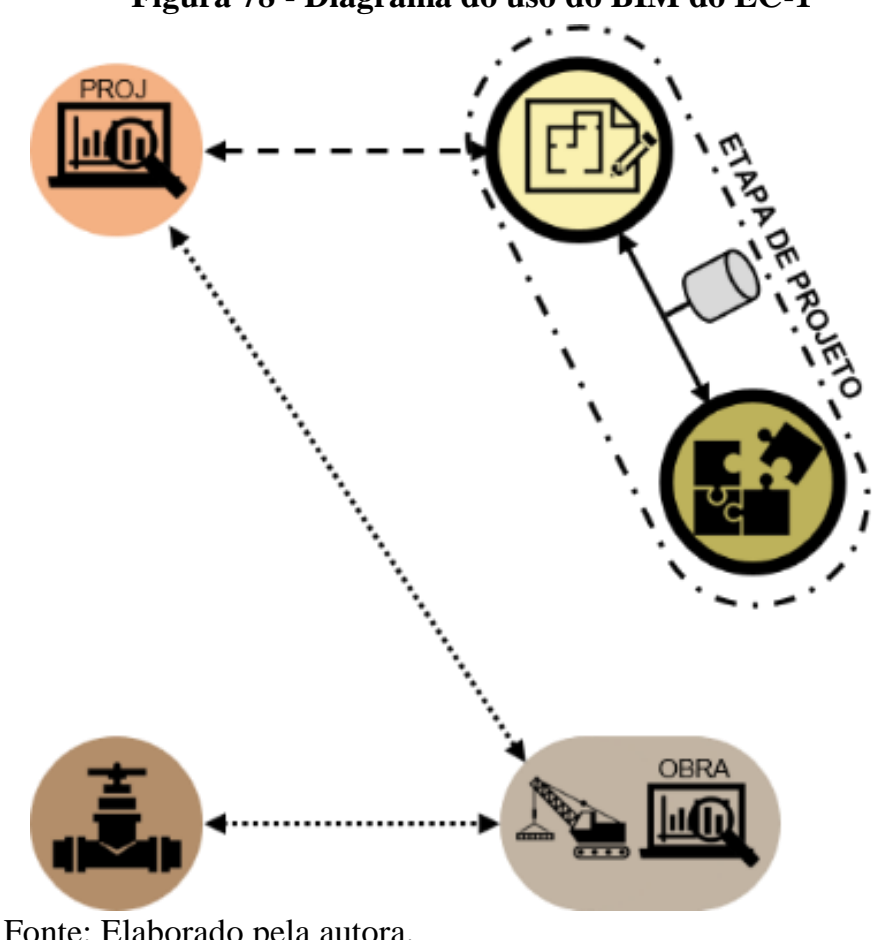

Fonte: Elaborado pela autora. 
A iniciativa pelo uso do BIM teve início com o escritório de arquitetura, que já trabalhava com esse tipo de processo. Como a maior parte dos projetistas complementares também trabalhava com o BIM, grande parte dos projetos foram desenvolvidos em BIM. No caso de alguns projetistas que entregaram os arquivos em 2D - luminotécnica, acústica e paisagismo - foi necessário que o escritório de arquitetura inserisse as informações de projeto no modelo BIM. Cada projetista complementar desenvolveu seu projeto em um arquivo próprio, tendo como base o modelo do projeto arquitetônico. Posteriormente, um agente do escritório de engenharia ficou responsável por compatibilizar os projetos complementares, utilizando uma ferramenta de "análise de interferências" (clash detection). Quando não foi possível encontrar uma solução para as incompatibilidades, os arquitetos foram solicitados a modificar o projeto. Os projetos complementares em BIM, já compatibilizados, foram entregues ao escritório de arquitetura que ficou responsável por inserir as informações dos projetos complementares no modelo de arquitetura BIM.

No escritório de arquitetura, o modelo BIM foi compartilhado entre os profissionais, sendo que sete arquitetos trabalharam ao mesmo tempo no modelo. Foram criados três modelos BIM a partir da subdivisão do edifício em: edificação existente, edificação nova e píer de acesso das aeronaves. Isso foi feito para reduzir o tamanho do arquivo e permitir que a velocidade de upload das modificações não fosse um empecilho para o uso eficiente do modelo.

O uso do BIM na etapa de projeto permitiu que os sistemas construtivos industrializados fossem detalhados antecipadamente no processo, identificando suas interferências com os demais sistemas do edifício. Sem isso, os possíveis erros durante a compatibilização dos projetos seriam identificados somente durante o desenvolvimento do Projeto para Produção ou somente na obra, o que no caso da construção industrializada poderia refletir em incompatibilidades técnicas, pois os componentes pré-fabricados não permitem ajustes durante sua montagem.

Além disso o uso do BIM reduziu o impacto do retrabalho devido a entrada do construtor no processo. A execução das alterações, solicitadas pelo construtor, no Projeto Executivo foram realizadas de maneira mais eficiente, se comparado ao processo convencional. Como todas as informações do projeto estavam vinculadas ao modelo BIM, elas foram atualizadas automaticamente assim que as modificações foram feitas pelos projetistas.

O gestor de projeto não trabalhava com o BIM, sendo necessário que os projetistas elaborassem formatos $2 \mathrm{D}$ e documentação digital do modelo para a validação das atividades. No entanto, como o gestor apenas validava as entregas, ou seja, ele não alterava o desenho e nem realizava 
compatibilizações entre as disciplinas, não foi necessário inserir informações definidas pelo gestor no modelo BIM de arquitetura.

O BIM não foi utilizado no EC-1 desde o início do processo, mas sim a partir do desenvolvimento do anteprojeto, tendo como base o levantamento da edificação existente e o projeto conceitual elaborado pelo cliente. Além disso, o BIM não foi utilizado na etapa de execução, sendo que as entregas do projeto executivo foram feitas da forma convencional.

Isso fez com que o fluxo de informações não fosse contínuo no processo, reduzindo as possibilidades de benefícios que o BIM poderia proporcionar na etapa de construção. Além disso, no momento em que o escritório de arquitetura recebeu o projeto conceitual do cliente, foi necessário desenvolver o modelo BIM a partir dos arquivos 2D.

\subsection{Estudo de Caso 2 (EC-2) - Processo como linha de produção}

O segundo estudo de caso com o uso de industrialização aberta (EC-2), é o processo de produção dos empreendimentos de uma empresa do ramo de locação de espaços de depósito na Região Metropolitana de São Paulo, SP. O cliente, que trabalhava com esse tipo de empreendimento nos Estados Unidos, trouxe esse modelo de negócio em 2012 para o Brasil, tendo atualmente três unidades em funcionamento e com a previsão de edificar de seis a oito unidades por ano.

O cliente do EC-2 optou por estabelecer um modelo padrão para a produção dos empreendimentos, de forma que seu processo produtivo se assemelhasse a uma linha de produção, visando torná-lo cada vez mais eficiente. Para isso, o cliente estabeleceu parcerias com os profissionais, para que eles trabalhem em mais de um empreendimento, mantendo relações de trabalho de longo prazo e possibilitando o aprimoramento contínuo.

A coleta de dados desse estudo de caso ocorreu quando o cliente já possuía três unidades em funcionamento, três edificações na etapa de execução e dois empreendimentos na etapa de anteprojeto. Nesse período o cliente já havia estabelecido o processo padrão para todos os empreendimentos.

Como o cliente necessitava de uma obra veloz para ter um retorno financeiro rápido dos empreendimentos, foi definida a utilização de sistemas pré-fabricados para a maior parte dos edifícios e o uso da racionalização nas atividades realizadas in loco. Além disso, a especificação de uma tipologia com espaços de depósito com dimensões padronizadas, gerou a necessidade 
de definir uma modulação para os projetos, o que viabilizou o uso da industrialização, resultando em um processo padrão para o desenvolvimento dos projetos.

Existem duas tipologias para as unidades: edificação nova e retrofit. No caso das edificações novas, são utilizados sistemas construtivos industrializados, sendo na maior parte dos casos estrutura de concreto pré-fabricado e fachadas revestidas com painéis metálicos termoisolantes. No caso de retrofit, são selecionados galpões que possuem um espaço adequado para a instalação das unidades de armazenamento, sem muitas divisões internas. Nesse caso, também são utilizados painéis metálicos termoisolantes para as fachadas.

\subsubsection{Integração Contratual}

Para os dois tipos de empreendimento - edificação nova e retrofit - foi contratado o mesmo escritório de arquitetura e o mesmo gestor do processo (Figura 79). No caso das construtoras, o cliente estabeleceu uma parceria com três delas, sendo que a contratação variou conforme o tipo de empreendimento.

Como o cliente tem seu próprio quadro técnico e um histórico de desenvolvimento de empreendimentos dessa tipologia, toda definição de viabilidade e requisitos do projeto foram feitos por ele. O processo de produção de todos os empreendimentos segue o mesmo padrão.

Com a demanda de uma nova unidade, é feita a contratação do projetista de arquitetura para desenvolver todo o projeto, desde o conceitual até o executivo. Após a entrega do anteprojeto, o cliente faz a aquisição do terreno, pois nesse momento ele tem a segurança de que o empreendimento é econômico e tecnicamente viável. Posteriormente, o cliente realiza a concorrência para a seleção do construtor.

A contratação do construtor ocorre antes da elaboração do projeto executivo, possibilitando a colaboração entre as disciplinas de projeto e execução. O construtor é responsável por fornecer os projetos complementares, ou subcontratar os projetistas, caso não tenha alguma disciplina em seu corpo técnico. Isso permite que o projeto executivo seja desenvolvido colaborativamente com os projetos dos sistemas prediais, eliminando possíveis interferências entre as disciplinas. 
Figura 79 - Diagrama de contratação do EC-2

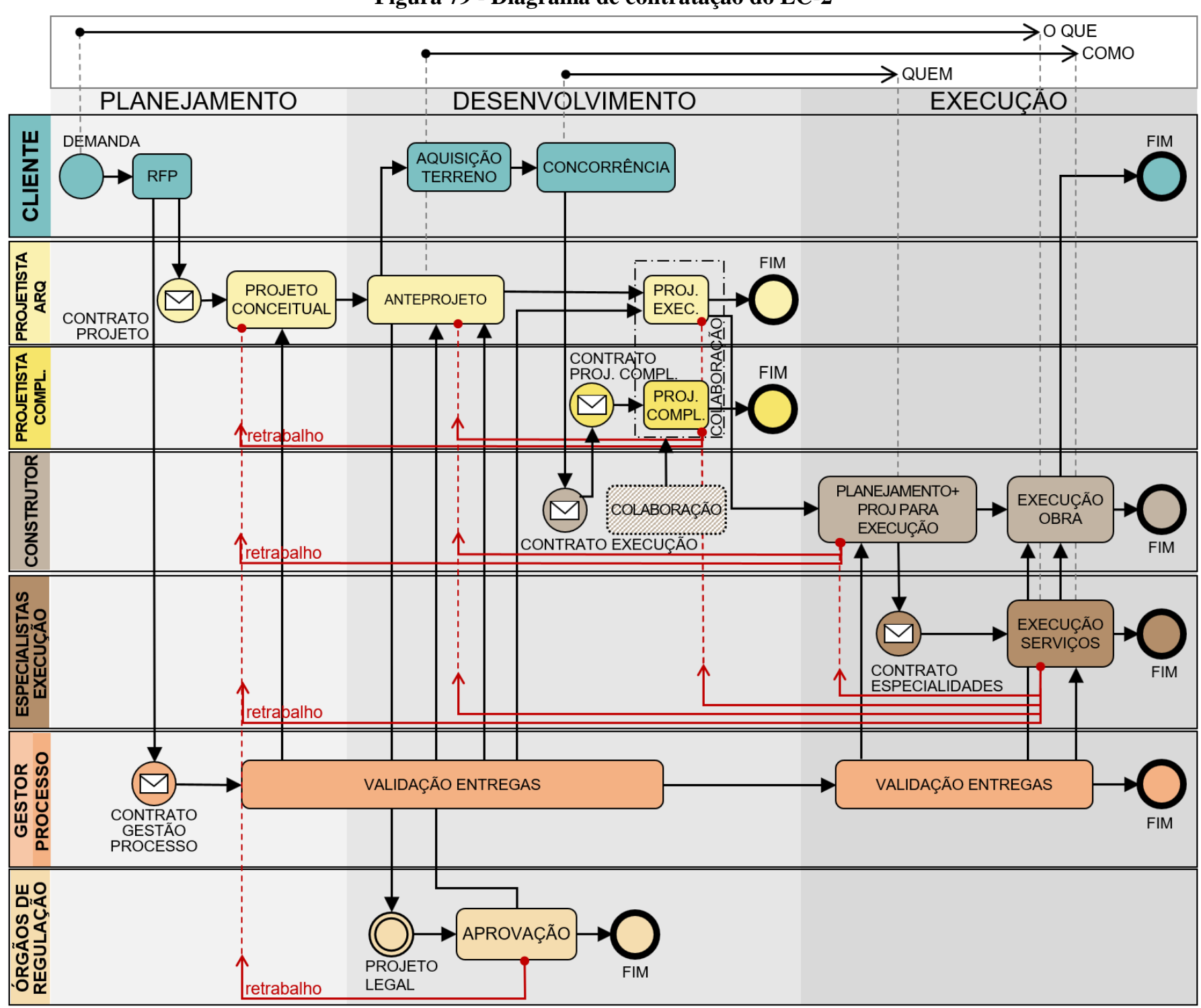

Fonte: Elaborado pela autora. 
Nos empreendimentos já executados do EC-2, os projetistas complementares foram subcontratados pelas construtoras. A maior parte dos especialistas de execução e dos fornecedores participaram de todos os empreendimentos, pois alguns componentes construtivos são específicos para o funcionamento dessas edificações, tendo pouca oferta no mercado.

A participação dos profissionais de projeto no processo termina com a entrega do projeto executivo, não sendo especificado no contrato o acompanhamento da obra. Somente caso existam modificações muito significativas, os projetistas são solicitados a realizar as alterações, sendo que o projeto como construído (as built) é de responsabilidade da construtora. Isso permite que conflitos aconteçam por ocasião da entrega do empreendimento, por inadequações com o que foi especificado no projeto.

No EC-2 existem possibilidades de retrabalho pela entrada dos projetistas complementares, construtor, especialistas de execução e os órgãos de regulação. Os primeiros empreendimentos desse estudo de caso tiveram mais retrabalhos devido à falta de informações de execução durante o desenvolvimento do projeto conceitual e o anteprojeto. As possibilidades de retrabalho indicam o motivo pelo qual as tomadas de decisão no processo do EC-2 se estendem à etapa de execução, pois os profissionais de execução podem solicitar modificações no projeto. No entanto, a repetição de empreendimentos com tipologias semelhantes e a relação de trabalho de longo prazo entre os agentes, fez com que os profissionais de arquitetura e os projetistas complementares já considerassem questões construtivas no desenvolvimento do projeto. Problemas de incompatibilidades entre disciplinas identificadas em processos anteriores foram previamente considerados e solucionados nos novos empreendimentos.

O uso de sistemas pré-fabricados e de uma tipologia modular para o projeto foi facilitado pelo trabalho de longo prazo estabelecido pelos participantes. Como todos estavam cientes do processo de produção dos empreendimentos do EC-2, foi possível escolher as melhores soluções projetuais, compatíveis com os componentes selecionados, reduzindo ou eliminando as interferências na etapa de execução.

Apesar da presença de um único gestor durante todo o processo, não existe a colaboração entre esse agente e as demais disciplinas. Ele se responsabiliza apenas por estabelecer um cronograma do processo de produção, exigir os prazos de execução das atividades e validar as entregas dos agentes, tanto na etapa de projeto quanto na execução. 


\subsubsection{Integração Organizacional}

Apesar de o cliente estabelecer um contrato específico com cada profissional, para cada empreendimento, a relação de trabalho de longo prazo facilitou a colaboração entre a equipe. O acúmulo de experiência da equipe, por meio do aprimoramento contínuo está presente no EC-2 como em uma linha de produção, o que potencializa a integração organizacional.

No EC-2, a colaboração (Figura 80) está presente principalmente durante o desenvolvimento do projeto, em que existe a participação efetiva do construtor e dos projetistas complementares. Essa colaboração não é recíproca, ou seja, não existe a participação dos projetistas na etapa de execução. No entanto, a repetição das equipes de projeto e execução e a existência de uma tipologia padrão para os empreendimentos, permitiu que o empreendimento fosse desenvolvido de uma maneira sistêmica, mesmo com a ausência da colaboração em todo o processo.

Ao trabalhar com projetos semelhantes, os arquitetos e projetistas complementares têm conhecimento de como ocorre a execução de cada etapa do empreendimento. Além disso, os profissionais de projeto anteveem possíveis interferências entre as disciplinas. Isso refletiu positivamente no uso da construção industrializada, pois o projeto executivo continha detalhes específicos dos sistemas construtivos efetivamente usados pelos construtores, evitando o retrabalho no momento de desenvolvimento do Projeto para Produção.

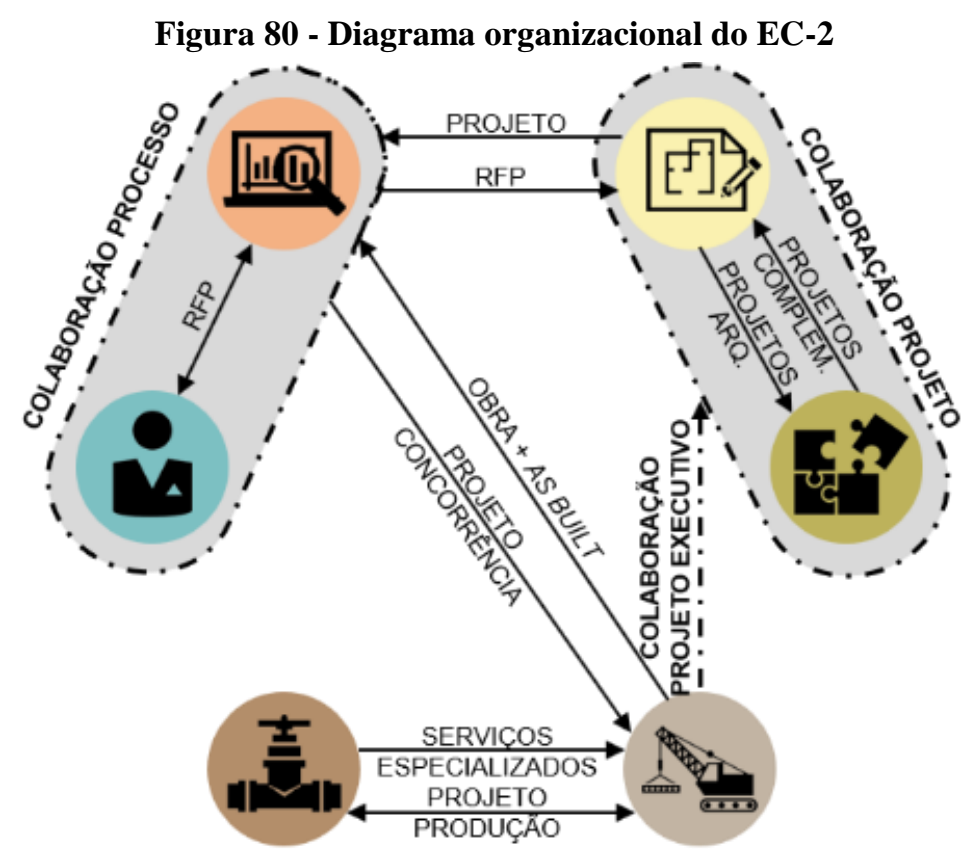

Fonte: Elaborado pela autora. 
A presença do gestor do processo poderia criar mais uma possibilidade de colaboração, o que não acontece no EC-2. A falta de participação efetiva desse agente no desenvolvimento do projeto e execução da obra, faz com que a gestão do processo ocorra apenas para controlar e garantir o cumprimento do planejamento físico-financeiro do processo.

\subsubsection{Integração pela Tecnologia de Informação}

No EC-2 o BIM foi utilizado somente no desenvolvimento do projeto, pelos arquitetos (Figura 81), com trocas de arquivos entre os demais agentes por meio de uma plataforma online de gestão de arquivos. O BIM foi utilizado pela equipe de arquitetura desde a etapa de concepção até o detalhamento do projeto. Isso permitiu que, desde as primeiras decisões, fossem incluídas e analisadas o maior número de informações do edifício, além de facilitar o estudo de diferentes soluções para o mesmo empreendimento.

Figura 81 - Diagrama do uso do BIM do EC-2

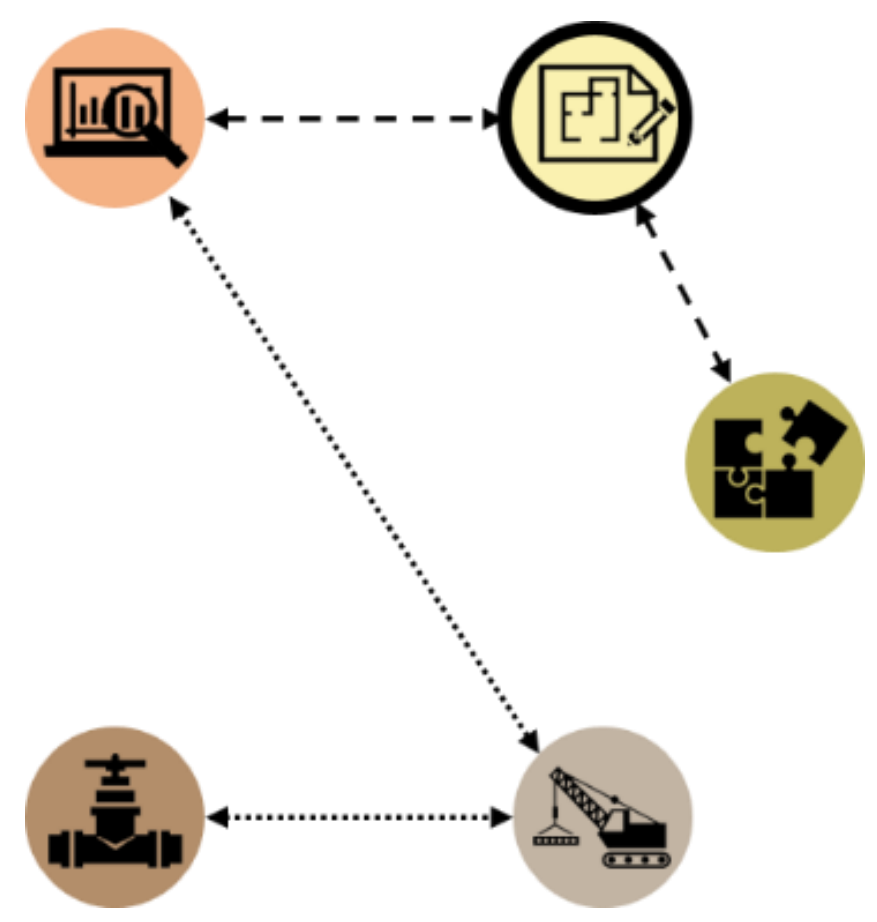

Fonte: Elaborado pela autora.

A decisão pelo uso do BIM, partiu dos próprios profissionais de arquitetura, que perceberam os benefícios no desenvolvimento do projeto: automatização de alguns procedimentos, como na 
definição dos módulos dos espaços de locação; facilidade na visualização do edifício e das interferências com as demais disciplinas; e facilidade de modificação do projeto.

O uso de tipologias padrão e modulação dos espaços dos empreendimentos do EC-2 foi identificado pelo projetista de arquitetura como um facilitador para a definição de procedimentos padrão no desenvolvimento do modelo BIM, se comparado com os demais projetos desse agente. Os arquitetos desenvolveram um sistema automatizado para identificar as possíveis soluções de distribuição dos espaços de locação, de forma a identificar a combinação mais eficiente para cada empreendimento.

As vantagens do uso do BIM no EC-2 foram percebidas apenas pelo escritório de arquitetura, pois não houve interesse do cliente, nem do construtor para inserir o BIM nos próximos empreendimentos. Isso gerou a necessidade de uma nova atividade no processo, sob responsabilidade dos arquitetos, pois toda vez que existiu uma entrega de arquivos 2D pelos projetistas complementares, na etapa de desenvolvimento do projeto, foi necessário inserir as informações no modelo BIM. Com isso, não existiu uma continuidade no fluxo de informações, perdendo eficiência e qualidade no processo.

\subsection{Estudo de Caso 3 (EC-3) - Gestão do processo sem BIM}

O EC-3 é o processo de produção de um empreendimento institucional privado na cidade de São Paulo, SP. Trata-se de um centro cultural, voltado a exposições de arte, cujo edifício tem sete andares, totalizando cerca de $8.600 \mathrm{~m}^{2}$ construídos, e é composto por amplos espaços expositivos, um cinema/auditório, biblioteca, salas de aula, restaurante e café.

Em 2011, teve início o processo de produção do EC-3, com a realização de um concurso de arquitetura para selecionar a melhor proposta. A obra foi iniciada no final de 2013 e o centro cultural foi inaugurado no segundo semestre de 2017. A coleta de dados do EC-3 foi feita quando o processo de produção já havia sido finalizado, ou seja, o edifício já estava entregue ao cliente e em funcionamento.

A necessidade de uma obra rápida e sem muito resíduo norteou a escolha pela construção industrializada em grande parte dos componentes do edifício e racionalização das atividades realizadas in loco. A estrutura do edifício é mista, com um núcleo de concreto armado, e demais estruturas em perfis metálicos, além de lajes pré-fabricadas de concreto, com fechamentos em drywall e fachadas com painéis de vidro. 
Devido às restrições do terreno, toda logística para a entrada de materiais e equipamentos requereu um planejamento cuidadoso. O local de implantação do edifício fica em uma região de acesso restrito a veículos de carga pesada. Além disso, o fato de o edifício ocupar a quase totalidade do terreno deixou pouco espaço de canteiro para sua obra. As atividades de execução seguiram um cronograma planejado, para que apenas o estoque de materiais necessários às atividades em andamento, ou a iniciar, estivessem no canteiro de obras, além de especificar detalhadamente quais atividades poderiam ocorrer de forma simultânea, sem conflitos.

\subsubsection{Integração Contratual}

O processo de produção do EC-3 (Figura 82) teve início com a contratação de um gestor para todo o processo - projeto e execução - como um representante do cliente para acompanhar a execução do empreendimento. Por não ser da área, o cliente não tinha conhecimento técnico da construção civil.

A definição do RFP foi realizada com a colaboração do gestor, que definiu o programa para a realização do concurso de arquitetura, a partir dos requisitos do cliente para os espaços expositivos do empreendimento. Além disso, o gestor foi responsável pela pré-seleção dos seis escritórios de arquitetura convidados para o concurso.

$\mathrm{Na}$ entrega do projeto conceitual deveria constar uma sugestão de projetistas complementares para compor a equipe definitiva do projeto. Por meio de consultorias, o escritório de arquitetura vencedor do concurso desenvolveu o projeto conceitual de forma colaborativa com a equipe de projetistas complementares. Esses agentes são profissionais que já trabalharam juntos em outros empreendimentos. A maior parte desses profissionais foram contratados pelo cliente do EC-3 para a continuidade do processo.

Após o aceite da proposta do concurso, o cliente estabeleceu contratos bilaterais com o escritório de arquitetura e os projetistas complementares, para desenvolver o anteprojeto e o projeto executivo. Apesar de não constar no contrato, o trabalho deveria ser feito de forma colaborativa entre os arquitetos, os demais projetistas e o gestor do processo, que considerou questões de execução precocemente no projeto. 
Figura 82 - Diagrama de contratação do EC-3

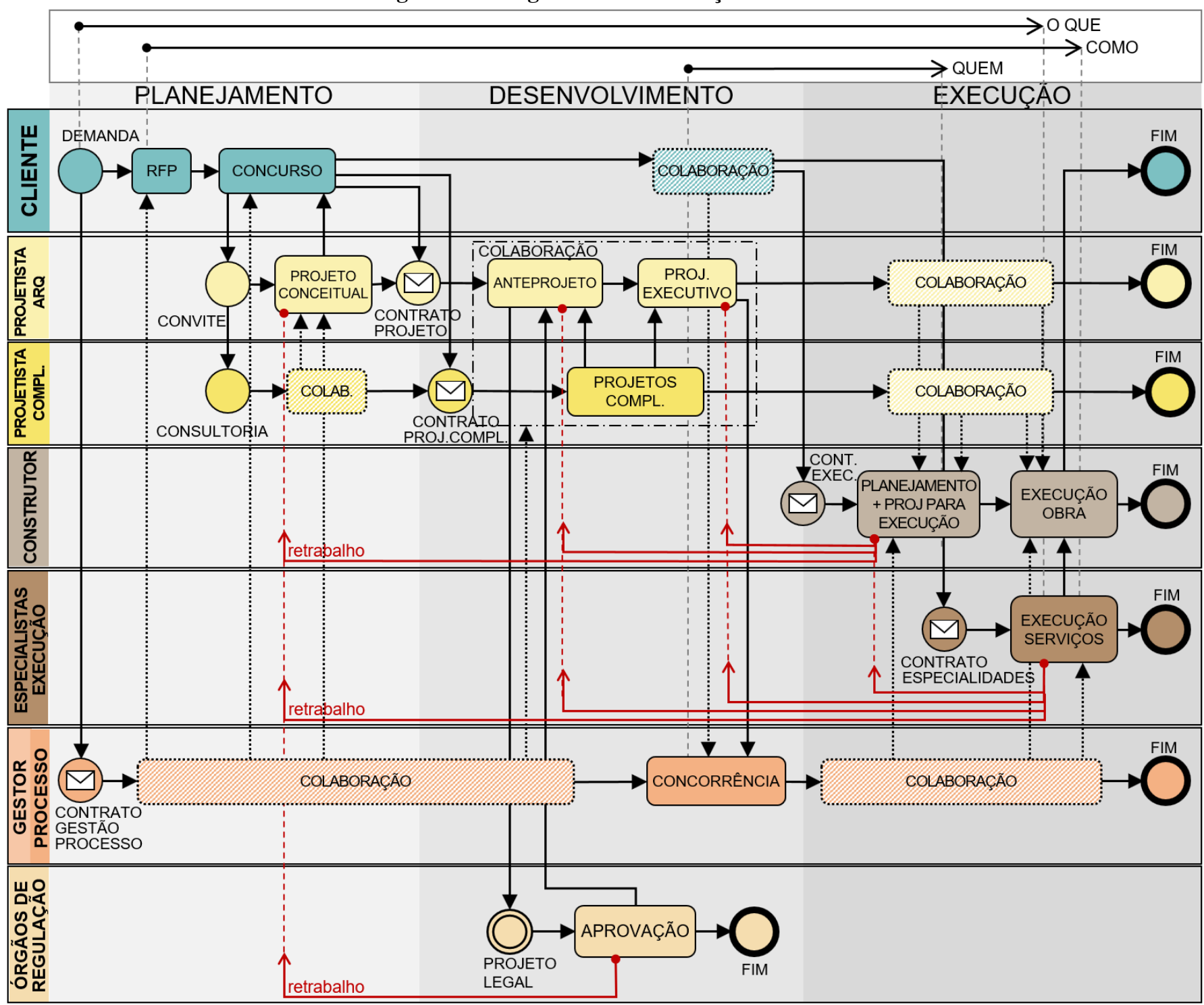

Fonte: Elaborado pela autora. 
Com o desenvolvimento do projeto executivo, o gestor ficou responsável por selecionar um construtor principal, que se responsabilizou por compatibilizar a execução dos diferentes serviços dos especialistas, como fachada, instalações elétricas e hidráulicas, sistema de elevadores e vedações; além de executar algumas atividades da obra, como pintura e acabamento.

O gestor foi responsável pela atividade de concorrência das especialidades de execução, que foram contratadas somente no momento em que sua disciplina era solicitada para a obra, por exemplo, os fornecedores da fachada só foram contratados no momento em que a estrutura de todo o edifício já havia sido finalizada. Todos os contratos de execução também foram estabelecidos bilateralmente entre o cliente e os profissionais.

O EC-3 tem menos possibilidades de retrabalho, se comparado com os demais estudos de caso. A entrada simultânea dos projetistas complementares com o de arquitetura, eliminou a necessidade de alterações no projeto conceitual e anteprojeto, pois essas atividades tiveram a colaboração de ambos agentes.

Em relação ao uso da estrutura mista, a colaboração dos projetistas complementares desde o projeto conceitual, principalmente no caso do calculista foi essencial para garantir o êxito na etapa de execução. Um mesmo profissional foi responsável pelo projeto dos dois sistemas, concreto e aço.

O detalhamento do núcleo de concreto deveria prever os pontos de apoio da estrutura metálica, que não permitiriam ajustes no momento de sua execução, pois as peças foram fabricadas com as dimensões estipuladas no Projeto para Produção. O desenvolvimento de toda a etapa de projeto por meio do trabalho colaborativo permitiu que poucos ajustes fossem necessários durante o desenvolvimento do Projeto para Produção, garantindo a qualidade do empreendimento.

No entanto, ainda existiu a possibilidade de retrabalho pela entrada do construtor, especialista de execução e os órgãos de regulação. Ainda que questões de execução foram consideradas no desenvolvimento do projeto, a entrada dos especialistas de execução demandou modificações de detalhamento no projeto do EC-3.

A cada contratação dos fornecedores dos sistemas especializados durante a execução da obra, foi necessário realizar ajustes no detalhamento do projeto. No Projeto Executivo foram definidos genericamente os sistemas utilizados para o projeto, com suas especificidades técnicas necessárias. 
No entanto, o projeto somente foi considerado como finalizado depois da compatibilização das especificações técnicas dos especialistas com o Projeto Executivo, o que resultou em modificações e adequações de projeto. No caso do uso da construção industrializada, as alterações tiveram um maior impacto, pois foi necessário compatibilizar os sistemas construtivos utilizados pelos especialistas, com os demais sistemas pré-fabricados do edifício, principalmente em relação à estrutura metálica.

Como os projetistas de arquitetura e complementares foram contratados para acompanhar a obra, esses agentes foram responsáveis por realizar as alterações e desenvolver o projeto como construído na entrega do empreendimento. A entrada tardia dos especialistas de execução indica o avanço de todas as tomadas de decisão na etapa de execução.

A colaboração efetiva do gestor nesse processo permitiu que o impacto do retrabalho no processo fosse reduzido, mantendo a visão sistêmica do empreendimento. Ao considerar questões técnicas de execução desde a elaboração do programa do edifício para o concurso, como a escolha das características necessárias para o sistema construtivo, foi possível antecipar a tomada de decisão de como o empreendimento seria executado.

No caso do retrabalho em relação à entrada dos órgãos de regulação, a mudança das regras na legislação urbanística da cidade de São Paulo teve um grande impacto no empreendimento. Com a redução na necessidade de vagas de garagem, o cliente solicitou a eliminação dos andares de subsolo que estavam destinados para esse uso.

Esse retrabalho ocorreu com a obra em andamento, sendo necessário realizar modificações significativas no Projeto Executivo e a atualização do Projeto para Produção em uma etapa avançada do processo de produção. Como resultado, houve um aumento no prazo de execução do projeto, que impactou no adiamento da entrega da obra.

A decisão pela modificação do projeto partiu do cliente, que assumiu as consequências pelo aumento no tempo de execução do projeto e a paralização da obra para adequação às modificações. No entanto, a colaboração dos projetistas complementares e do gestor desde o início do processo reduziu o impacto desse retrabalho no processo, pois todos os profissionais já estavam cientes das características do projeto e quais disciplinas poderiam ser impactadas na eliminação dos andares de subsolo.

Uma diferença do EC-3 em relação aos demais estudos de caso relatados, diz respeito à permanência de todos os agentes do processo. Todos, com exceção dos órgãos de regulação, participam até a entrega final da obra. Isso foi um requisito especificado no contrato e previsto 
desde o edital do concurso. A participação dos projetistas na etapa de execução permitiu um maior controle sobre as modificações no projeto de arquitetura, demandadas pelos especialistas de execução, já que esses agentes participaram das tomadas de decisão durante a execução e da escolha final dos fornecedores dos sistemas construtivos do edifício.

\subsubsection{Integração Organizacional}

A presença do gestor no processo de produção do EC-3, como um representante do cliente (Figura 83), indica que esse foi o agente central do processo. Ele foi responsável por validar todas as entregas das disciplinas, realizar a seleção da construtora e dos especialistas, além de colaborar em todo o processo. Como resultado, o cliente, por meio do gestor, teve um controle maior do processo de produção do EC-3, se comparado aos demais estudos de caso relatados.

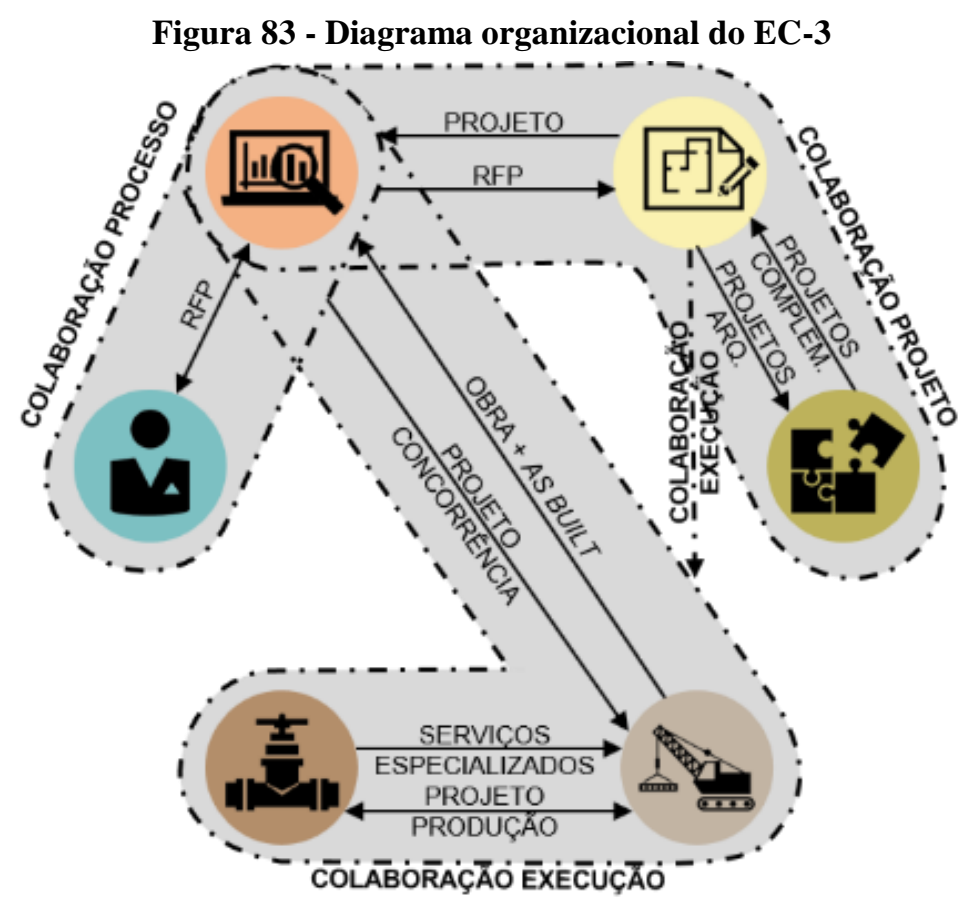

Fonte: Elaborado pela autora.

No EC-3 o trabalho colaborativo esteve presente em quase toda a equipe, sendo que a participação efetiva do gestor favoreceu a colaboração entre todas as disciplinas. No entanto, a colaboração nas atividades de execução aconteceu em apenas um sentido, ou seja, os profissionais de projeto colaboraram nessas atividades, mas os agentes da execução não colaboraram no desenvolvimento do projeto. 
Conforme descrito pelos projetistas de arquitetura, cada vez que uma empresa ou profissional de execução foi contratado, foi necessário alterar o detalhamento do projeto para as especificidades do sistema construtivo. O projeto final executado pelos arquitetos indicou o tipo de sistema a ser usado, com seus requisitos de desempenho e características estéticas. No entanto, cada empresa contratada detinha um sistema com detalhes específicos, o que demandou por ajustes no projeto, resultando em retrabalho e aumento de prazo de desenvolvimento do projeto.

\subsubsection{Integração pela Tecnologia de Informação}

Todo o processo de produção do EC-3 foi executado de forma convencional (Figura 84), com elaboração do projeto em software CAD e trocas de arquivos por meio de uma plataforma online de gestão. A ausência do uso do BIM pode ter prejudicado a colaboração entre as disciplinas, pois impediu que houvesse uma continuidade nas análises do projeto.

Figura 84 - Diagrama do uso do BIM do EC-3

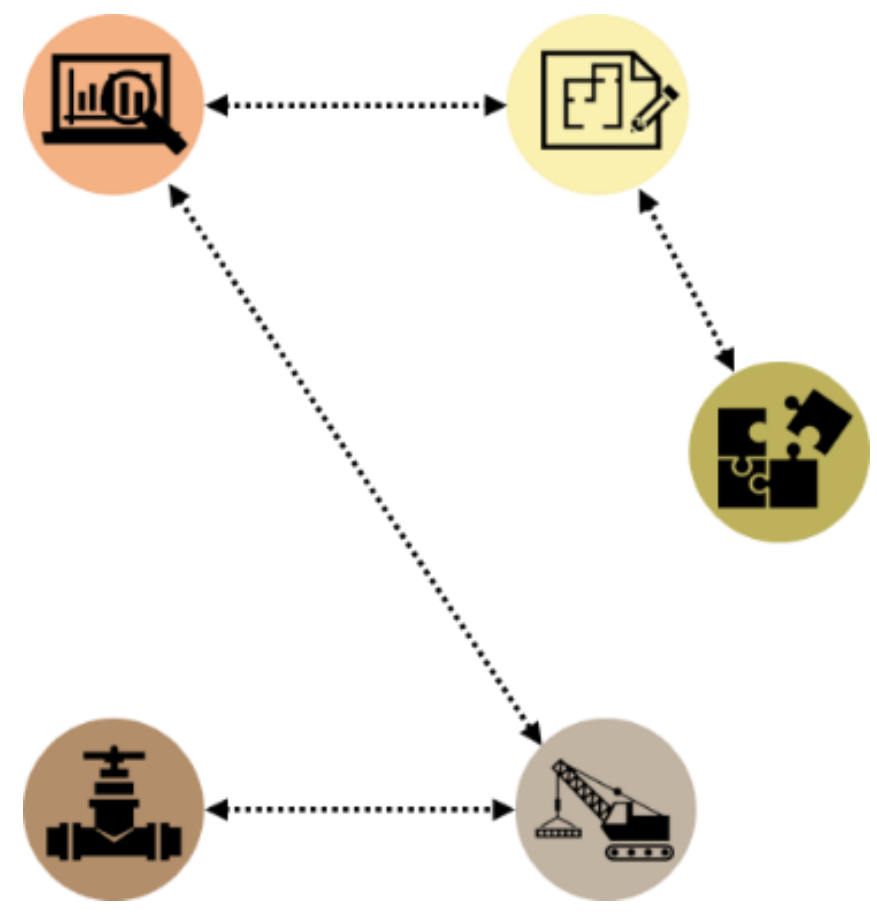

Fonte: Elaborado pela autora.

Apesar de existir um mesmo tipo de formato na troca e acesso dos arquivos de projeto arquivos 2D e documentos digitais - o uso do BIM desde o início do processo poderia facilitar 
a antecipação na identificação de algumas interferências entre disciplinas. O gestor poderia ter um controle maior do processo com análises de custo, planejamento e logística da execução desde o projeto conceitual, o que resultaria em um projeto mais completo e condizente com a realidade.

Os retrabalhos identificados durante o processo poderiam impactar menos o processo com o uso do BIM. No momento em que fosse solicitada alguma modificação no projeto, os arquitetos poderiam atualizar o modelo BIM, que atualizaria automaticamente as demais informações do projeto, como quantitativos e desenhos de representação - plantas, corte e fachada.

Além disso, um modelo BIM do edifício como construído poderia ser utilizado ao longo do ciclo de vida do empreendimento, em atividades de manutenção ou reforma. Isso se mostra ainda mais importante por se tratar de um edifício complexo, ou seja, com diferentes tipos de instalações que precisam de um controle rigoroso no seu funcionamento, para garantir que as obras expostas nas galerias não sejam danificadas.

\subsection{Estudo de Caso 4 (EC-4) - Gestão do processo com BIM}

O quarto estudo de caso (EC-4) é um empreendimento institucional privado para uso educacional, com uma área de aproximadamente $1.800 \mathrm{~m}^{2}$. Tendo como uso principal uma biblioteca, o edifício de três pavimentos é composto também por um ambiente para estudos e uma área livre de convívio dos usuários. Localizado dentro da área de uma escola privada da cidade de São Paulo, SP, o edifício substituirá a antiga biblioteca.

O projeto teve início no ano de 2017, com a elaboração de um programa de necessidades para a realização de um concurso para o projeto de arquitetura. Com a finalização do projeto executivo no final de 2018, a previsão de entrega da obra é em 2019. A coleta de dados foi feita quando o projeto executivo havia sido finalizado, sendo que o cliente estava aguardando a liberação da obra pelos órgãos de regulação. Apesar de a obra ainda não ter iniciado no momento em que foram feitas as entrevistas, o cliente já havia definido como seria estabelecido todo o processo de produção, inclusive a forma de contratação dos agentes de execução.

Mesmo não sendo uma edificação de grande área, existe uma complexidade nos sistemas construtivos e prediais utilizados, como: climatização, iluminação, elevadores, fachada com brises, segurança e incêndio, comunicação visual e paisagismo. Além disso, existe a dificuldade em executar a obra com o colégio em funcionamento. 
A escolha do uso de sistemas construtivos pré-fabricados e a racionalização dos componentes produzidos in loco se deu pela necessidade de uma obra rápida, organizada e com menor interferência possível no entorno. Por isso, foi selecionado o uso de estruturas metálicas e fechamento em drywall e painéis de vidro, que possibilitaram planejar melhor a execução, e o controle do momento de chegada do material ao canteiro de obras e do tempo de montagem.

\subsubsection{Integração Contratual}

O processo de produção do EC-4 (Figura 85) é semelhante ao do EC-3 na participação dos profissionais de projeto - arquitetura e complementares. $\mathrm{O}$ cliente realizou um concurso por meio de convite a alguns escritórios de arquitetura pré-selecionados para escolher a melhor solução arquitetônica para o edifício. No momento do convite, os arquitetos deveriam apresentar uma lista de projetistas complementares, a serem priorizados na contratação para o restante do processo.

O cliente no EC-4 tem um engenheiro contratado, que ficou responsável por conduzir o processo. O RFP foi definido por esse engenheiro, com base nas demandas de uso do espaço da biblioteca, considerando as restrições para a execução da obra, que deve acontecer com a escola em funcionamento.

Para a elaboração do projeto conceitual para participar do concurso, o escritório de arquitetura vencedor teve a colaboração dos projetistas complementares, como uma consultoria. Esses profissionais possuíam um histórico de trabalharem juntos em outros empreendimentos, o que facilitou a colaboração sem que houvesse um contrato de trabalho.

Após a definição do projeto vencedor do concurso, o cliente estabeleceu contratos bilaterais com os projetistas de arquitetura e os projetistas complementares. Nesse caso, a maior parte da equipe de complementares indicada pelos arquitetos foi contratada pelo cliente, o que facilitou a continuidade no desenvolvimento do projeto. 
Figura 85 - Diagrama de contratação do EC-4

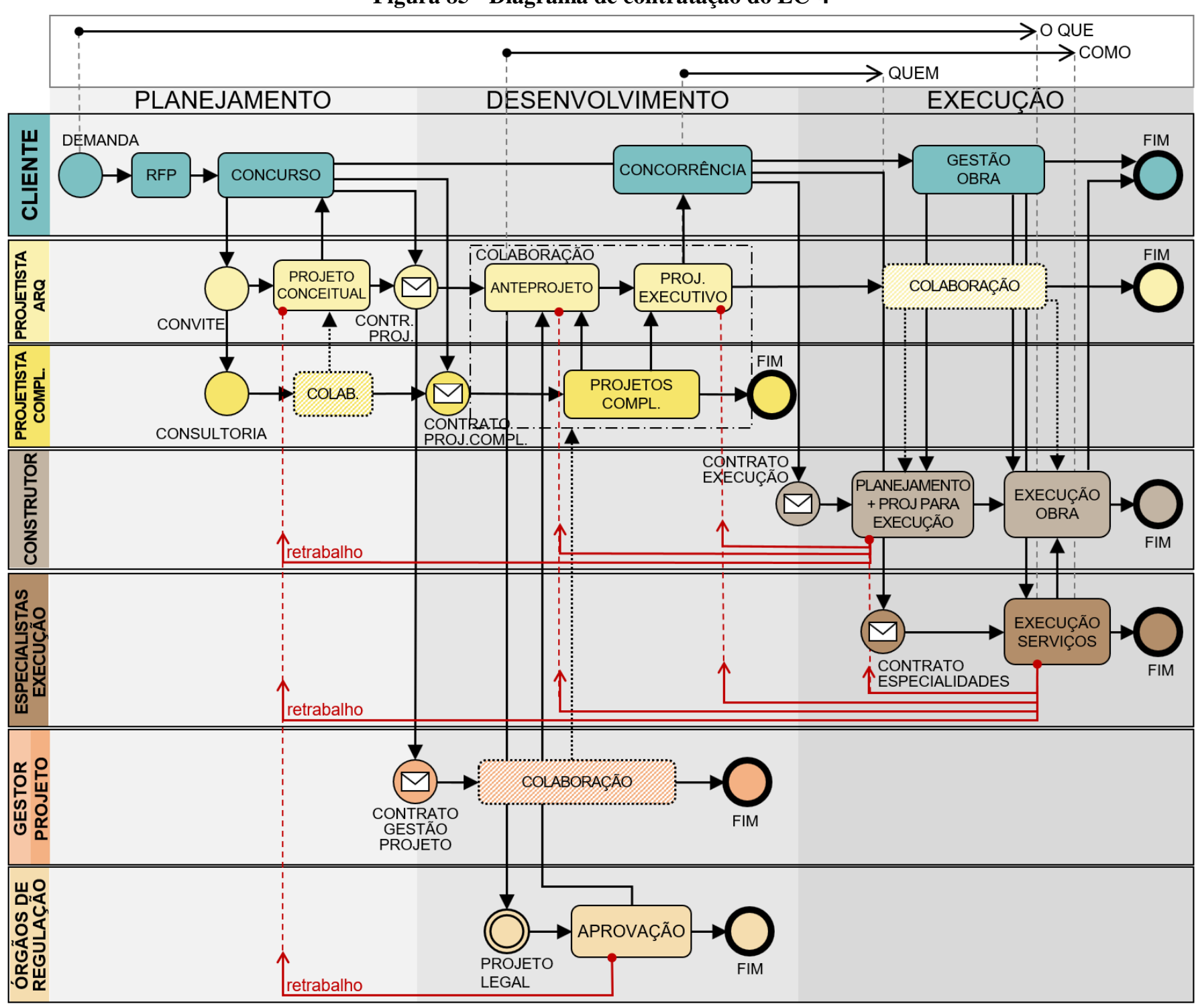

Fonte: Elaborado pela autora. 
Junto com a contratação dos projetistas, o cliente contratou um gestor somente para a etapa de projeto. Como o engenheiro da equipe do cliente não tem experiência na execução e gestão de projetos, a responsabilidade por acompanhar, planejar e compatibilizar o desenvolvimento de projeto foi passada para o gestor contratado. No entanto, sua participação terminará com a finalização do projeto executivo.

A gestão da etapa de execução será de responsabilidade do cliente, que ficará responsável também pela seleção do construtor e dos especialistas de execução. Cada profissional de execução será contratado bilateralmente pelo cliente, sem nenhuma especificação de colaboração durante a atividade de execução.

No EC-4 existem três possibilidades de retrabalho, com a entrada do construtor, dos especialistas de execução e dos órgãos de regulação. A falta de colaboração entre as disciplinas de projeto na execução do edifício permite que detalhes dos sistemas construtivos possam alterar significativamente o projeto.

A presença do projetista de arquitetura na etapa de execução é opcional, pois não está estipulada no contrato e é uma decisão dos arquitetos, que têm como premissa de trabalho acompanhar a obra. Isso prejudica a qualidade do empreendimento, pois cria uma divisão entre as etapas de projeto e execução, segmentando o processo de produção.

A seleção e contratação tardia dos profissionais de execução indica que o fim das tomadas de decisão de $o$ que e como sejam feitas na etapa de execução, possibilitando que incompatibilidades sejam identificadas tardiamente no processo. Isso teria um maior impacto no processo pelo uso da construção industrializada, pois modificações realizadas sobre o Projeto para Produção poderiam indicar a revisão de todas as interferências entre os sistemas, que por serem pré-fabricados, não permitem ajustes durante a execução.

No caso do possível retrabalho pela entrada dos órgãos de regulação, a incompatibilidade do sistema de elevadores com o limite de altura imposto pela legislação municipal demandou alterações no Anteprojeto. Foi necessário selecionar outro tipo de sistema que não tivesse a necessidade da instalação de casa de máquinas na cobertura do edifício. No entanto, como foi uma modificação pontual, esse retrabalho não teve grande impacto sobre o desenvolvimento do projeto e não alterou o prazo de execução do mesmo.

A falta de continuidade na gestão do processo, prejudicou a integração do processo de produção do EC-4. Apesar da consideração das questões de execução durante a elaboração do projeto pela efetiva colaboração do gestor de projeto, com a saída desse agente do processo, não é 
possível estabelecer o acompanhamento e atualização das modificações solicitadas pelos profissionais de execução.

Além disso, a ausência do gestor desde o início do processo não permitiu que a colaboração ocorresse durante a etapa de planejamento do projeto - RFP e elaboração do edital do concurso - como foi identificado no EC-3. No entanto, como a etapa de execução ainda não foi iniciada nesse estudo de caso, não é possível indicar se os retrabalhos ocorreram, devido à ausência de um mesmo gestor no processo, e qual o impacto deles no empreendimento.

\subsubsection{Integração Organizacional}

A integração organizacional no EC-4 ocorreu somente na etapa de projeto (Figura 86). Desde a elaboração do projeto conceitual existiu a colaboração entre os projetistas de arquitetura e os complementares, o que permitiu desenvolver um Anteprojeto bem mais completo e adequado a todas as disciplinas. Isso possibilitou a redução das incompatibilidades durante a execução do projeto executivo, pois diferentes perspectivas de projeto foram consideradas para as primeiras soluções projetuais.

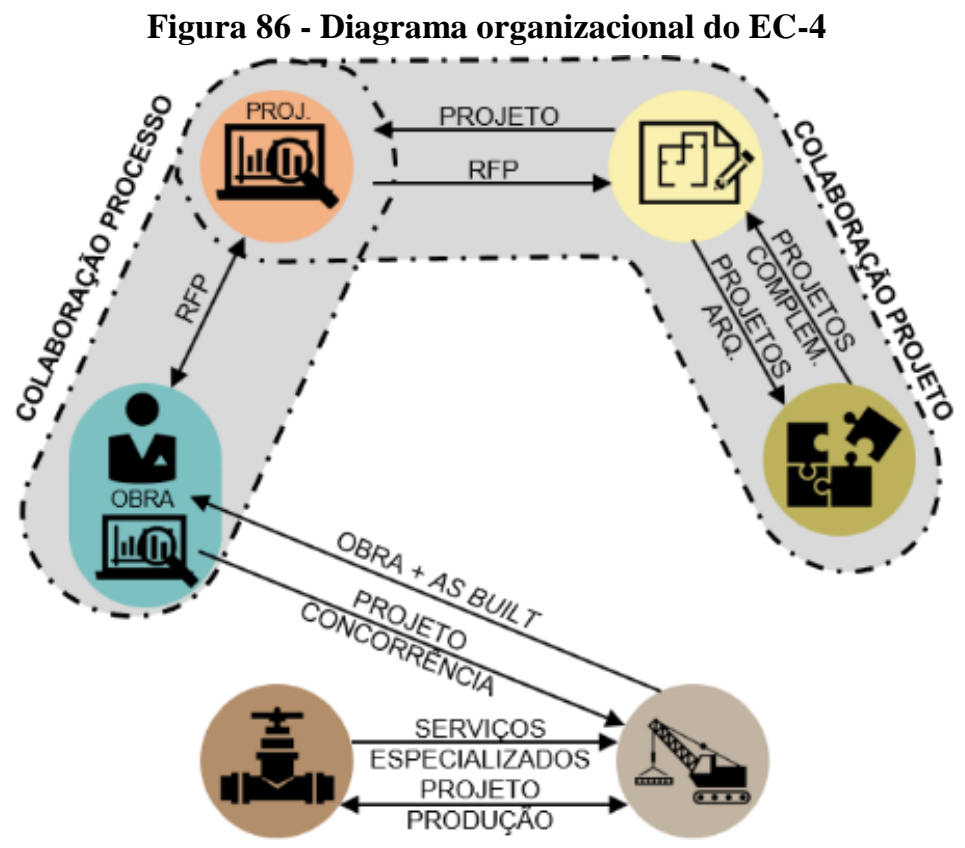

Fonte: Elaborado pela autora.

No entanto, o trabalho colaborativo não deverá acontecer nas atividades da etapa de execução, devido à saída do gestor de projeto e da não participação dos projetistas nas tomadas de decisão 
da obra. O cliente optou por centralizar as atividades de execução no engenheiro de sua equipe, como um gestor de obra. A atividade de gestão da execução no EC-4 está voltada para a validação e controle das entregas pelos profissionais, pois não foi previsto a colaboração efetiva desse agente no desenvolvimento do planejamento e dos projetos para produção.

\subsubsection{Integração pela Tecnologia de Informação}

No processo de produção do EC-4 foi usado o BIM em todas as atividades de projeto e por todos os profissionais que participaram dessa etapa - projetista de arquitetura, projetistas complementares e gestor de projeto (Figura 87).

Figura 87 - Diagrama do uso do BIM do EC-4

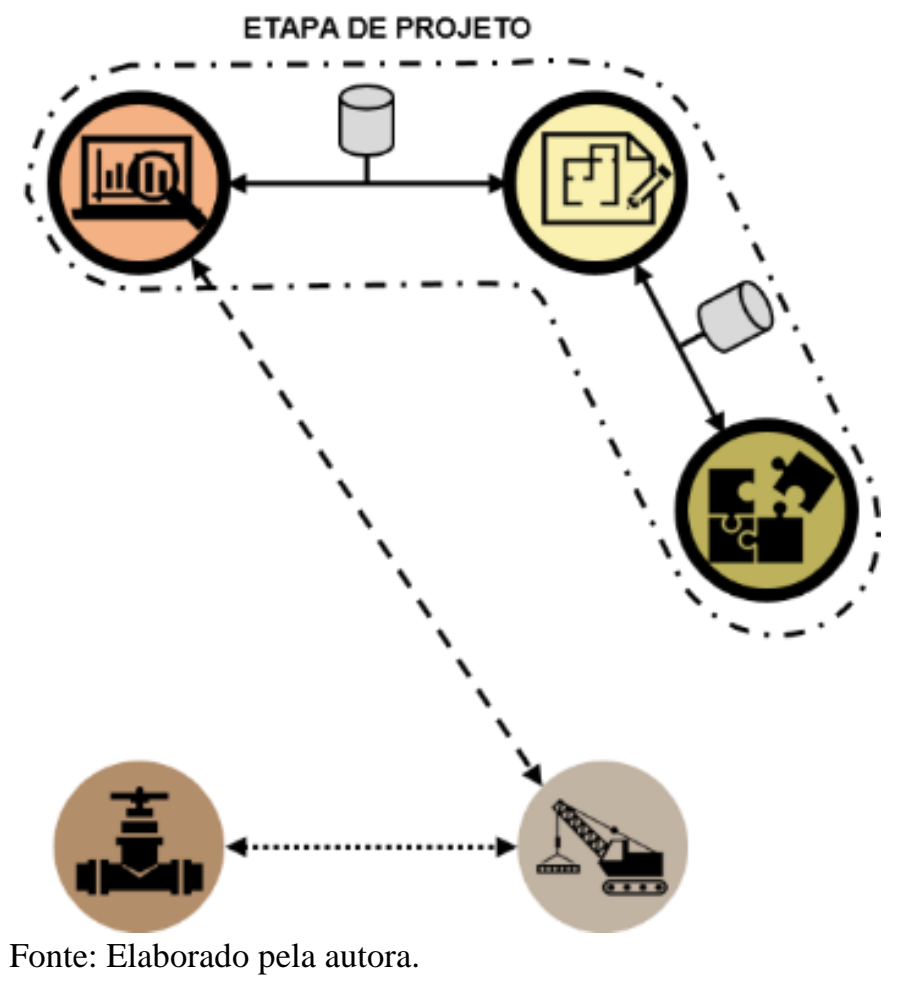

A escolha pelo uso do BIM partiu do cliente junto com o escritório de arquitetura, que já havia desenvolvido o projeto conceitual em BIM para a participação no concurso. Como o cliente já teve problemas nas obras anteriores do colégio, por incompatibilidades de projeto, o engenheiro propôs usar o BIM como uma forma de garantir a qualidade e confiabilidade do projeto executivo. 
No entanto, o engenheiro não tem conhecimento técnico e de produção com o BIM. Por esse motivo, a continuidade do processo depende da forma de trabalho dos profissionais contratados para a execução. Caso nenhum dos agentes de execução trabalhe com o BIM, todo o planejamento da obra e desenvolvimento do Projetos para Produção serão elaborados da forma convencional, não sendo possível garantir a continuidade da integração da tecnologia de informação entre as etapas - projeto e execução.

A equipe de projetistas complementares já sabia desde o início que todo o desenvolvimento do projeto seria realizado em BIM. A maior parte deles já trabalhava com esse tipo de processo e alguns profissionais que trabalhavam com software CAD se dispuseram a trabalhar com software BIM. Isso gerou uma dificuldade inicial, mas que foi sendo resolvida ao longo do processo, não impactando no prazo de desenvolvimento do projeto.

Apenas algumas disciplinas complementares desenvolveram seus projetos da forma convencional, como: comunicação visual, iluminação e paisagismo. Nesses casos o projetista de arquitetura foi responsável por compatibilizar as informações em 2D para o modelo BIM.

O gestor de projeto no EC-4 teve uma participação efetiva no trabalho colaborativo do projeto, pois as tomadas de decisão sempre passaram pela sua validação e a compatibilização era de sua responsabilidade. A atividade de compatibilização entre as disciplinas ocorreu ao longo do desenvolvimento do projeto, desde o anteprojeto, o que foi feito no modelo BIM, por meio da ferramenta de análise de interferências. No caso de interferências, o gestor buscava soluções primeiro entre os complementares e, quando não era possível, solicitava uma nova solução projetual para os arquitetos.

A forma de trabalho em BIM foi feita com o compartilhamento das informações por meio de um modelo único. Cada disciplina trabalhava em um arquivo próprio e inseria as modificações em um arquivo central. Para realizar as alterações no modelo BIM central, havia uma regra de uso, sendo que os projetistas complementares não tinham acesso para alterar o modelo, somente inserir suas informações de projeto.

\subsection{Comparação dos estudos de caso}

Para avaliar a integração dos estudos de caso e realizar uma comparação entre eles, foram utilizados os níveis de integração de cada perspectiva - contratual, organizacional e de tecnologia de informação (Figura 29, Figura 49 e Figura 74). Além disso, foram identificados 
os fatores que promoveram a integração do processo de produção dos empreendimentos (Tabela 19).

O intuito dessa comparação não é avaliar qual dos modelos adotados é o melhor para o processo de produção, mas sim observar como são as relações entre os profissionais na prática e identificar qual perspectiva mais interfere na integração do processo de produção e no uso da construção industrializada.

Tabela 19 - Comparação dos níveis de integração dos estudos de caso

\begin{tabular}{ccccc}
\hline $\begin{array}{c}\text { Estudos de } \\
\text { caso }\end{array}$ & Contratual & Organizacional & $\begin{array}{c}\text { Tecnologia da } \\
\text { Informação }\end{array}$ & $\begin{array}{c}\text { Fatores que promoveram a } \\
\text { integração }\end{array}$ \\
\cline { 2 - 4 } $\begin{array}{c}\text { EC-0 } \\
\text { (Lélé/Prouvé) }\end{array}$ & 3 & $3+$ & 0 & $\begin{array}{c}\text { Industrialização de ciclo fechado; } \\
\text { relação de longo prazo }\end{array}$ \\
$\begin{array}{c}\text { EC-1 } \\
\text { turnkey) }\end{array}$ & $1+$ & $1++^{\mathrm{a}}$ & 2 & $\begin{array}{c}\text { Antecipação da participação do } \\
\text { construtor; uso do BIM na etapa de } \\
\text { projeto }\end{array}$ \\
$\begin{array}{c}\text { EC-2 } \\
\text { (linha de } \\
\text { produção) }\end{array}$ & 0 & $1+^{\mathrm{a} \text { c }}$ & 1 & $\begin{array}{c}\text { Relação de longo prazo; antecipação da } \\
\text { participação do construtor; projetos } \\
\text { com tipologia padrão }\end{array}$ \\
$\begin{array}{c}\text { EC-3 } \\
\text { (gestão sem } \\
\text { BIM) }\end{array}$ & 0 & $2+^{\mathrm{b}}$ & 0 & $\begin{array}{c}\text { Participação efetiva de um gestor em } \\
\text { todo o processo; relação de longo } \\
\text { prazo (somente projetistas) }\end{array}$ \\
$\begin{array}{c}\text { EC-4 } \\
\text { (gestão com } \\
\text { BIM) }\end{array}$ & 0 & $1+^{\mathrm{b}}$ & $2+$ & $\begin{array}{c}\text { Uso do BIM na etapa de projeto; } \\
\text { relação de longo prazo (somente } \\
\text { projetistas) }\end{array}$ \\
\hline
\end{tabular}

${ }^{a}$ participação limitada do gestor, apenas na validação das entregas.

${ }^{\mathrm{b}}$ participação dos projetistas na etapa de execução.

${ }^{c}$ participação dos construtores na etapa de desenvolvimento do projeto.

Fonte: Elaborado pela autora.

No EC-0 (Lelé/Prouvé), percebe-se um alto nível de integração contratual e organizacional, sem o uso da integração pela tecnologia da informação. Como os profissionais são contratados para a produção de diversos empreendimentos, eles participam do processo desde o início, sendo que os modelos de contrato adotados por Lelé e Prouvé podem ser comparados a um contrato relacional, como o PP e PA (nível 3 de integração contratual), ou seja, integração de todos os agentes exceto os órgãos de regulação.

No caso da integração organizacional, o processo de produção do EC-0 tem uma colaboração total (nível 3+ de integração organizacional), com a participação de um gestor do processo projeto e obra - que é representado pelos próprios arquitetos Lelé e Prouvé. Isso indica que a equipe estabelece um trabalho colaborativo ao longo de todo o processo, mantendo a visão sistêmica na produção dos empreendimentos. 
Como no EC-0 não se tem o uso do BIM, não existe a integração pela perspectiva de tecnologia da informação (nível 0 de integração pela tecnologia da informação). No entanto, isso não impediu que os empreendimentos tivessem um nível elevado de industrialização, indicado pelo uso da industrialização de ciclo fechado.

No empreendimento do EC-1 (contratação turnkey), foi identificado um certo nível de integração pelo sistema contratual, com o uso de um contrato semelhante ao Design and Build (DB) (nível 1+ de integração contratual), ou seja, a contratação de uma associação entre os projetistas e o construtor. Mesmo que esse sistema contratual não tenha sido aplicado a todo o processo, foi observado que um certo nível de integração se fez em grande parte do processo de produção - desenvolvimento do projeto e execução.

O tipo de contratação do EC-1 refletiu no nível de integração organizacional, que se caracterizou pelo turnkey, com a presença de um gestor (nível 1++ de integração organizacional). No entanto, observou-se que a participação do gestor não indicou a colaboração efetiva desse agente no desenvolvimento do projeto e na execução, pois sua responsabilidade estava limitada em validar as entregas dos agentes no prazo e na qualidade estipulada para o processo.

Em relação à tecnologia da informação, foi identificado que o uso do BIM aconteceu entre duas disciplinas (nível 2 de integração pela tecnologia da informação) - arquitetura e complementares. Não foi identificado o uso do BIM entre etapas, ele foi usado somente em disciplinas de projeto. No EC-1 foram utilizados sistemas construtivos pré-fabricados na maior parte da obra, sem, no entanto, especificar técnicas de racionalização no desenvolvimento do projeto.

O EC-2 (processo como linha de produção) possui um modelo de contrato semelhante ao Design-Bid-Build (nível 0 de integração contratual), ou seja, cada profissional é contratado bilateralmente pelo cliente com as responsabilidades limitadas apenas à sua disciplina. No entanto, existe a presença de uma relação de trabalho de longo prazo que não está especificada no contrato, mas sim na forma de organizar a equipe.

Isso se reflete no nível de integração organizacional do EC-2 (nível 1+ de integração organizacional), pois existe a colaboração entre os profissionais de projeto - arquitetura e complementares - além da participação do construtor na elaboração do Projeto Executivo. No entanto, essa colaboração não é recíproca, ou seja, os projetistas não colaboram na etapa de execução. Além disso, do EC-2 existe a participação de um gestor não colaborativo, ou seja, 
responsável apenas pela validação das entregas do processo de produção conforme o planejamento.

O BIM foi usado em apenas uma disciplina do EC-2 (nível 1 de integração pela tecnologia da informação) - projetista de arquitetura. No entanto, isso não impediu a presença de um nível alto de industrialização. A integração sob a perspectiva organizacional favoreceu a industrialização tanto pelos sistemas construtivos, quanto pela racionalização do processo, principalmente pelo estabelecimento de relações de trabalho de longo prazo. Nesse estudo de caso, existiu um aprimoramento contínuo do processo que refletiu na escolha das melhores soluções para os empreendimentos.

No EC-3 (gestão do processo sem BIM) existe uma forte integração sob a perspectiva organizacional (nível 2+ de integração organizacional) e nenhum nível de integração pelo tipo de contratação nem pela tecnologia da informação (nível 0 de integração contratual e pela tecnologia da informação). Como o modelo de contrato foi semelhante ao DBB e não houve o uso do BIM, a integração alcançada pelo processo de produção do EC-3 se deu apenas pela forma de organizar a equipe.

A presença do gestor no processo todo e atuante na colaboração das atividades de planejamento e desenvolvimento de projeto, bem como da execução, garantiu o trabalho colaborativo da equipe. No entanto, a colaboração entre as etapas de projeto e execução ocorreu de forma limitada, pois apenas os projetistas colaboraram na etapa de execução, sendo que o gestor foi o único agente que colaborou durante todo o processo e em todas as atividades.

No entanto, a ausência de um contrato integrado e do uso do BIM não impediu um nível alto de industrialização, com o uso de sistemas pré-fabricados e da definição de procedimentos racionais de execução da obra desde o desenvolvimento do projeto. $\mathrm{O}$ trabalho colaborativo, principalmente dos projetistas complementares, desde o desenvolvimento do projeto conceitual, favoreceu o uso de sistemas industrializados de forma eficiente, com a compatibilização entre os demais componentes da obra.

O EC-4 (gestão do processo com o BIM) usou um tipo de contrato semelhante ao DBB, o que refletiu na ausência de integração pela perspectiva contratual (nível 0 de integração contratual). Em relação à perspectiva organizacional, o EC-4 possui nível médio de integração (nível 1+ de integração organizacional). Com a presença de um gestor de projeto que atua no trabalho colaborativo em todas as atividades do desenvolvimento do projeto - Anteprojeto e Projeto Executivo - foi observada a integração na forma de organizar a equipe. No entanto, essa 
integração é limitada a etapa de projeto, o que impediu que o trabalho colaborativo acontecesse ao longo de todo o processo.

O BIM também foi utilizado apenas na etapa de projeto, sem a continuidade do fluxo de informações entre etapas. Como a colaboração no uso do modelo BIM ocorreu entre três disciplinas - arquitetura, complementares e gestão de projeto - existiu um nível alto de tecnologia da informação no EC-4 (nível 2+ de integração pela tecnologia da informação), o que representa o nível mais alto dentre os estudos de caso analisados.

Mesmo com a falta de integração em todas as três perspectivas, o EC-4 conseguiu estabelecer um nível alto de industrialização, pois além do uso de componentes pré-fabricados, os sistemas moldados in loco foram planejados seguindo uma racionalização para sua execução.

Com a análise dos cinco estudos de caso, percebe-se que a integração organizacional é perspectiva que mais está presente nos processos de produção. Essa perspectiva tem um índice elevado, mesmo nos casos em que não existe a integração contratual, nem pela tecnologia da informação. Isso indica que a forma de organizar a equipe, buscando estabelecer um trabalho colaborativo foi o fator que mais influenciou na tomada de decisão do cliente em estabelecer os processos de produção.

Como a seleção dos projetos teve como premissa o uso da construção industrializada, todos os estudos de casos apresentam certo nível de industrialização. No entanto, o estudo de caso que apresentou o maior nível de industrialização - EC-0 - também foi o que teve o maior nível de integração organizacional. Essa informação indica que a integração organizacional pode ser essencial para o efetivo uso da industrialização.

A perspectiva da integração menos desenvolvida nos estudos de caso foi a contratual, sendo que apenas dois casos utilizaram um sistema diferente do DBB. Isso indica que o trabalho colaborativo da equipe pode estar presente mesmo quando não existe exigência de integração definida no contato. As relações de trabalho de longo prazo, identificadas no EC-1 e o histórico de trabalhos anteriores no EC-3 e EC-4, foram instrumentos que favoreceram um ambiente de confiança entre os agentes, que percebem os benefícios do trabalho colaborativo para o desenvolvimento de sua própria atividade e em relação ao empreendimento como um todo.

Em relação a perspectiva de tecnologia da informação, percebe-se uma maior diversificação dos estudos de caso, desde processos que não utilizaram o BIM e processos com o compartilhamento do modelo em uma mesma etapa. Em nenhum estudo de caso foi usado o 
BIM entre as etapas de projeto e execução, sendo que nenhum processo alcançou o maior nível de integração pela perspectiva da tecnologia da informação.

Por essa informação é possível identificar que o uso do BIM não é indispensável para garantir a integração do processo, nem para alcançar um alto nível de industrialização. No entanto, seu uso favorece o trabalho colaborativo, permitindo uma continuidade na troca de informações e a antecipação na identificação de interferências entre disciplinas, principalmente em relação aos sistemas pré-fabricados. O uso concomitante do BIM e da construção industrializada permitiu que o Projeto para Produção fosse elaborado com base em informações mais precisas sobre os sistemas construtivos, reduzindo as interferências entre as disciplinas. 


\section{CONSIDERAÇÕES FINAIS}

A necessidade de aprimorar o processo de produção da construção civil resultou na busca constante de melhores práticas para executar um empreendimento. Dentre as melhorias, a integração do processo de produção se mostrou como uma solução coerente, para aperfeiçoar os processos da construção civil, principalmente no uso da industrialização.

A integração exerce influência de diferentes formas no processo de produção, podendo ser consideradas três perspectivas: contratual, organizacional e de tecnologia da informação. A aplicação dos instrumentos de cada perspectiva indica que existe uma interdependência entre elas, ou seja, um instrumento para a integração sob uma perspectiva pode favorecer a integração sob as demais.

Nesta pesquisa foi realizada uma análise pormenorizada das perspectivas de integração indicadas na literatura. Criou-se formas de análise comparativas e de comunicação com o uso de notações gráficas adequadas a cada uma. Com isso, criou-se um método que não apenas permite a comparação entre os modelos gerais descritos na literatura de cada perspectiva, como aqueles observados nos estudos de caso abordados.

No caso da perspectiva contratual, partiu-se dos diagramas estereotipados do AIA (AMERICAN INSTITUTE OF ARCHITECTS, 2014), aos quais se adicionou elementos do BPMN. Em relação à perspectiva organizacional, os diagramas elaborados, com base no modelo publicado por Molenaar e Sobin (2009), permitiu que se criasse uma hierarquização de suas várias formas. No caso da perspectiva de tecnologia da informação, os diferentes níveis de maturidade BIM definidos por Succar (2009) foram detalhados de acordo com as possibilidades de troca de informações e no uso dos modelos da construção pela equipe - BIM e/ou convencional.

Na sequência desse desenvolvimento, criou-se uma tabela indicativa do nível de integração decorrente de cada perspectiva. A tabela consolidada também indica as interdependências entre as perspectivas.

\subsection{Conclusão}

A aplicação efetiva da integração na construção civil é considerada por diferentes autores como uma melhoria que deve abranger as três perspectivas - contratual, organizacional e de tecnologia da informação. Para eles é necessário alterar significativamente todo o processo, 
para se alcançar todos os benefícios para o empreendimento. No entanto, de acordo com a hipótese inicialmente levantada, verificou-se que é possível obter um processo com certo nível de integração, sem que sejam alteradas, em sua totalidade, as três perspectivas.

Verificou-se, tanto com base na literatura como nos estudos de caso, que a construção industrializada pode ser aprimorada principalmente com a integração organizacional. A antecipação da participação dos agentes no desenvolvimento do projeto e a presença de colaboração durante o desenvolvimento das atividades, permitem a antecipação das tomadas de decisão, que vão impactar na etapa de execução. Com a presença de profissionais que inserem questões de execução e dos sistemas construtivos desde as primeiras soluções de projetos, a etapa de execução é realizada com base em um projeto muito mais coerente com a realidade, sem que seja necessário realizar modificações significativas.

Isso possibilita que os componentes construtivos pré-fabricados possam ser previamente selecionados e suas interfaces com os demais sistemas do edifício possam ser solucionadas, resultando em uma obra mais precisa e eficiente. Além disso, a antecipação de questões construtivas na etapa de projeto permite planejar previamente a execução das atividades de execução, tornando a racionalização dos processos mais eficiente.

A integração por meio do sistema contratual não foi considerada como o fator determinante para a integração do processo e o uso da industrialização. Observou-se, nos estudos de caso da industrialização aberta, que é possível manter o trabalho colaborativo da equipe, sem que essa colaboração estivesse definida como uma cláusula de contrato. No entanto, a integração sem a perspectiva contratual requer a presença de instrumentos organizacionais, como as relações de trabalho de longo prazo ou a presença de um gestor no processo.

Em relação ao gestor, percebeu-se que somente a sua contratação não garante a integração do processo. A presença desse agente favorece a integração, apenas nos casos em que ele for um agente colaborativo no desenvolvimento do projeto. O contrato, nesse caso, não é o fator determinante para estabelecer a integração, mas sim a definição de suas responsabilidades no processo, o que reforça a importância da perspectiva organizacional.

Em relação a integração pela tecnologia da informação, seu uso não é o fator determinante para alcançar a integração do processo, nem um alto nível de industrialização. No entanto, o uso do BIM para o desenvolvimento do projeto possibilita o aprimoramento da integração organizacional. Com o desenvolvimento e compartilhamento do modelo BIM na etapa de 
projeto, é possível estabelecer uma continuidade no fluxo de informações e reduzir o impacto dos retrabalhos identificados durante a etapa de execução.

Além disso, o uso do BIM permite maior eficiência no desenvolvimento de soluções projetuais para o uso da industrialização, seja na definição da modulação do projeto, antecipação do planejamento de execução, ou na verificação precoce das interferências entre os sistemas préfabricados. Isso resulta em um Projeto Executivo mais completo, pois ele contém informações precisas e confiáveis sobre o edifício, reduzindo as necessidades de retrabalho na etapa de execução.

Portanto, verificou-se que a ausência da integração em uma perspectiva não impede que exista algum nível de integração no processo de produção do empreendimento. Dos estudos de caso verificou-se que a integração sob a perspectiva organizacional tem maior influência sobre a integração do empreendimento. Isso indica que a forma como a equipe é organizada, o momento em que os agentes participam do processo e a presença de um gestor que colabore ao longo de todo o processo, é essencial para o êxito no uso da industrialização na construção civil.

\subsection{Limitações e futuros desdobramentos da pesquisa}

O presente estudo ocorreu em um contexto real, envolvendo intervenientes com disponibilidade limitada, em empreendimentos diversificados e em diferentes fases de desenvolvimento. Este contexto apresentou desafios adicionais à investigação, ainda que os dados levantados tenham permitido se chegar a uma contribuição inovadora.

Como desdobramentos futuros sugere-se o desenvolvimento de maior números de estudos de caso, com características distintas, que permitam generalizar as conclusões obtidas.

No caso da industrialização, indica-se o desdobramento da análise feita nessa pesquisa para verificar os impactos da integração do processo de produção entre os diferentes tipos de construção industrializada: com o uso de sistemas construtivos pré-fabricados e a racionalização do processo. Nesta pesquisa ambas abordagens da industrialização foram observadas nos estudos de caso; no entanto, cada uma pode ser analisada separadamente, de forma a compreender como a integração do processo pode aperfeiçoá-las.

Em relação ao uso do BIM, não foi possível perceber os benefícios dele na sua totalidade, pois em nenhum dos casos estudados ele foi usado em todo o processo, ou seja, não existiu o compartilhamento do modelo entre as etapas de projeto e execução. Recomenda-se que futuros 
estudos envolvam o uso do BIM não apenas durante o projeto, mas também na etapa de execução.

Outro desdobramento da pesquisa pode se dar em relação aos tipos de estudos de caso, ou seja, diferentes usos do empreendimento podem indicar diferentes perspectivas para a interdependência entre a construção industrializada e a integração do processo de produção. Como exemplo tem-se o setor imobiliário, que possui especificidades, principalmente com o estabelecimento de relações de trabalho de longo prazo, ainda que não estabelecidos em contrato, mas pelo histórico de participação em empreendimentos similares, e com o uso de técnicas de racionalização da construção. 


\section{REFERÊNCIAS}

AGÊNCIA BRASILEIRA DE DESENVOLVIMENTO INDUSTRIAL. GUIA 1 - Processo de Projeto BIM. ABDI, 2017a.

. GUIA 4 - Contratação e elaboração de projetos BIM na arquitetura e engenharia. ABDI, 2017b.

GUIA 5 - Avaliação de desempenho energético em Projetos BIM. ABDI, 2017c.

Manual da Construção Industrializada - Conceitos e Etapas - Volume 1: Estrutura e Vedação. ABDI, 2015.

ALI, Ahmed K; BADINELLI, Ralph. Novel Integration of Sustainable and Construction Decisions into the Design Bid Build Project Delivery Method Using BPMN. Procedia Engineering, v. 145, 2016.

ALRESHIDI, Eissa; MOURSHED, Monjur; REZGUI, Yacine. Cloud-Based BIM Governance Platform Requirements and Specifications: Software Engineering Approach Using BPMN and UML. Journal of Computing in Civil Engineering, v. 30, n. 4, 2016.

AMERICAN INSTITUTE OF ARCHITECTS. AIA Contract Document Families. AIA. Disponível em: <https://www.aiacontracts.org/contract-doc-pages/21182-contract-documentfamilies>. Acesso em: 10 fev. 2019.

Defining the Architect's Basic Services. AIA, 2007b.

Integrated Project Delivery: A Guide. AIA National e AIA California Council, 2007a.

Integrated Project Delivery - An updated working definition - Version 3. AIA California Council, 2014.

AMSTEL, Frederick M.C. van; et al. Expensive or expansive? Learning the value of boundary crossing in design projects. The Engineering Project Organization Journal, v. 6, n. 1, 2016.

ANUMBA, Chimay J.; KAMARA, John M.; CUTTING-DECELLE, Anne-Francoise. Concurrent Engineering in Construction Projects. Oxon: Taylor \& Francis, 2007.

ASOCIACIÓN LATINOAMERICANA DEL ACERO. América Latina en cifras 2018. ALACERO, 2018. Disponível em: <https://www.alacero.org/sites/default/files/publicacion/ america_latina_en_cifras_2018_es-en.pdf $>$. Acesso em: 29 nov. 2018. 
ASSOCIAÇÃO BRASILEIRA DA CONSTRUÇÃO INDUSTRIALIZADA DE CONCRETO. Anuário ABCIC 2015. ABCIC, 2015.

. Anuário ABCIC 2016. ABCIC, 2016.

ASSOCIAÇÃO BRASILEIRA DA CONSTRUÇÃO METÁLICA. Cenário dos fabricantes de estruturas de aço. ABCEM; Centro Brasileiro da Construção em Aço - CBCA, 2017a.

. Cenário dos fabricantes de estruturas de aço. ABCEM; Centro Brasileiro da Construção em Aço - CBCA, 2018a.

Cenário dos fabricantes de perfis galvanizados para Light Steel Frame e Drywall. ABCEM; Centro Brasileiro da Construção em Aço - CBCA, 2015 b.

. Cenário dos fabricantes de perfis galvanizados para Light Steel Frame e Drywall. ABCEM; Centro Brasileiro da Construção em Aço - CBCA, 2016 b.

. Cenário dos fabricantes de perfis galvanizados para Light Steel Frame e Drywall. ABCEM; Centro Brasileiro da Construção em Aço - CBCA, 2017 b.

. Cenário dos fabricantes de perfis galvanizados para Light Steel Frame e Drywall. ABCEM; Centro Brasileiro da Construção em Aço - CBCA, 2018 b.

- Perfil dos fabricantes de estruturas de aço. ABCEM; Centro Brasileiro da Construção em Aço - CBCA, 2015a.

Perfil dos fabricantes de estruturas de aço. ABCEM; Centro Brasileiro da Construção em Aço - CBCA, 2016a.

ASSOCIAÇÃO BRASILEIRA DE NORMAS TÉCNICAS. NBR 9062 - Projeto e execução de estruturas de concreto pré-moldado. ABNT: Rio de Janeiro, 2006.

. NBR 15575-1 - Edificações habitacionais - Desempenho Parte 1: Requisitos gerais. ABNT: Rio de Janeiro, 2013.

. NBR 15965-1 - Sistema de classificação da informação da construção. Parte1: Terminologia e estrutura. ABNT: Rio de Janeiro, 2011.

NBR 15965-3 - Sistema de classificação da informação da construção. Parte 3: Processos da construção. Rio de Janeiro: ABNT, 2014. 
informação - organização da informação da construção. Parte2: estrutura para a classificação da informação. Rio de Janeiro: ABNT, 2010.

ASSOCIAÇÃO BRASILEIRA DOS GESTORES E COORDENADORES DE PROJETOS. Manual de escopo de serviços para coordenação de projetos. 2. ed. São Paulo, 2012.

ASSOCIATION OF CONSULTANT ARCHITECTS. PPC2000 - The ACA Standard Form of Contract for Project Partnering: Introduction and Explanatory Notes. ACA, 2005.

The PPC Suite Partnering Contracts. ACA. Disponível em <http://www.ppc2000. co.uk>. Acesso em $19 \mathrm{dez} 2018$.

AUSTRALIAN GOVERNMENT. National Alliance Contracting Guidelines - Guidance Note 2 - Insurance in Alliance Contracting: Selling Insurable Risk. Department of Infrastructure and Regional Development, 2015b.

National Alliance Contracting Guidelines - Guidance Note 6 - Early Contractor Involvement and Other Collaborative Procurement Methods, 2015c.

National Alliance Contracting Guidelines - Guide to Alliance Contracting. Department of Infrastructure and Regional Development, 2015a.

AZARI, Rahman; KIM, Yong-Woo. Integration Evaluation Framework for Integrated Design Teams of Green Buildings: Development and Validation. Journal of Management in Engineering, v. 32, n. 3, 2015.

AZHAR, Nida; KANG, Youngcheol; AHMAD, Irtishad. Critical Look into the Relationship between Information and Communication Technology and Integrated Project Delivery in Public Sector Construction. Journal of Management in Engineering, v. 31, n. 5, set. 2015.

BAIDEN, B. K.; PRICE, A. D. F. The effect of integration on project delivery team effectiveness. International Journal of Project Management, v. 29, n. 2, p. 129-136, 2011.

BAIDEN, B. K.; PRICE, A. D. F.; DAINTY, A. R. J. Looking beyond processes: human factors in team integration. In: 19th Annual ARCOM Conference, University of Brighton. Association of Researchers in Construction Management, Vol. 1, 233-42, 2003.

The extent of team integration within construction projects. International Journal of Project Management, v. 24, n. 1, 2006.

BALLARD, Glenn. Lean Project Delivery System - LCI White Paper 8. Arlington: Lean Construction Institute, 2000. 
. The Lean Project Delivery System: An Update. Lean Construction Journal, 2008.

BALLARD, Glenn; et al. Roadmap for Lean Implementation at the Project Level. Austin: Construction Industry Institute, 2007.

BAROUGHA, Azin Shakiba; SHOUBIA, Mojtaba Valinejad; SKARDIB, Moohammad Javad Emami. Application of Game Theory Approach in Solving the Construction Project Conflicts. Procedia - Social and Behavioral Sciences, v. 58, p. 1586 - 1593, 2012.

BLISMAS, Nick; PASQUIRE, Christine; GIBB, Alistair. Benefit evaluation for off-site production in construction. Construction Management and Economics, v. 24, n. 2, fev. 2006.

BOUKENDOUR Saï; HUGHES, Will. Collaborative incentive contracts: stimulating competitive behaviour without competition. Construction Management and Economics, v. 32, n. 3, 2014.

BRAVETTI, Alessandro; PADILLA, Pablo. An optimal strategy to solve the Prisoner's Dilemma. Scientific Reports, v. 8, 2018.

BUILDINGSMART. About. Disponível em: 〈https://www.buildingsmart.org/about>. Acesso em: 19 dez. 2018b.

Information Delivery Manuals. buildingSMART. Disponível em: <http://iug.buildingsmart.org/idms/information-delivery-manuals>. Acesso em: 19 dez. 2018a.

BYGBALLE, Lena E.; INGEMANSSON, Malena. The logic of innovation in construction. Industrial Marketing Management, v. 43, n. 3, p. 512-524, abr. 2014.

BYGBALlE, Lena E.; JAHRE, Marianne; SWÄRD, Anna. Partnering relationships in construction: A literature review. Journal of Purchasing \& Supply Management, v. 16, n. 4, p. 239-253, 2010.

CÂMARA BRASILEIRA DA INDÚSTRIA DA CONSTRUÇÃO - CBIC. A produtividade da Construção Civil brasileira. São Paulo: GD7 Consultoria e Comunicação, 2012. Disponível em: <http://www.cbicdados.com.br/media/anexos/066.pdf >. Acesso em: 19 dez. 2018.

CARDOSO, Francisco. Stratégies d'entreprises et nouvelles formes de rationalisation de la production dans le bâtiment au Brésil et en France. 1996. Tese (Doctorat en Économie et sciences sociales) École Nationale des Ponts et Chaussées. Paris: 1996.

CERAN, Turan; DORMAN, Albert A. The complete project manager. Journal of Architectural Engineering, v. 1, n, 2, 1995. 
CHAN, Albert P. C.; SCOTT, David; CHAN, Ada P. L. Factors Affecting the Success of a Construction Project. Journal of Construction Engineering and Management, v. 130, n. 1, 2004.

CHEUNG, Sai On; YIU, Kenneth T. W.; CHIM, Pui Shan. How Relational are Construction Contracts? Journal of Professional Issues in Engineering Education and Practice, v. 132, n. 1, 2006.

CHEUNG, Sai On; YIU, Tak Wing; LAM, Man Chung. Interweaving Trust and Communication with Project Performance. Journal of Construction Engineering and Management, v. 139, n. 8, 2013.

ÇIDIK, Mustafa Selçuk; BOYD, David; THURAIRAJAH, Niraj. Innovative Capability of Building Information Modeling in Construction Design. Journal of Construction Engineering and Management, v. 143, n. 8, 2017.

COLLEDGE, Barbara. Relational Contracting - Creating Value Beyond the Project. Lean Construction Journal, v. 2, n. 1, abr. 2005.

CONSTRUCTION INDUSTRY COUNCIL. Guidelines on Partnering - Version 1. CIC, 2010.

CONSTRUCTION INDUSTRY INSTITUTE. Knowledge Base from CII - Best Practices. CII. Disponível em: <https://www.construction-institute.org>. Acesso em: 19 dez. 2018.

CONSTRUCTION MANAGEMENT ASSOCIATION OF AMERICA. An owner's guide to Construction and Program Management: Enabling project success under any delivery method. CMAA, 2011.

An owner's guide to Project Delivery Methods. CMAA, 2012.

Managing Integrated Project Delivery. CMAA, 2009.

CONSTRUCTION SPECIFICATIONS INSTITUTE. The Project Resource Manual - CSI Manual of Practice. 5 ed. CSI e Mc Graw-Hill, 2005.

COSTA, António Aguiar; et al. Guia de Contratação BIM. Instituto Superior Técnico, Universidade de Lisboa. 2017.

DEPARTMENT OF MAIN ROADS. Standard Contract Provisions Roads: Volume 6 Early Contractor Involvement (ECI) Contract - Introduction. Department of Main Roads, 2009. 
DEPARTMENT OF TREASURY AND FINANCE. In Pursuit of Additional Value - A benchmarking study into alliancing in the Australian Public Sector. Department of Treasury and Finance of Victoria, Evans \& Peck e University of Melbourne, 2009.

. The Practitioners' Guide to Alliance Contracting. Department of Treasury and Finance of Victoria, 2010.

DESIGN-BUILD INSTITUTE OF AMERICA. Choosing a Project Delivery Method. DBIA, 2015.

. What is Design-Build? A Design-Build done Right Primer. DBIA. 2014.

DEWITT, Steven; et al. Construction Management Practices in Canada and Europe. U.S. Department of Transportation; Federal Highway Administration, 2005.

DORST, Kees. Describing Design: A comparison of paradigms. 1997. Tese (Doutorado). Technische Universiteit Delft. Delft, Netherlands, 1997.

EASTMAN, Chuck; et al. BIM Handbook: A Guide to Building Information Modeling for Owners, Managers, Designer, Engineers and Contractors. 2. ed. Hoboken: John Wiley \& Sons, Inc., 2011. $634 \mathrm{p}$.

EGAN, John. Accelerating Change. London: Rethinking Construction, Strategic Forum for Construction, 2002.

. Rethinking Construction. London: UK Department of Trade and Industry, Construction Task Force, 1998.

EL-ADAWAY, Islam; ABOTALEB, Ibrahim; ETEIFA, Seifeldeen. Framework for Multiparty Relational Contracting. Journal of Legal Affairs and Dispute Resolution in Engineering and Construction, v. 9, n. 3, 2017.

EL ASMAR, Mounir; HANNA, Awad S.; LOH, Wei-Yin. Evaluating Integrated Project Delivery Using the Project Quarterback Rating. Journal of Construction Engineering and Management, v. 142, n. 1, jun. 2015.

. Quantifying Performance for the Integrated Project Delivery System as Compared to Established Delivery Systems. Journal of Construction Engineering and Management, v. 139, n. 11, nov. 2013.

EMMITT, Stephen; GORSE, Christopher. Communication in Construction Teams. London: Routledge, 2006. 
ERIKSSON, per Erik. Cooperation and partnering in facilities construction - empirical application of prisoner's dilemma. Facilities, v. 25, n. 1/2, 2007.

Partnering in engineering projects: Four dimensions of supply chain integration. Journal of Purchasing \& Supply Management, v. 21, n. 1, p. 38-50, 2015.

. Partnering: what is it, when should it be used, and how should it be implemented?

Construction Management and Economics, v. 28, n. 9, set. 2010.

EUBIM. Handbook for the introduction of Building Information Modelling by the European Public Sector. EUBIM Task Group, 2017.

FABRICIO, Márcio Minto. Industrialização das construções: revisão e atualização de conceitos. Pós. Revista do Programa de Pós-Graduação em Arquitetura e Urbanismo da FAUUSP, v. 20, n. 33, jun. 2013.

Projeto simultâneo na construção de edifícios. 2002. Tese (Doutorado em Engenharia Civil) Escola Politécnica, Universidade de São Paulo. São Paulo, 2002.

FISCHER; et al. Integrating Project Delivery. Hoboken: Wiley, 2017.

FORBES, Lincoln H.; AHMED, Syed M. Modern Construction Lean Project Delivery and Integrated Practices. 1. ed. Boca Raton: CRC Press - Taylor \& Francis Group, 2011. 524 p.

FOSTER, Jack Stroud. Structure and Fabric. England: Longman Scientific \& Technical, 1994.

FRANCOM, Tober; ARIARATNAM, Samuel T; EL ASMAR, Mounir. Industry Perceptions of Alternative Project Delivery Methods Applied to Trenchless Pipeline Projects. Journal of Pipeline Systems Engineering and Practice, v. 7, n. 1, 2016.

FRANZ, Bryan; et al. Impact of Team Integration and Group Cohesion on Project Delivery Performance. Journal of Construction Engineering and Management, jun. 2016.

FULLER, Buckminster. Concebendo uma nova indústria. São Paulo: GFAU-USP, 1963. $105 p$.

GADDE, Lars-Erik; DUBOIS, Anna. Partnering in the construction industry - Problems and opportunities. Journal of Purchasing \& Supply Management, v. 16, n. 4, dez. 2010.

GERRARD, Robert. Relational Contracts - NEC in Perspective. Lean Construction Journal, v. 2, n. 1, abr. 2005. 
GIBB, Alistair G. F. Off-site Fabrication: Prefabrication, Pre-assembly and Modularization. Scotland: Whittles Publishing. 1999.

GIBB, Alistair G. F. Standardization and pre-assembly- distinguishing myth from reality using case study research. Construction Management and Economics, v. 19, n. 3, p. 307-315, 2001.

GIBB, Alistair G. F; ISACK, Frank. Re-engineering through pre-assembly: client expectations and drivers. Building Research \& Information, v. 31, n. 2, 2003.

GIRMSCHEID, Gerhard. Context of Industrialisation - Introduction. In: New Perspective in Industrialisation in Construction - A State-of-the-Art Report, GIRMSCHEID, Gerhard; SCHEUBLIN, Frits (Ed.). Council for Research and Innovation in Building and Construction - CIB. Zurich: Eigenverlag des IBB an der ETH, 2010, p. 3-13.

GIRMSCHEID, Gerhard; SCHEUBLIN, Frits (Ed.). New Perspective in Industrialisation in Construction - A State-of-the-Art Report. Council for Research and Innovation in Building and Construction - CIB. Zurich: Eigenverlag des IBB an der ETH, 2010.

GOH, Edward; LOOSEMORE, Martin. The impacts of industrialization on construction subcontractors: resource based view. Construction Management and Economics, v. 35, n. $5,2017$.

GRILO, António; JARDIM-GONCALVES, Ricardo. Value proposition on interoperability of BIM and collaborative working environments. Automation in Construction, v. 19, n. 5, p. 522-530, 2010.

HARPER, Christofer M.; MOLENAAR, Keith R.; CANNON, Joseph P. Measuring Constructs of Relational Contracting in Construction Projects: The Owner's Perspective. Journal of Construction Engineering and Management, v. 142, n. 10, out. 2016.

HARPER, Christofer Michael. Measuring Project Integration Using Relational. 2014. Thesis (Doctoral degree - Civil, Architectural, and Environmental Engineering). University of Colorado. Boulder, 2014.

HERAVI, Amirhossein; COFFEY, Vaughan; TRIGUNARSYAH, Bambang. Evaluating the level of stakeholder involvement during the project planning processes of building projects. International Journal of Project Management, v. 33, n. 5, p. 985-997, 2015.

HM GOVERNMENT. Construction 2025. HM Government 2013.

HOOVER, Sabine; TROMBITAS, Paul; COWLES, Ethan. Prefabrication: The Changing Face of Engineering and Construction. Denver: Fails Management Institute - FMI/BIMForum Prefabrication Survey, 2017. 
IBRAHIM, Khairil Izam; COSTELLO, Seosamh B.; WILKINSON, Suzanne. Key practice indicators of team integration in construction projects: a review. Team Performance Management, v. 19, n. 3/4, 2013.

INTERNATIONAL COUNCIL FOR RESEARCH AND INNOVATION IN BUILDING AND CONSTRUCTION. Research Roadmap Report - Integrated Design \& Delivery Solutions (IDDS). CIB, 2013.

KHAN, Wasim A.; RAOUF, Abdul. Standards for Engineering Design and Manufacturing. Boca Raton: CRC Press, 2005.

KIFOKERIS, Dimosthenis, XENIDIS, Yiannis. Constructability: Outline of Past, Present, and Future Research. Journal of Construction Engineering and Management, v. 143, n. 8, ago. 2017.

KPMG. Global Construction Survey 2016 - Building a technology advantage. KPMG, 2016.

LAHDENPERÄ, Pertti. Making sense of the multi-party contractual arrangements of project partnering, project alliancing and integrated project delivery. Construction Management and Economics, v. 30, n. 1, fev. 2012.

LATHAN, Michael. Constructing the team. London: HMSO, 1994.

LAWSON, Bryan. How Designers Think - The design process demystified. 4 ed. Oxford: Architectural Press, 2006.

LAZAR, Frederick D. Project partnering: improving the likelihood of win/win outcomes. Journal of Management in Engineering, v. 16, n. 2, 2000.

LIGNY, Emilia van Egmond-de Wilde de. Conditions for Industrialisation and Innovation in Construction. In: New Perspective in Industrialisation in Construction - A State-of-the-Art Report, GIRMSCHEID, Gerhard; SCHEUBLIN, Frits (Ed.). Council for Research and Innovation in Building and Construction - CIB. Zurich: Eigenverlag des IBB an der ETH, 2010, p. 67-75.

LOVE, PED; GUNASEKARAN, A.; LI, H. Concurrent engineering: a strategy for procuring construction projects. International Journal of Project Management, v. 16, n. 6, p. 375-383, 1998.

LIU, Yan; NEDERVEEN, Sander van; HERTOGH, Marcel. Understanding effects of BIM on collaborative design and construction: An empirical study in China. International Journal of Project Management, v. 35, n. 4, p. 686-698, 2017. 
LIU, Hui; SKIBNIEWSKI, Miroslaw J.; WANG, Mengjun. Identification and hierarchical structure of critical success factors for innovation in construction projects: Chinese perspective. Journal of Civil Engineering and Management, v. 22, n. 3, 2016.

LU, Shaokai; HAO, Gang. The influence of owner power in fostering contractor cooperation: Evidence from China. International Journal of Project Management, v. 31, n. 4, p. 522-531, 2013.

LUKIANTCHUKI, Marieli A.; CAIXETA, Michele C. B. F.; FABRICIO, Márcio M. Integrated design of industrialized building systems: The Technology Center of the Sarah Network- CTRS, Brazil Gestão e Tecnologia de Projetos, São Paulo, v. 10, n. 1, p.99-114, jan./jun. 2015. http://dx.doi.org.br/10.11606/

MARTINEZ, Santiago; et al. Building industrialization: robotized assembly of modular products. Assembly Automation, v. 28, n. 2, p. 134-142, 2008.

MARTINEZ, Santiago; et al. Flexible field factory for construction industry. Assembly Automation, v. 33, n. 2, p. 175-183, 2013.

MATTHEWS, Owen; HOWELL, Gregory A. Integrated Project Delivery an Example of Relational Contracting. Lean Construction Journal, v. 2, n. 1, abr. 2005.

MELHADO, Silvio Burratino. Coordenação de projetos de edificações. São Paulo: O Nome da Rosa, 2005.

MCGRAW HILL CONSTRUCTION. Prefabrication and Modularization: Increasing Productivity in the Construction Industry. Bedford: McGraw Hill Construction, 2011.

. The Business value of BIM for owners. Bedford: McGraw Hill Construction, 2014.

MITROPOULOS, Panagiotis; TATUM, C. B. Management-driven integration. Journal of Management in Engineering, v. 16, n. 1, 2000.

MOLENAAR, Keith R.; et al. Early Contractor Involvement and Target Pricing in U.S. and UK Highways. Transportation Research Record: Journal of the Transportation Research Board, n. 2040, 2007.

MOLENAAR, Keith; SOBIN, Nathaniel. Sustainable, High Performance Projects and Project Delivery Methods: A State-of-Practice Report. Charles Pankow Foundation; DesignBuild Institute of America (DBIA), 2009.

MOLLAOGLU-KORKMAZ, Sinem; SWARUP, Lipika; RILEY, David. Delivering Sustainable, High-Performance Buildings: Influence of Project Delivery Methods on 
Integration and Project Outcomes. Journal of Management in Engineering, v.29, n. 1, jan. 2013.

MOSEY, David (Ed.). 10 Years of Partnering Contracts: PPC2000/TPC2005. Association of Consultant Architects (ACA), 2010.

MOSEY, David. Early Contractor Involvement in Building Procurement: Contracts, Partnering and Project Management. Oxford: John Wiley \& Sons, Ltd., 2009.

MOSTAFAVI, Ali; KARAMOUZ, Mohammad. Selecting Appropriate Project Delivery System: Fuzzy Approach with Risk Analysis. Journal of Construction Engineering and Management, v. 136, n. 8, ago. 2010.

MURRAY, Mike; LANGFORD, David (Ed.). Construction Reports 1944-1998. Oxford: Willey-Blackwell, 2003.

NAM, C. H.; TATUM, C. B. Noncontractual Methods of Integration on Construction Projects. Journal of Construction Engineering and Management, v. 118, n. 2, jun. 1992.

NATIONAL ASSOCIATION OF STATE FACILITIES. CM/GC Guidelines for Public Owners. NASFA, 2007.

NATIONAL INSTITUTE OF BUILDING SCIENCE. National BIM Standard-United States. NBIMS-US, 2015a.

National BIM Standard-United States Version 3. NBIMS-US, $2015 b$.

NEDERVEEN, Sander van; BEHESHTI, Reza; RIDDER, Hennes de. Supplier-Driven Integrated Design. Architectural Engineering and Design Management, v. 6, n. 4, 2010.

NEW ZEALAND GOVERNMENT. Early Contractor Involvement. NZ Transport Agency, 2015.

OBJECT MANAGEMENT GROUP. Business Process Model and Notation (BPMN) Version 2.0. OMG, 2011. Disponível em <http://www.omg.org/spec/BPMN/2.0>. Acesso em 19 dez 2018.

OLIVEIRA, Ana Beatriz de Figueiredo. Inserção de sistemas construtivos industrializados de ciclo aberto estruturados em aço no mercado da construção civil residencial brasileira. 2013. 155p. Dissertação (Mestrado em Engenharia Civil) - Escola de Minas, Universidade Federal de Ouro Preto. Ouro Preto, 2013. 
OLIVEIRA, A. B. D. F., GIACAGLIA, M. E. Integração da produção pela perspectiva organizacional. In: Encontro Nacional de Tecnologia do Ambiente Construído, 17., 2018, Foz do Iguaçu. Anais... Porto Alegre: ANTAC, 2018.

OMNICLASS CONSTRUCTION CLASSIFICATION SYSTEM. Introduction and User's Guide. OMNICLASS, 2006.

. Table 31 - Phases. OMNICLASS, 2012.

OTTER, Ad den; EMMITT, Stephen. Design Team Communication and Design Task Complexity: The Preference for Dialogues. Architectural Engineering and Design Management, v. 4, n. 2, 2008.

OWEN, Robert. CIB White Paper on IDDS - Publication 328. Rotterdam, The Netherlands: International Council for Research and Innovation in Building and Construction - CIB, 2009.

OWEN, Robert; et al. Challenges for Integrated Design and Delivery Solutions. Architectural Engineering and Design Management, v. 6, n. 4, 2010.

PAN, Wei; GIBB, Alistair G. F.; DAINTY, Andrew R. J. Strategies for Integrating the Use of Off-Site Production Technologies in House Building. Journal of Construction Engineering and Management, v. 138, n. 11, nov. 2012.

PAPADONIKOLAKI, Eleni; WAMELINK, Hans. Inter- and intra-organizational conditions for supply chain integration with BIM. Building Research \& Information, v. 45, n.6, 2017.

POST, Nadine M. Integrated-Project-Delivery Boosters Ignore Many Flashing Red Lights. Architectural Record, mai. 2010.

RAHMAN, M. Motiar; KUMARASWAMY, Mohan M. Relational Selection for Collaborative Working Arrangements. Journal of Construction Engineering and Management, v. 131, n. 10, out. 2005.

RICHARD, Roger-Bruno. Five Degrees of Industrialised Building Production. In: New Perspective in Industrialisation in Construction - A State-of-the-Art Report, GIRMSCHEID, Gerhard; SCHEUBLIN, Frits (Ed.). Council for Research and Innovation in Building and Construction - CIB. Zurich: Eigenverlag des IBB an der ETH, 2010, p. 79-89.

ROWLINSON, Steve. Building information modelling, integrated project delivery and all that. Construction Innovation, v. 17, n. 1, 2017.

ROYAL INSTITUTE OF BRITISH ARCHITECTS. BIM Overlay: to the RIBA Outline Plan of Work. RIBA, 2012. 
RIBA Plan of Work 2013 - Overview. RIBA, 2013.

SABBATINI, Fernando Henrique. Desenvolvimento de métodos, processos e sistemas construtivos - formulação e aplicação de uma metodologia. 1978. 321p. Tese (Doutorado em Engenharia Civil) - Escola Politécnica, Universidade de São Paulo. São Paulo, 1978.

SACKEY, E.; TUULI, M.; DAINTY, A. Sociotechnical Systems Approach to BIM Implementation in a Multidisciplinary Construction Context. Journal of Management in Engineering, v. 31, n. 1, 2015.

SACKS, Rafael; et al. Interaction of Lean and Building Information Modeling in Construction. Journal of Construction Engineering and Management, v. 136, n. 9, set. 2010.

SALAS, J. De los sistemas de prefabricación cerrada a la industrialización sutil de la edificación: algunas claves del cambio tecnológico. Informes de la Construcción, v. 60, n. $512,2008$.

SANTIAGO, Alexandre K; FREITAS, Arlene M. S.; CRASTO, Renata C. M. Steel Framing: Arquitetura. 2. ed. Rio de Janeiro: Instituto Aço Brasil/CBCA, 2012. 151 p.

SAUNDERS, Katie; MOSEY, David. PPC2000: Association of Consultant Architects standard form of project partnering contract. Lean Construction Journal, v. 2, n. 1, 2005.

SCHEEPBOUWER, Eric; HUMPHRIES, Adam B. Transition in Adopting Project Delivery Method with Early Contractor Involvement. Transportation Research Record: Journal of the Transportation Research Board, v. 2228, 2011.

SINDUSCON - MG - SINDICATO DA INDÚSTRIA DA CONSTRUÇÃO CIVIL NO ESTADO DE MINAS GERAIS. Manual para Contratação de Projetos para o Desempenho de Edificações Habitacionais. Belo Horizonte: Sinduscon-MG, 2016.

SINDICATO NACIONAL DA INDÚSTRIA DO CIMENTO. Números Relatório Anual. SNIC. Disponível em: <http://snic.org.br/numeros-relatorio-anual.php> Acesso em: 19 dez. 2018.

SUCCAR, Bilal; Building information modelling framework: A research and delivery foundation for industry stakeholders. Automation in Construction, v. 18, n. 3, p. 357-375, 2009.

SUCCAR, Bilal; KASSEM, Mohamad. Macro-BIM adoption: Conceptual structures. Automation in Construction, v. 57, p. 64-79, 2015. 
SUCCAR, Bilal; SHER, Willy; WILLIAMS, Anthony. An integrated approach to BIM competency assessment, acquisition and application. Automation in Construction, v. 35, p. 174-189, 2013.

SUPRAPTO, Mohammad; BAKKER, Hans L.M.; MOOI, Herman G. Relational factors in owner-contractor collaboration: The mediating role of teamworking. International Journal of Project Management, v. 33, n. 6, p. 1347-1363, 2015.

TAM, Vivian W.Y.; et al. Towards adoption of prefabrication in construction. Building and Environment, v. 42, n. 10, out. 2007.

TATUM, C. B.; VANEGAS, J. A.; WILLIAMS, J. M. Constructability improvement using prefabrication, preassembly, and modularization. Stanford: Stanford University. 1987.

TRIGO, Cristina Câncio. Pré-fabricados em argamassa aramada: material, técnica e desenho de componentes desenvolvidos por Lelé. Dissertação (Mestrado em Arquitetura e Urbanismo) Faculdade de Arquitetura e Urbanismo, Universidade de São Paulo. São Paulo, 2009.

TURK, Ziga. Ten questions concerning building information modelling. Building and Environment, v. 107, p. 274-284, 2016.

UNITED NATIONS. Government Policies and the Cost of Building. Economic Commision for Europe, Geneva. 1959.

US ARMY CORPS OF ENGINEERS. Engineering and Construction Bulletin: № 2009-4. USACE, 2009.

WIX, Jeffrey. Quick guide to Business Process Modeling Notation (BPMN). buildingSMART, 2007.

WONG, Peter S. P; CHEUNG, Sai On; HO, Peter K. M. Contractor as Trust Initiator in Construction Partnering - Prisoner's Dilemma Perspective. Journal of Construction Engineering and Management, v. 131, n. 10, 2005.

WONG, Peter S. P.; ZWAR, Charles; GHARAIE, Ehsan. Examining the Drivers and States of Organizational Change for Greater Use of Prefabrication in Construction Projects. Journal of Construction Engineering and Management, v. 143, n. 7, jul. 2017.

WORLDSTEEL ASSOCIATION. Steel Markets: Buildings and infrastructure. Disponível em: <https://www.worldsteel.org/steel-by-topic/steel-markets.html>. Acesso em: 29 nov. 2018. 
XIA, Bo; CHAN, Albert; MOLENAAR, Keith. Determining the Appropriate Proportion of Owner-Provided Design in Design-Build Contracts: Content Analysis Approach. Journal of Construction Engineering and Management, v. 138, n. 9, set. 2012.

YALCINKAYA, Mehmet; SINGH, Vishal. Patterns and trends in Building Information Modeling (BIM) research: A Latent Semantic Analysis. Automation in Construction, v. 59, nov. 2015.

YOU, Jingya; et al. Uncertainty, opportunistic behavior, and governance in construction projects: The efficacy of contracts. International Journal of Project Management, v. 36, n. $5,2018$. 


\section{APÊNDICE A \\ QUESTIONÁRIO DOS ESTUDOS DE CASO 1 a 4}

\section{PROJETO:}

Início do Projeto: (mês/ano)

Entrega da Obra: (mês/ano)

Uso:

\section{PROCESSO DE PRODUÇÃO}

1.1. Descrever o empreendimento e os sistemas construtivos utilizados. (identificar quais os sistemas pré-fabricados utilizados e como se deu a escolha durante o processo - desde o início; por razões técnicas, como terreno ou prazo; por iniciativa do cliente, do arquiteto, do engenheiro, ou do construtor.).

1.2. Quais etapas foram realizadas neste processo de produção? (Viabilidade, Projeto esquemático, Anteprojeto; Projeto Executivo, Projetos Complementares, Planejamento de obra, Execução...) (Identificar as atividades, e o vínculo entre elas - dependentes ou executadas em paralelo.)

1.3. Quais profissionais/empresas participaram de cada atividade? (identificar os participantes principais - responsáveis pelas atividades - e os secundários/consultores.) (não é necessário indicar o nome dos profissionais/empresas, mas somente sua especialidade.)

Obs.: A partir desses dados montarei um esquema com o processo e retorno para vocês confirmarem ou indicar algumas mudanças.

1.4. Em qual etapa do processo foi tomada a decisão pelo uso da construção industrializada? Se no início do processo, qual a importância dessa decisão no processo como um todo? Se no meio/final do processo, quais as consequências/mudanças no projeto? 


\section{2. ÁREA ORGANIZACIONAL}

2.1. Os profissionais/empresas já trabalharam juntos em outro empreendimento do escritório? Caso afirmativo, cite os profissionais e indique os empreendimentos.

2.2. Quando cada um dos profissionais/empresas passou a participar do processo? (identificar o(s) participante(s) que participou(aram) ao longo de todo o processo - planejamento, desenvolvimento do projeto e execução.)

2.3. Como a equipe - arquitetura, projetos complementares, engenharia - estava disposta? Em um único local ou em diferentes endereços?

2.4. Como foram realizadas as interações da equipe? Presencial, email, videoconferência ou telefone?

2.5. Com que frequência ocorreram as interações/reuniões? (separar essa frequência por tipo de profissional/empresa/disciplina e por etapa do processo de produção - planejamento, desenvolvimento do projeto e execução)

2.6. Como foram distribuídas as informações do projeto? Todos tinham acesso ou as trocas de informações foram seletivas?

2.7. Como foi a interação entre o escritório de arquitetura e o fornecedor do sistema construtivo industrializado? $\mathrm{O}$ contato foi feito direto com o fabricante ou com um fornecedor terceirizado? Em qual etapa foi feita a escolha do fornecedor? Existiu alguma necessidade de adaptar o sistema para o projeto em questão? Teve alguma dificuldade, se sim, qual? 


\section{3. ÁREA CONTRATUAL}

3.1. Como cada profissional/empresa foi vinculado ao processo de produção do empreendimento? (identificar o tipo e número de contratos e subcontratos; e se os contratos foram feitos com o cliente, gerente/coordenador, ou entre profissionais/empresas.)

3.2. Como foi feita a seleção dos construtores e empresas subcontratadas (serviços de instalações elétricas, hidráulicas, ar condicionado, ...)? Teve alguma pré-qualificação dos profissionais/empresas; baseado na experiência prévia; ou pelo custo?

3.3. As interações descritas anteriormente (Área Cultural) tiveram alguma base/obrigação no modelo de contrato estabelecido? Ou foram de iniciativa dos profissionais? Caso estejam especificadas no contrato, identifique de quem partiu a iniciativa e por qual motivo.

3.4. Existiu alguma cláusula contratual diferente daquelas presentes nos projetos que não utilizaram construção industrializada? Caso afirmativo, descreva a cláusula e identifique o agente que teve a iniciativa de inserir esta cláusula.

3.5. Em algum momento do processo de produção as cláusulas de contrato foram revistas? Caso afirmativo, quando e por qual motivo.

\section{4.}

4.1. Quais tecnologias foram usadas para a elaboração dos projetos em cada atividade? (identificar o software e descrever quais as ferramentas utilizadas. Ex.: AutoCAD, Revit/Archicad - modelagem 3D, lista de componentes, sistema estrutural, custo, planejamento de obra, ...) 
4.2. Como ocorreram as trocas de informações entre as disciplinas/atividades/etapas? (DWG, RVT, IFC, PDF, impresso, ...)

4.3. Como foram distribuídos os projetos entre a equipe? Um único modelo compartilhado, vários modelos vinculados, vários modelos independentes, ...?

4.4. Foi utilizada alguma ferramenta para integrar/compatibilizar os projetos? Ou identificar erros ou interferências nos projetos? Caso afirmativo, cite as ferramentas utilizadas. Caso negativo, descreva como foram compatibilizados os projetos. (identifique o(s) profissional(is) responsáveis por essa atividade.)

4.5. Caso tenha usado o BIM ne empreendimento, como foi tomada a decisão pelo seu uso? De quem partiu a iniciativa? 


\section{APÊNDICE B \\ TERMO DE CONSENTIMENTO LIVRE E ESCLARECIDO}

Eu, abaixo assinado(a) e identificado(a), autorizo o uso de informações, documentos, fotos e imagens, devidamente referenciadas, sem a identificação de profissionais e empresas envolvidas, fornecidas por ocasião e em decorrência da entrevista concedida à arquiteta Ana Beatriz de Figueiredo Oliveira, RG 11.121.682, CPF 110.820.827-40, Nº USP 9242705, email: anabeatrizfig@ usp.br, para a sua pesquisa de doutorado, desenvolvida no Programa de Pós Graduação em Arquitetura e Urbanismo da Universidade de São Paulo - FAUUSP, sob a orientação do professor Dr. Marcelo Eduardo Giacaglia, pertencente ao quadro docente da Universidade de São Paulo - Faculdade de Arquitetura e Urbanismo - FAUUSP.

Declaro ter sido informado(a), verbalmente e por escrito, de forma suficiente a respeito da pesquisa supracitada. Estou ciente de que os dados fornecidos serão destinados para divulgação científica ao público em geral e/ou para formação de acervo acadêmico/histórico, considerando: a mídia impressa (tese, livros, catálogos, revistas, jornais, entre outros), bem como mídia eletrônica (internet, banco de dados informatizado multimídia, CD ROM, DVD (digital video disc), entre outros), para divulgação científica sem qualquer ônus a Ana Beatriz de Figueiredo Oliveira ou a terceiros, por esta expressamente autorizados, que poderão utilizá-los em todo e qualquer trabalho de natureza sociocultural voltado ao fomento acadêmico e cultural, em todo território nacional e no exterior.

Por esta ser a expressão da minha vontade, autorizo os usos acima descritos sem que nada haja a ser reclamado a título de direitos conexos à imagem, ou a qualquer outro, e assino a presente autorização esclarecendo que o conteúdo e informações prestadas são de responsabilidade exclusiva do entrevistado e não representam a opinião da Instituição e Unidade as quais pertence.

de de

Assinatura

\begin{tabular}{|l|}
\hline Nome: \\
\hline RG No: \\
\hline CPF N $^{\text {: }}$ \\
\hline Telefone para contato: \\
\hline E-mail: \\
\hline
\end{tabular}

